\title{
Open-Access Resources and International Trade
}

\author{
by
}

\section{Michael Peter Francis}

\author{
A thesis submitted to \\ the faculty of Graduate Studies \\ in partial fulfillment of \\ the requirements for the degree of \\ Doctor of Philosophy \\ Carleton Lniversity \\ Ottawa. Ontario \\ September 1999. \\ C copyright \\ 1999. Michael Peter Francis
}


National Library

of Canada

Acquisitions and Bibliographic Services

395 Wellington Street Otlawa ON K1A ON4 Canada
Bibliothèque nationale du Canada

Acquisitions et services bibliographiques

395, rue Wellington

Ottawa ON K1A ON4

Canada
The author has granted a nonexclusive licence allowing the National Library of Canada to reproduce, loan, distribute or sell copies of this thesis in microform, paper or electronic formats.

The author retains ownership of the copyright in this thesis. Neither the thesis nor substantial extracts from it may be printed or otherwise reproduced without the author's permission.
L'auteur a accordé une licence non exclusive permettant à la Bibliothèque nationale du Canada de reproduire, prêter, distribuer ou vendre des copies de cette thèse sous la forme de microfiche/film, de reproduction sur papier ou sur format électronique.

L'auteur conserve la propriété du droit d'auteur qui protège cette thèse. Ni la thèse ni des extraits substantiels de celle-ci ne doivent être imprimés ou autrement reproduits sans son autorisation. 


\begin{abstract}
This thesis was concerned with one particular, but important. aspect of the "trade and the environment" debate: the inter-relationship between international trade, trade policy. and renewable open-access resources such as fisheries. In order to develop models for analysis, a standard (Gordon-Schaefer) model of renewable resources is integrated into the general equilibrium Ricardian and Hechscher-Ohlin international trade models. While such stylized models have limitations, they capture the property that the overexploitation of renewable resources lowers productivity of the resource-harvesting industry relative to other industries reducing output despite increased effort.
\end{abstract}

A key finding of this thesis is that. although free trade and capital mobility is not optimal when resources are open access. this need not imply that restricted trade and capital mobility is better, at times. subsidized trade may be best. Three main cases are considered in the thesis First. second-best trade policy for a small open economy is considered It is demonstrated that welfare can be improved by a tariff in the case of a fish exporting country and a trade subsidy in the case of a fish importing country Second, capital mobility is allowed for and it is shown that a small open economy can unambiguously gain from permitting free capital mobility if it is capital scarce and fishing is labour intensive. The welfare effects of an unfettered capital outflow however. are ambiguous. Lastly, endogenous world prices are considered within the context of a two-country specification. It is shown that when trade occurs between conservationist and open-access economies there is always a trade policy that can improve welfare. 


\section{ACKNOWLEDGMENT}

First and foremost I am especially grateful to my thesis supervisor. Professor Larry Schembri, not only for his valuable advice and guidance throughout the writing of this thesis, but also for his encouragement and dedication as a supervisor. Thanks also goes to the thesis committee members for their valuable comments and suggestions. In addition, I would like to especially thank other members of the economics deparment Professors Steve Ferris and Nick Rowe who took time to carefully read drafts and provide useful and stimulating comments and suggestions. The assistance of department staff. and that of Ginette Harte in particular. is also gratefully acknowledged. I would also like to thank Professors Brian Erard. Fen Hampson. Aileen Thompson. and Stan Winer for their support and the experience I received as their research assistants

Apart from academic support. the support of friends and family has been invaluable There are many people to whom I am indebted. but I would like to take this opportunity to thank a few in particular to Beatrice. David and Antonio for countless letters. to Andy who has been so "accommodating". to Judy and Greg for the beer and burgers. to Steve and Ina for everything from a roof at times to chocolate mousse, to Neville and my Grandfather for their constant care anc support, to Mum and Dad whose love extended thousands of miles made me feel that I had never really left home, and to Varuna for her love. support. stress management. and patience as I devoted time to writing and away from all else. to you all I say thank you. your support has made writing this acknowledgment possible. 


\section{Table of Contents}

Acceptance Sheet ................ ii

Abstract ............................

Acknowledgments $\ldots \ldots \ldots \ldots \ldots$ is

Table of Contents $\ldots \ldots \ldots \ldots \ldots \ldots \ldots$

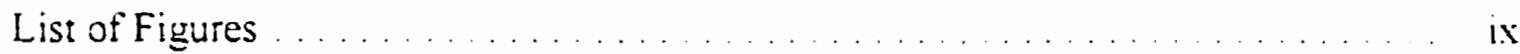

Chapter 1 Introduction ..................

Chapter 2 Production Possibilities 9

2.1 Fishing in a Simple Two Sector Model

2.2 The Diagrammatic Presentation of the Production Possibilities 15

Appendix 2.1: The Sustainable Production Possibilities Set -

the Ricardian Case ............. 2

Chapter 3 Bionomic Equilibrium _... . .

31 Introduction $\ldots \ldots \ldots \ldots$

32 The Open-access Case $\ldots \ldots \ldots \ldots$

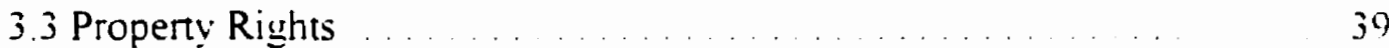

3.4 The Supply of Fish $\quad \ldots \ldots \ldots \ldots$

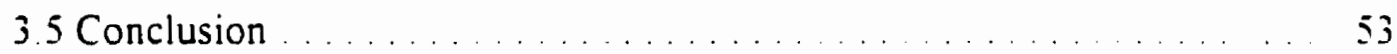

Appendix 3.1 Approaches to the Common Property Fishery

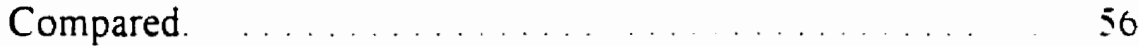

Appendix 3.2: Equilibrium Dynamics . . . . . . . . . . . . . . 59 
Appendix 3.3: The Inverse Relationship Between the Relative

Chapter 4 The Small Country Case $\ldots \ldots \ldots \ldots \ldots \ldots \ldots \ldots \ldots \ldots$

4.1 Introduction . . . . . . . . . . . . . $78 \ldots \ldots \ldots$

4.2. Possible Solutions to the Over-Fishing Problem $\ldots \ldots \ldots \ldots$

4.3 Comparative Advantage . . . . . . . . . . . . 97

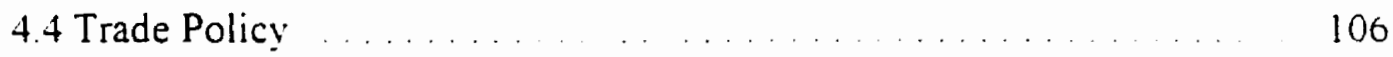

4.5 The Role of Cobb-Douglas Preferences and the Ricardian

Production Structure .......... 119

+6 Conclusion ....... 123

Appendix +1 The Equivalence Between the Harest Tax and

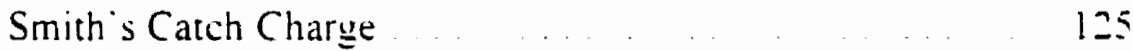

Appendix 4.2 Equilibrium Linder Open Access: the Optimal

Harvest Tax: and Equilibrium When Steady-State Welfare is

Maximized

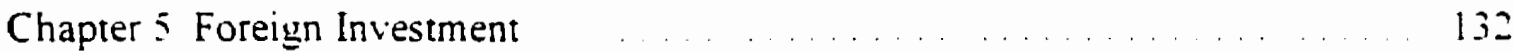

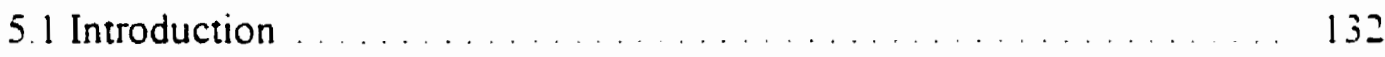

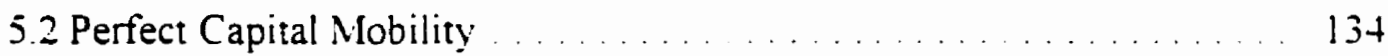

5.3 The Optima! Harvest Tax - Stock of Foreign Capital Fixed . . . . . . It?

5.4 Foreign Investment with an Exogenous Level of Fisheries 
5.5 Government Policy Towards Foreign Investment and Fisheries

Management.

5.6 Conclusion

Appendix 5.1 Proof of Proposition 5.1

Chapter 6 Trade Policy in The Two Country Model

6.1 Introduction

6.2 Trade Between Open-access Economies 170

6.3 Trade Between Conservationist and Open-Access Economies 198

6.4 Trade Between Conservationist and Open-Access Economies - differences in tastes

6.5 Conclusion

Appendix 6.1: The Effects of Home (Open-Access) Country Trade Policy on the Home Offer Curve.

Appendix 6.2 Proof of Proposition 6.2: The Effect of an Export Tax Imposed by the Foreign (Fish-exporting) Country

Appendix 6.3: Proof of Proposition 6.3

Chapter 7 Conclusion

7.1 Motivation and Summary of Main Findings

7.2 Limitations of the Analysis and Possibilities for Future Research 236

References 


\section{List of Figures}

Figure 2.1 The "simple" logistic case for two different constant harvest rates

Figure 2.2 The yield-effort curve.

Figure 2.3 The derivation of the sustainable production possibilities locus the Ricardian case

Figure 2.4 The derivation of the sustainable production possibilities locus the Heckscher-Ohlin case

Figure 3.1 Bionomic equilibrium in the Ricardian open-access model

Figure 3.2 Bionomic equilibrium in the Ricardian open-access model - the response to a change in world prices

Figure 3.3 Bionomic equilibrium in the Heckscher-Ohlin open-access model

Figure 3.4 Bionomic Equilibrium in the Heckscher-Ohlin open-access case the response to a change in the terms of trade

Figure 3.5 Comparison of equilibria under open access and property rights - the static case.

Figure 3.6 The effect of the divergence between world and domestic producer prices under optimal regulation.

Figure 3.7 The supply of fish, discount rates. and general equilibrium

Figure 4.1 The effects of changes in fishing effort on $\eta$

Figure 4.2 Total allowable catch quota

Figure 4.3 Monopsony power in the fishery: the effect on the level of fishing effort 
Figure 4.4 Monopsony power in the fishery: the effect on GDP

Figure 4.5 Temporary autarkic equilibria.

Figure 4.6 Sustainable autarkic equilibrium

Figure 4.7 True and apparent comparative advantage

Figure 4.8 Autarkic and free trade equilibrium in the Ricardian model - I

Figure 4.9 Autarkic and free trade equilibrium in the Ricardian model - II

Figure 4.10 Deriving the consumption locus for a fish-exporting country

Figure 4.11 Deriving the consumption locus for a fish-importing country

Figure +.12 Multiple equilibria in the Ricardian open-access model

Figure 4.13 Free trade may dominate autarky for a fish exporter

Figure 5.1 The relationship between the har est tax and foreign capital under perfect capital mobility

Figure 5.2 The sustainable production possibilities under perfect capital mobility

Figure 53 The optimal harest tax with a fixed stock of foreign capital

Figure 5.4 The welfare maximising stock of foreign capital with fixed fisheries regulation - the $k k$ locus

Figure 5.5 Steady-state welfare. fisheries regulation and foreign capital

Figure 5.6 Welfare worsening capital outflow

Figure 5.7 Welfare improving capital inflow

Figure 5.8 The amplification effect

Figure 5.9 A deviation from the optimum worsens welfare

Figure 6.1 Consumption and production under free trade - I 
Figure 6.2 The offer curve for the fish-exporting country

Figure 6.3 Consumption and production under free trade - II

Figure 6.4 Offer curve for a fish-importing country

Figure 6.5 Free trade equilibrium in the two country model

Figure 6.6 Free trade equilibrium

Figure 67 The sustainable consumption locus for the fish-exporting country

Figure 68 The effects of a foreign export tax on the relative price of fish at home

Figure 6.9 The home country tariff when the forelgn offer curve is highly inelastic

Figure 6.10 The home country tariff when the foreign offer curre is elastic

Figure 6.11 The effect of changes in the elasticity of the foreign offer curve on home consumption

Figure 612 A Pareto improving trade subsidy

Figure 6.13 The effects of a conserationist s tish tariff on the home (open-access) economy

Figure 6.14 The effects of a conseriationist s tish export tax on the home (openaccess) economy 


\section{Chapter 1}

\section{Introduction}

The last 15 years have constituted a period of great expansion in international trade - the value of world trade increasing almost threefold from LS\$2034B in 1980 to US\$5375B in 1998. This expansion has spurred considerable debate. On one side are free traders and main stream economists. on the other are environmentalists and a growing number of economists sympathetic to their cause. Free traders see trade expansion as the basis for increasing world income as countries specialise according to comparative advantage and improve the efficiency with which the world"s resources are used Environmentalists. on the other hand. have long argued that the expansion in trade puts undue pressure on the world's natural resources. At the hear of the issue is whether or not the earth's natural resources are being correctly valued. If these resources are under valued, then trade may be founded upon an 'artificial' comparative advantage and cause more harm than good The objective of this thesis is to explore the relationship between international trade and the exploitation of national renewable resources such as fisheries and forests where access is often unrestricted. Without some type of intervention. these "open-access" resources (Clark 1990, p. 24) will be under-valued and over-exploited. The trade patterns

' Reported on the WTO web site (hщp MTwר Wto org wito statis stat htm1) 
and the normative consequences for trade policy are not immediately obvious. While a failure to address an open-access problem tends to create a competitive advantage for the renewable-resource harvesting industry, the eventual degradation of the resource may be so severe that the country becomes a net importer of the resource using good (Brander and Taylor (1997b)). Furthermore. if the resource intensive good is "essential" in consumption, then, in the absence of trade. this economy may extinguish the resource leading to the ultimate demise of the economy International trade may therefore be necessary for the survival of the open-access economy

The relationship between trade. resource explottation. and biological growth is clearly complex and needs to be simplified The approach taken in this thesis involves integrating a standard economic model of resource growth (the Gordon-Schaefer model) into the iwo sector Heckscher-Ohlin and Ricardian models of international trade theory The Gordon-Schaefer model is among the most popular models used in the economic literature on renewable resources. It combines the economic model of the "commonproperty" fishery dereloped by H. Scott Gordon (1954) with the relatively simple biological model of fisheries growth developed by $M$. Schaefer (1957). In a partial equilibrium context, Clark (1990) provides an excellent treatment of the GordonSchaefer model and other models of renewable (biological) resource exploitation. Munro and Scott (1985) also provide a useful survey: while many texts on optimal control also provide limited treatment of the dynamic versions of the model (see for example. Leonard and Long (1992), and Conrad and Clark (1988)). 
During the 1970's, a series of papers appeared that incorporated Gordon's open-access fishery into a two-sector general equilibrium environment. Notable amongst these is the paper by Smith (1974) In that paper. Smith built upon an earlier model posited by Scott and Southey (1969) and the optimal control model of Quirk and Smith (1969) to derive the temporary and sustainable steady-state production possibility sets for a closed economy Smith's model allowed the competitive laissez-fairc equilibrium and the equilibrium that maximises steady-state welfare to be neatly illustrated on a single diagram. The closed economy model was refined by Lesourne (1976). while the open economy model was developed primarily by McRae (1978) who considered the dynamic optimization problem facing a central planner for an open economy. and compared this to the laissce-fuire open-access equilibrium. From there on. in the face of the oil crisis. the literature on trade and natural resources took a different turn and focussed instead on the problem facing economies exploiting an exhaustible resource (see the survey by Kemp and Long (1984)). The problem faced by an economy exploiting a renewable (but possibly depletable) open-access resource has since remained dormant until the recent work of James Brander and Scott Taylor who produced a series of four papers on the topic (Brander and Taylor (1997a,b. 1998a,b)).

The basic structure of all these general equilibrium models is the same. They assume a two-sector economy and one pure primary factor. labour. Labour is assumed to move freely between the two sectors combining with the stock of the renewable resource in one sector to produce a final good for consumption. In the second sector. labour alone is 
used to produce a second consumption good. manufactures These assumptions are sufficient to illustrate the role played by the renewable resource in the model. the impact of free access, and the effects of trade policy. However, for some purposes, such as the impact of foreign investment, or the distributional consequences of policy changes. a model that incorporates a second purely primary factor, capital. is useful. One of the contributions of this thesis is to allow for a second pure primary factor by introducing a fishing sector into a Heckscher-Ohlin framework. This is done in Chapters 2 and 3

Chapter 3 is devoted to the derivation of equilibrium in the Ricardian and HeckscherOhlin models. When the fishery is open access. the analysis shows that the behaviour of the two types of models is quite similar: however. there is one kev difference between the two models. While all the rents associated with the fishery are eventually dissipated in the Ricardian model. some of the rents persist in the Heckscher-Ohlin model. As a result the normative properties of the two types of models are likely to differ. Chapter 3 also develops a dynamic model of the general equilibrium fishery using the Heckscher-Oh!in version of the model. The modified golden rule for the fishery is derived. and the optimal steady-state supply curve for fish is illustrated

Chapter 4 examines optimal regulation for a small open economy and the role for trade policy when regulation is not possible. In examining the set of possible regulatory solutions to the open-access problem, it is shown that a harvest tax is generally the firstbest solution. Other solutions such as sole ownership. quotas. and transferable quotas 
suffer from drawbacks such as rent seeking and the potential exploitation of market power. The general equilibrium implications of implementing these policies are examined. In the case of the quota, for example, it is shown that the level of fishing effort in the Ricardian model with a quota may exceed the level of fishing effort under open access. Comparing the open-access and optimally regulated equilibria also allows a better understanding of the relationship between true comparative advantage, that exists when the economy is optimally regulated. and "apparent" comparative advantage that exists when the resource is open access. As noted by Brander and Taylor (1997b) an optimally regulated "conservationist" country may well have a comparative advantage in the resource dependent sector while an othenwise identical open-access economy may deplete and degrade its resource to the point where it tinds it has an "apparent" comparative advantage in manufacturing

In addition to regulation of the fisher: Chapter + also examines the role of trade policy: for a small open economy when regulation is not feasible. With the exception of Brander and Taylor (1997a. 1998a). the role for trade policy, and its effect on the welfare of a country with a renewable open-access resource has largely gone unnoticed since the work of Scott and Southey (1969). Applying the theory of the second best, Scott and Southey pointed out that the elimination of a trade restriction would not ensure a welfare improvement in the presence of an open-access fishery. Since then. Brander and Taylor (1997a) using a Ricardian model (as posited by Scott and Southey (1969)) have provided a clarification of this result. They show that, for a diversified, fish-exporting, open- 
access country, autarky always Pareto dominates free trade. Lising the Ricardian model. the results of Brander and Taylor (1997a) are extended to show that a fish-importing country can always benefit from an export subsidy, while a fish-exporting country can benefit from a tariff. Interestingly, it is shown that in some cases a fish-exporting country may benefit from a prohibitive tariff cum export subsidy that reverses the pattern of trade. It is also demonstrated that a fish-exporting country need not always lose from free trade once the Ricardian production structure is replaced with a Heckscher-Ohlin structure. In that case it is possible that a fish-exporting country could gain from free trade

Chapter 5 considers capital mobility. This is an issue that cannot be dealt with fully in the standard Ricardian framework in a straightforward way. Consequently. the analysis of capital mobility in the presence of renewable. potentially open-access. resources has gone unaddressed in the literature to date The lack of analysis that incorporates foreign investment and capital mobility has been a matter of concern for many who see the proposed multilateral agreement on investment as a bigger threat to environmental resources than free trade. One unresolved issue is whether the strategic use of environmental policies to attract foreign capital can lead a "race to the bottom." or for that matter. to the top. in the presence of renewable resources. That is. will competition for foreign capital lead countries to progressively lower or raise their environmental standards away from the optimum and so deplete. or hoard, their natural resources? 
The results from Chapter 5 suggest that countries have no incentive to deviate from their optimal policies to attract foreign capital. Nevertheless, there may be a correlation between capital inflows and the stringency of resource regulation for legitimate and less sinister reasons. For example, the optimal policy for a capital scarce country may well involve an inflow of foreign capital and a lowering of the optimal harvest tax. This possibility arises because the capital inflow may expand other sectors of the economy and reduce the pressure on the environmental resource. Furthermore. Chapter 5 demonstrates that capital mobility itself may provide the government with a tool to improve economic welfare when environmental regulation is either not possible or excessively costly to enforce.

Chapter 6 extends the analysis of Chapter + to a two-country world in which each country is large enough to affect its terms of trade Two broad cases are considered. One in which the renewable resource is han ested under open access in both countries. and another in which one country is "conservationist" and regulates its renewable resource optimally, and the other country s resource is open-access. The analysis reveals that the policy prescriptions of Chapter 4 do not necessarily extend to a two-country world Moreover, developing the approach taken by Brander and Tayior (1998a) Chapter 6 demonstrates that there may be a set of trade policies which lead to a Pareto improvement in global welfare in both circumstances. This is shown to be true even if the differences in regulation arise due to differences in preferences across countries rather than in the ability to restrict access per se. This last result is particularly 
interesting because it is generally assumed that if trade is motivated by differences in preferences over environmental resources then free trade is optimal. Another interesting finding is that, for countries that face severe depletion of open-access renewable resources, due to population pressure for example, a trade subsidy may be appropriate The trade subsidy encourages expansion of other industries other than harvesting of the resource. thereby partially alleviating the overfishing problem. Furthermore, it is shown that in such cases foreign welfare is unambiguously improved if the foreign country is optimally regulated. This result nuns contrary to the belief that restrictive trade policies should be pursued to protect the world's environmental assets. The final chapter of the thesis provides a summary of the key findings and suggests possibilities for further research. 


\section{Chapter 2}

\section{Production Possibilities}

The purpose of this chapter is to set up the supply side of the models that are used throughout this thesis. The basic production structures used in this thesis build on the traditional two sector Ricardian and Heckscher-Ohlin models. The main difference between the Ricardian and Heckscher-Ohlin models presented here. and their traditional counterparts. is that one sector of the economy produces fish for final consumption according to a standard model of renewable resource grouth. To keep matters relatively simple. the economy is assumed to produce just one other good. manufactures. In what follows, the subscripts 1 and 2 denote the fishing and manufacturing sectors respectively. The demand side specification and general equilibrium analysis is left to subsequent chapters

\subsection{Fishing in a Simple Two Sector Model.}

At any given moment. the harest of fish. $K_{1}$. depends on the amount of fishing etfort. $F$. applied to the current fish stock. $S$.

$$
X_{1}=H(F, S)
$$

The functional form of $H$ can be simplified by making two assumptions. First. given the level of fishing effor, the catch is assumed to be directly proportional to the fish stock. Second. given the stock of fish. the catch per unit of fishing effort is constant. The 
second assumption rules out a congestion externality - an interesting problem in its own right that appears in the literature concerning fisheries. Nevertheless, the assumption is justified since the open-access problem, and not the crowding externality, is a principle concern of this thesis. Thus. define $H(F, S)$ as

$$
H(F, S)=q S F
$$

Where. $q$, is a constant reflecting the productivity of fishing effort in catching fish Combining ( 2.1$)$ and (2.2) gives

$$
H_{2}=q S F
$$

Fishing effort is treated as an intermediate good into the hariesting process. and is modelled as the output of a standard neo-classical production function t number of different assumptions could be made. The simplest would be that the output of fishing effort is directly proportional to the input of labour. This is the Ricardian assumption employed. for example. by Brander and Taylor. Alternatively. it could be assumed that the output of fishing effort depends on the input of labour. $N$. and some other nonspecific primary factor such as land or capital. $K$. This is the assumption employed in the Heckscher-Ohlin framework and will be employed in much of this thesis. ${ }^{2}$ Under the Ricardian assumption. the production function for fishing effort can be written as

$$
F=N_{i}
$$

2 Another standard assumption that could be made would be to allow the output of fishing effort to depend on the input of labour and some other sector specific factor. 
While under the Heckscher-Ohlin assumption it is given by

$$
F=F\left(K_{1}, N_{1}\right)
$$

where, $K_{i}$, and $N_{i}$ are the inputs of capital and labour to fishing effort respectively. The production function, $F\left(K_{1}, N_{1}\right)$ is assumed to be homogeneous of degree one in capital and labour. Furthermore, the marginal products of labour and capital are assumed to be positive but diminish with increases in input use.

In economic models of fisheries. there is always an opportunity cost associated with fishing. Much of the existing literature simply takes this cost as exogenously given. An alternative approach is to endogenise it as part of a general equilibrium model. as is done here. The opportunity cost of fishing effort is assumed to be the output of another good (manufactures) foregone when resources are moved into fishing. As with fishing. manufactures are produced according to a neo-classical production function. Linder the Ricardian assumption. this is given by

$$
X_{2}=N_{2}=N_{-i} N_{1}
$$

While under the Heckscher-Ohlin assumption it is given by

$$
X_{2}=G\left(K_{2}, N_{2}\right)
$$

where. once again. $G\left(K_{2}, N_{2}\right)$ is assumed to be homogeneous of degree one in capital and labour and the marginal products of capital and labour are assumed to be positive but diminish with increased input use 
Equations (2.1) to (2.4), along with the usual resource constraints, form the backbone of the model. With the interpretation that $K_{\text {: }}$ is a primary. non-specific factor, equations (2.3b) and (2.4b) look like the production side of the static Heckscher-Ohlin model. By adding equations (2.1) and (2.2) the structure is preserved - the only modification is that $S$ is a third factor of production which affects fish production in a Hicks neutral way like Meade's (1952) atmosphere variable.

In reality. the stock of tish is not fixed but endogenous. In the absence of harresting. Its growth over time is affected by a number of environmental factors and its natural rate of population growth. It is assumed that this process can be described by a differential equation. $\dot{S}=L(S)$. Because biological growth is a complicated process to describe. some simplifying assumptions about the function $L\left(S^{\prime}\right)$ are often made. Perhaps the most common assumption is that. in the absence of har esting. the fish stock grows according to the logistic equation

$$
L(S)=\gamma S\left(1-\frac{S}{c}\right)
$$

This equation captures the notion that starting trom a small initial stock. the fish population increases at a decreasing rate until it reaches some maximum carring capacity, c. This can be seen by dividing both sides of $(2.5)$ by $S$, and noting that the proportional growth rate starts at the intrinsic growth rate. $\%$, but declines continuously reaching zero when $S=c$ : 
Other forms of the logistic function could also be used. For example. a simple generalisation of $(2.5)$ is

$$
L(S)=\gamma S^{\alpha}\left(1-\frac{S}{c}\right)
$$

If $\alpha>1$ involves the fish population growing at an increasing rate when the population is relatively small, and at a decreasing rate once the fish population is significantly large ${ }^{3}$ While this is an interesting and plausible description. it adds considerable complexity to the analysis in later sections. For this reason, unless otherwise stated. the assumption that the population grows according to the simple logistic equation given in equation 25 is retained throughout. ${ }^{+}$

The actual growth of the population. $\Gamma(S)$ is determined by the interplay of the natural. or biological. rate of grouth and the harrest rate. Assuming that the act of harresting does not interfere with the natural process of population growth. the actual growth of the population can be written as

$$
\Gamma(S)=L(S)-H(F, S) \text {. }
$$

If the harvest rate exceeds the natural population growth rate the population will decline. while if the harvest rate is less than the natural population growth rate the population will

${ }^{3}$ This type of population growth is referred to as "depensation". see Clark (1990) for more details. On the other hand. population growth governed by the standard logistic equation (2.5) is said to exhibit compensation.

${ }^{4}$ For most of the analysis in this thesis. the exact functional form of the logistic equation is not important. What is important is the shape of the function - generally all that is required is that it be a concave function of $S$ with $L^{\prime}(0)>0, L^{\prime}(c)<0, L(0)=L(c)=0$. 
grow. When $\Gamma(S)=0$, the harvest just equals the natural increase and the system is said to be in (biological) equilibrium. (i.e. $\dot{S}=0$ ). This is illustrated in Figure 2.1

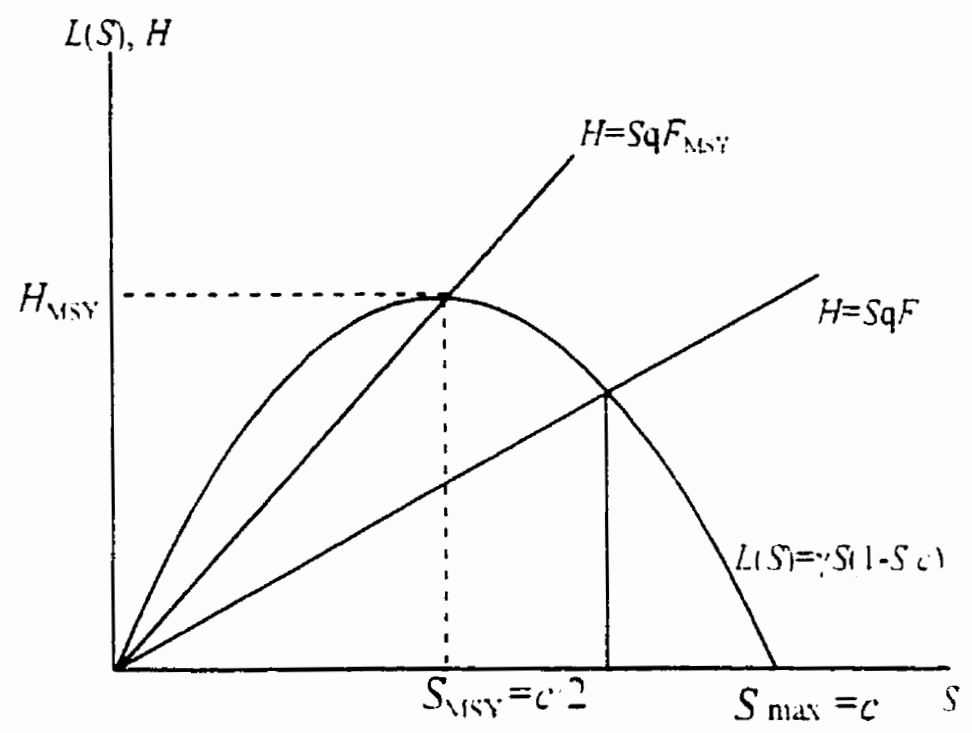

Figure 21

The "simple" logistic case for two different constant harvest rates

Taken altogether. equations $(21)$ to $(26)$ give a complete dynamic specification of the production side of the model. When $\Gamma(S)=0$ these equations describe. what may be called. the sustainate production possibilities locus, that is. the ser of outputs that are compatible with biological equilibrium. This can be found graphically by using a simple four quadrant diagram as explained in the next section.

s Note that when depensation is allowed for $(\alpha=2)$ the system may have more than one equilibrium stock. 


\subsection{The Diagrammatic Presentation of the Production Possibilities}

Before illustrating how the sustainable production possibilities locus can be derived. an additional tool is needed. The yield-effort curve (Figure 2.2 below) shows the relationship between a given amount of fishing effort and the sustainable havest. To derive this relationship. start from a large stock in Figure 2.1, such as $S_{\max }$, and consider the effect that an increase in the amount of fishing effor. $F$. would have. Initially. the increase in effort will increase the sustainable harvest (or yield) from zero. The harvest continues to increase with fishing effort until $F=F_{\text {ISY. }}$. At this level of effort (shown below in Figure 2.2) the har'est reaches a maximum. $H_{\text {MSSY. }}$ and reduces the (sustainable) stock from its maximum level to $S_{\text {Is: }}$ as shown in the Figure 21 . As $f$ is increased further. the har est declines until both it and the stock have reached zero The relationship between fishing effor and yield is illustrated in Figure 2.2 by the yeld-effort diagram. From Equation (2.6). also note that the amount of fishing effort needed to extinguish the stock is given by $\frac{\gamma}{q}$ 


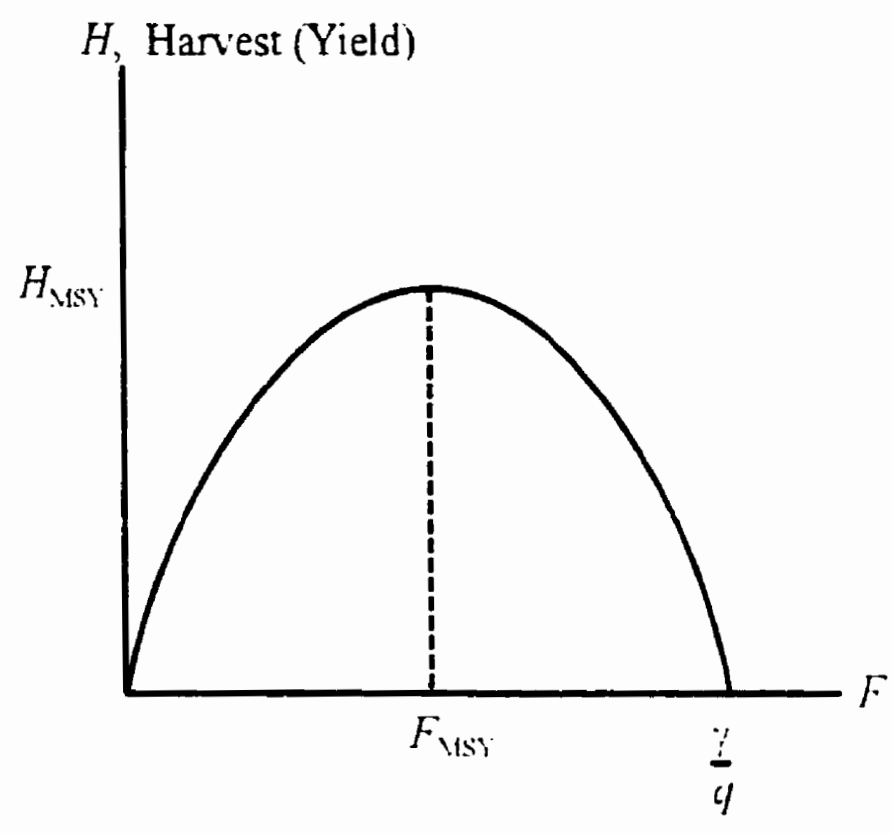

Figure 2.2

The vield-effort curve

The sustainable production possibilities frontier can now be derived using a diagrammatic technique similar to that presented by Anderson (1986)." In Figure 23 . the upper left hand quadrant shows the transformation cur e TT' transforming manufactures into fishing effort. In this case assume that the production structure is Ricardian. It is referred to as the Brander - Taylor case since this is the assumption made by Brander and Taylor (1997 and 1998a). In this case. fishing effort and manufacturing are described by the production functions ( $2.3 \mathrm{a})$ and $(2 .+\mathrm{a})$. The upper right-hand quadrant shows the combinations of fish and manufactures that can be harvested and

${ }^{6}$ Vernon Smith (1974) seems to be the first to formally derive and illustrate the sustainable production possibilities set for a general equilibrium model similar to that used here. but did not provide a diagrammatic derivation of the sustainable production possibilities set. See also Lesourne (1976) and McRae (1978). 
produced respectively. It is important to distinguish between the temporary relationship that exists at any given moment in time. given the existing fish stock, and that which is sustainable over time with an endogenous fish stock. Since the harvest of fish is a scalar multiple of fishing effort, the temporary production possibilities frontier $\mathrm{Tp}^{\prime}$ is linear. reflecting the Ricardian transformation of manufactures into fishing effort. There is a family of temporary production possibilities frontiers. one for every value of $S$. The slope of each is just $1 / q S$ of the slope of $\mathrm{TT}^{\prime}$. Of all the points along $\mathrm{Tp}^{\prime}$. only one is sustainable. The complete set of points forming the sustainable production possibilities set is found by using the yield effor curve in the lower left hand quadrant. and the $45-$ degree construction line in the lower right-hand quadrant. Start by picking a point on the transformation cure TT'. in the upper left-hand quadrant Next. find the corresponding sustainable yield (and implicitly the sustainable stock) in the quadrant below ('se the construction line to bring this harest rate into the (fish. manufactures) space. This gives a point on the sustainable production possibilities set. This point also lies on a temporary production possibility set taking the corresponding stock as given. The sustainable production possibilities locus can also be derived algebraically (see Appendix 2.1). 


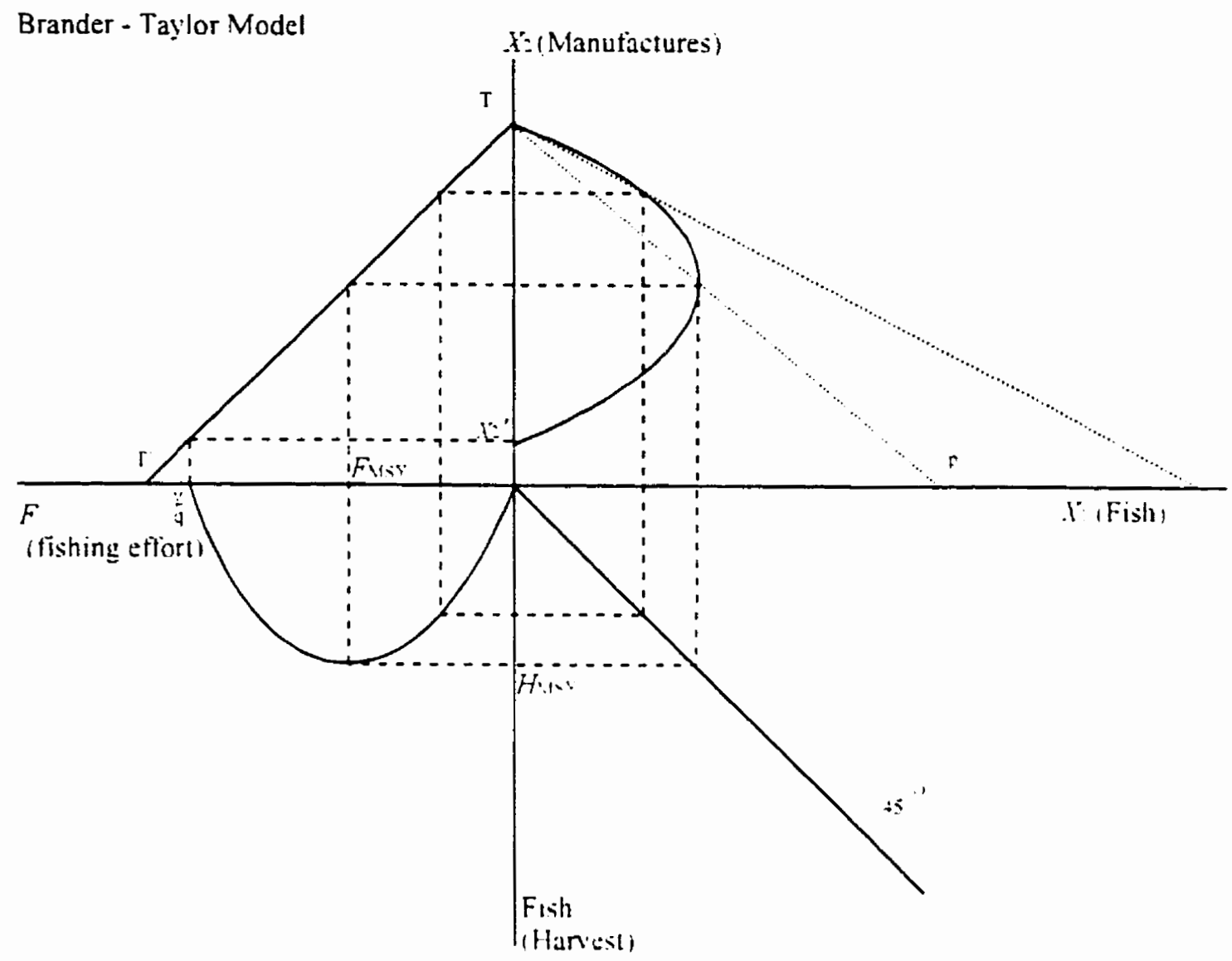

Figure 2.3

The derivation of the sustainable production possibilities locus The Ricardian Case 
The sustainable production possibilities set has a distinctive "D-type" shape. This shape simply reflects the mapping of the yield-effort relationship into the (fish. manufactures) space and can be understood as follows. Starting from a situation in which all resources are devoted to manufacturing, if fishing effor is increased then the harvest of fish rises This reflects, not only the extra effort, but more importantly the larger sustainable harvest that occurs with a lower stock of fish The supply of manufactured goods falls As the amount of fishing effort is increased further. the maximum sustainable harrest is eventually reached. With this level of fishing effort. the harrest of fish is maximised Any additional fishing effort will reduce the sustainable harvest and results in a fall in the output of both manufactures and fish Votice that it is possible that the economy may extinguish the fish stock if it devotes too much effor to fishing. This occurs if the amount of tishing effor produced exceeds $\frac{\gamma}{q}$. This possibility is shown on the diagram and results in $Y_{2}^{\prime}$ units of manufactures and zero units of fish being produced. ${ }^{-}$

Using the same technique. a sustainable production possibility set can be derived for the Heckscher-Ohlin framework as shown below. Once again the upper left-hand quadrant represents the transformation curve that maps manufactures into fishing effort. The

"If the hariest function had assumed "diminishing returns to the fish stock". i.e $\mathrm{x}_{1}=H\left(N_{1}, S\right)$ with $H_{3}>0, H_{3:}<0$. as assumed by Smith $(1974)$ then the sustainable production possibilities set may have a "loop" shape (see Smith (1974) or McRae(1978)). It can also be verified using the techniques developed here that if depensation (see footnote 4) is present in the population growth function the sustainable set will also be "looped". While such possibilities are interesting. for the purposes of this thesis. they unnecessarily complicate the analysis. 
lower left-hand quadrant shows the yield-effort curve that maps fishing effort into the sustainable harvest. Using the 45 degree line in the lower right-hand quadrant allows the relationship between the output of manufactures and the sustainable harvest of fish to be traced out. In this case. Figure 2.4 shows the possibility that the supply of resources in the economy is not sufficient to produce a level of fishing effort in excess of $\frac{\gamma}{q}$ and therefore the fish stock cannot be extinguished. ${ }^{8}$ The temporary production possibilities frontier, such as TB'p. can be found using the following technique. To derive this frontier, take a ray from the origin passing through $B$ " in the lower left-hand quadrant This represents the temporary yeld - effort relationship. holding the fish stock fixed at that level that would give a sustainable harest of $\mathrm{H}_{\mathrm{H}}$. Now using the same technique as before. trace out the temporary PPF

The benefit of these diagrams is that they provide a relatively simple framework to describe the complex relationship between the temporan and steady-state production equilibria for an economy with a renewable. open-access resource. However. the demand side is missing. This is addressed in the next chapter which presents an analysis of the competitive equilibrium with an open-access fishery as well as the equilibrium for a centrally-planned economy that takes the dynamic aspect of the fishery into account. Together the framework presented here and the results of the next chapter provide the

${ }^{8}$ This is for illustration and is not a feature of the Heckscher-Ohlin framework. If there were sufficient resources so that the economy could produce a level of fishing effort in excess of $y / q$ then the possibility of resource depletion arises 
foundation for an analysis of various important economic questions that are the focus of the remaining chapters in the thesis.

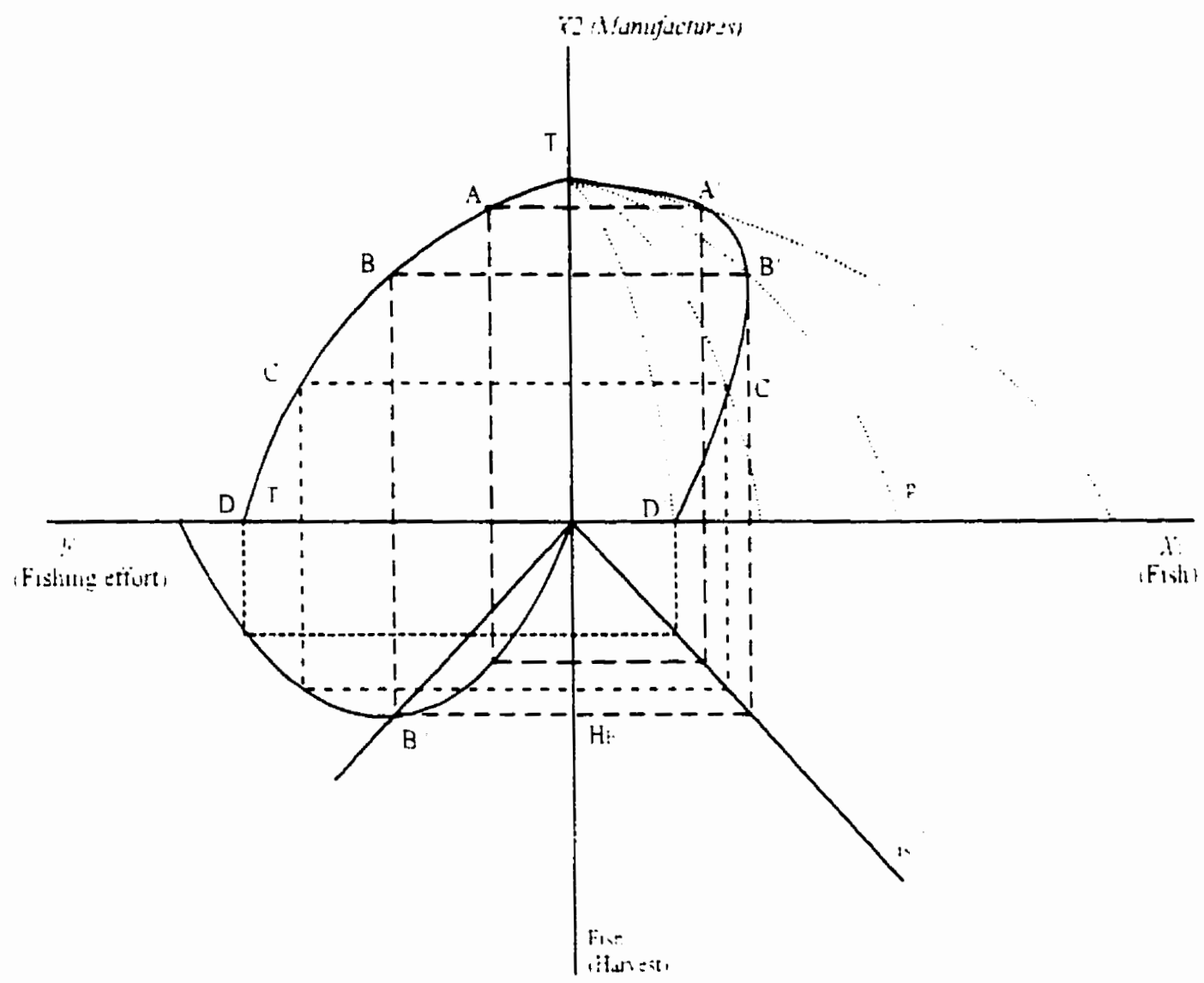

Figure 2.4

The derivation of the sustainable production possibilities locus -

The Heckscher-Ohlin case 


\section{Appendix 2.1: The Sustainable Production Possibilities Set - the Ricardian Case.}

This section derives the sustainable production possibilities locus for the Ricardian model.

Recall that the points on the sustainable locus must be consistent with both temporary production possibilities (i.e output taking the stock as fixed) and biological equilibrium (zero population growth). The (temporary) outputs of fish and manufactures are given by the production functions (2.2) (combined with (2.3a)) and (2.4a).

$$
\begin{aligned}
& x_{1}=q S V_{i} . \\
& K_{2}=V-V_{1}
\end{aligned}
$$

A sustainable production point occurs when the stock of tish is constant. That is, when the harest rate just matches the natural growth rate of the fish population

$$
\Gamma(S)=L(S)-X_{1}=0
$$

Substituting the logistic equation (25) and $(.12 .1)$ into $(.12 .3)$ gives

$$
\gamma S\left(1-\frac{S}{c}\right)=q S N_{1}
$$

Which upon rearranging to solve for $S$, gives

$$
S=c\left(1-\frac{q}{\gamma} N_{1}\right)
$$

Substituting (A2.5) into (A2.1) gives

$$
X_{1}=q c\left(1-\frac{q}{\gamma} N_{1}\right) N_{1}
$$

Now simply subsitute for $V_{1}$ from (A2.2) to write $Y_{1}$ as a function of the output of manufacturing 


$$
X_{1}=q c\left[1-\frac{q}{\gamma}\left(N-X_{2}\right)\right]\left(N-X_{2}\right) .
$$

Notice that this has a quadratic form which gives the sustainable production possibilities its " $D$ " like shape.

Note that in Equation (A2.6), should $N_{1}$ exceed $\hat{N}\left(\hat{N}=\frac{\gamma}{q}\right)$ then $X_{1}$ becomes negative. This corresponds to the case when the fish stock is extinguished (the output of fish is simply zero since negative levels of the fish stock are ruled out). If the total supply of labour..$\dot{ }$ is less than $\hat{N}$ then the fish stock cannot be extinguished In this case. the sustainable production possibilities locus intersects with the fish axis. If however $1-\hat{N}$. then extinction is possible and the sustainable production possibilities locus will intersect with the vertical manufactures axis. 


\section{Chapter 3}

\section{Bionomic Equilibrium}

\subsection{Introduction}

The seminal work on the economics of open-access renewable resources was done by $\mathrm{H}$. Scott Gordon (1954). He noted that when property rights over resources. such as fisheries. are poorly defined. regulation of the resource can be welfare improving Gordon demonstrated this by comparing a common property fishery, in which no communal mechanism existed to restrict individual access. to a monopoly-owned fishery. where access was strictly limited to (or controlled solely by) the monopoly owner Where property rights were ineffective and access was unrestricted. fishers exploited the resource until the rents associated with the fishery were driven to zero. On the other hand. the monopoly owner could restrict use to maximise the value of the rent

This chapter re-examines Gordon's analysis in the context of the Ricardian and Heckscher-Ohlin models developed in the previous chapter. To do so requires the introduction of economic decision making to the models. The next section assumes that individuals have open access to the resource and behave in a self interested fashion maximising individual utility and profits. Later in the chapter the equilibrium in which a central planner acts to maximise economic welfare of the economy is considered Generally: the focus of this chapter is on the steady-state equilibrium which involves 
both biological and economic equilibrium. The coincidence of both equilibria was referred to by Gordon as bionomic equilibrium.

\subsection{The Open-access Case}

This section integrates Gordon's economic analysis of the fishery with the production structures developed in the previous chapter. The focus is primarily on the production choices of firms. Initially, it will be assumed that each firm is competitive in the usual sense - that is. each firm is assumed to maximise profit. there is free entry and exit. and consequently. profits in each sector are driven to zero. In this section of the thesis it is also assumed that all firms have unhindered free access to the fishery. This is known as the open-access, or using Gordon's terminology. the common property assumption. The effects of regulation will be dealt with in Chapter 4 of the thesis

The current literature makes a point of stressing the difference between what is meant between open access and common property. By open access. I will mean the absence of an effective property right that can restrict access to the fishery - "everybody"s access is nobody 's property" as Bromley (1997, p. 11) puts it. In this sense. it is different from assuming common property. Common property still implies a shared right to access and hence a common right to exclude. and there may well be a set of cultural or economic norms which regulate use of the resource. However, if there was no effective way of monitoring access by the members, or no economic way to enforce the norms. the system by which the common use of the resource is regulated would fail. The common property 
resource then degenerates into an open-access resource. Gordon presumably had this state of affairs in mind when he used the term common property. Similarly, both private and state property become open access if any mechanism to enforce the property right is absent or too costly to implement.

Under open access. the use of the fishery and the fish it yields are considered a free input by the fisher. This leads to a variety of different problems including over fishing. congestion of the fishery, and habitat destruction. This paper is concerned with only the first of these problems. Under open access. an individual fisher will not stop fishing as long as the private value of the fish that he catches exceeds the private cost to him of catching it The private cost is the labour and capital costs associated with providing the fishing effort required to catch the fish The private value of the fish is the price the fisher can sell it for. The fisher attaches no private value to fish left behind in the fisher: Open access implies that any rent associated with these fish will immediately be appropriated by competitors and hence an individual fisher derives no private benetit from a fish foregone today. A competitive fisher therefore maximises his instantaneous profits treating the current stock as a parameter and in doing so has a negative external effect on the stock and the productivity of fishing effort in the future. Even though each fisher may realise that his actions today will affect future harvests. acting otherwise will worsen his private profits both today and in the future. 


\subsubsection{The Ricardian model of Brander and Taylor}

\subsubsection{Temporary equilihrimm}

Focussing first on the Ricardian model of Brander and Tavlor (1997). consider the equilibrium for a small open economy that faces a fixed set of world prices. There are three plausible temporary equilibria - complete specialisation in manufactures; complete specialisation in fish: and a diversified equilibrium in which the economy produces both goods. In the case of diversification. equilibrium requires that price equals average cost (this is the zero profit condition) Recall (22). (2.3a) and (2. ta). which gave the output of fish and manufactures

$$
\begin{aligned}
& \mathrm{r}_{\mathrm{i}}=4 . \mathrm{s} \% \\
& =4 . \% \text {. } \\
& I_{i}=l_{2}
\end{aligned}
$$

With manufactures as the numeraire. with a price of unity. and relative world price of fish. $p_{1}$. the zero profit conditions are

and by $(2+a)$.

$$
1=\frac{w N_{2}}{X_{2}}
$$

$$
=11
$$

for manufactures: and consequently.

$$
\begin{aligned}
p_{1} & =\frac{w N_{1}}{q S N_{1}} \\
& =\frac{1}{q S}
\end{aligned}
$$

for fishing. It will be recalled that $\frac{1}{q S}$ is the slope of the temporary Ricardian PPF when 
the stock is fixed at $S$. That is, for the economy to be in a diversified equilibrium, the slope of the trade line (given by the relative price of fish) must also be equal to the slope of the temporary production possibilities frontier (given by the opportunity cost of fish)

A temporary diversified equilibrium is unlikely in the Ricardian model when the stock of fish is fixed. If $p_{1}>\frac{1}{q S}$ then profits in the fishing sector will cause the economy to specialise in fishing. If $p_{1}<\frac{1}{q S}$ then the fishing sector cannot cover its costs and the economy will specialise in manufacturnng. However in this model $S$ is endogenous. and changes in $S$ affect the slope of the Ricardian PPF and the nature of the equilibrium

\subsection{2 Sustainable equilihrium}

Figure 3.1 shows a sustainable production possibilities locus and temporan. PPF. this PPF could be derived in the same manner used to derive the upper right quadrant in Figure 23 Consider first the case when the slope of the temporan: PPF is the same as the trade line (slope $\left.=-p_{1}\right)$ i.e. $p_{1}=\frac{1}{q S}$ In the standard Ricardian model. the production point on this frontier is indeterminate for a small open economy." However. when $S$ is endogenous. only one point can be a sustainable equilibrium. Given the current fish stock, only one harvest rate will match the natural rate of increase in the fish stock leaving the stock neither growing nor falling. This occurs at the intersection of the temporary and sustainable production possibilities sets, shown as point A in Figure 31

${ }^{9}$ Normally the equilibrium production point is determined by domestic preferences and a restriction on the international cross-hauling of goods 


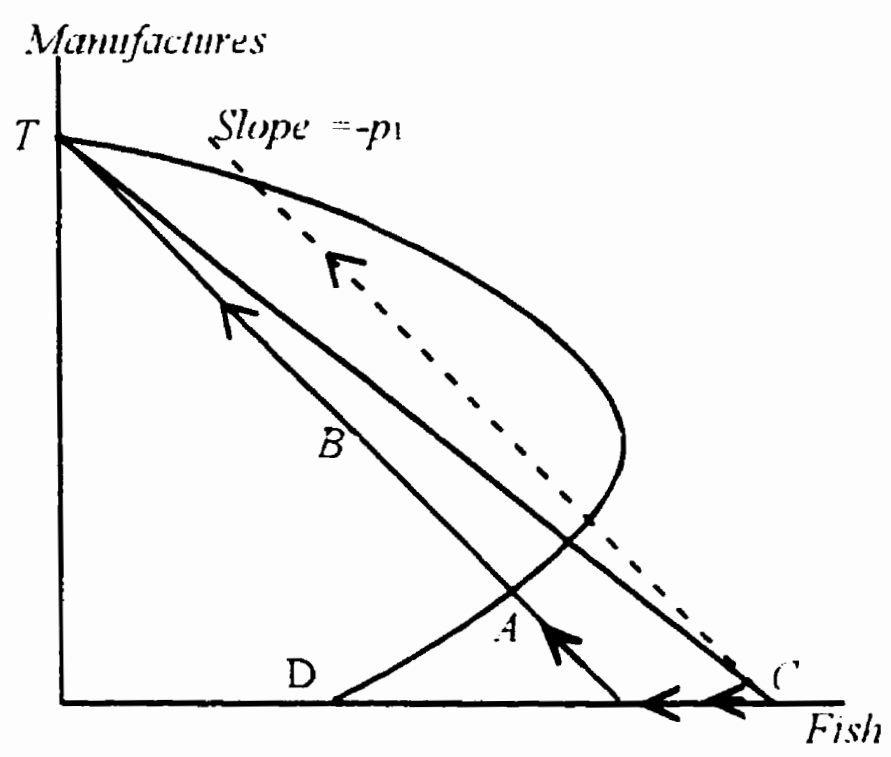

Figure 3.1

Bionomic equilibrium in the Ricardian open-access model

Along TBA. the trade line and the temporar. PPF are coincident If the economy were to operate at a point such as B to the left of point $A$. then the harvest would be less than that which just equals the natural population increase. and the fish stock would grow Recall that the fish stock. $S$. acts as a productivity parameter in the fishing sector is. grows the temporary PPF pivots outwards (to TC for example). Facing the same world price, the economy specializes at $C$. In this case, however $C$ lies to the right of the sustainable production possibilities locus. producing a harvest greater than that which is sustainable. Consequently, the stock falls to its original level. and the PPF pirots back in to TBA. A similar story could be told for a point to the right of A causing a fall in the fish stock. Only point $A$ is both a temporary economic equilibrium and a biological long-run equilibrium 
Referring to Figure 3.2. now consider the implications of an increase in the world price of fish from $p_{1}$ to $p_{1}{ }^{\prime}$ say. The economy would immediately specialize in the production of fish, producing at point $G$. However $G$ does not lie on the sustainable frontier and involves a level of fishing effor greater than that which is sustainable. Consequently, the stock of fish falls. There are two possibilities. Either a new diversified equilibrium can be reached, such as $\mathrm{K}$, where the stock has fallen sufficiently to restore the equilibrium condition $p_{1}^{\prime}=\frac{1}{q S^{\prime}}$; or, if the increase in fish price is large enough. and the capacity of the fishery sufficient. the economy could become completely specialised in production of fish at point $D$. If the economy becomes specialised at $D$. the slope of the temporary PPF is less than (in absolute terms) the slope of the trade line. $-p_{1}$ However. since no further resources can be devoted to supplying fishing effort. the fish stock has reached the minimum level that is feasible Therefore. the temporary PPF will no longer pivot in further and the economy remains specialised at $D$

If instead the world price of fish were to fall. to $p_{1}$ " (not shown). then the economy would move to a temporary equilibrium at $\mathrm{T}$. At $\mathrm{T}$ no fishing is being undertaken and the stock of fish begins to rise. Once again. the economy will settle at one of two equilibria. Either the economy will move to a new diversified equilibria at a point on the sustainable locus such as point $J$, where the stock has fallen sufficiently to restore the condition for a diversified equilibrium $p_{1}^{\prime \prime}=\frac{1}{q S^{\prime \prime}}$, or the economy will completely specialize at point $T$. Complete specialisation will occur if $p_{1}^{\prime \prime}<\frac{1}{q c}$. where $c$ is the carrying capacity of the fishery, i.e. the maximum sustainable size of the fish stock 


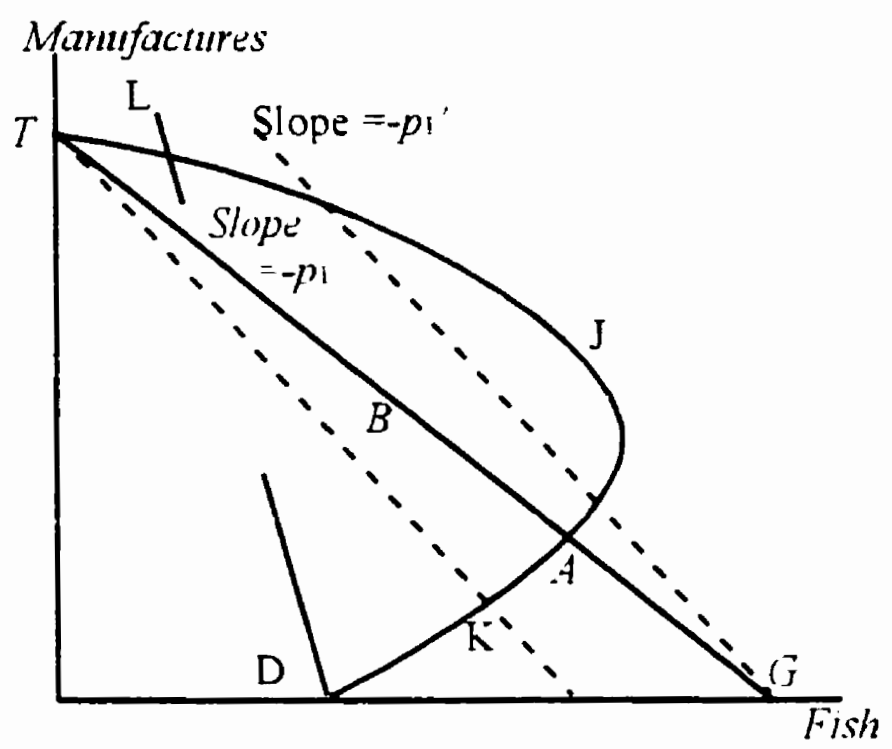

Figure 32

Bionomic equilibrium in the Ricardian open-access model the response to a change in world prices

These properties of the Ricardian model give rise to interesting welfare implications that are worth noting and are referred back to in Chapters + and 6 . Starting from a diversified equilibrium such as $A$ in Figure 3.2. any decrease in the relative price of fish will improve welfare in this economy (assuming some consumption of fish). This follows from the simple observation that any decrease in the relative fish price leads to a reduction in fishing effort. an increase in the fish stock. and an expansion in the consumption set as it pivots out from $T$. If the price of fish were to rise. long-run welfare in the economy would fall so long as the economy moved to a diversified equilibrium such as $\mathrm{K}$. If the price of fish were to rise enough and the fishery was sufficiently large. so as to not be completely fished out, then the economy could become completely specialised at $D$. If this were to happen. welfare in steady-state may rise or fall. To see 
that welfare may rise, simply note that once the economy has become specialised at $D$, and the stock can be depleted no further, that the consumption set. as defined by the trade line (shown as DL in Figure 3.2). intersects with the original consumption set (defined by the temporary possibility ftontier TBA) Notice that these welfare effects are independent of whether the country was initially an exporter or imporer of fish. Therefore. there exists the potentia! for a worsening of a country's terms of trade to improve its welfare

Furthermore, note that in steady state under free trade. there is no welfare gain to a country that has an open-access fishery: in a diversitied equilibrium That is. if we compare the steady-state welfare of two economies that each have the same population. but let one have an open-access fishery. while the other is without a fishery. then both will have the same level of steady-state welfare. In the long-run. the presence of a fishery conveys no benefit to a country fortunate enough to be endowed with one This is because free access allows all the rents associated with the tishery to be dissipated in this model. This can be seen by noting that the country without the fishery produces at point $T$ in Figure 3.1 and trades along TB.A. While the same country endowed with a fishery faces the same set of world prices and produces at point $A$. This country also trades along $\underline{\underline{y}}$ TB.A. and hence has the same steady-state consumption possibilities set as it would if the fishery was absent. 


\subsubsection{The Heckscher-Ohlin model}

Suppose the Ricardian framework is replaced with the Heckscher-Ohlin setup. In this case the production functions for fish and manufactures are written as

$$
\begin{aligned}
& x_{i}=q S F\left(K_{i}, N_{j}\right), \text { and } \\
& x_{i}=G\left(K_{2}, N_{j}\right) .
\end{aligned}
$$

\subsubsection{Temporary equilibrium}

In this case profit maximising firms. takıng the fïsh stock as given. hıre labour and capital to the point where the value of their marginal products (private to each firm) equal the market wage and rental rates respectively " These conditions are

$$
\begin{gathered}
p_{1} \frac{\partial X_{1}}{\partial N_{1}}=p_{1} q S F_{V}=w . \\
\frac{\partial X_{2}}{\partial N_{2}}=G_{X}=w .
\end{gathered}
$$

I"In the literature on common property resources. it is often said that individuals enter so as to equate the average product of labour with the wage rate. Thus, there may seem to be a contradiction between the first order conditions and this standard rule. In this case, there are two things to note. First, competitive firms hire workers (and capital) so as to equate the privale marginal benefit of labour with the wage rate. In this case. the competitively operated firms. supplying fishing effort (having hired factors of production in competitive factor markets). enter the fishery until such a point where the average benefit of fishing effort equals the average cost (this is just the zero profit condition). Because firms do not take into account the effect of additional fishing on the stock (i.e. the external cost of fishing effort) they do not equate the social marginal benefit of fishing effort with the marginal cost; consequently the average product of fishing effor exceeds its marginal product and there is over fishing. This is explained further in Appendix 3.1. The optimal level of fishing effort and the optimal regulation of the fishery will be developed in the next section. 


$$
p_{1} \frac{\partial X_{1}}{\partial K_{1}}=p_{1} q S F_{K}=r
$$

and,

$$
\frac{\partial X_{2}}{\partial K_{2}}=G_{K}=r
$$

Because the production functions $F$ and $G$ are linearly homogeneous, the profit maximising conditions also imply the zero profit conditions

$$
p_{i} X_{i}=w N_{i}+r k
$$

and. recalling that good 2 is the numeraire

$$
r_{i}=w L_{-}-r K_{2}
$$

These conditions imply a tangency between the temporan production possibilities frontier and the trade line This can be contirmed by totally differentiating I I (using $2.3 b)$ and 2 tb to obtain

$$
\frac{d X_{2}}{d X_{1}}=\frac{G_{K} d K_{2}+G_{N} d N_{2}}{q\left(S F_{K} d K_{1}+S F_{N} d N_{1}+F d S\right)}
$$

since.$"$ is treated as a constant by firms. d. ${ }^{\prime}=0$ Hence $(3.9)$ can be written as

$$
\begin{aligned}
& \left.\frac{d X_{2}}{d X_{1}}\right|_{\text {temp }}=\frac{G_{K} d K_{2}+G_{\Lambda} d N_{2}}{q S\left(F_{K} d K_{1}+F_{N} d N_{1}\right)} \\
& =\frac{\frac{G_{K}}{G_{N}} d K_{2}+d N_{2}}{q S\left(\frac{F_{K}}{F_{N}} d K_{1}+d N_{1}\right)} \frac{G_{N}}{F_{N}}
\end{aligned}
$$

Factor supplies are assumed to be inelastic. thus $d K^{\circ}=-d K_{2}$ and $d N^{\prime}=d N_{2}$, and since

$$
\frac{G_{K}}{G_{N}}=\frac{F_{K}}{F_{N}}=\frac{r}{w} .\left(3.9^{\prime}\right) \text { becomes }
$$




$$
\begin{aligned}
=-\frac{\frac{F_{K}}{F_{N}} d K_{1}+d N_{1}}{F_{K}} \frac{G_{N}}{F_{N}} \\
\left.=-\frac{G_{N}}{q S F_{N}} d K_{1}+d N_{1}\right)
\end{aligned}
$$

Using ( 33 ) and $(34)$, this gives

$$
\left.\frac{d X_{2}}{d X_{1}}\right|_{\text {teme }}=-p_{1} .
$$

\subsubsection{Sustainahle' équilibrium}

As in the Ricardian model, the stock of fish acts as a Hicks neutral productivity parameter. Any change in $S$ has the effect of causing the temporary. PPF to piv ot outwards through $T$. This is shown in Figure 33 it follows that for any world price ratio. there exists a unique long-run sustainable equitibrium The locus of points JJ reflects the set of temporary equilibria as described by (3.11) for different values of .1 Only the equilibrium that coincides with the sustainable locus can be a long-run sustainable equilibrium. Points on JJ. to the left of $\mathrm{A}$. correspond to temporary equilibria when the fish stock is small. Consequently, the temporary equilibrium produces a harvest that is less than the natural rate of increase. and therefore $S$ increases and the equilibrium point moves along $\mathrm{J}$ towards $\mathrm{A}$. The opposite is true when the stock is high, producing a temporary equilibrium at a point to the right of $\mathrm{A}$ 


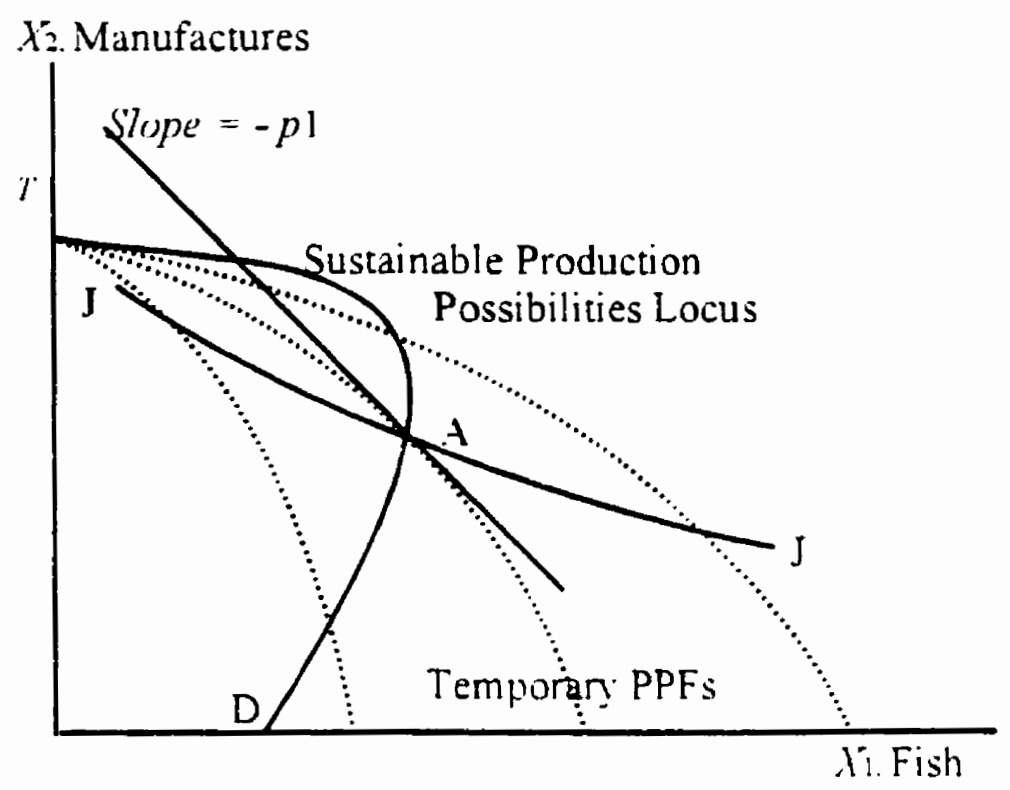

Figure 33

Bionomic equilibrium in the Heckscher-Ohlin open-access case

In Figure $3 . t$ it can be seen that the Heckscher-Ohlin model generally behaves in a similar fashion to the Ricardian model. The essential difference between the two models is that the marginal cost of fishing effor is increasing. The implications of an increasing marginal cost of fishing eftort can be seen by considering an increase in the relative price of fish. First. note that in this case. a country derives a steady-state benefit from being endowed with an open-access fishery. This can be seen in Figure 3.4 by noting that the consumption possibilities set for a country producing at point $\mathrm{A}$. and trading along the trade line at prices $p_{1}$, are greater than the consumption possibilities set for the same country. but without the fishery, producing at $T$ (i.e. specialised in manufactures) and 
trading at the same set of world prices. Thus, while citizens in a Ricardian economy, if they care only about their steady-state welfare. are indifferent between being endowed with a fishery and having no fishery at all, the citizens of the Heckscher-Ohlin economy prefer to be endowed with a fishery The reason is that. in the Heckscher-Ohlin model. the opportunity cost of fishing effort is increasing. while in the Ricardian model the opportunity cost of fishing effort is constant. Thus, in the Heckscher-Ohlin model some of the economic rent from the fishery accrues to the factors that combine to produce fishing effor. This rent persists after entry has driven the profit from fishing to zero. On the other hand, in the Ricardian model. the opportunity cost is constant and hence no economic rent from the fishery accrues to labour. and in the long-run. all the rents associated with the fishery are eliminated

Second. note that a country exporting fish may gain from an improvement in its terms of trade in the Heckscher-Ohlin case. This is shown in Figure $3+$ Begin at point $A$. An increase in the relative price of fish produces a new temporary equilibrium where the new trade line (not shown) is tangent with the current temporary production possibilities frontier TAG. This harvest exceeds the sustainable harvest and consequently the temporary PPF pivots inwards. A new sustainable equilibrium is eventually reached at B. Now compare welfare at the higher relative price of fish with welfare at the lower price. It can be seen that welfare may rise or fall. For example. if consumption initially. occurred at $C_{A 1}$. a plausible new consumption point may occur at $C_{B 1}$ with a lower level of welfare. However, it is equally plausible that welfare might rise. Consumption points 
$C_{A 2}$ and $C_{B 2}$ illustrate this possibility. The possibility of a welfare improvement in this case can be thought of as a variation on the immizerising growth result of Bhagwati ( 1958) and Johnson (1967)"

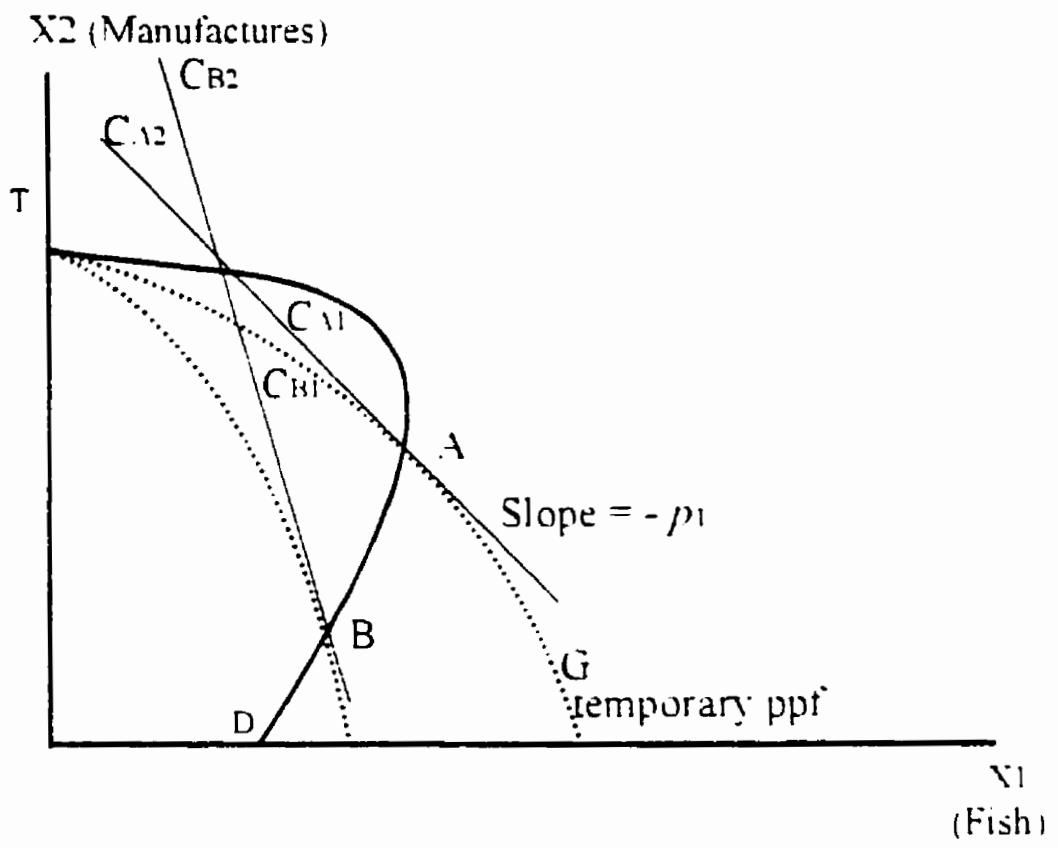

Figure 34

Bionomic equilibrium in the Heckscher-Ohlin open-access case the response to a change in the terms of trade

"The standard result has (productivity) growth induce a change in the terms of" trade. In this case the terms of trade change induces a change in fishing "productivity" by affecting the level of fishing effort which induces a change in the fish stock. 


\subsection{Property Rights}

\subsubsection{The "static" case}

I now turn to the case where property rights are well defined and enforced. It is simplest to imagine that the fishery is in the hands of the state ${ }^{12}$. For now it will be assumed that the state maximises steady-state welfare. The "dynamic" model, in which the cost of waiting for the fish stock to accumulate is accounted for, is left to the next section In essence then this can be thought of as akin to the static central planner's problem. where the objective is to maximise steady-state welfare.

The solution is straight fonward Graphically; it can be seen that the central planner will wish to choose the level of fishing effort so as to produce at a tangency between the trade line and the sustainable production possibilities locus: or. algebraically, when $\left.\frac{d X_{2}}{d X_{1}}\right|_{\text {sust }}=-p_{1}$. That is. where the social marginal cost of harested fish equals the marginal benefit (i.e the relative price of fish). This is shown in Figure 35 as point .1 Note that this must involve production on the negatively sloped portion of the sustainable production possibilities locus This implies that the harrest of fish is less than. and the stock of fish greater than. the hariest and stock associated with the maximum sustainable yield.

${ }^{12}$ One benefit of this assumption is that it avoids the possibility that a private sole owner might attempt to use its monopsony power in the factor markets thereby adding an additional complication to the model. The state or central planner is not assumed to behave in such a manner (unless it produced a welfare benefit, which in this case it does not) 


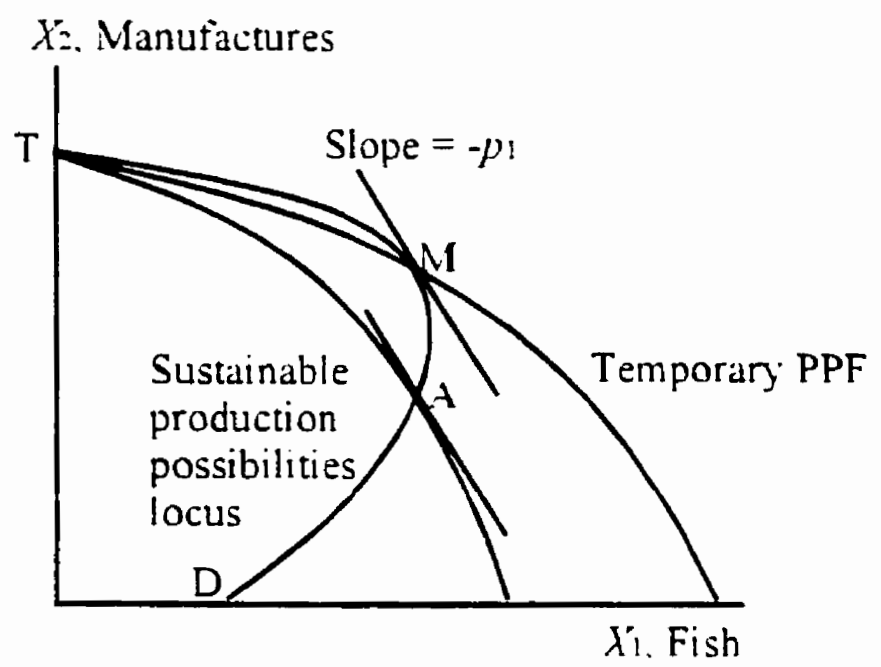

Figure 35

Comparison of equilibria under open access and property rights - the static case

Vext. consider the relationship between the temporary PPF and the sustainable production possibilities locus. Recall that the slope of the temporary PPF was found by totally differentiating equations $(2.1)$ and $(2+b)$. holding the fish stock fixed. In this case the stock of fish is endogenous and evolves according to the the logistic function (in the absence of harvesting).

Totally differentiating (2.1) (using (2.2)) and ( $2+b)$. taking $S$ as endogenous

$$
\left.\frac{d X_{2}}{d X_{1}}\right|_{\text {sust }}=\frac{d X_{2}}{q S d F+q F \frac{\partial S}{\partial F} d F}
$$

Which. after a little manipulation, gives 


$$
=\frac{d X_{2}}{\left(1+\frac{F}{S} \frac{\partial S}{\partial F}\right) q S d F}
$$

Thus the relationship between the sustainable locus and temporary PPF can be uritten as

$$
\left.\frac{d X_{2}}{d X_{1}}\right|_{\text {sust }}=\left.\frac{1}{1+\eta} \frac{d X_{2}}{d X_{1}}\right|_{\text {teemp }}
$$

where $\eta$ is the elasticity of the fish stock with respect to fishing effort. Since $\eta$ is negative. (3.12) says that at any point on the sustainable production possibilities locus. the slope of the sustainable locus must exceed (in absolute terms) the slope of the temporary PPF that passes through that point. That is. the opportunity cost of fishing. taking the stock as given. is less than the opportunity cost when the endogenous nature of $S$ is taken into account

Since steady-state welfare is maximised. $\left.\frac{d X_{2}}{d X_{1}}\right|_{\text {sust }}=-p_{1}$. Hence 1312 ) can be written as

$$
\left.\frac{d X_{2}}{d X_{1}^{*}}\right|_{\text {tcmp }} \frac{1}{(1+\eta)}=-p_{1}
$$

In this form. the solution reveals that the social optimum. in which steady-state welfare is maximized. could be produced through the imposition of a Pigovian ad ralorem tax of $-\eta$ on fish landings. The optimal harrest tax is discussed in more detail in Chapter $t$.

This analysis has abstracted from the cost of moving along the sustainable production possibilities locus. The analysis treats the opportunity cost of an additional landed fish as just the manufactures foregone. as illustrated by the slope of the sustainable locus. In reality there is another element - time. A reduction in the harvest. producing a 
movement from one point along the locus to another. takes time The population of fish needs to reproduce, grow and mature. But the cost of waiting for this to happen has been ignored - it was either assumed that this happened instantly or that the fishery owner was infinitely patient. The next subsection deals with the problem of time explicitly.

\subsubsection{Optimal exploitation of the fishery over time - the dynamic case}

The owner of the fishery will want to balance the benefit of postponing current production by leaving a fish in the fishery for later. with the cost to him of waiting to harest the fish at some point in the furure. Maximising steady-state welfare ignores the cost to the fishery owner of the transition to steady state and therefore likely involves under exploitation of the fishery (leading to too large a fish stock) . For simplicity. continue to assume the existence of a central planner whose objective is to maximise the utility of a representative individual. Given the assumptions made so far. most notably: the absence of the congestion externality. the central planner's problem can be seen as producing equilibrium conditions equvalent to those that would prevail when the economy is competitive. and a tax on fish landings li.e a har est tax or "user fee" for the fishery) is charged by the state

\subsubsection{The central planner's prohlem}

The objective of the central planner. with a discount rate of $\delta$. is to maximise the present discounted value of economic welfare. If the economy is small and open. the central planner can maximise welfare by maximising the present value of GDP at fixed world 
prices. The dynamic optimization problem of the central planner is formally set out below as problem $(\mathrm{P} 3.1){ }^{13}$

$$
\max \int_{0}^{\infty} e^{-\delta t}\left(p_{1} X_{1}+X_{2}\right) d t
$$

subject to

$$
\begin{aligned}
& \dot{S}=L(s)-X_{1} ; \\
& X_{1}=q S F\left(N_{1}, K_{1}\right), \\
& X_{2}=G\left(N_{2}, K_{2}\right): \\
& K \geq K_{1}+K_{2} . \\
& N \geq N_{1}+N_{2}, \text { and }
\end{aligned}
$$

non-negativity constraints on $K_{1}, K_{2}, \nu_{1}$, and $V_{2}$

It may be helpful to think of the central planner's problem as consisting of two separate parts A dynamic problem and a static problem The static problem is to make the best use of capital and labour so as to produce outputs of tishing effirt and manutactures on the temporary transformation frontier at a point reflecting the full set of prices. The dynamic aspect of the problem is to value or price the resource for which there is no market (the fish in the fishery) so that it is utilised to maximise welfare. taking into account the central planner's rate of time preference and the rate at which the fish population will grow over time. Viewed in this way. the dynamic part of the problem

${ }^{13}$ Markusen (1976) and McRae (1978) consider a similar optimal control problem for a large country. Moreover, they consider the case in which the economy has only one pure primary factor of production and not the Heckscher-Ohlin framework used here. 
can be thought of as a capital accumulation problem with the stock of fish playing the role of a type of capital. These two relatively simple problems are subsumed into the one problem (P3.1) above.

To solve this problem, substitute for $X_{1}$ and $X_{2}$ and form the present value Hamiltonian and Lagrangian

$$
\begin{aligned}
\mathcal{H}\left(K_{1}, K_{2}, N_{1}, N_{2}, S, \lambda\right)=p_{1} S q F\left(K_{1}, N_{1}\right)+G\left(K_{2}, N_{2}\right)+\lambda\left(L(S)-q S F\left(K_{1}, N_{1}\right)\right. \\
\mathscr{L}\left(K_{1}, K_{2}, N_{1}, N_{2}, S, \lambda, \rho, \omega\right)=p_{1} S q F\left(K_{1}, N_{1}\right)+G\left(K_{2}, N_{2}\right)+\lambda\left(L(S)-q S F\left(K_{1}, N_{1}\right)\right) \\
+p\left(K-K_{1}-K_{2}\right)+\omega\left(N-N_{1}-N_{2}\right)
\end{aligned}
$$

and apply the maximum principle This guves the following set of necessary conditions for a maximum

$$
\begin{aligned}
& \frac{\partial \mathscr{I}}{\partial K_{1}}=(p l-\lambda) q S F_{K}-\rho \leq 0 . \quad K_{1} \geq 0 \text { and } K_{1} \frac{\partial \mathscr{L}}{\partial K_{1}}=0 \\
& \frac{\partial \Psi^{\prime}}{\partial K_{2}}=G_{K}-\rho \leq 0 \quad K_{2} \geq 0 \text { and } K_{2} \frac{\partial \Psi^{\prime}}{\partial K_{2}}=0 \\
& \frac{\partial \Phi}{\partial N_{1}}=(p l-\lambda) q S F_{N}-\omega \leq 0 \quad N_{1} \geq 0 \quad \text { and } \quad N_{1} \frac{\partial \Psi}{\partial N_{1}}=0 \\
& \frac{\partial \mathscr{I}}{\partial N_{2}}=G_{N}-\omega \leq 0 \quad N_{2} \geq 0 \text { and } N_{2} \frac{\partial \mathscr{I}}{\partial N_{2}}=0 \\
& \lambda-\delta \lambda=-\frac{\partial^{\prime} \mathcal{H}}{\partial S}=-\left[p_{1} q F\left(K_{1}, N_{1}\right)+\lambda \frac{\partial L(S)}{\partial S}-\lambda q F\left(K_{1}, N_{1}\right)^{-}\right. \\
& \dot{S}=L(S)-q S F\left(K_{1}, N_{1}\right)
\end{aligned}
$$




\subsubsection{Temporary equilibrium.}

Equations (3.15a)-(3.15d) define the temporany equilibrium in which the fish stock is fixed and the value of $\lambda$ is taken as given. This is the solution to the static component of the problem. The costate variable. $\lambda$. can be interpreted as a shadow price In this case it is the economic value that the central planner places on a fish remaining in the fishery The central planner takes this value into account. and so engages in fishing effort until the marginal benefit of fishing (i.e. the price received for the fish minus the cost associated from removing it from the fishery) equals the opportunity cost of engaging in fishing effor (i.e the output of other goods foregone) Formally. recall that the opportunity cost of fishing effor (the manufactures that are foregone to produce it). is the slope of the transformation curce between manufactures and fishing effort. Once again. by differentiating the production functions for manufacturing and fishing effort gives

$$
\frac{d X_{2}}{d F}=\frac{G_{K} d K_{2}+G_{1} d N_{2}}{F_{R} d K_{1}+F_{A_{1}} d N_{1}}
$$

Then using the assumption that factor supplies are inelastically supplied. $d K^{\circ}=-d K_{:}$and $d N_{:}=d N_{2}$ along with the first order conditions (3.15 a-d) that imply $\frac{G_{K}}{G_{N}}=\frac{F_{K}}{F_{N}}=\frac{\rho}{\omega}$. the slope of the rate of transformation between manufacturing and fishing effort can be found to be

$$
\frac{d X_{2}}{d F}=-\frac{G_{N}}{F_{N}}
$$

Which. making use of the first-order conditions ( $3.15 \mathrm{c}$ and $d)$ can be re-written as 


$$
\frac{d X_{2}}{q S d F}=\left.\frac{d X_{2}}{d X_{1}}\right|_{\text {remp }}=-\left(p_{1}-\lambda\right)
$$

Equation (3.18) shows that the solution to the central planner's problem leaves a discrepency between the temporary marginal rate of transformation and the world price ratio. reflecting the additional value that the central planner places on fish not caught. Notice, that if $\lambda=0$, and the central planner places no value on the remaining fish stock. then $(3.15 a)-(3.15 b)$ and therefore ( 3.18$)$ resemble the competitive first-order conditions ( 3.3$)-(3.6)$ and tangency condition $(3.11)$ from the open-access model Whereas if $\lambda>0$. as might be expected. then this induces a reduction in fishing effort for any given value of the fish stock. The divergence between domestic prices and world prices is illustrated by Figure 3.0

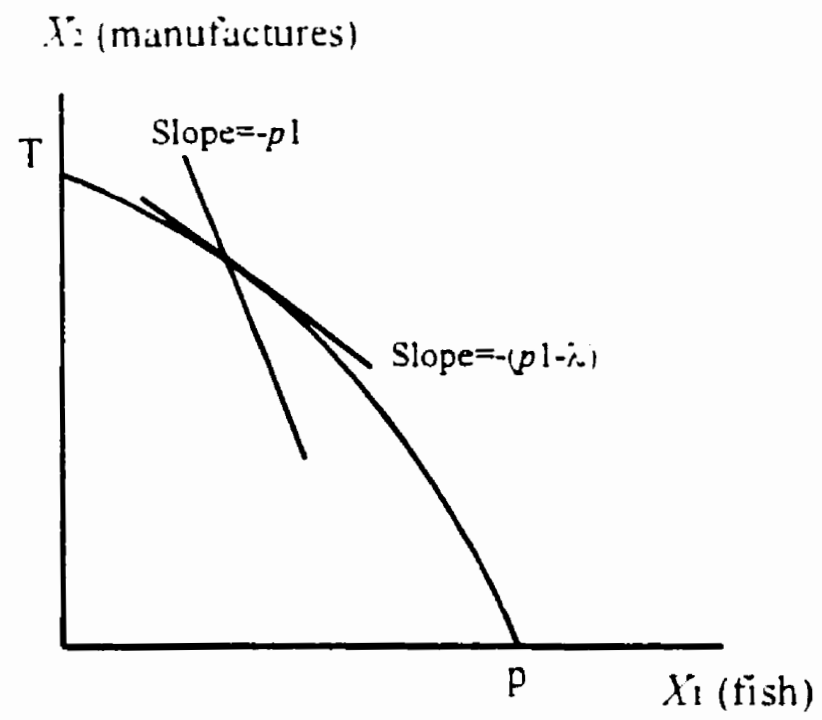

Figure 36

The effect of the divergence between world and domestic producer prices under optimal regulation 


\subsubsection{Steady-state equilibrium}

The steady-state solution to the central planner's problem requires. not only that the economy be in a temporary equilibrium. but also that this equilibrium be sustainable This requires that that $\hat{\lambda}=0$ and $\dot{S}=0$ in equations (3.16) and (3. 17). That is.

$$
\begin{gathered}
\delta \lambda-p_{1} q F-\lambda L^{\prime}(s)+\lambda q F=0 \\
L(S)-q S F=0
\end{gathered}
$$

as well as the condition for temporary equilibrium (3.18) hold (i.e. $\left.\frac{d X_{2}}{d X_{1}}\right|_{\text {remp }}=-\left(p_{1}-\lambda\right)$ ) By varying $\lambda$. equations $\left(3.17^{\prime}\right)$ and $(3.18)$ can be combined to trace out the sustainable production possibilities locus. From Equatıon (3.16') the point on this locus that solves the central planner's problem ( $\mathrm{P} 3$ 1) can be found Together. all three solve for the fisheries management rule that the central planner should follow in steady state

In order to derive this rule. start by rearranging ( 316$)$

$$
\delta=\frac{\left(p_{1}-\lambda\right)}{\lambda} q F+L^{\prime}(S)
$$

where the prime indicates the partial derivative. Then using (3.18). note that

$$
\frac{\left(p_{1}-\lambda\right)}{\lambda}=-\frac{\left.\frac{d X_{2}}{d X_{1}}\right|_{\text {remp }}}{p_{1}+\left.\frac{d X_{2}}{d X_{1}}\right|_{\text {remp }}}
$$

Equation (3.20) can now be substituted into (3.19) along with $\frac{L(S)}{S}$ for $q F$ (from 3.17) 
This re-arrangement of (3.19) gives the "modified golden rule" for the two-sector fishing economy

$$
\delta=L^{\prime}(S)-\frac{\left.\frac{d X_{2}}{d X_{1}}\right|_{\text {temp }}}{p+\left.\frac{d X_{2}}{d X_{1}}\right|_{\text {temp }}} \frac{L(S)}{S} .
$$

The two components of the right-hand side of $(321)$ can be explained as follows If the opportunity cost of fishing effor was zero. then the second term on the right-hand side of (3.21) would be zero and (3.21) would simplify to

$$
\delta=L^{\prime}(S)
$$

This simplified version of ( 321 ) resembles the modified golden rule of capital accumulation with the fish stock playing the same role as the capital stock. and the logistic function effectively being the production function for fish. Equation (3 2I') requires that fish be accumulated to the point where the marginal product of tish in the fishery (its own rate of interest) equals the discount rate

Now consider the role of the second term in (3.21). Clark and Munro (1975) derive a term similar to

$$
-\frac{\left.\frac{d X_{2}}{d X_{1}}\right|_{\text {temf }}}{p+\left.\frac{d X_{2}}{d X_{1}}\right|_{\text {temp }}} \frac{L(S)}{S}
$$

which Clark and Munro refer to as the marginal stock effect. In this particular case the marginal stock effect reflects two things. Firstly it captures what Munro and Clark 
(1975) call the stock thinning effect - as the stock is reduced, the productivity of fishing effort decreases and the returns from fishing therefore fall. This can be seen by noting that $\left.\frac{d X_{2}}{d X_{1}}\right|_{\text {temp }}=\frac{d X_{2}}{q S d F}$ and hence as $S$ falls, the right-hand side becomes larger. Therefore. the optimal equilibrium fish stock implied by (3.21) is larger as a result. The second effect, captured by the marginal stock effect, is the increasing opportunity cost of fishing effort in terms of manufactures introduced via the Heckscher-Ohlin production structure As fishing effort is increased, celeris parihus, the term $\frac{d X_{2}}{d F}$ increases (in absolute terms). Once again the presence of this effecr tends to mitigate fishing effort and leads to a higher stock and lower level of fishing effort compared to the case when the opportunity cost of fishing effort in terms of manufactures was constant.

\subsection{The Supply of Fish}

This section explores the optimal steady-state supply of fish. In doing so. first use $(3 \geq 1)$ to show that. as one would expect. there is a negative relationship between the world price ratio. $p_{1}$. and the stock of fish. This is done in Appendix 3.3 . This relationship also implies that the level of fishing effort must rise with the relative price of fish Consequently, if the price should rise by a sufficient amount, then the level of fishing effort will exceed the level that produces the maximum sustainable vield (MSY) and the sustainable harvest of fish will fall (that is, the supply of fish will bend back). To show this. all that is necessary is to show that there is some price. $\dot{p}_{1}$. at which the harrest equals the MSY and therefore both the sustainable locus and the supply curve are vertical. At the MSY. $L^{\prime}(S)=0$, so (3.21) becomes 
or, after rearranging,

$$
\delta=-\frac{\left.\frac{d X_{2}}{d X_{1}}\right|_{\text {temp }}}{\hat{p}_{1}+\left.\frac{d X_{2}}{d X_{1}}\right|_{\text {temp }}} \frac{L(S)}{S}
$$

$$
\hat{p}_{1}=-\left.\frac{d X_{2}}{d X_{1}}\right|_{\text {remp }}\left[1+\frac{L(S)}{S} \frac{1}{\delta}\right]
$$

Since $\left.\frac{d X_{2}}{d X_{1}}\right|_{\text {temp }}$ and $S$ are given and constant at the MSY. equation (3.22) gives the price as a function of $\delta$. Therefore there exists. for a given $\delta>0$. a positive price. $\hat{p}_{1}$. such that the harvest produced is equal to the MSY. It follows therefore that any further increase in $p$ : bevond $\hat{p}_{1}$ would produce a fall in the sustainable output of fish (that is. the supply of fish is backward bending ${ }^{\text {it }}$

Note from (3.22) that there is a negative relationship berween $\tilde{o}$ and $\dot{p}_{1} \quad$ That is. the higher the rate of discount. the lower the relative price that produces the MSY in equilibrium. From this it can be said that the likelihood of operating on the backward bending portion of the supply curve is greater the higher the discount rate

\subsubsection{Comparison of dynamic equilibrium with static equilibria.}

It is well known that the equilibrium conditions to the dynamic problem mimic the static optimally regulated and open-access equilibria when $\delta=0$ and $\delta=x$ respectively (see

${ }^{14}$ Note that if $\delta=0$, the relative price of fish must reach infinity before the MSY is reached and consequently the relative price of fish can not rise sufficiently for the supply curve to bend back 
Clark (1990), Munro and Scott (1985)). ${ }^{\text {s }}$

This can be confirmed by noting that when $\delta=0 .(3.21)$ can be re-written as

$$
\left.\frac{d X_{2}}{d X_{1}}\right|_{r e m p} \frac{\frac{L(S)}{S}-L^{\prime}(S)}{L^{\prime}(S)}=p_{1}
$$

Now: the second term on the LHS can be shown to be equal to $-\frac{1}{\eta+1}$ where $\eta$ is the elasticity of the stock with respect to fishing effort. " That is. (3.21) becomes.

$$
-\left.\frac{d X_{2}}{d X_{1}}\right|_{\text {temp }} \frac{1}{1+\eta}=p_{1}
$$

From the earlier analy'sis in this chapter. it is known that this version of the modified golden rule implies that in equilibrium the sustainable production possibilities locus is tangent to the trade line This is just the condition for welfare maximisation in the static model as derived in the previous section. When $\delta=x$. it can be seen that $(321)$ implies (311), which is just the open-access equilibrium condition that $\left.\frac{d X_{2}}{d X_{1}}\right|_{\text {remr }}=-p$.

Is Strictly speaking. in order for problem P3 I to have a solution. 8 can not equal zero. we will assume that $\delta$ is arbitrarily close to zero

${ }^{16}$ Totally differentiating the steady-state condition for a sustainable yield. $L(S)=q S F$, gives $\frac{d S F}{d F} \frac{q F}{S}=\frac{q F}{L^{\prime}(S)-q F}$ or $\eta=\frac{L / S}{L^{\prime}(S)-L / S}$ from which it is straight forward to derive 3.23 .

${ }^{17}$ Alternatively. with the restrictions that $\lambda=0$ and $\dot{S}=0$. (3.16) and (3.17) could be combined to find an expression for $\lambda_{L(S)}$

$$
\lambda=\frac{p_{1} \frac{L(S)}{S}}{\frac{L(S)}{S}-L^{\prime}(S)+\delta}
$$


Lastly, note that the slopes of the sustainable production possibilities locus and the temporary PPF when no fishing effort takes place are the same. This can be demonstrated by the relationship between the two

$$
\left.\frac{d X_{2}}{d X_{1}}\right|_{\text {temp }} \frac{1}{1+\eta}=\left.\frac{d X_{2}}{d X_{1}}\right|_{\text {sust }}
$$

When the level of fishing effort is zero and the steady-state stock, $S$, is equal to the capacity of the fishery. $c$, then $F S(d S d F)=0$. Hence the two have the same slope The implication is that no matter what the discount rate. the price that induces the first unit of fish to be produced is the same. This can be calculated to be

$$
d X_{2} /\left.d X_{1}\right|_{\text {tempF=0 }}=\left.\frac{1}{q c} \frac{d X_{2}}{d F}\right|_{F=0}
$$

Lising the information from this section. the supply curve for fish. and the corresponding equilibrium in output space, can be drawn as illustrated in Figure 3.7 . The figure shows that as the discount rate is reduced from infinity. the equilibrium in the output space moves anti-clockwise around the sustainable production possibilities frontier. The case when $\delta=0$. corresponds to the equilibrium that maximises welfare as derived for the static model. Similarly, the case when $\delta=x$ mimics the open-access case.

As $\delta$ approaches infinity. $\lambda$ approaches 0 . and therefore the first-order conditions ( $3.15 \mathrm{a}$ d) mimic those for the open-access case (Equations (3.3)-(3.6)). 


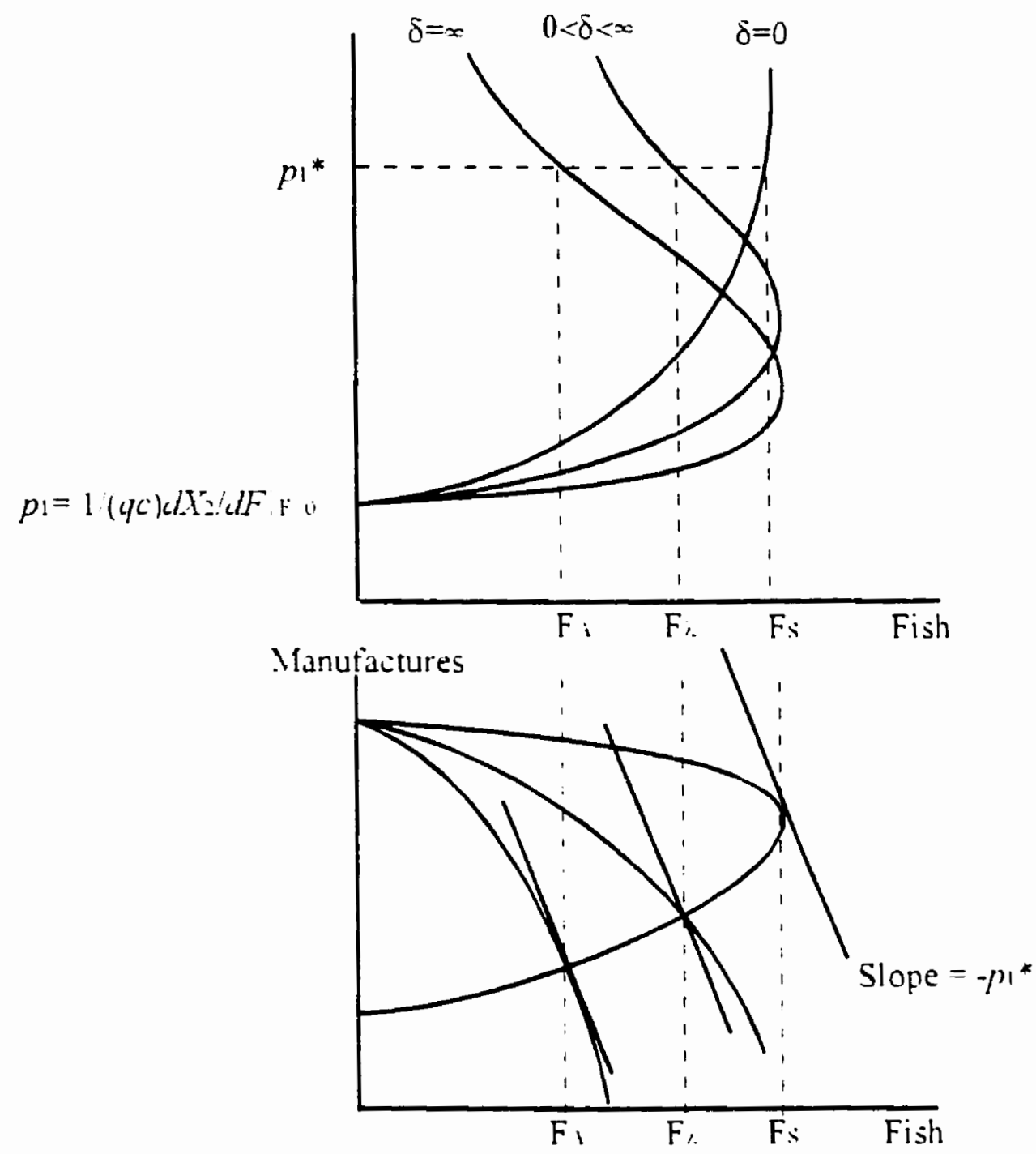

Figure 37

The supply of fish. discount rates. and general equilibrium

\subsection{Conclusion}

The objective of this chapter was to develop and compare the static and dynamic general equilibrium models of renewable resource harresting. The chapter first compared the Ricardian and Heckscher-Ohlin models assuming open access. It was shown that the 
Ricardian model resulted in complete dissipation of all rents associated with the fishery while. in the case of the Heckscher-Ohlin model. some of the rents from the fishery accrued permanently to labour and capital This result arises because the opportunity cost of fishing effort is constant in the Ricardian model but increasing in the HeckscherOhlin model. Thus, citizens of a country who care only about steady-state welfare would be indifferent between the presence or absence of an open-access fishery if the production structure was Ricardian. but would prefer the presence of the fishery if the production structure was Heckscher-Ohlin The presence of these rents in the HeckscherOhlin model may have important implications for the effects of trade. For example. it was shown that if a country was exporing tish. then an increase in the relative price of fish on the world market would unambiguously worsen welfare in a diversified. openaccess. Ricardian model. The reason is that all the rents associated with the improvement in the terms of trade are dissipated. and consumers (who earn only wage income. which is unchanged) are simply left facing a higher world price of tish. In the Heckscher-Ohlin case. some of the economic rent associated with the improvement in the terms of trade also accumulates with other factors of production. capital and labour. and persist through time. Thus, welfare in the Heckscher-Ohlin economy man be improved by an improvement in the terms of trade. This is potentially an important result that must be kept in mind when considering the implications of analysis undertaken with the Ricardian model.

This chapter also developed a dynamic Heckscher-Ohlin model, in which the authorities 
(a central planner) maximized the present value of GDP, rather than the steady-state value of GDP. It was shown that in the case where the discount rate lies between the two extremes of 0 and infinity that the equilibrium fish stock will be greater than under open access and less than when steady-state welfare is maximised. This gives rise to the possibility that the economy will produce on the backward bending portion of the sustainable production possibilities frontier and that an increase in the relative price of fish may. in the long-run, result in a fall in the output of both fish and manufactures. a result similar to that found in the open-access case. However. in this case it arises because agents discount the future. rather than being unable (or unwilling) to enforce the property right associated with the fishery

In the rest of this thesis the static models will be employed to consider the effects of trade and foreign investment policy. In much of the analysis the Ricardian model will be employed. leaving aside the Heckscher-Ohlin model. While such assumptions limit the results. it considerably simplifies the analysis. Nevertheless the results of this chapter are able to give some insight into how a relaxation of these assumptions might affect the analysis. 


\section{Appendix 3.1 Approaches to the Common Property Fishery Compared.}

It may be useful to put the static analysis of the model set out at the beginning of this chapter into the context of a more traditional approach to the analysis of the fishery. It is often explained that fishers enter the fishery until the average product of fishing effort equals the cost of providing that effort. (When labour is the only factor, labour enters the fishery until the average product of labour equals the wage). It can be shown that this is the case with the open-access model set out above. Intuitively. recall the open-access equilibrium illustrated by point $A$ in Figure 3.3. At A. fishers equate private opportunity (marginal) costs with the relative price of fish. Since competitive fishers maximise current profits, taking the stock of fish as given. private marginal benefits of fishing (i.e the price of fish in terms of manufactures. $p_{1}$ ) must equal private marginal costs. That is. fishers enter until $p_{1}=\left.\frac{d X_{2}}{d X_{1}}\right|_{\text {temp }} \quad$ The zero protit condition also ensures that $p_{1}=. H^{\circ}$ $=\frac{w \cdot v_{1}+r K_{1}}{X_{1}}$. Because the firms hire labour and capital in competitive labour markets. this equilibrium also has the privule marginal products of labour and capital equal to the market wage and rental rates respectively. Similarly, the zero profit condition can also be re-expressed as the condition that the value of the average product of fishing effort ( $\left.L A P_{F E}\right)$ equals the price of fishing effort. This can be seen by simply multiplying the zero profit condition by $q S$.

$$
\begin{aligned}
& \frac{p_{1} q S F}{F}=\frac{w N_{1}+r K_{1}}{F} \\
& I A P_{F E}=P_{F E} .
\end{aligned}
$$

Where $P_{F E}$ is the unit price of fishing effort 
It can also be found that the social marginal product of fishing effort is less than the price of fishing effort and the value of the average product of fishing effor and hence that there is overfishing. This can be seen by calculating the value of the social marginal product of fishing effort.

$$
\begin{aligned}
V S M P_{F E} & =\frac{\partial\left(p_{1} q S F\right)}{\partial F} \\
& =p_{1} q S\left(\frac{\partial S}{\partial F} \frac{F}{S}+1\right) \\
& =p_{1} q S(\eta+1)
\end{aligned}
$$

Where $\eta$ is the elasticity of the stock with respect to fishing effor Since the stock falls

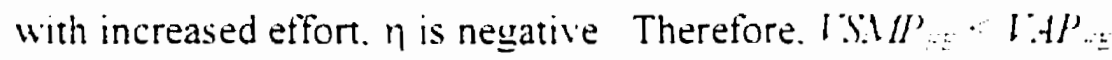

Lastly, it is shown that the optimal level of fishing effort requires the value of the social marginal product of fishing effor to be equal to the price of fishing effor. That is

$$
\begin{gathered}
\quad \text { SSI } / P=P_{E E} \\
\text { or. } \quad p_{1} q S(\eta+1)=\frac{w N_{1}+r K_{1}}{F}
\end{gathered}
$$

Rearranging $(A 31+)$ gives

$$
\begin{aligned}
p_{1} & =\frac{1}{(\eta+1)} \frac{w N_{1}+r K_{1}}{q S F} \\
& =\frac{1}{\eta+1} A C_{X_{1}} \\
& =\frac{1}{\eta+1} P M C_{X_{1}}
\end{aligned}
$$

that is,

$$
p_{1}=-\left.\frac{1}{\eta+1} \frac{d X_{2}}{d X_{1}}\right|_{\text {temp }}
$$


As derived in the main body of the chapter. Equation (A3.1.5) is just the requirement for steady-state welfare to be maximised ( $i$ e. that the trade line be tangent to the sustainable production possibilities locus). 


\section{Appendix 3.2: Equilibrium Dynamics}

Using a phase diagram analysis, this appendix provides a qualitative analysis of the dynamic properties of the economy governed by the set of equilibrium conditions ( 3.15 a-d), (3.16) and (3.17).

$$
\begin{aligned}
& \frac{\partial \mathscr{L}}{\partial K_{1}}=(p l-\lambda) F_{K}-\rho \leq 0 . \quad K_{1} \geq 0 \quad \text { and } \quad K_{1} \frac{\partial \mathscr{L}}{\partial K_{1}}=0 \\
& \frac{\partial \Psi^{\prime}}{\partial K_{1}}=p_{2} G_{K}-\rho \leq 0 \quad K_{2} \geq 0 \quad \text { and } \quad K_{2} \frac{\partial \mathscr{L}}{\partial K_{2}}=0 \\
& \frac{\partial \Psi}{\partial N_{1}}=(p 1-\lambda) q S F_{N}-\omega \leq 0 . \quad N_{1} \geq 0 \quad \text { and } \quad N_{1} \frac{\partial \Phi}{\partial N_{1}}=0 \\
& \frac{\partial \Psi}{\partial N_{2}}=p_{2} G_{N}-\omega \leq 0 \quad N_{2} \geq 0 \text { and } \quad N_{2} \frac{\partial L_{1}}{\partial N_{2}}=0 \\
& \hat{\lambda}-\hat{\partial} \dot{\lambda}=-\frac{\partial \mathcal{H}}{\partial S}=-\left[p_{1} q F\left(K_{1}, N_{1}\right)+\lambda \frac{\partial L(S)}{\partial S}-\lambda q F\left(K_{1}, N_{1}\right) .\right. \\
& \dot{S}=L(S)-q S F\left(K_{1}, N_{1}\right)
\end{aligned}
$$

This set of equilibrium conditions can be thought of as consisting of two parts - the equations describing the dynamics of the system ( 316$)$ and (3.17). and equations ( 3.15 ad) describing the equilibrium for the static component of the central planner s problem in which the values of $S$ and $\lambda$ are taken as given.

Drawing the phase diagram involves plotting the isoclines for the state and costate variables (that is, the loci of points in $(S, \lambda)$ space for which $\dot{S}=0$ and $\dot{\lambda}=0$ respectively) 
This involves plotting equations (3.16) and (3.17) with $\dot{S}$ and $\lambda$ set equal to zero. Note that these two equations involve the level of fishing effort. $F$ Fishing effort is itself an endogenous variable determined by the solution to the static component of the problem This must first be solved for and substituted in to (3.16) and (3.17) before the isoclines can be plotted.

From $(3.15 \mathrm{a}-\mathrm{d})$ it can be seen that the equilibrium values of $K_{1}, K_{2}, N_{1}$ and $V_{2}$ can be determined as functions of $p_{\mathrm{t}} S$ and $\lambda$ (as well as total factor supplies which are assumed to be in fixed supply). In particular. note that we can define a new variable $\pi=\left(p_{1}-\lambda_{2}\right) \varphi_{S} S$ Substituting $\pi$ into ( $3.15 \mathrm{a}$ and $c)$ Notice that with this substitution. equations $(315 \mathrm{a}-\mathrm{d})$ have the form of the standard Heckscher-Ohlin model with $\pi$ playing the role of a relative price It can be seen that the equilibrium level of factor employment in each industry. and the outputs of each. can be written as functions of $\pi$. Therefore. let the equilibrium value of fishing effort that comes from solving $(3.15 \mathrm{a}$-d) be defined by the function $\Phi=\Phi(\pi)$. The standard properties of the Heckscher-Ohlin model ensure that $\Phi$ has the following properties: $\Phi^{\prime}>0 . \Phi^{\prime \prime}>0$, with $\Phi_{\lambda}$ and $\Phi_{,}<0$ and $>0$ respectively (an increase in the user cost. or shadow price of fish. reduces fishing effor. while an increase in the fish stock improves the productivity of fishing and increases fishing effort). The phase diagram can now be analysed. 
Start by substituting $\Phi$ into (3.16) and (3.17) and setting $\dot{S}$ and $\dot{\lambda}$ equal to zero. This gives

$$
\begin{aligned}
& \delta \lambda-p_{1} q \Phi(\pi)-\lambda L^{\prime}(s)+\lambda q \Phi(\pi)=0 \\
& L(S)-q S \Phi(\pi)=0
\end{aligned}
$$

Equation ( $\left.3.16^{\prime}\right)$ defines the $\lambda$ isocline. and $\left(3.17^{\prime}\right)$ defines the $S$ isocline. Begin with the latter. leaving the more complicated $\lambda=0$ locus until last.

Without resorting to specific functional forms, it is difficult to simply express $\lambda$. as a function of $S$. This is not a particular problem since the objective here is to illustrate the nature of the solution. All that is required is that the shape and position of the isocline be determined. The set of points $(S, \lambda)$ that solve (3.17') are most simply illustrated using Figure A3.2.1.

The top portion of this Figure A3.2. I illustrates the logistic growth function. $/ .($.$) ) and the$ harrest function. $\dot{H}\left(S, p_{1}, \lambda\right)=q S \Phi$ The harrest function is a positively sloped convex function of $S$. This can be determined by differentiating $\dot{H}$ with respect to $S$ and making use of the properties of $\Phi(\pi)$ as stated above. ${ }^{\text {Ix }}$

${ }^{18}$ The first and second order partial derivatives of $\dot{H}$ can be found to be.

$\frac{\partial \tilde{H}}{\partial S}=q \Phi+S q \Phi \Phi_{S}>0$. Furthermore. it can be confirmed that $\tilde{H}$ can only intersect once with $L(S)$ since $\frac{\tilde{H}}{S}$ is strictly increasing in $S$. while $\frac{L(S)}{S}$ is strictly decreasing. 
The position of this function is determined by the values of $\lambda_{2} p_{1}$, and $q\left(p_{1}\right.$, and $q$ are taken as parameters). From the properties of $\Phi(\pi) . \frac{\partial \tilde{H}}{\partial \lambda}<0$. Thus for higher values of $\lambda$ the lower the level of harvesting for any given size of the fish stock (i.e., a higher value placed. by the central planner, on fish in the fishery reduces the level of fishing effor and the harvest). When $\lambda=0$ some positive amount of the fish stock is needed to induce some harvest of fish (this follows since it is assumed that $\pi$ must be greater than zero to induce some fishing effort). As $\lambda$ is increased, the harvest schedule shifts downwards (however. note that. by assumption. negative han'ests are not permitted - fish cannot be put back)

By varying $i$. the value of $S^{\prime}$ that solves $\left(3,7^{\prime}\right)$ can be determined from the intersection of the harvest and logistic functions. This allows the $S$ isocline to be traced out in the bottom half of Figure $A 3=1$. It is upward sloping until the value of $\lambda$ is reached that produces zero fishing effort. $\bar{\lambda}$. Once this level is reached. the fishery has reached its natural capacity. Again. since negative harests are not permitted (nor can effort be devoted to increasing the natural capacity of the fishery), any further rise in $i$ will leave the fish stock unchanged at its maximum steady-state level $S_{\text {. }}$. Hence the $S$ isocline becomes vertical values of $\lambda_{>}>\lambda^{\prime}$ 


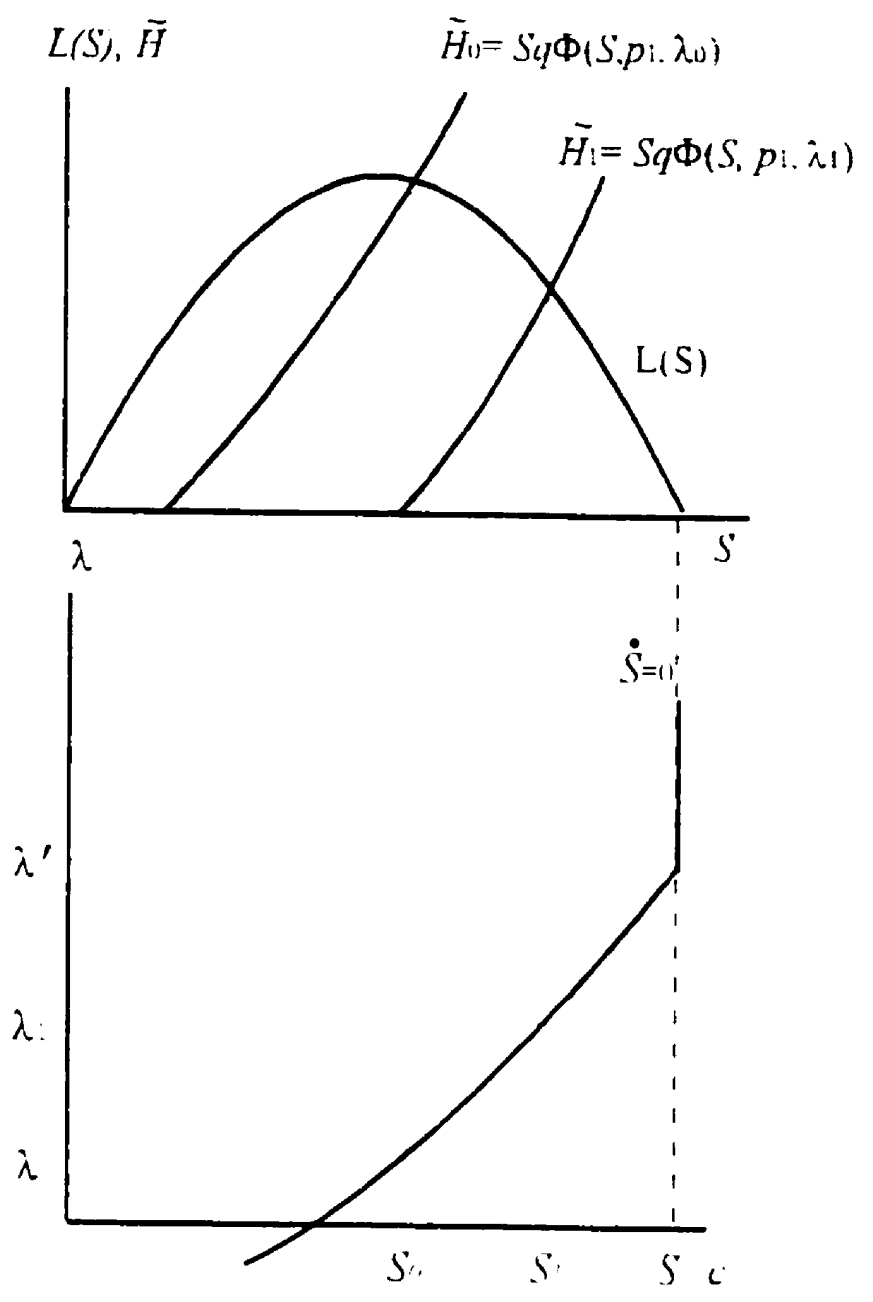

Figure 4321 
Now consider the $\lambda$ isocline. Along this locus. $\dot{\lambda}=0$. That is, the present value of a fish left in the fishery, $\lambda$, is neither growing nor falling. Essentially this is just an arbitrage condition., If $\dot{\lambda}>0$. then the present value of a fish in the fishery at time $t$ is less than at some time thereafter, say, $t+\varepsilon$; the central planner could therefore gain by leaving. at time t. an additional fish uncaught, in order that it be caught in the future, at $t+\varepsilon$ say.

To start with. recall (3 16')

$$
\delta \lambda-p_{1} q \Phi(\pi)-\lambda L^{\prime}(s)+\lambda q \Phi(\pi)=0
$$

or. after rearranging.

$$
\frac{\left(p_{1}-\lambda\right)}{\lambda} q \Phi=\delta-L^{\prime}(S)
$$

This can be simplified further by substituting in for $L^{\prime}(S)$. Recall the logistic equation

$$
L(S)=\gamma S\left(1-\frac{S}{c}\right)
$$

From which the partial derivative can be found to be

$$
L^{\prime}(S)=\gamma\left(1-\frac{2 S}{c}\right) \text {, }
$$

where it will be recalled that $y$ is the intrinsic growth rate of the stock. Substituting (A3.2.2) back into (A3 2.1) gives.

$$
\frac{\left(p_{1}-\lambda\right)}{\lambda} q \Phi=\delta-\gamma\left(1-\frac{2 S}{c}\right)
$$

Equation ( $A 32.3$ ) will be used to plot the $\lambda$ isocline Lnfortunately. its shape and position are somewhat more complicated to derive than the isolcine for the state variable. 
It is helpful to define the following functions for the left- and right-hand sides of (A3.2.3)

$$
A(S, \lambda)=\frac{\left(p_{1}-\lambda\right)}{\lambda} q \Phi
$$

and. $\quad B(S)=\delta-\gamma\left(1-\frac{2 S}{c}\right)$

Then by graphing.$A(S, \lambda)$ and $B(S)$ the $\lambda$ isocline can be derived in a fashion similar to that used to derive the $S$ isociine.

The graph plotting the right-hand side of (A3.2.3). i.e. $B(S)$. is straight forward (see Figure (3A.2.2a)) Note that the intercept depends on the value of $\delta$ relative the intrinsic growth rate. $\%$

The graph for the left-hand side. i e $f(S, \lambda)$, is composed of two parts the function $\Phi(S)$ i.). and the coefficient $\frac{\left(p_{1}-\lambda\right)}{\lambda}$. Recall that $\Phi\left(S \lambda_{2}\right)$ is a positively sloped concave function of $\triangle$ For a given $\triangle \Phi$ intersects the horizontal $S$ axis at $.5(\lambda)$. This level of the fish stock is sufficiently small to induce no fishing effort. given the value of $\%$. In Figure (A3.2.2b) when $\lambda=0$ (i.e. there is no cost from fishing the fishery). $S(0)$ is small compared to the case when the user cost is relatively large and a large stock is required before fishers find it profitable to enter It follows that when $\lambda=0$, and the slope coefficeint. $\frac{\left(p_{1}-\lambda\right)}{\lambda}$. goes to infinity, and hence $f(S, 0)$ is vertical at $S(0)$. As $\lambda$ is increased. $\underline{S}(\lambda)$ increases. and the slope coefficient $\frac{\left(p_{1}-\lambda\right)}{\lambda}$ falls and consequently the 
function $A(S, \lambda)$ shifts rightwards and pivots downward. This is illustrated in Figure (3.A.2.2b)

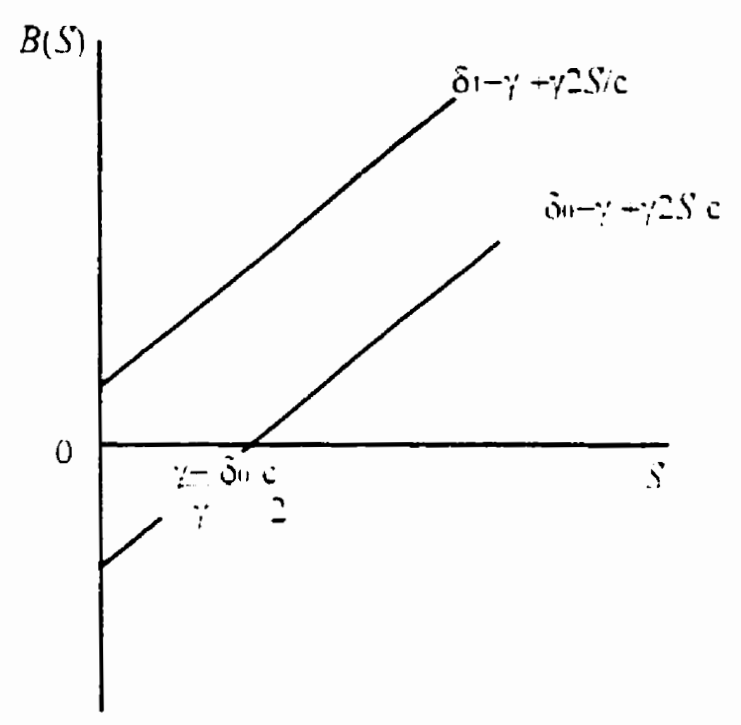

Figure $A 322 a$

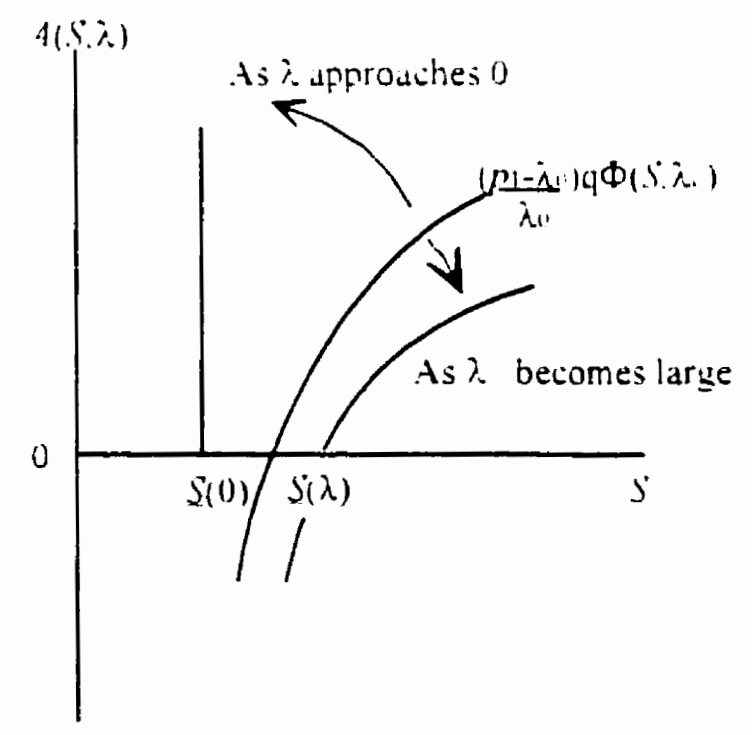

Figure $13.2 .2 b$ 
Figures (A3.2.2a) and (A3.2.2b) can be combined to derive the $\lambda$ isocline. In Figure (A3.2.3) this is done by simply varying $\lambda$ to determine the values of $S$ that produces an intersection between $A$ and $B$. There are two points to notice. First, the concavity of $A$ may result in two solutions for a given value of $\lambda$. This is shown in Figure A3.2.3 where it can be seen that $A$ and $B$ intersect twice when $\lambda=\lambda^{\prime}$ Second, in some cases there may be an intersection between $A$ and $B$ below the horizontal axis (once again this is illustrated as one of the possible solutions in Figure ( $(3.23))$ This involves negative values for $f$ and hence negative values of $\Phi$ also This solution corresponds to small values of $S$. points to the left of the horizontal intercept of $B(S)$. (i e. . $S<\frac{(\gamma-\delta)}{\gamma} \frac{c}{2}$ ) and hence relatively small discount rates $\mathcal{S} \cdots \%$ The intuition behind this type of solution is that the fish stock is growing so fast at the current level of $S$ and the discount rate sufficiently low. that in order for the arbitrage condition to hold. the central planner would want to be employing fishing effort to antificially increase the stock in the current period That is. the central planner would benefit from placing a fish in the fish stock and reaping the harvest in the future Since this behaviour is ruled out. such points on the $\lambda$ isocline are not considered feasible (such points are illustrated by the dashed portion of the isocline in the figures that follow). ${ }^{11}$

19 One could imagine that this could technically be achieved by the central planner if she could borrow resources to increase the output of manufactures and then sell them for fish to add to or replenish the fishery. This type of investment is implicitly what is being ruled out here. 


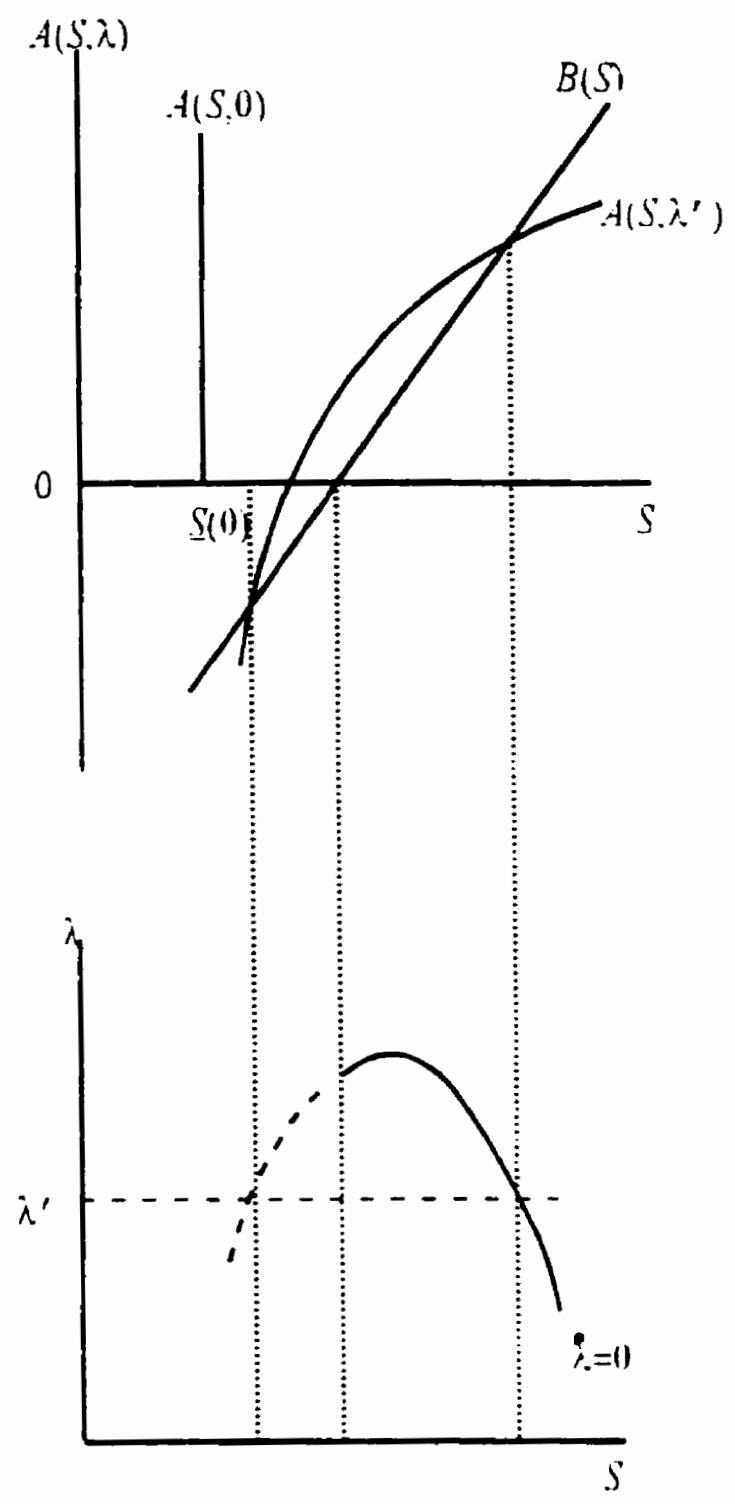

Figure +3 2.3 
It is useful to consider two cases: (1) when $B(S)$ intersects the horizontal axis at or to the right of $A(S, 0)$, i.e to the right of $S(0)$, and (2) when $B(S)$ is strictly positive for all positive values of $S$, or $B(S)$ intersects the horizontal axis to the left of $A(S, 0)$. These two cases are considered separately.

CASE 1: $(B(S)$ intersects the horizontal axis at or to the right of $A(S, 0))$ : Referring to Figure A3.2.4. it can be seen that small values of $\lambda$ may produce negative values of $\Phi$ Note for example the case when $i=0$. ts $i$ is increased however. the concavity of $\Phi$ ensures that there is some value of $\lambda_{\text {. such as }} i_{0}$. that will produce a solution with a positive $\Phi$. It can be seen that this will involve a large value of $S$ since. at the intersection of $t$ and $B$. $A(S, \lambda)$ cuts $B($.$) from above and f(S$.$) is thatter than B\left(S^{\circ}\right)$ ts

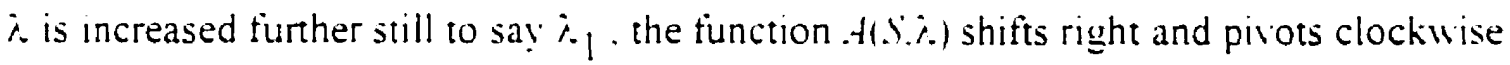
and the value of $S^{\prime}$ that satisfies $\left(316^{\prime}\right)$ with $\Phi>0$ ) becomes smaller $\left(S_{1}\right)$ Eventually. with increases in $\lambda$, the possibility arises that $\Phi\left(S, \lambda_{1}\right)=0$ when $A$ and $B$ intersect on the horizontal axis. ( $S=\frac{\gamma-\delta}{\gamma} \frac{c}{2}$ ). Denotethe value of $\lambda$ that produces this result by $\lambda$ This is the lowest value of $S$ that corresponds to a feasible solution to ( $\left.316^{\prime}\right)$ for any value of $\lambda$. Any additional increase in $\lambda$ will produce two feasible solutions if $A$ is steeper than B or two negative values of $\Phi$ and therefore no feasible solutions. The former is illustrated in Figure (A3.2.4). In this case it can be seen that the $\lambda$ isocline is hump shaped 


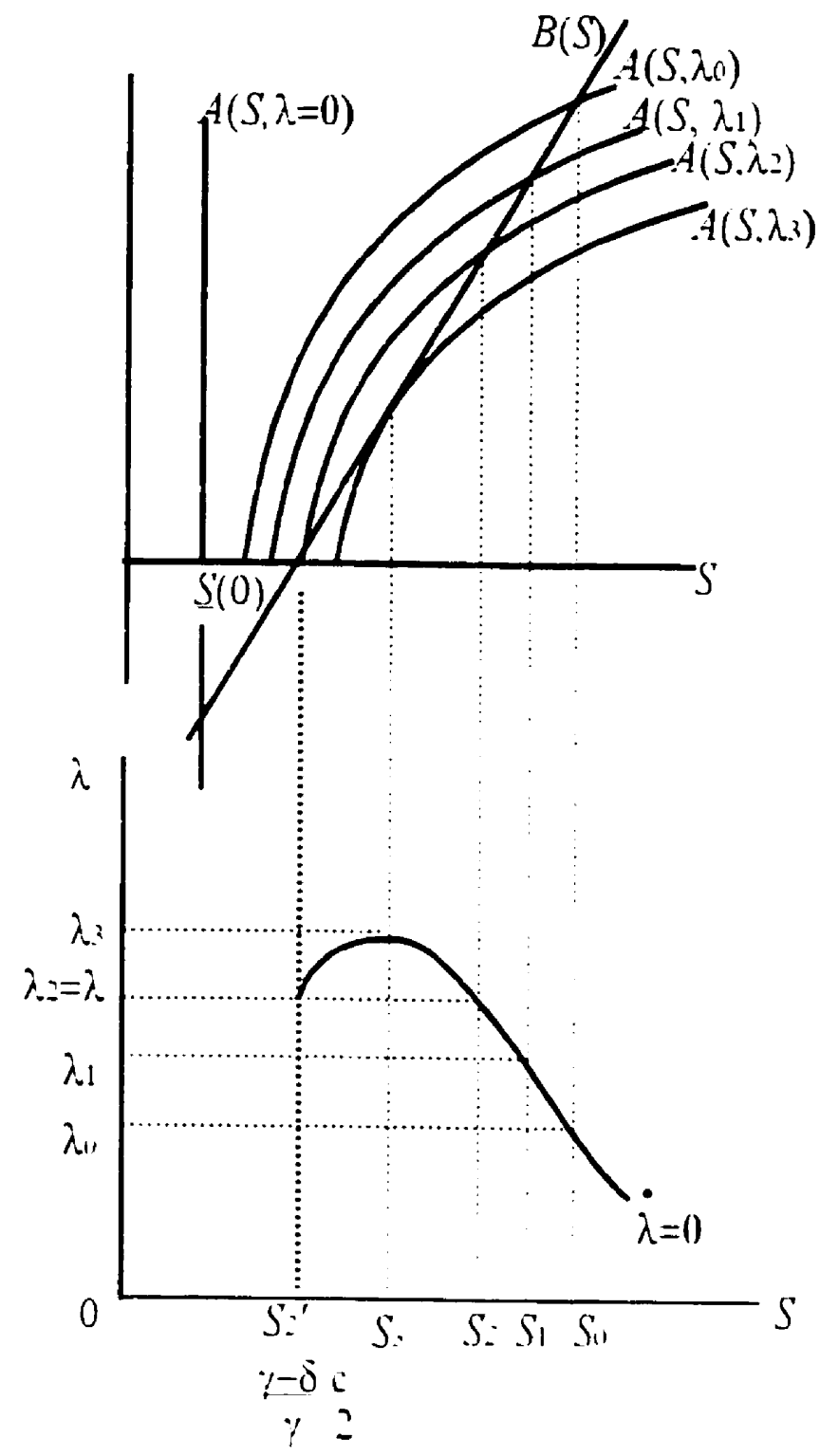

Figure $+32+$ 
CASE 2: $(B(S)$ intersects the horizontal axis to the left of $A(S, 0)):$ In this case. the discount rate is relatively high, and unlike the previous case we would not expect the central planner to be patient enough to put effort into "putting fish into the fisher.". even when the rate of growth of the fish stock is relatively high. This can be seen to be the case and consequently, all solutions corresponding to a positive value of $\lambda$ are feasible By increasing $\lambda$ from zero it can be seen that the $\lambda$ isocline will initially be positively sloped. and may have a hump shape as illustrated below on Figure ( $A 3.2 .5)$

Note that increases in $\delta$ shift the $B(S)$ line upwards, as a result, the response of $S$ to a change in $i$ is greater when $\delta$ is greater In the limit, when $\delta=x$. the response is pertectly elastic. and the $i$ isocline is coincident with the $S$ axis That is. when the central planner places no value on the future, the present value of a fish in the fishery that satisties the arbitrage condition is zero 


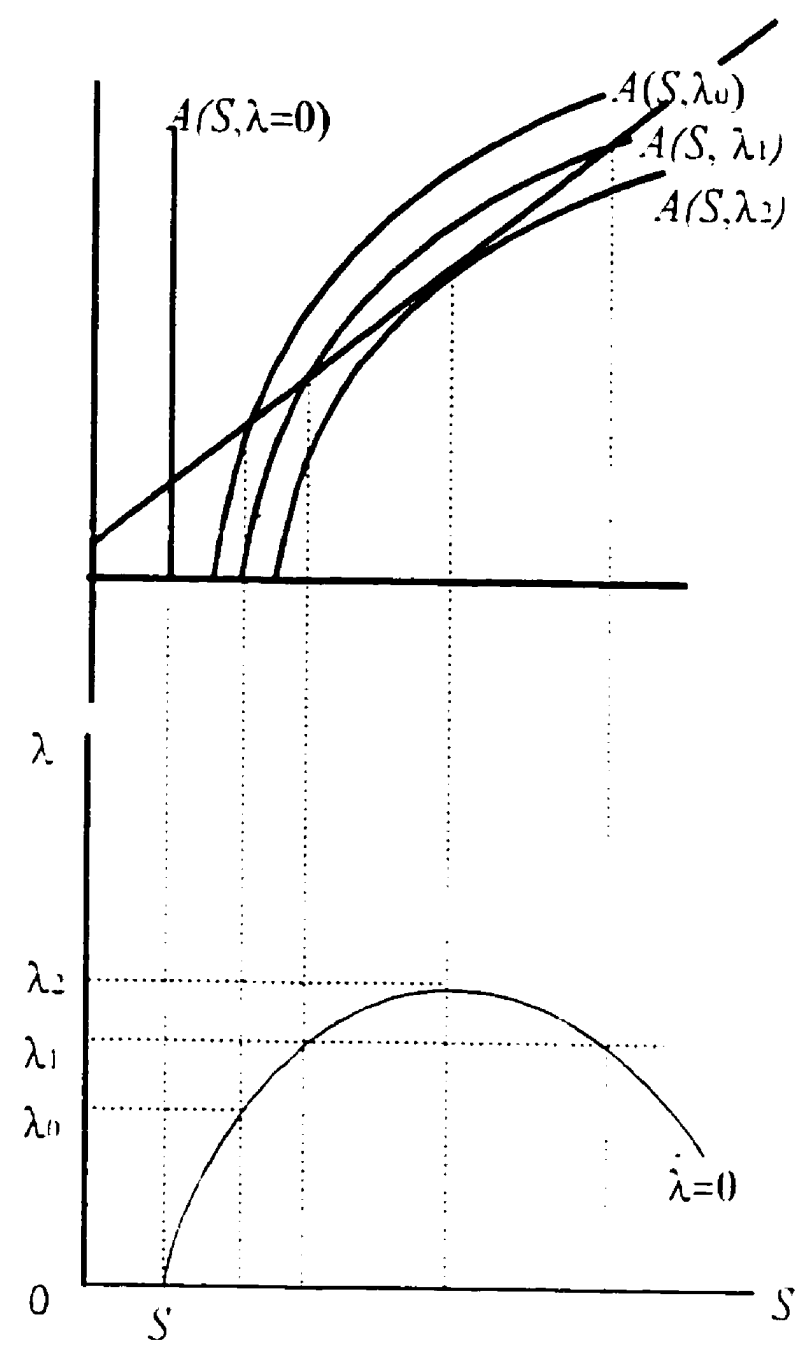

Figure t. 325 
The next step is to combine the two isoclines and add the arrows of motion. In Case 2. where $B(S)$ intersects the horizontal axis to the left of $A(S .0)$. note that the value of $\underline{S}$ where the $\lambda$ isocline intersects that horizontal axis (i.e. when $\lambda=0$ ) is less than the value of $S$ for which the $S$ isocline cuts the horizontal axis. To see this recall that $S$ is the value of $S$ that induces zero fishing effort when $\lambda=0$. However. if $S<c$ and fishing effort was zero then the stock would grow. Therefore. in this case $\lambda$ would have to be negative (fishers paid to engage in fishing effort) to induce a level of fishing effort that keeps $\dot{S}=0$ This implies that the $\lambda$ isocline intersects the horizontal axis to the left of the $\mathrm{S}$ socline

In case $1 . B(S)$ intersects the horizontal axis at or to the right of $f(S)$ (1) From Figure $(A 32+)$ recall that the lowest feasible value of $S$ for the $\%$ isocline was given by the.${ }^{\prime}$ intercept for the line $B(S)$. This value of $S$ was therefore equal to $\hat{S}=\frac{\gamma-\delta}{\gamma} \frac{c}{2}$ Recall that it was shown that the $\dot{\lambda}$ isocline lies above the $S$ axis for $S=\hat{S}$ with $\hat{\lambda}=\hat{\lambda}$. We can now show that the $S$ isocline passes beneath the $\lambda$ isocline for this value of $S$. Recall that $\dot{\lambda}$ makes $\Phi=0$ when $S=\hat{S}$. As before. if $\Phi=0$ the stock will be growing. Therefore. a value of $\lambda<\hat{\lambda}$ is needed to make $\dot{S}=0$. That is, in this case the $S$ isocline passes beneath the $\lambda$ isocline when $S=\frac{\gamma-\delta}{\gamma} \frac{c}{2}$. The isoclines are shown on the phase diagrams in Figures (A3.2.5 $\mathrm{a}$ and $\mathrm{b})$. 
The last step is to add the arrows of motion These can be found by differentiating the $\dot{\lambda}$ and $\dot{s}$ equations with respect to $\lambda$.

$$
\begin{gathered}
\frac{d \dot{d}}{d \lambda}=\left(\hat{\delta}-L^{\prime}(S)+\frac{L(S)}{S}\right)-\left(p_{1}-\lambda\right) q \frac{\partial \Phi}{\partial \lambda}>0 \\
\frac{d \dot{S}}{d \lambda}=-S q \frac{\partial \Phi}{\partial \lambda}>0
\end{gathered}
$$

Equations ( $A 324)$ and (A3.25) can be explained as follows. The dynamics of the costate can be understood by first considering a point on the $\lambda$ isocline. We know that given the current stock. the present value of a fish is unchanging. However. if the present value of the shadow price of fish was arbitrarily raised. then the new higher price can only be an equilibrium if it includes a premium for capital gain. Thus we expect that $\lambda$ must be increasing through time Equation (A3.2.5) has a much more straight forward explanation. Start at a point on the.$\dot{S}$ isocline. then increase $\lambda$. This reduces fishing effort. and consequently the reduction in the catch causes the fish stock to grow

With the equations of motion added to the diagram. it can be seen by inspection that the system has a unique saddle point equilibrium (shown by point $E$ ) which is saddle path stable 20 The saddle path is shown by the curve ss on the diagrams below (Figure A3.26

${ }^{20}$ The origin would also be an equilibrium. however we assume that there is some positive initial stock of fish. If this is the case then ss represents the only path to the saddle point equilibrium 
$a$ and b) which are drawn to reflect the two special cases described above.

Case 1

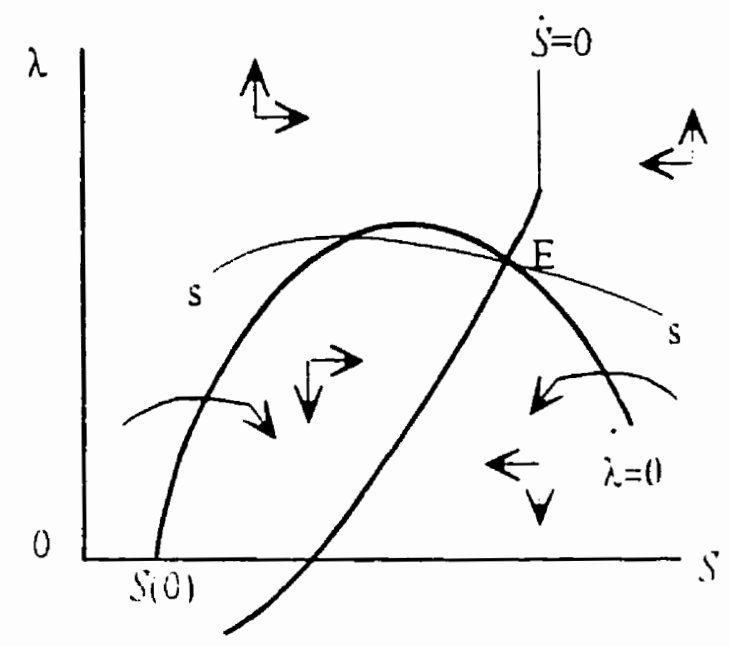

Figure $A 3$ 20a
Case 2

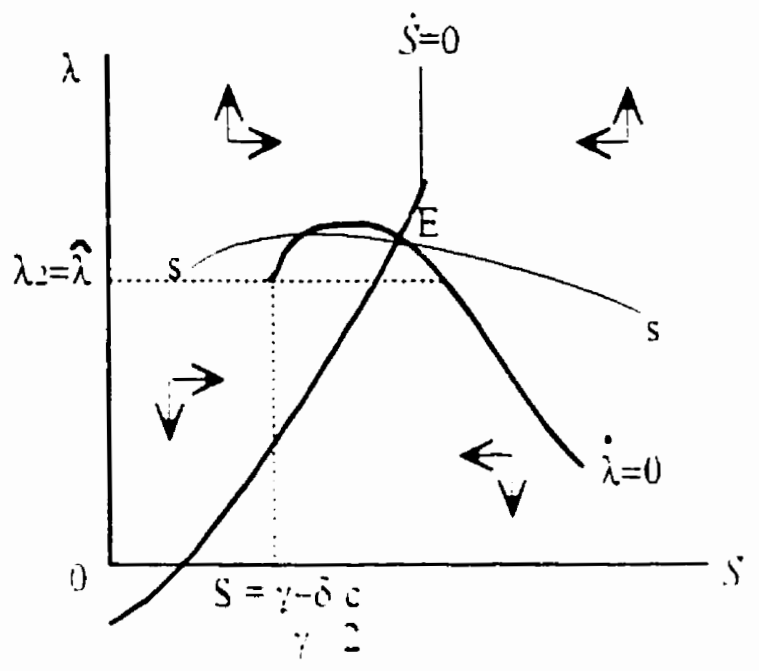

Figure $+326 b$ 
Appendix 3.3: The Inverse Relationship Between the Relative Price of Fish and the

\section{Optimal Fish Stock}

The optimal fish stock is related to the relative price of fish by the modified goiden rule of "fish" accumulation as given by Equation (3.2I). The slope of the temporary production possibilities frontier can be thought of average cost of producing fish. taking the fish stock as constant Thus, replace $-\left.\frac{d X_{2}}{d X_{1}}\right|_{\text {remp }}$ from Equation (3.21) with ( (S) Where $C(S)$ is the average cost facing firms evaluated at the equilibrium value of $S$.

$$
\delta=L^{\prime}(S)+\frac{C(S)}{p_{1}-C(S)} \frac{L(S)}{S}
$$

In equilibrium. the cost of production tacing firms is lower when the equilibrium value of $S$ is higher. There are two reasons tor this. First. the productivity of fishers is greater when the fish stock is higher Second. the fish stock is higher if fishing effort is lower. and if tishing effort is lower then the opportunity cost of fishing effor is lower

The relationship between the price and the optimal steady-state tish stock can be found by totally differentiating equation (A3.3.1). Doing so gives

$$
\begin{aligned}
0=L^{\prime \prime}(S) d S+ & \frac{L(S) / S}{p_{1}-C(S)} \frac{\partial C(S)}{\partial S} d S \\
& -\frac{C(S) L(S) / S}{\left(p_{1}-C(S)\right)^{2}}\left[d p_{1}-\frac{\partial(C(S))}{\partial S} d S\right]
\end{aligned}
$$




$$
+\frac{C(S)}{p_{1}-C(S)} \frac{\partial(L(S) / S)}{\partial S} d S
$$

From the formula for logistic equation, $L^{\prime \prime}(S)=-2 \gamma(c), L(S) / S=\gamma(1-S / c)$, and $\partial(L(S) / S) / 2 S=-y / c$. Making the substitutions and rearranging

$$
\frac{d S}{d p_{1}}=\frac{C(S) /\left[p_{1} C(S)\right]^{2}}{\left[-2 \gamma / c+\frac{\gamma(1-S / c) C^{\prime}(S)}{p_{1}-C(S)}+\frac{C(S) C^{\prime}(S) \gamma(1-S / c)}{\left[p_{1}-C(S)\right]^{2}}-\frac{\gamma / c) C(S)}{p_{1}-C(S)}\right.}
$$

The numerator is positive. since costs are postive. while the denominator is negative since ("(S) is negative as explained above This contirms that.$"$ is a negative function of $p_{1}$ 


\section{Chapter 4}

\section{The Small Country Case}

\subsection{Introduction}

The open-access problem is a market failure that results in the open-access resource being under-priced and over-used. As a result. the laisse: faire, market equilibrium is not optimal: and. international trade. founded upon what appears to be comparative advantage, may in fact be based on incorrect market signals. This chapter is concerned with two major issues. the choice and adoption of a tirst-best policy. and second. the role for trade policy as an indirect. second-best tool to address the over fishing problem

The optimal regulation of the general equilibrium fishery has been examined by Smith (1974) who showed that Pareto efficiency could be achieved by implementing a har'est tax. Gordon (1954) suggested a sole-owner solution. While transferrable quotas have also been examined by a number of authors (see Clark (1990)). Section 2 of this chapter examines the above set of possible solutions to the over fishing problem. It is shown that while all of these solutions lead to conseriation of the fish stock. only a harrest tax can generally lead to an economically efficient level of regulation - at least in theory

The imposition of the first-best policy also provides an opportunity to examine the concept of comparative advantage in the presence of renewable resources. Linder a regime of optimal regulation, the resulting set of prices reflects the true costs of 
production and hence provides an indication of the country's "true" or "actual" comparative advantage. The absence of regulation. as would occur under open access. effectively provides the fishing industry with a competitive advantage vis-a-vis the rest of the economy, allowing the industry to expand beyond its optimal size It is tempting to argue that this competitive advantage may translate into an "artificial" or "apparent" comparative advantage for the fishery (Chichilnisky (1994)). However. the expansion of fishing effort may induce such severe degradation and loss in fishing productivity that any comparative advantage in fishıng is lost. despite the competitive advantage it enjoys relative to the rest of the economy (Brander and Taylor (1997b)). The distinction between "true" and "apparent" comparative advantage is the topic of discussion in Section 3.

Section $t$ examines the role of second-best trade policy under open access it is demonstrated that. generally speaking. some trade is always beneficial to the economy In the case of a tish-importing country. this section establishes that the optimal policy generally involves an export subsidy to manufacturing. In the case of a fish-exporting country, it is shown that welfare can be improved by the imposition of a tariff on manufactures and in some cases by the combination of a prohibitive tariff and a trade subsidy that reverses the pattern of trade in favour of manufactures.

Throughout this chapter it is assumed that agents care only about their steady-state welfare. That is, the discount rate is assumed to be arbitrarily close to zero This 
assumption is particularly convenient as it simplifies the analysis considerably, while still allowing many of the important economic issues to be examined.

\subsection{Possible Solutions to the Over-Fishing Problem}

This section demonstrates that a harvest tax can be used to achieve a Pareto efficient allocation of resources and explains the economic intuition betind the tax. A number of other possible solutions to the open-access problem are also examined. The analysis reveals that many of the common alternative solutions pose theoretical problems

\section{+.2.1 The harvest tax}

It is well known that a hariest tax applied at an appropriate rate is an optimal policy to address the over fishing problem (see for example Smith (1974) or Clark (1990)). Proposition +1 states this result in the context of the model presented here.

Proposition 4.1: An economy. with am open-access fishery can achieve a Pareto optimal allocation of resources by imposing a hanest ax on fish. The ad lalorem harlest tax rate reflects the loss in productiving dwe to the reduction in the fish stock cansed by a marginal increase in fishing effort.

Proposition 4.1 follows from the conditions for a social optimum derived in Chapter 3 . In the static case, in which the objective is to maximize steady-state welfare, the condition for an optimum was shown to require a tangency between the sustainable 
production possibilities locus and the trade line (as illustrated by Figure 3.5). Formally:

this tangency condition can be expressed as

$$
\left.\frac{d X_{2}}{d X_{1}}\right|_{\text {sust }}=-p_{1}
$$

or, as found in Chapter 3 ,

$$
\left.\frac{1}{1+\eta} \frac{d X_{2}}{d X_{1}}\right|_{\text {temp }}=-p_{1}
$$

(3.12) may be re-arranged to give.

$$
\left.\frac{d X_{2}}{d X_{1}}\right|_{\text {temp }}=-p_{1}(1+\eta)
$$

Where $\eta$ is the elasticity of the fish stock with respect to fishing effor

This implies an ad ialorem harest tax of $\eta$ will maximize steady-state welfare $W$ ith an ad valorem harest tax of $t$. the competitive profit-maximizing conditions for fishers facing an open-access resource become

$$
\begin{gathered}
p_{1}(1-t) q S F_{N}=w . \\
G_{N}=w . \\
p_{1}(1-t) q S F_{K}=r . \\
G_{K}=r .
\end{gathered}
$$

for the Heckscher-Ohlin model and

$$
\begin{gathered}
p_{1}(1-t) q S F_{N}=p_{1}(1-t) q S=w . \\
G_{N}=1=w .
\end{gathered}
$$

for the Ricardian version of the model. The first-order conditions result in the following equilibrium condition

$$
\left.\frac{d X_{2}}{d X_{1}}\right|_{\text {remp }}=-p_{1}(1-t)
$$


By comparing Equations (4.2) and (4.7), it can be seen that an ad valorem harvest tax equal to $-\eta$ is required for a Pareto optimum That is, the Pigovian tax that maximizes social welfare is that which causes the fisher to account for the loss in fishing productivity incurred by the fishing industry due to his own fishing efforts

Similar conditions can be found in Smith (1974) and Brander and Taylor (1997b) . However. the intuitive relationship between the harvest tax and loss in productivity due to additional fishing implicit in this condition was not noted. (Appendix +.1 shows the equivalence between the condition derived in Smith (197f) and that derived here.)

Ultimately. I am interested in how the optimal value of the harvest tax is affected by changes in the parameters of the model Appendix +2 shows that the elasticity of the fish stock with respect to fishing effort is given by the following simple relationship when the fish population evolves according to the logistic function, $L(S)=\gamma S\left(1-S^{\circ} c\right)$.

$$
\eta *=1-c / S *
$$

This expression for $\eta$ is useful because it shows that there is a simple relationship between the stock elasticity and the fish stock. As the stock decreases from the maximum sustainable value, $c$, the elasticity decreases from 0 . passes through -1 when $S=0.5 c=\mathrm{S}_{\mathrm{XSY}}$, and towards negative infinity as the stock approaches 0 (See Fig 2.1.p 14). The value of $S$ is endogenous in the model. thus, exogenous changes to the economy that cause an increase in fishing effort and hence decrease the fish stock will 
increase the absolute value of $\eta$. The effects of increased fishing effort on the stock. and the elasticity of the stock with respect to fishing effort. are illustrated in Figure 4.1 Figure 4.1 shows that as fishing effort is increased from $F_{10}$ through to $F_{z}$ the absolute value of $\eta$ increases also.

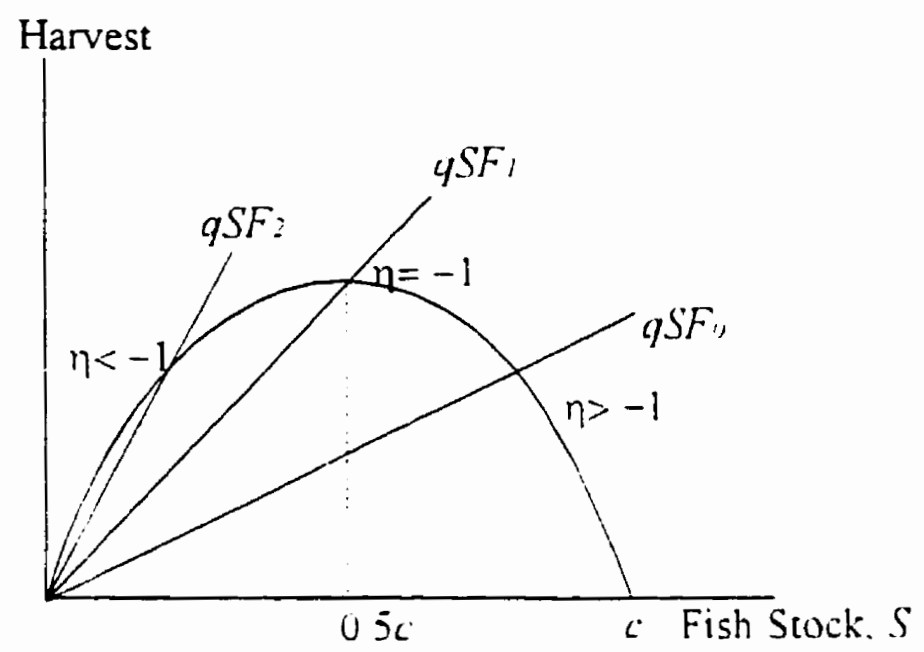

Figure +1 1

The effects of changes in tishing effort on $\eta$

The next step is to derive a closed-form solution for the optimal hariest tax. $t$.

Unfortunately. this is not possible without resorting to explicit functional forms.

Nevertheless. Appendix 4.2. shows that the tax rate can also be written as

$$
t=\frac{p_{1} c q+\frac{d X_{2}}{d F}}{p_{1} c q-\frac{d X_{2}}{d F}}
$$

In the Ricardian model developed here, the marginal rate of transforming fishing effort into manufactures. $\frac{d X_{2}}{d F}$. is constant and equal to -1 . Hence the optimal harvest tax rate 
in the Ricardian model is given by.

$$
t=\left(q c p_{1}-1\right) /\left(1+q c p_{1}\right) \text {. }
$$

Equation (4.10) reveals that an increase in the relative price of fish. the productivity of fishing effort (in the language of Clark, the "catchability" of the fish). $q$. or the capacity of the fishery. all cause an increase in the optimal harvest tax in the Ricardian model.' Intuitively, the role of each of the parameters can be explained as follows An increase in the relative price of fish leads to an increase in fishing effort and the har est. The fish stock is depleted. the elasticity of the fish stock with respect to fishing effort rises. and hence the optimal tax is higher. An increase in the capacity of the fishery. ceteris parihus, causes the steady-state stock to rise but. if fishing effort is unchanged. leaves $\eta$ unchanged." However. with a higher fish stock. the productivity of fishing effort is

'This particular expression for the optimal harcest tax was also derived by: Brander and Taylor ( 1997b).

- The effect of an increase in c, holding the level of fishing effort constant. is illustrated in the following diagram. It can be seen that. while the scale of the diagram is changed. the slope of the logistic curres at $S^{*}$ and $S^{* \prime}$ are unchanged and hence. $\eta$ is left unaffected by the change in $c$. Formally. recall. $\eta=1-c S$. and from the condition that $L(S)=q S F, S c=1-q F \%$, therefore. $\eta=1 /(\gamma-q F)$, which is independent of $c$ for a given $F$.

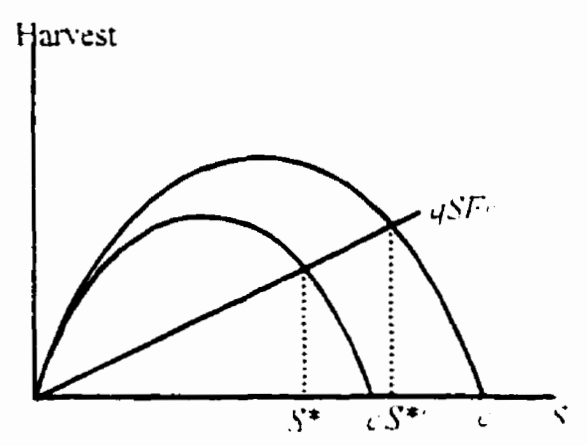


increased, and hence fishing effort increases. The fish stock is depleted. and $\eta$ increases (in absolute terms). Hence, the optimal harvest tax rate rises with $c$. An increase in the catchability coefficient. $q$, increases the profitability of fishing: fishing effort increases. and the stock elasticity increases (in absolute terms). As a result, the optimal har est tax rate rises with increases in $q$.

An explicit expression for the optimal harvest tax in the Heckscher-Ohlin model is considerably more complicated to derive and will likely depend on other key parameters of the model such as factor supplies. and the intrinsic growth rate of the fish population. For example. While the tax rate is independent of the labour supply in the Ricardian model, it is not in the Heckscher-Ohlin model. This is because the opportunity cost of fishing effor is not constant in the Heckscher-Ohlin model. An increase in the labour supply. given prices and existing taxes. leads to an increase in fishing effort assuming fishing is relatively labour intensive (due to Rybszynski) The expansion in fishing effor leads to an increase in haresting and a fall in the equilibrium stock. W'ith a lower fish stock. the elasticity of the fish stock with respect to fishing effort is greater in absolute terms, hence the equilibrium harvest tax rate is higher.

\subsubsection{Other possible solutions}

A number of solutions. other than the harvest tax. have been posed to solve the overfishing problem; these include a total catch quota. sole ownership and transferrable 
quotas. This sub-section examines each of these possibilities and examines the effects of each on welfare. In general, the analysis demonstrates that each of these alternative solutions may result in a sub-optimal equilibrium.

\section{i) A total allowable catch quota}

A total allowable catch quota restricts the total catch to the optimal level (that is, the level that produces a tangency between the sustainable production possibilities locus and the world trade line). If the fishery was already over fished, this policy may initially require a moratorium on fishing. or some other restriction. so that the stock grows to a level for the quota to be binding. However. assuming the quota binds, it is well known that the imposition of a total catch quota will induce forms of competitive rent seeking behaviour as fishers seek to capture the maximum share of the restricted total catch In order to compete for the associated rents, a fishing company, for example, may respond to the imposition of a quota by increasing the number of boats in its fleet. This process is clearly inefficient resulting in many more boats than is necessañ to capture the allowable catch. Vonetheless. it is sometimes employed by authurities seeking to consere the fish stock.

The effects on the equilibrium level of welfare and employment, are most simply illustrated using the Ricardian model. Figure 4.2 illustrates the basic result. The harvest quota, $\mathrm{H}_{\mathrm{Q}}$, is shown by the vertical dashed line. The open-access equilibrium is illustrated by point $E_{1}$, where the temporary production possibilities frontier is conincident with the 
trade line, having slope of $-p_{1}$. and intersects with the sustainable production possibilities locus. The value of GDP, in terms of manufactures. is measured on the vertical axis. Under open access. GDP is equal to OT Since it is assumed that it takes one unit of labour to produce each unit of manufactures, the total number of workers employed in manufacturing is given by $0 \mathrm{M}_{1}$, leaving $\mathrm{TM}_{1}$ workers employed in fishing

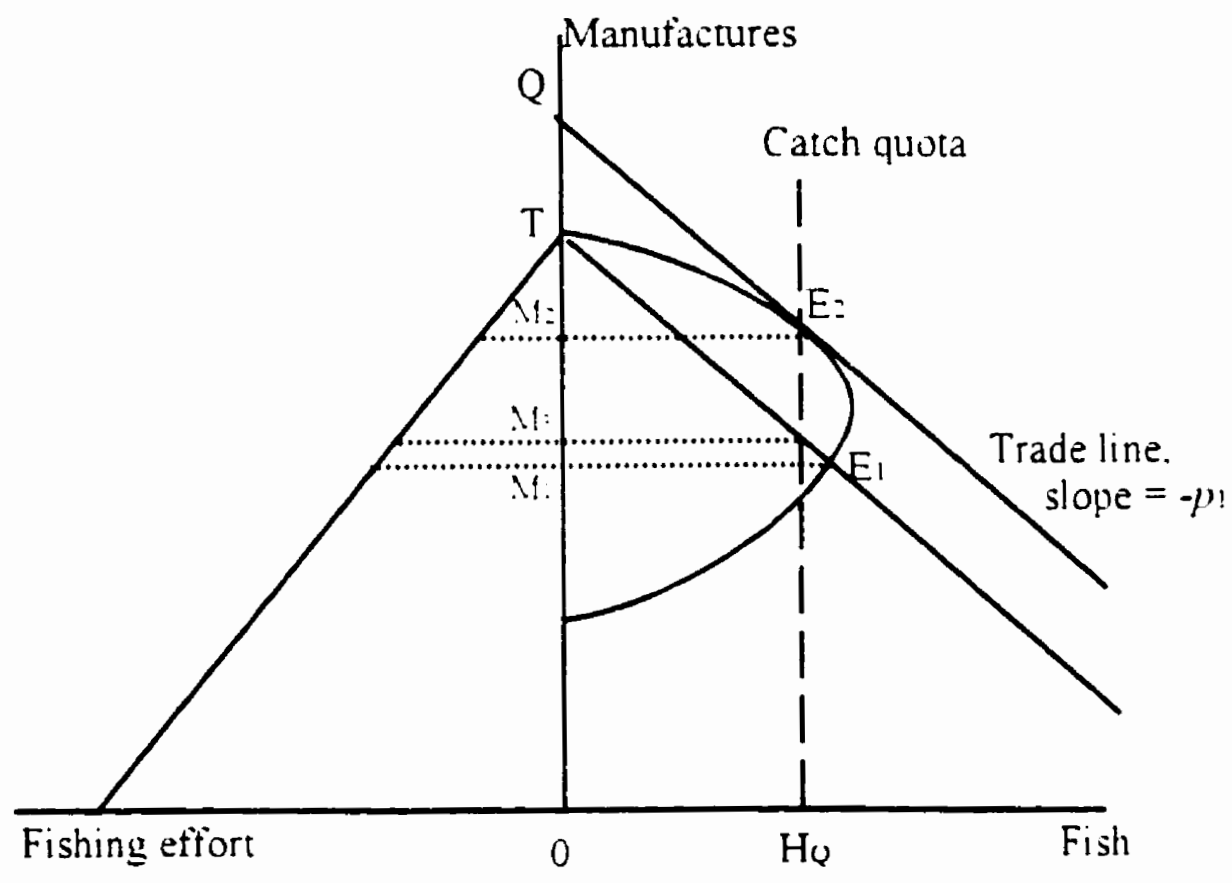

Figure 42

Total allowable catch quota

Now consider the equilibrium when the quota is a binding constraint on the activities of fishers. First. assume that there is no competitive rent seeking. and therefore the equilibrium is the same as that under a harvest tax. Referring to Figure 4.2. the production point occurs at $E_{2}$. The number of workers employed in fishing effort is $\mathrm{M}_{2}$ 
leaving $\mathrm{TM}_{2}$ workers employed in the fishery Now decompose GDP into wage income and the rents from the fishery. Total GDP is equal to $0 Q$ manufactures. Since the output of manufactures is equal to the number of workers in manufacturing, the marginal product of labour. and therefore the wage. is equal to unity. It follows that the total wage bill is $N$. In terms of manufactures, the value of the wage bill is illustrated by point $T$. Thus. the total rent associated with the fishery is equal to 0Q-OT = QT

The impact of competitive rent seeking behaviour can now be analyzed. Assume that this behaviour takes the form of entry by additional fishers attempting to capture a share of the rents. It takes one unit of labour to produce each additional unit of tishing effor Fishers will therefore enter as long as their share of the rents exceeds the wage rate Thus in Figure 4. 2. fishers enter as long as $0 \mathrm{Q}$ exceeds $\mathrm{OT}$ and $\mathrm{QT}$ is positive. These fishers will not be able to harest in excess of the total quota. The authorittes will simply close the fishery after the total allowable catch has been landed. Each additional fisher. beyond that which would have successfully caught the quota. (that is. each fisher in excess of $\mathrm{TM}_{2}$ ) is therefore wasted, harvesting no additional fish . As a result. each additional fisher that enters the industry only acts to reduce the size of GDP. Workers in manufacturing become fishers until all workers earn the wage rate available in manufacturing (which equals unity) and GDP is equal to $\mathrm{OT}$. This occurs when the level of fishing effort has increased to $\mathrm{TM}_{3}$. Thus, in the Ricardian model, a total allowable catch system results in the same level of income as under open access. There are two differences in the equilibrium. First under the quota. the fish stock is conserved. Second. 
the level of fishing effort under a quota. $\mathrm{TM}_{3}$, will almost certainly differ from that under open access and may well exceed the open-access level of fishing effort $\mathrm{TM}_{1}$. Whether or not this is the case will depend on the relative price of fish and the properties of the fishery. Proposition 4.2 summarizes the impact of imposing a total catch quota on the equilibrium.

Proposition 4.2: In the Ricardian economy, a total catch guota that restricts the harvest 10 that which would arise from the imposition if an optimal hamest tax, produces rent seeking that results in:

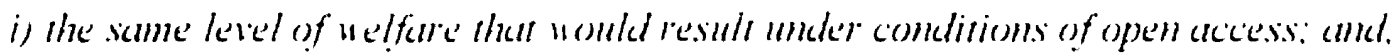
ii) a level of fishing effort that mat he higher than that under open access if the relative price of fish is sufficiently high. or less than that under open access if the relative price of fish is sufficiemly low:

Proof:

Appendix +2 derives the following equations for optimal fish stock and fish harest

$$
\begin{aligned}
& S^{\circ}=\frac{1}{2}\left(c+\frac{1}{p_{1} q}\right): \text { and } . \\
& F^{\prime}=\frac{\gamma}{2 q}\left(1-\frac{1}{q p c}\right)
\end{aligned}
$$

The economic rent associated with the fishery is the difference between GDP and wage income

$$
\text { Rent }=X_{2}^{*}+p_{1} \varphi S^{*} F^{*}-w N
$$

Recall that the output of manufactures. $Y_{2}$. is just equal to the number of workers 
employed in manufacturing, $N_{2}$, and hence the wage rate is unity. Thus. (4.13) can be rewritten as

$$
\text { Rent }=N_{2}^{*}+p_{1} \varphi S^{*} F^{*}-\lambda
$$

Similarly, since the supply of fishing effort equals the level of employment in fishing.

$$
\text { Rent }=\left(p_{1} q S^{*}-1\right) F^{*}
$$

Substituting (411) and (4.12) gives

$$
\text { Rent }=\left[\frac{p_{1} q}{2}\left(c+\frac{1}{p_{1} q}\right)-1\right]\left[\frac{\gamma}{2 q}\left(1-\frac{1}{q p_{1} c}\right)\right]
$$

or, after rearranging

$$
\text { Rent } \left.=\frac{\left(p_{1} c q-1\right)}{2}\left[\frac{\gamma}{2 q} \frac{\left(p_{1} q c-1\right)}{q p_{1} c}\right)\right] .
$$

or.

$$
\text { Rent }=\frac{\left(p_{1} c q-1\right)^{2}}{4 q p_{1} c} \frac{\gamma}{q}
$$

Linder a total catch quota. firms will enter until the rents have been dissipated That is. until the benefit to the firm from capturing his share of rents equals the opportunity cost of entering (in this case. the opportunity cost is the wage rate which is unity). Thus. the equilibrium condition with rent-seeking is:

$$
\operatorname{Rent} / A_{1}=1
$$

or, using (4.14).

$$
N_{1}=\frac{\left(p_{1} c q-1\right)^{2}}{4 q p_{1} c} \frac{\gamma}{q}
$$

Since the earning per fisher from fishing has been driven down to the market wage rate total GDP for the economy is just. 


$$
w N_{1}+w N_{2}=w N=N
$$

That is, in the Ricardian model, GDP under rent-seeking is the same as under open access.

Now compare the level of employment in the fishery under the two regimes. Denote the level of employment under the total allowable catch (with rent seeking) by $N_{1}{ }^{\mathrm{T}}{ }^{\mathrm{C}}$, and let $N_{1}{ }^{1}$ denote the level of employment in the fishery under open access. Thus. from (4.15)

$$
N_{1}{ }^{\mathrm{r} M}=\frac{\left(p_{1} c q-1\right)^{2}}{4 q p_{1} c} \frac{\gamma}{q} .
$$

and. from equation $(.+2.28)$ in $A$ ppendix +2

$$
N_{1}^{\prime \prime}=\frac{\left(p_{1} q c-1\right)}{p_{1} q c} \frac{\gamma}{q}
$$

Employment in the fishery will be greater under the total allowable catch system than under open access if $\mathrm{N}_{1}^{\prime} \mathrm{r}^{\prime}-. \mathrm{N}_{1}^{\prime \prime}>0$

$$
\begin{aligned}
N_{1}^{\prime}+\cdots & -V_{1}^{\prime \prime}=\frac{\left(p_{1} c q-1\right)^{2}}{4 q p_{1} c} \frac{\gamma}{q}-\frac{\left(p_{1} q c-1\right)}{p_{1} q c} \frac{\gamma}{q} \\
& =\left[\frac{\left(p_{1} c q-1\right)}{4}-1\right] \frac{\left(p_{1} q c-1\right)}{p_{1} q c} \frac{\gamma}{q} \\
& =\left[\frac{\left(p_{1} c q-4-1\right)}{4}\right] \frac{\left(p_{1} q c-1\right)}{p_{1} q c} \frac{\gamma}{q} \\
& =\left[\frac{\left(p_{1} c q-5\right)}{4}\right] \frac{\left(p_{1} q c-1\right)}{p_{1} q c} \frac{\gamma}{q}
\end{aligned}
$$

Recall that in the Ricardian temporary equilibrium. $p_{1}=1 / q S$. Thus the economy will be 
specialized in manufactures if $p_{1}<1 / q c$. However, it is assumed that the fish price is high enough to induce fishing so $p_{1}>1 / q c$. Thus. $N_{1}{ }^{\mathrm{T}+C}-N_{1}{ }^{1}$ is positive if $p_{1}>5 / q c$, while fishing effort under open access exceeds that under a total allowable catch if $p_{1}<5 / q c$ This completes the proof of Proposition 4.2.

ii) Sole Onnership

The problem with the total allowable catch quota is that it fails to address the open-access problem. An altemative solution posed by Scott Gordon (1954). was to give the fisher: over to a sole owner. The solution conveys a property right over the fishery and. as a result, the sole owner takes into account any adverse effects on the stock and future productivity of his tishery that his actions may have. However. while this property right solves the over-fishing problem. it also gives the owner the right to market power Because of the small country assumption. the owner is not able to influence the world price and therefore has no monopoly power However. he may have monopsony power in the input markets. particularly if the economy is small and highly dependent on the fishery. The use of monopsony power may lead to an inefficient use of resources as summarized by Proposition 4.3.

Proposition 4.3: Sole ownership imparts the owner with a degree of monopsony power in input markets. If the opportunity cost of fishing effort increases with increases in fishing effort, then the sole-owner solution is inefficient. 
Proposition 4.3 can be verified by considering the profit maximization problem facing the sole owner. In its simplest form. the owner's profit maximization problem can be expressed as

$$
\max _{F} \quad \Pi=p_{i} \varphi S(F) F-F \theta(F)
$$

Where all variables are defined as before, except that $\theta(F)$ is the opportunity cost of fishing effort as given by the slope of the transformation frontier transforming fishing effort into manufactures. and the fish stock has been written as an explicit function of fishing effor

The first order condition for the problem is

$$
\frac{\partial \Phi}{\partial F}=p_{1} q F \frac{\partial S}{\partial F}+p_{1} q S-\theta(F)-F \theta^{\prime}(F)=0
$$

Equation (4.19) can be rewritten as

$$
p_{\mathrm{i}} q S\left(1+\frac{F}{S} \frac{\partial S}{\partial F}\right)=\theta(F)+F \theta^{\prime}(F)
$$

or.

$$
p_{1} q S(1+\eta)=\theta(F)+F \theta^{\prime}(F)
$$

In this form. the first order condition $(+20)$ reveals that the sole ouner internalizes the effect of additional fishing effort on the fish stock in much the same way as the central planner does by charging a harest tax. However. the sole owner also takes into account the additional cost of hiring additional fishing effor. This is accounted for by the last term in (4.20). The sole owner realizes that the opportunity cost of fishing effort may be rising, in which case he will choose to restrict the amount of fishing effort he hires in an effort to keep the cost of fishing effort low 
In the Ricardian model, the opportunity cost of fishing effort, $\theta(F)$, is constant - one unit of fishing effort transforms into one unit of manufactures. Thus. $\theta^{\prime}(F)=0$. In the Heckscher-Ohlin model, the opportunity cost of fishing effort is an increasing function $\theta^{\prime}(F)>0$. Hence, while replacing open access with a sole owner eliminates one distortion. it may also create another in which the owner produces too little fishing effort. and catches too few fish.

Figures +3 and +4 compare the outcomes under open access and sole ownership Figure 4.3 shows the first order conditions, while Figure +4 illustrates the equilibrium in output space. In Figure 4.3, under open access. fishers enter until the average product of fishing effort equals the opportunity cost of fishing effort. $\phi(F)$. resulting in a level of fishing effort. $F_{A}$. The optimal level of tishing effort requires a level of fishing effort that equates the social marginal product of fishing effort with the opportunity cost of effort. as shown by the level of fishing effort. $F^{*}$ Under sole ownership. the owner internalizes the fishing externality and operates on the social marginal product curve. However. he also exploits whatever market power he has in the factor markets to keep the opportunity cost of fishing effor low. Thus. the sole owner chooses to employ a level of fishing effort such that the marginal cost of hiring addition effort (the marginal factor cost of fishing effort, as illustrated by the curve. $\phi^{s}(F)$ ) equals the marginal product of fishing effor at $F_{\mathrm{S}}$. Welfare under sole ownership is less than that under the har'est tax as long as the opportunity cost of fishing effort is increasing. In Figure 4.4. the open-access 
equilibrium is shown by point $E_{A}$, the social optimum is $E^{*}$ and the monopsony equilibrium is $E_{s}$. Figure 4.4 illustrates that. with less than the optimal number of fishers employed, both the equilibrium harvest and GDP are below the socially optimal level. It has not been possible to determine whether welfare under sole ownership could be less than that under open access.

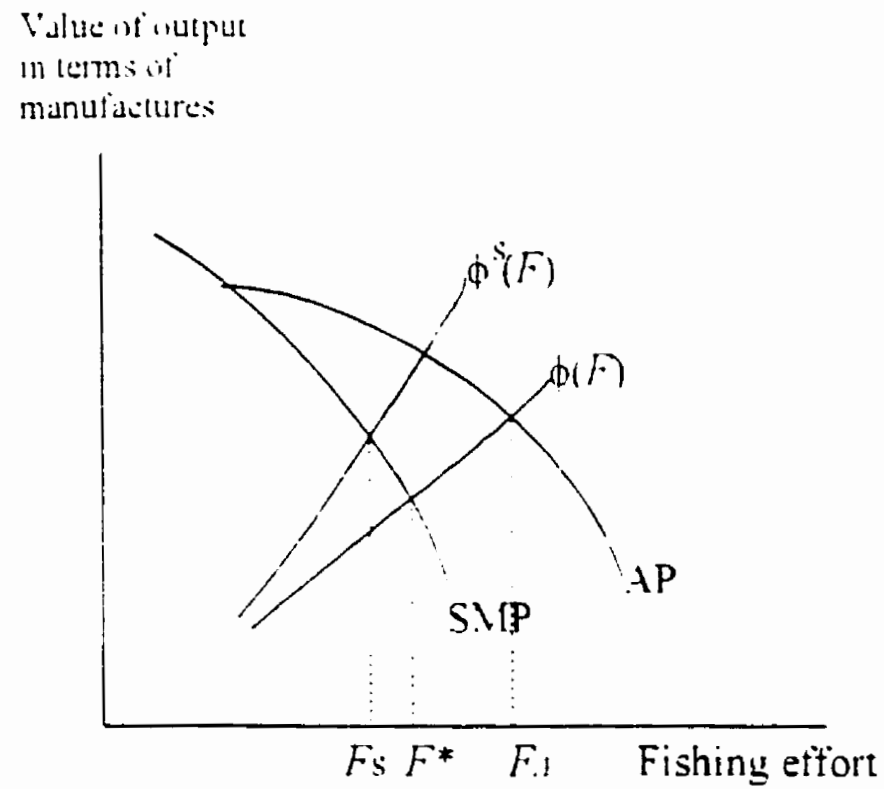

Figure 43

Monopsony power in the fishery: the effect on the level of fishing effort 


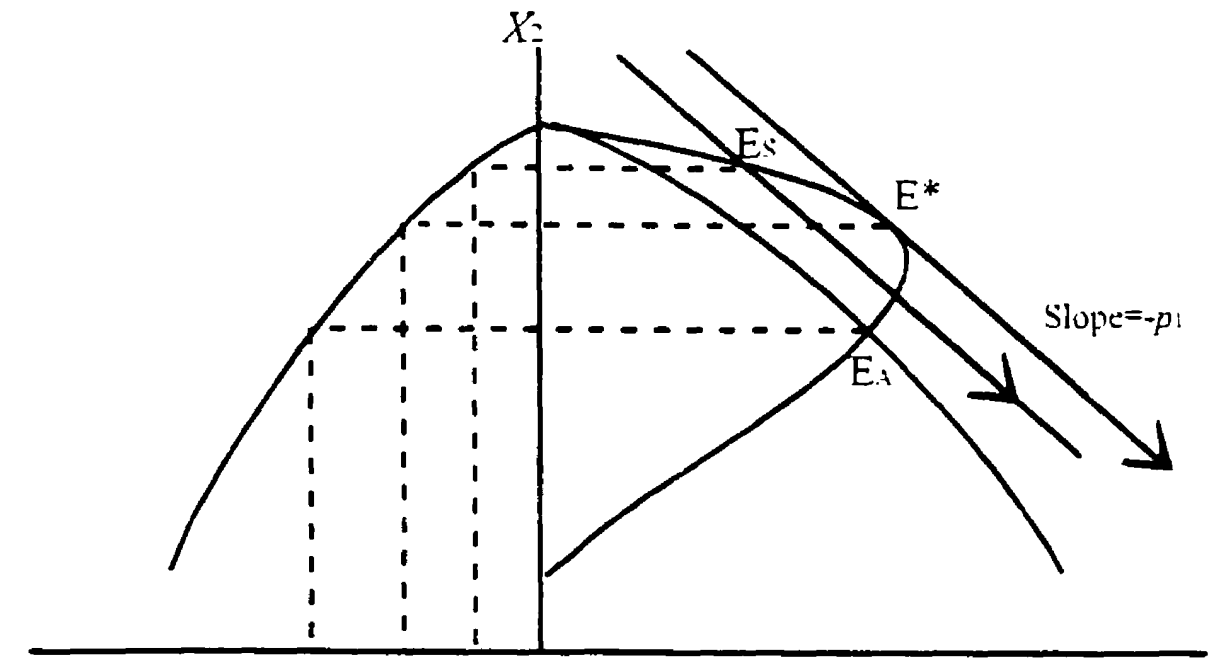

Fishing Eftort $F_{t} \quad F^{*} F^{*}$

Fish (Harrest)

Figure 4.4

Monopsony power in the fisher: the effect on GDP

\section{iii) Individual Iransiferrable yusias}

An altemative strategy may be to issue a large number of transferrable quotas The benefit of such a scheme is that it allows the most efficient firms to buy the right to fish from inefficient firms. while also restricting the right to fish. However, the quotas still result in the right to exclude entry; and hence the potential right to market power It seems plausible that the attraction of monopsony profits may result in most of the quotas being held by a small number of fishing firms As with sole ownership. this problem may be especially important in small economies which are heavily dependent on the fishery for economic viability. Clark (1990. p259) argues that legislation may be used to prohibit the quotas from becoming concentrated amongst a few firms.

The proceeding analysis gives rise to the following interesting proposition: 
Proposition 4.4: When the economy has a Ricardian structure, a hanest tax, sole owner. or transferrable individual quota system can produce an optimal allocation of resources. However, when the opportunity cost of fishing effort is increasing. as might be the case when the production structure is Heckscher-Ohlin, then of these three alternatives only a harvest cax can produce a Pareto efficient outcome.

This section has derived the optimal harest tax for the economy. The analysis demonstrates that. in the context of this model. a harvest tax can produce an optimal allocation of resources Although this Pigovian solution is well known. it is often argued that other solutions. such as monopoly ownership or transferrable quotas. can also produce an efficient outcome. However. in the general equilibrium context of this thesis. these two solutions lead to the potential for exploitation of monopsony power in factor markets - a problem that may be especially problematic in economies that are heavily dependent on the fishery. The total allowable catch solution. which is known to produce rent-seeking in practice. may lead to a level of fishing effort greater than that under open access. The next section considers the concept of comparative adrantage. Traditional concepts of comparative advantage assume that economies are optimally regulated. new notions of comparative advantage stress institutional factors that may lead to inefficiencies such as the absence of property rights.

\subsection{Comparative Advantage}

An interesting discussion has developed in the "trade and the environment" literature 
since Lawrence Summers was credited with asking whether developing countries have a comparative advantage in dirty industries. and if so is it not more efficient that they specialize in industries that are environmentally intensive in production? ? $^{23}$ The debate essentially comes down to the question of whether or not the full environmental costs of production are factored into the relative prices of tradable goods (Daly (1993)). If not. then what appears to be a comparative advantage may not be based on correct market signals about the true cost of production: that is. an "apparent" comparative advantage may not be a "true" comparative adrantage

This section explores the relationship between "true" comparative advantage. "apparent" comparative advantage. and "competitive" advantage True comparative compares the relative opportunity cost of tish with the world price when the external costs of tishing are internalized: true comparative advantage reflects the slope of the sustainable production possibilities frontier (if citizens care about their steady-state welfare only). "Apparent" comparative advantage reflects the opportunity cost of fish when it is perceived that the fish stock is unaffected by additional fishing effort. it reflects the slope of the temporary production possibilities frontier. "Competitive" advantage is used here to mean the cost advantage afforded to the industry compared to a situation in which the industry is regulated and must pay a tax on the harest of fish. It reflects the lower unit costs a fishing firm has in the provision of fishing effort.

23 See The Economist 1992. Vol. 322. p 66; cited in Chichilnisky (1994). 
In order to develop the concept of comparative advantage. it is necessary to introduce preferences into the model. This permits a comparison of the relative costs of production under autarky with the relative world prices For illustrative purposes, it is simplest to follow Brander and Taylor (1997a), who have derived some key results in this area They assume Cobb-Douglas preferences and a Ricardian production structure. These assumptions have some limitations that are discussed below, but they are justified on the grounds of simplicity and clarity of presentation

To the basic Ricardian structure developed in Chapters 2 and 3. I now introduce the preference assumption.

$$
I^{\prime}=C^{\prime} \beta^{\prime}: 1-\beta
$$

Where $C_{1}$ is the consumption of fish and $C_{:}$is the consumption of manufactures

Following Brander and Taylor (1997a), in the absence of any taxes. all income in autarky is derived solely from labour. Therefore. in autarkic equilibrium. a fraction. (1- $\beta$ ). of society s wage income is devoted to purchase manufactures and the remainder. $\beta$. is expended on fish. This gives rise to the following demand functions for fish and manufactures respectively.

$$
\begin{aligned}
& C_{1}=\beta w N p_{i} \text {. and } \\
& C_{2}=(1-\beta) \cup \lambda .
\end{aligned}
$$

where $w$ is the wage rate..$M$ is the supply of labour. $C_{1}$ and $C_{z}$ are the consumption of fish 
and manufactures respectively, and $p_{1}$ is the relative price of fish.

The temporary Ricardian equilibrium can now be derived. Recall from Chapter 2 that the production functions for fishing effor and manufactures are given by

$$
\begin{aligned}
& F=N_{1:} \text { and, } \\
& Y_{2}=N_{2}:
\end{aligned}
$$

while the harvest of fish. given the stock of fish. $S$. is given by

$$
H_{1}=q S \%
$$

The zero profit condition in fishing requires total revenue equal total cost copen access implies that fishers treat the fishery as a free input)

$$
p_{i} H_{1}=w H_{1}
$$

Rearranging Equation $(+27)$ and using $(+24)$ and $(+26)$ gives the equilibrium condition that

$$
p:=1 ; q S
$$

as was derived in Chapter 3

Then. equating demand with supply.

$$
r_{1}=\beta w \nu_{i}
$$

and substituting for $p_{1}$ using equation $(4.28)$ gives

$$
X_{1}=q S \beta w X
$$

Since the marginal product of labour from (4.25) is unity, the wage rate in a diversified equilibrium is also unity. Thus. the temporary autarkic equilibrium supply of fish is 
given by

$$
X_{1}=q S \beta N
$$

and the supply of manufactures

$$
Y_{2}=(1-\beta) N
$$

It follows that $\beta N$ people are employed in fishing (that is, $V_{1}=\beta N$; while employment in manufacturing is $N_{2}=(1-\beta) i$.

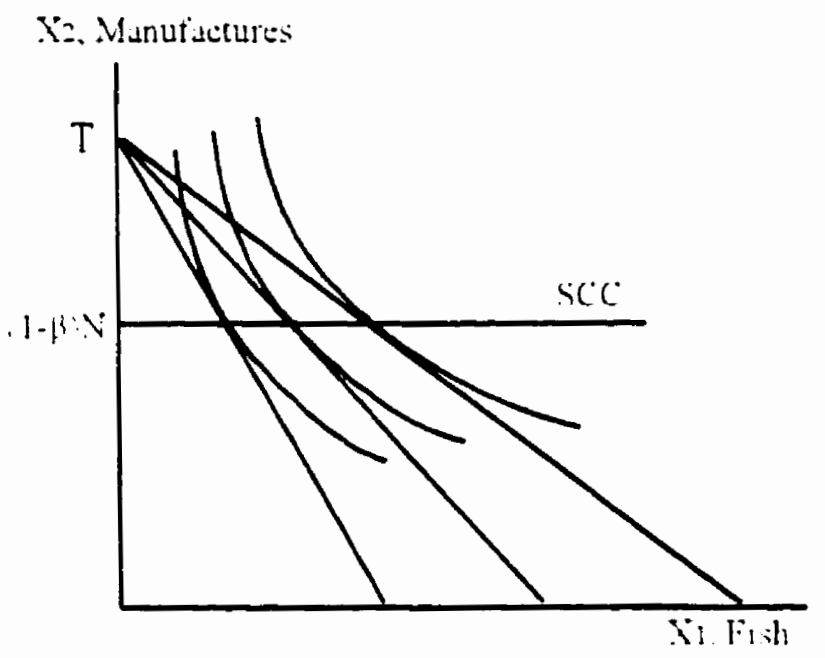

Figure +5

Temporary autarkic equilibria

The derivation of the set of temporary autarkic equilibria can be illustrated using a diagram such as Figure 4.5. The diagram shows a family of temporary Ricardian production possibility frontiers that arises from allowing the fish stock to vary. As $S$ is increased. the temporary PPF pivots outwards through $T$ To this diagram a set of 
community indifference curves consistent with the Cobb-Douglas preference assumption is added. Under open access, equilibrium involves a tangency between the temporary PPF and a community indifference curve. In the absence of trade the locus of equilibrium consumption points traces out, what may be termed, the "Stock Consumption Curve" or SCC. Because of the Cobb-Douglas preference assumption, the consumption of manufactures is independent of the fish stock. and the SCC is a horizontal line with $f_{2}=(1-\beta) V^{\prime}$

Of all the temporary autarkic equilibria. only one is sustainable. The steady-state stock of fish is determined by equating the harest with the natural growth of the fish stock

$$
X_{1}=L(S)
$$

or. $\quad q S N_{1}=\gamma S(1-S / c)$

which can be rearranged to give.

$$
S=c\left(1-\frac{q}{\gamma} N_{1}\right)
$$

where it will be recalled that $c$ is the capacity of the fishery, and $\%$ is the intrinsic growth rate of the fish stock. Therefore the autarkic steady-state fish stock. $S_{j}$, is

$$
S_{a}=c\left(1-\frac{q}{\gamma} \beta N\right)
$$

Recall that the hariest of fish. $\mathfrak{H}_{1}$. can be expressed as

$$
X_{i}=q S V_{i}
$$

and therefore in autarky the output of fish is given by.

$$
X_{\mathrm{L}}=q \beta N c\left(1-\frac{q}{\gamma} \beta N\right)
$$


Figure 4.6 combines the SCC and the sustainable production possibilities locus on the same diagram. The autarkic optimally regulated sustainable equilibrium. $E^{*}$. occurs where the sustainable production possibilities locus is tangent to a community indifference curve. The sustainable autarkic equilibrium under open access is indicated by the intersection of the SCC and the sustainable production possibilities locus as shown by point $E_{t}$ where the Ricardian PPF is tangent to a community indifference curve

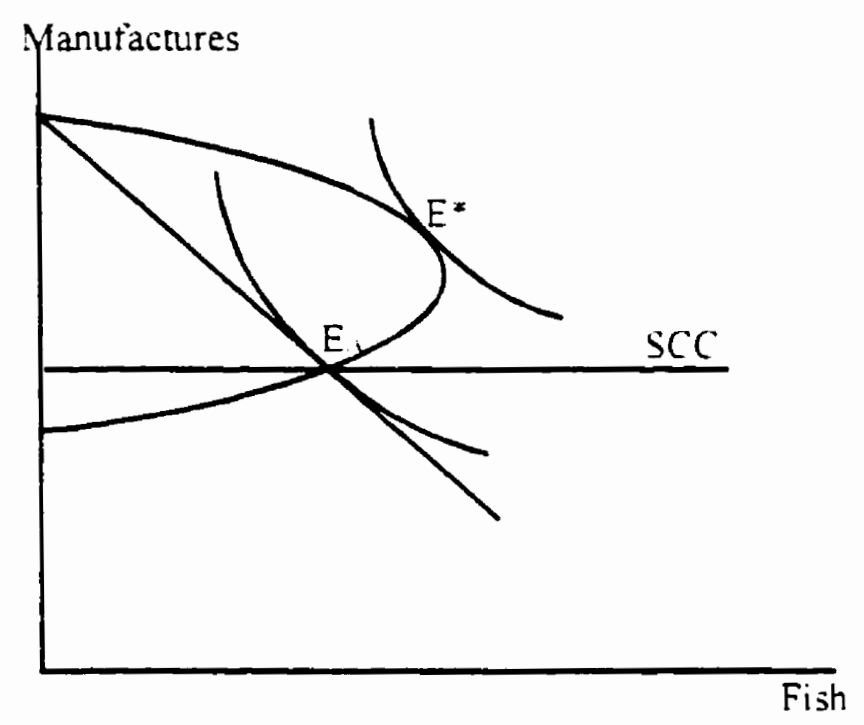

Figure 4.6.

Sustainable autarkic equilibria

Having derived and illustrated the open access and optimal autarkic equilibria. now return to the notion of comparative advantage in the model. Chichilnisky ( 1994 ) conducts the following thought experiment: Suppose that the relative price of fish in the world market is such that it is equal to the autarkic relative price under a system of optimal 
regulation (i.e., the economy has a true comparative advantage in neither good), then ask what would happen if the fishery became open access and the harvest tax was eliminated?

Compared to a situation of optimal regulation, a failure to regulate the fishing industry effectively provides it with a cost advantage vis $\dot{a}$ vis other sectors of the economy In this sense. it could be argued that under open access. fishers have a comperitive acrimlage aver other industries (having effectively been subsidized by the lack of regulation). It is this competitive advantage that allows the industry to expand beyond its optimal size

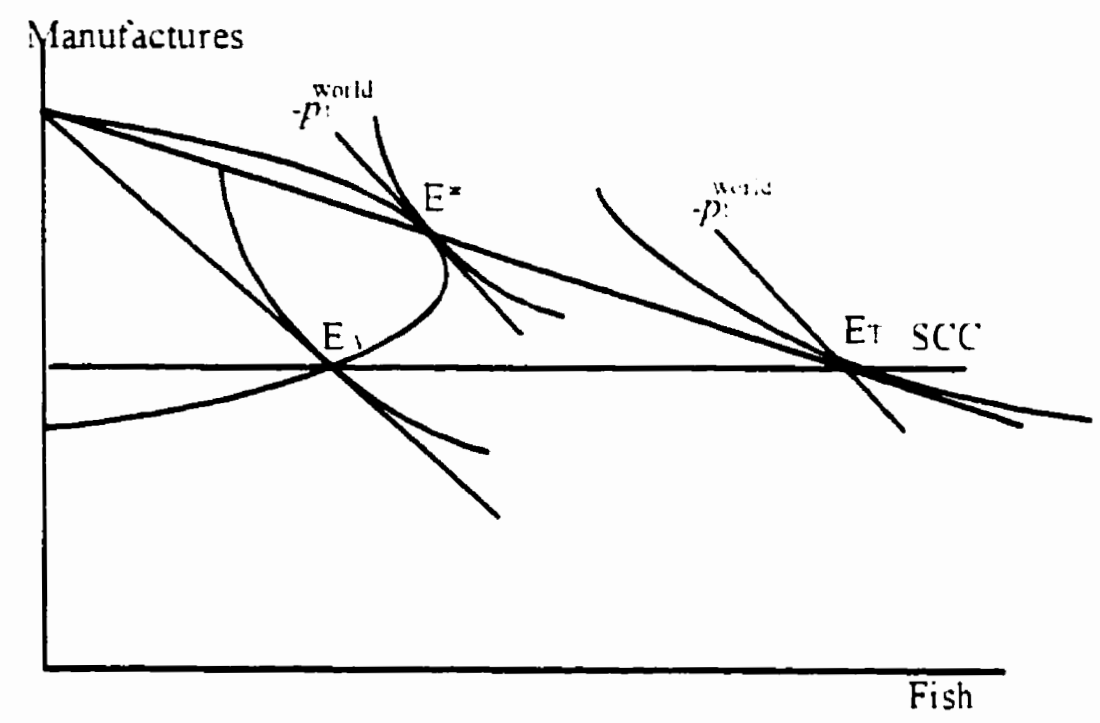

Figure 4.7.

True and apparent comparative advantage 
It is tempting to argue that this competitive advantage may translate into an artificial or apparent comparative advantage for the fishery (Chichilnisky (1994)) Referring to Figure 4.7, it is apparent that this is true in the short term. however it may not be true in the long-term. Once the harvest tax is eliminated, the production price is given by the slope of the Ricardian temporary production possibilities frontier passing through $E^{*}$ The production point moves along the temporary frontier until a temporary equilibrium is reached at $E_{T}$. where the temporary PPF intersects with the SCC Clearly. at $E_{T}$ the domestic autarky relative price of fish is now lower than the world price. and hence the economy has an apparent comparative advantage in fish. However, this may only be temporary . At $E_{\Gamma}$. the harvest of fish exceeds that which is sustainable and the fish stock falls The temporary production possibility frontier pivots inwards and the equilibrium production point moves in along the SCC untul the sustainable open-access equilibrium is reached at $E_{1}$. As Brander and Taylor (1997b) have shown. depending on preferences. the autarkic relative price at $E_{A}$ may be greater or less than at $E^{*}$. In autarky. if the expenditure share on fish is small enough. then the relative price of fish will be lower under open access than with optimal regulation. and. the open-access economy has an apparent comparative advantage in fish. Conversely, if the expenditure share on fish is sufficiently large enough. the relative autarkic price of fish will be greater under open access than with optimal regulation and the economy has an apparent comparative advantage in manufactures. In the latter case, Brander and Taylor (1997b) showed that the economy must be operating on the backward bending portion of the production possibilities frontier 
The results of Chichilnisky's thought experiment may be summarized as follows:

Beginning from a hypothetical, optimally regulated equilibrium. in which relative prices are such that the economy has a true comparative advantage in neither good. the elimination of the harvest tax conveys both a competitive advantage to the fishing industry vis-cit-iis manufacturing and a short-term apparent comparative advantage to fishing. While the competitive advantage persists, the apparent comparative advantage will be affected by the long-run decline in the fish stock since it is the fish stock that determines the productivity of the fishing sector. ${ }^{24}$ Thus. the absence of trade may create an apparent comparative advantage in either good. despite the economy having a true comparative advantage in neither good How free trade. under open access. affects equilibrium and welfare. and the role for trade policy to improve upon free trade. is the topic of the next section.

\section{4.t Trade Policy}

In many cases. direct regulation of the open-access resource may not be feasible or

${ }^{24}$ One could also perform the thought experiment from the opposite perspective and imagine that the economy starts from an open-access. autarkic equilibrium in which prices are such that the economy has an apparent comparative advantage in neither good Then ask what the effect of introducing a harvest tax would be on the equilibrium. The tax would initially raise the domestic relative price of fish, compared to the world price. and as a result give the economy a temporary true comparative advantage in manufactures. However. this equilibrium is short lived. As the fish stock grow's and the economy moves to a new equilibrium on the sustainable production possibilities frontier the nature of the true comparative advantage will change. From Brander and Taylor (1997b) we know that for small values of $\beta$, the sustainable true comparative advantage is in manufactures. On the other hand. if $\beta$ is sufficiently large then the regulated economy has a true comparative advantage in fish. 
desirable. ${ }^{25}$ This raises the question of whether trade policy can improve welfare as a second-best policy. This section. first reviews an important result due to Brander and Taylor (1997a). They find that if a country with a Ricardian production structure and an open-access resource has an apparent comparative advantage in fish, then its welfare is unambiguously worsened by the pursuit of free trade; while free trade unambiguously improves the welfare of a country with an apparent comparative advantage in manufactures. Second. the analysis demonstrates that, for a fish-exporting country. a tariff will unambiguously improve welfare Furthermore, under some circumstances. a prohibitive tariff cum trade subsidy (either to imports of fish or exports of manufactures) may lead to the greatest improvement in welfare For a fish-imporing country. the results reveal that the second-best trade policy involves an expansion in trade and hence an export subsidy to manufactures

\section{4.t.1 Autarky versus free trade}

The effects of moving from autarky to free trade can be illustrated in a straight forward manner. Consider first the effects of trade liberalization on the welfare of a country that has an apparent comparative advantage in fish. Figure 4.8 shows that an increase in the relative price of fish, due to free trade, initially results in complete specialization in fishing. However, as the fish stock declines from the increase in fishing effort. the temporary production possibilities frontier pivots inwards until it becomes coincident

¿sFor example. the common propery institution may be in place to ensure access to some minimum level or an equitable distribution of income within the economy: 
with the terms of trade line and a new sustainable equilibrium production point is reached at $\mathrm{Pl}$ with consumption at $\mathrm{C} 1$. In Figure 4.8 this is illustrated by a movement in the production point from $E_{A}$ to $P 1$ via point $B$. Since the consumption possibilities set and temporary production possibilities set are coincident in the Ricardian model, welfare is unambiguously worsened irrespective of the preference assumption (Brander and Taylor (1997a) Proposition 4). Notice, however that with Cobb-Douglas preferences, the economy exports fish. and imports manufactures in the free-trade equilibrium

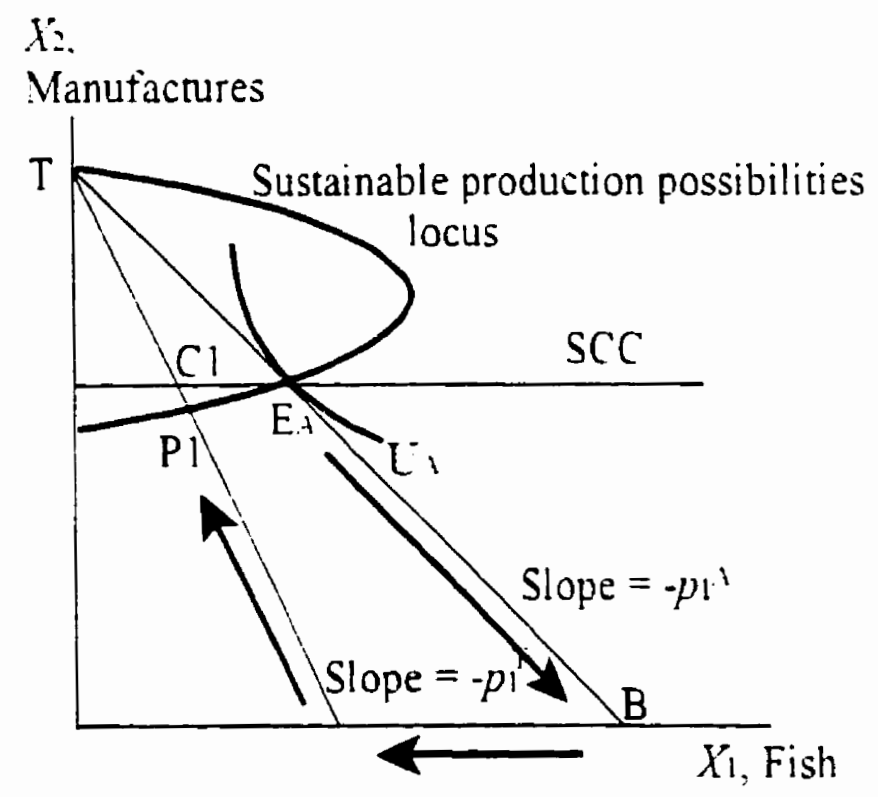

Figure 4.8

Autarkic and free trade equilibrium in the Ricardian model - I

Conversely. Figure 4.9 shows that the movement from autarky to free trade 
unambiguously improves welfare when the world price of fish is lower than that in autarky (Brander and Taylor (1997a) Proposition 6). In this case, the production moves from point $E_{A}$ to $P_{2}$ via a short-run equilibrium at $T$. Notice that this result does not rely on the Cobb-Douglas preference assumption. The implications of relaxing the preference assumption will be addressed in greater detail at the end of this chapter

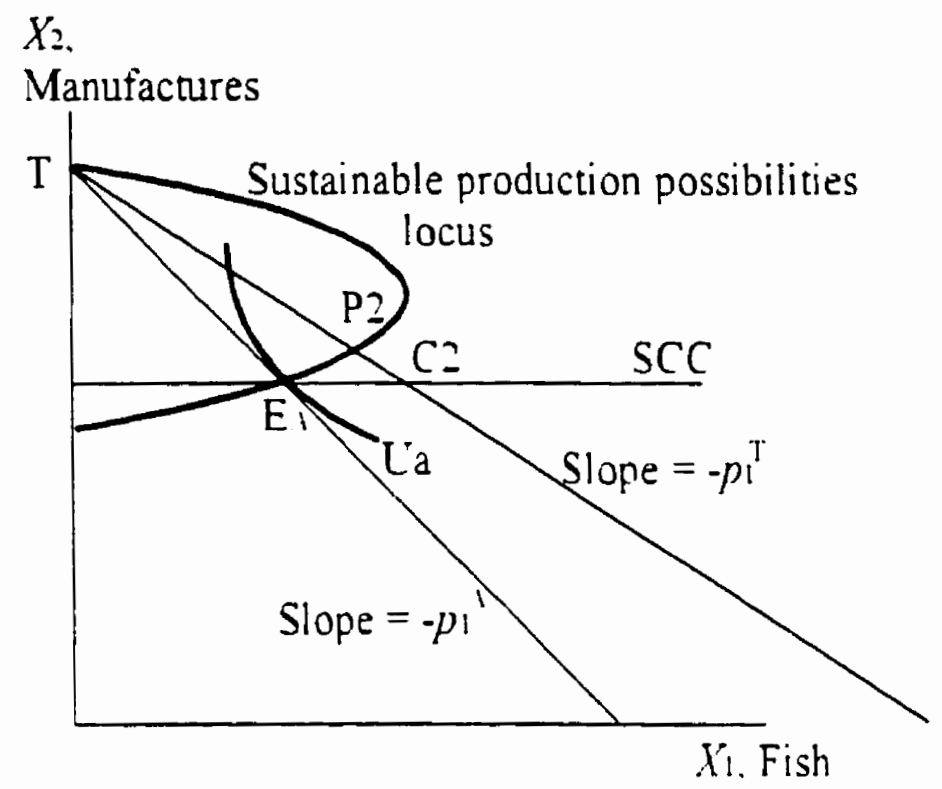

Figure 4.9

Autarkic and free trade equilibrium in the Ricardian model - II

\subsubsection{Second-best trade policy}

The effects of trade policy on outputs and welfare can be determined using a simple graphical technique (see Corden (1974)). The case when the economy is an exporter of fish is depicted in Figure 4.10. In the free trade equilibrium, the production and consumption points are illustrated by points $\mathrm{Pl}$ and $\mathrm{Cl}$ respectively. The effect of a tariff on the import of manufactures. or equivalently an export tax on fish (by Lerner's 
symmetry theorem the two have the same effects), is to drive a wedge between the domestic price of fish and the world price of fish such that the world price exceeds the domestic price. The introduction of an export tax on fish therefore lowers the domestic fish price causing a reduction in fishing effort, an increase in the fish stock, and the temporary PPF to pivot outwards to $\mathrm{TZP}_{2}$. The new production point is P2. To determine the new consumption point, I exploit some of the properties of Cobb Douglas preferences. It is understood that the stock consumption curve (SCC) is a horizontal line passing through $\mathrm{Cl}$. The SCC intersects the new temporary PPF at point $Z$. Because domestic consumers and producers face the same relative price of fish under the export tax. and because preferences are homothetic. the new consumption point must lie along the ray $\mathrm{OZ}$. Thus, the solution for the new consumption bundle. $\mathrm{C} 2$. is determined by the intersection of the ray $\mathrm{OZ}$ and the trade line emanating from $\mathrm{P} 2$ By repeating this process. a locus $\mathrm{C} \mathrm{Cl} \mathrm{C2} \mathrm{A} \mathrm{C}^{\prime}$ can be traced out showing the consumption bundles as the tariff is progressively increased. This locus is referred to as the sustainable consumption curve and should not be confused with the SCC. Vote that the consumption locus can be extended beyond the autarkic equilibrium. $A$. if a trade subsidy (either applied to imports of fish or an export subsidy applied to exports of manufactures) is used in conjunction with a prohibitive export tax on fish.

Welfare is maximized at the point where the sustainable consumption locus is tangent to a social indifference curve. This occurs on the negatively sloped portion of the consumption locus at a point such as $C_{3}$ in Figure 4.10. While it is clear from the diagram 
that the free trade equilibrium may be improved upon by a restrictive trade policy (tariff on the import of manufactures or a fish export tax) it is also possible that the welfare maximizing trade policy may involve a trade reversing export subsidy to manufactures In Figure 4.10, this would happen if the consumption locus ( $\mathrm{C} \mathrm{Cl} \mathrm{C} 2 \mathrm{C} 3 \mathrm{~A}$ ) cut from the left and below the Ricardian PPF, TAG, as the tariff passes through the prohibitive level

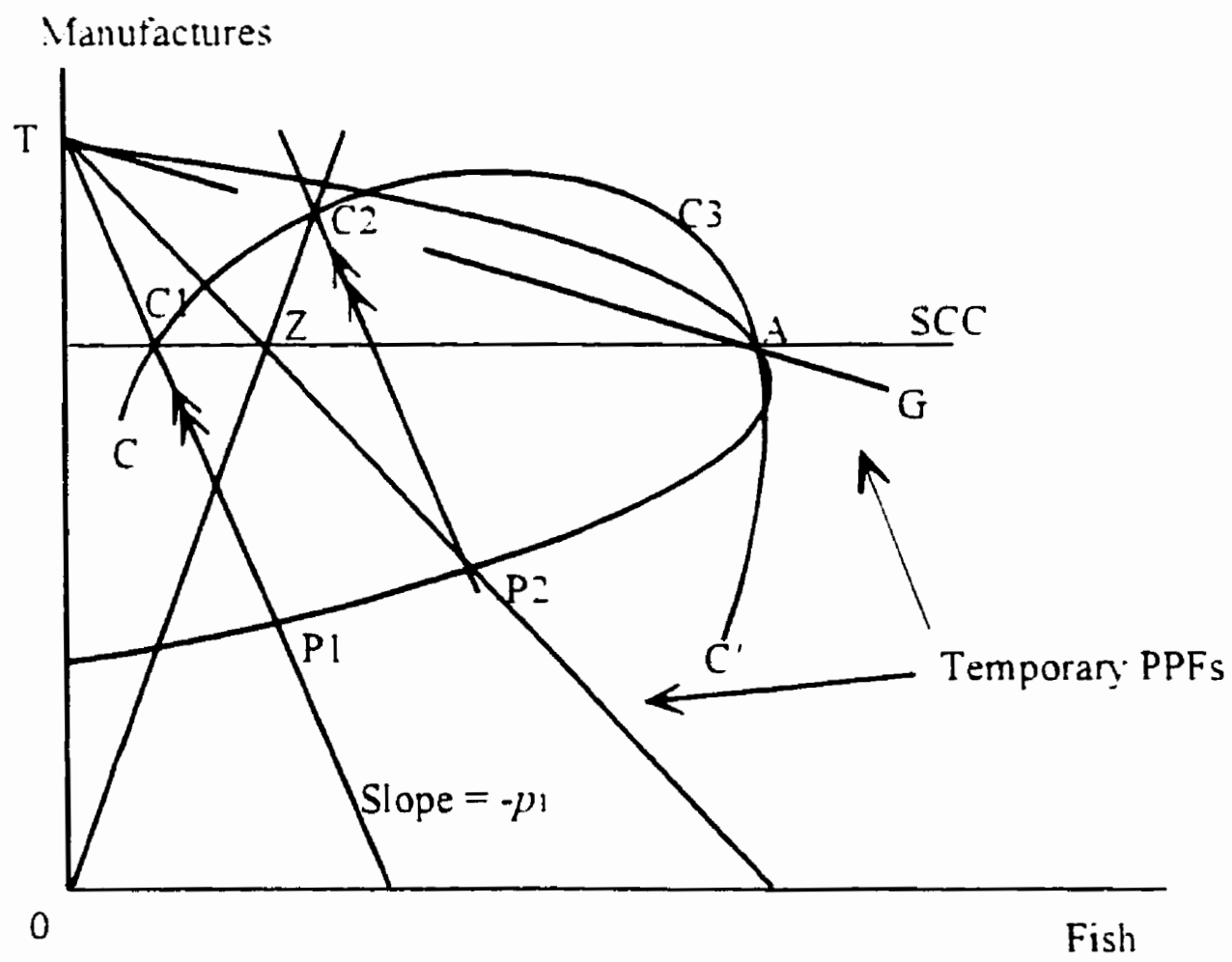

Figure 4.10

Deriving the consumption locus for a fish-exporting country 
In a similar fashion, Figure 4.11 shows how the sustainable consumption locus, $\mathrm{CC}_{2} \mathrm{C}_{1} \mathrm{C}^{\prime}$, for a fish-importing country can be traced out by varying the tariff on fish imports In this case, a tariff on fish imports increases the domestic price of fish and encourages an expansion in fishing effort. The corresponding increase in fishing reduces the fish stock and the temporary PPF pivots inwards. Since the fish stock falls with increases in the tariff, the tariff induces a negative income effect as well as a consumption distortion Welfare is therefore unambiguously worsened by a tariff. Conversely, starting from free trade. a small export subsidy applied to manufacturing improves welfare. This can be seen as the consumption locus $\left(\mathrm{C} 2 \mathrm{CI} \mathrm{C}^{\prime}\right)$ cuts through the free trade equilibrium consumption bundle. $\mathrm{Cl}$. from below the free trade line as the tariff is lowered through zero and the export subsidy is applied With Cobb-Douglas preferences. inspection of the diagram reveais there can be no reversal of the pattern of trade in this case This is because the expor subsidy, which encourages increased imports of fish as well as increased exports of manufactures. reinforces the original trade pattern 


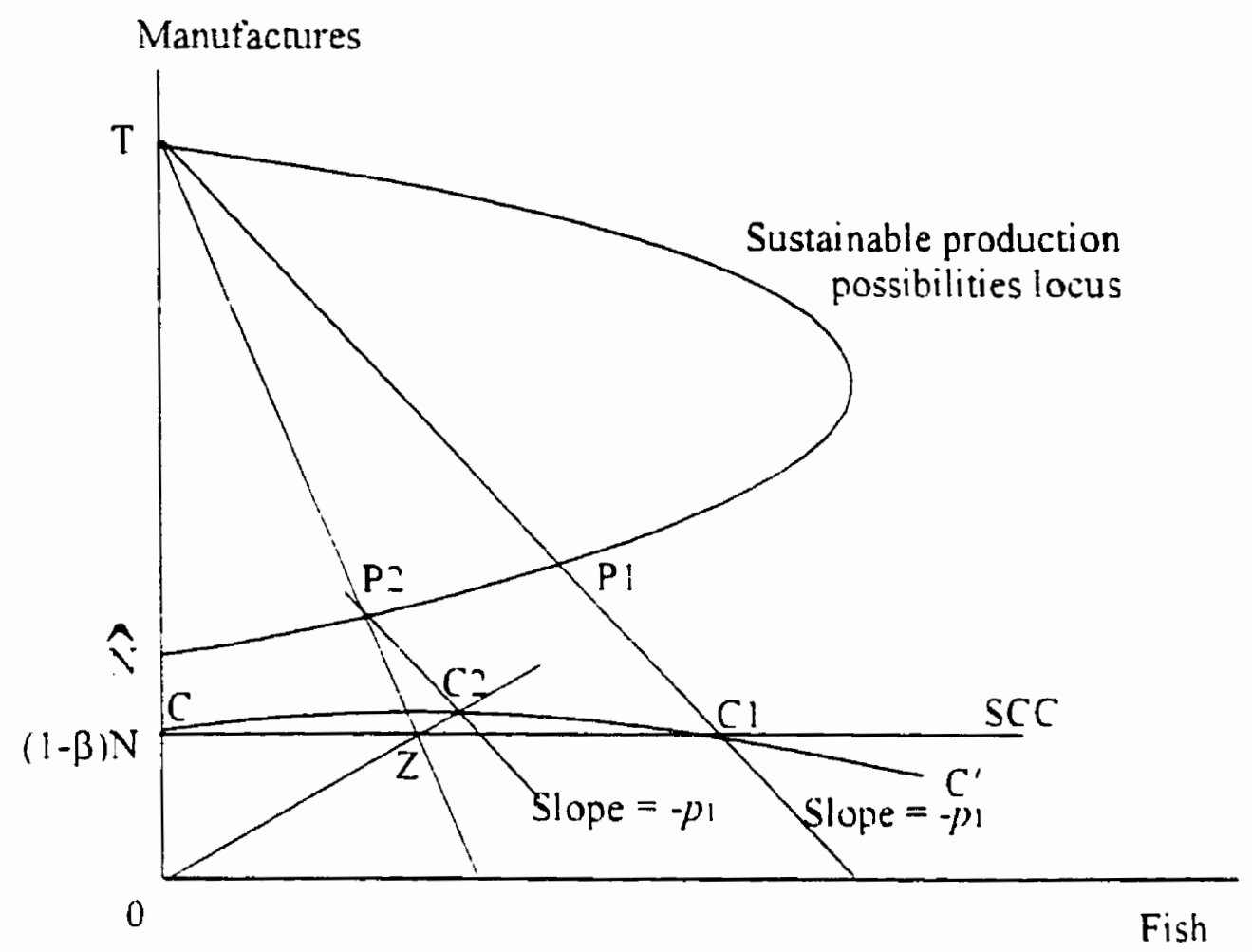

Figure 4.11

Deriving the consumption locus for a fish-importing country 
The following proposition summarizes the role trade policy can play to offset the openaccess problem.

Proposition 4.5: Under conditions of open access, with Ricardian technolog: and CobhDouglas preferences,

i) if the economy is a fish exporter under fiee trade, then the imposition of a small tariff requivalent export (ax) unambiguously generates an improvement in welfure:

ii) if the economy is a fish importer under free trade. then the imposition of a small trake subsidy will unambiguously improve welfare; and.

iii) in general, the second-best trade policy will imolve a tariff export subsidy: In the case where the economy is an exporter of fish the second-best Irade policy mal involie a prohihitive tariff cum trate suhsidn:

Proof

Consider the imposition of an export tax. $\tau$. imposed on exports of fish. $E_{1}$ In terms of manufactures. income. I equals wage income plus tax income. Since the wage rate is unity. income is $I=N+\tau E_{1}$. Consumers of fish face the export tax inclusive price. $p_{1}-\tau$. where $p_{1}$ is the constant world price. Thus. from (4.22) consumption of fish is given by $C_{1}=\beta I /\left(p_{1}-\tau\right)$, while consumption of manufactures is simply $C_{1}=(1-\beta) l$. Note that when $E_{1}$ is negative. the economy is importing fish. and $\tau$ can be interpreted as a trade subsidy given to the import of fish. The trade subsidy lowers the price paid by consumers and 
producers alike (assuming that cross hauling is prohibited by a prohibitive export tax on fish (see Casas (1991)).

To determine the equilibrium level of $E_{\mathrm{t}}$, first derive the equilibrium level supply of fish.

$$
X_{1}=q S F \text {. }
$$

Recall that the equilibrium fish stock is related to the producer price, $p_{1}-\tau$, as follows:

$$
S=1 /\left[q\left(p_{1}-\tau\right)\right]
$$

Substituting $(+37)$ along with the production function for fishing effort. $F=X_{1}$. into $(4.36)$ gives

$$
x_{1}=V_{1}\left[\left(p_{1}-\tau\right)\right] .
$$

Thus $E_{1}=K_{1}-C_{1}$. or

$$
\begin{aligned}
E_{1} & =N_{1}\left[\left(p_{1}-\tau\right)\right]-\beta I /\left(p_{1}-\tau\right) \\
& =\left[N_{1}-\beta\left(V+\tau E_{1}\right)\right] /\left(p_{1}-\tau\right)
\end{aligned}
$$

Next substitute in for the equilibrium level of employment in the fisher. Recall from (4.33) that employment in the fishery was related to the equilibrium stock

$$
S=c\left(1-\frac{q}{\gamma} N_{1}\right) .
$$

Rearranging (4.33) and substituting for $S$ using (4.37) the equilibrium level of employment is given by

$$
\mathrm{N}_{1}=\frac{\gamma}{q}\left[1-\frac{1}{q c\left(p_{1}-\tau\right)}\right]
$$

Thus (4.39) becomes

$$
E_{1}=\frac{\gamma}{q}\left[\frac{q c\left(p_{1}-\tau\right)-1}{q c\left(p_{1}-\tau\right)^{2}}\right]-\frac{\beta\left(N+\tau E_{1}\right)}{\left(p_{1}-\tau\right)}
$$


Equation (4.40) can be re-arranged to give $E_{1}$ as a function of prices, the trade subsidy and other parameters

$$
E_{1}=\frac{\frac{\gamma}{q} q c\left(p_{1}-\tau\right)-\frac{\gamma}{q}-\beta N q c\left(p_{1}-\tau\right)}{q c\left(p_{1}-\tau\right)^{2}+q c\left(p_{1}-\tau\right) \beta \tau}
$$

Now determine the effects of a trade tax on steady-state welfare. Substituting into the utility function (4.21) gives indirect utility function:

$$
L=\beta^{\beta}(1-\beta)^{(1-\beta)_{I /\left(p_{1}-\tau\right)^{\beta}}}
$$

Differentiating with respect to $\tau(4.42)$ gives

$$
\frac{d U}{d \tau}=\frac{\gamma\left(E_{1}+\tau \partial E_{1} / \partial \tau\right)}{\left(p_{1}-\tau\right)^{\beta}}+\frac{\beta \gamma\left(N+\tau E_{1}\right)}{\left(p_{1}-\tau\right)^{(\beta-1)}}
$$

When evaluated at the free trade equilibrium $(\tau=0) .(+t 3)$ becomes.

$$
\frac{d U}{d \tau}=\frac{\gamma\left(E_{1} p_{1}+\beta N\right)}{\left(p_{1}\right)^{(\beta-1)}} .
$$

From ( 4.44$)$ it can be seen that if $E_{1}$ is positive. with the economy exporting fish. an export tax on fish exports unambiguously improves welfare. While this result sounds counter-intuitive at first. it must be remembered that the imposition of the export tax leads to a pivot outwards of the Ricardian production possibilities frontier. This results in an improvement in welfare that is of first order in magnitude and more than offsets the consumption effect that is of second order of magnitude. This proves part $i$ ) of Proposition 4.5. 
The economy is importing fish when $E_{\mathrm{l}}$ is negative. In this case $\tau$ corresponds to an import subsidy on imports of fish. Equation (4.44) thus reveals that it is possible that welfare may be reduced by the imposition of a trade subsidy. For this to be true. the term $E_{1} p_{1}+\beta N$ must be negative.

To consider this possibility in more detail recall the equilibrium value of $E_{1}$.

$$
E_{1}=\frac{\frac{\gamma}{q} q c\left(p_{1}-\tau\right)-\frac{\gamma}{q}-\beta N q c\left(p_{1}-\tau\right)}{q c\left(p_{1}-\tau\right)^{2}+q c\left(p_{1}-\tau\right) \beta \tau}
$$

When evaluated a the free-trade equilibrium. $\tau=0$ and $(t+1)$ becomes

$$
E_{1}=\frac{\frac{\gamma}{q} q c p_{1}-\frac{\gamma}{q}-\beta N q c p_{1}}{q c p_{1}^{2}}
$$

Thus $E_{p} p_{1}+\beta, V$ is negative only if.

$$
\frac{\frac{\gamma}{q} q c p_{1}-\frac{\gamma}{q}-\beta N q c p_{1}+q c p_{1} \beta N}{q c p_{1}}<0
$$

or if. $q c p_{1}<1$. However as explained earlier in the Chapter (Section + 2.2 regarding equation 4.17). if $q c p_{1}<1$ then the economy is specialised in manufactures In order for the economy to be in a diversified equilibrium it is necessary that $p_{1}>1 /(q c)$. This proves part ii) of Proposition 4.5

Part iii) of Proposition 4.5 follows from the geometric presentation of the model as 
shown in Figures 4.10 and 4.11 . However, note that in the case where the economy exports fish and the government places a prohibitive export tax (import subsidy) on fish (such that $E_{1}=0$, and $\tau>0$ ) then utility will be improved if

$$
\frac{d U}{d \tau}=\frac{E_{1}\left(p_{1}-\tau\right) \gamma\left[\tau / E_{1}\left(\partial E_{1} / \partial \tau\right)\right]+\beta \gamma N}{\left(p_{1}-\tau\right)^{(\beta-1)}}>0 .
$$

Or.

$$
\left(p_{1}-\tau\right) \gamma\left[\tau \frac{\partial(\gamma S(1-S / c)-\beta N q S)}{\partial \tau}\right]+\beta \gamma N>0
$$

which after considerable manipulation becomes ${ }^{20}$

$$
-\frac{S}{c} \frac{\tau}{\left(p_{1}-\tau\right)}+\frac{\beta N}{\gamma / q}>0
$$

Because the country exports fish the second term must be a fraction (i.e. the economy does not extinguish the stock in autarky). In order for the condition to hold it is follows

$\therefore$ The condition. $\left(p_{1}-\tau\right) \gamma\left[\tau(\gamma(1-2 S / c)-\beta N q) \frac{\partial S}{\partial \tau}\right]+\beta \gamma N>0$. can be simplified as

$$
\left(p_{1}-\tau\right) \gamma\left[\tau \frac{\left(E_{1}-S^{2} \gamma / c\right)}{S} \frac{\partial S}{\partial \tau}\right]+\beta \gamma N>0
$$

Since $E_{1}=0$ in the autarkic equilibrium.

$$
\begin{aligned}
S=1 . q\left(p_{1}-\tau\right) . \text { so } & -\frac{\left(p_{1}-\tau\right) \gamma^{2} \tau S}{c} \frac{\partial S}{\partial \tau}+\beta \gamma N>0 \\
& -\frac{\left(p_{1}-\tau\right) \gamma^{2} \tau S}{c} \frac{1}{q\left(p_{1}-\tau\right)^{2}}+\beta \gamma N>0 \\
& -\frac{\gamma^{2} \tau S}{c} \frac{1}{q\left(p_{1}-\tau\right)}+\beta \gamma N>0 \\
& -\frac{\gamma}{q} \frac{\tau}{c} \frac{1}{q\left(p_{1}-\tau\right)^{2}}+\beta N>0
\end{aligned}
$$

From which the condition in the text follows directly. 
necessary that the autarkic fish stock be relatively small compared to the capacity of the fishery, and that the prohibitive tariff not be too large. This condition will hold if the size of the prohibitive export tax was sufficiently small. This proves part iii) of the proposition

This section has shown that, in general. free trade is not optimal for a small open economy with an open-access resource. This result should not be surprising. since it is well known that in the presence of a market failure. such as open access. free trade is unlikely to maximize welfare. Neverheless. the second-best solution was shown to involve some trade. No matter whether the country imported or exported fish. the second-best trade policy was one which encouraged a reduction in the net export of fish and an expansion in the net expor of manufactures Thus. in the case where the country imports fish. the second-best policy requires a trade subsidy to be implemented to encourage an expansion in manufacturing exports and an increase in fish imports. In the case of a fish-exporting country, the second-best policy was shown to be an export tax on fish. Furthermore. the analysis illustrates that the second-best policy for a fish-exporting country may involve a prohibitive export tax on fish combined with a trade subsidy to encourage fish imports and the export of manufactures.

\subsection{The Role of Cobb-Douglas Preferences and the Ricardian Production Structure}

This section briefly considers the effect of relaxing some of the assumptions in the model. First. consider a relaxation of the preference assumption and how it will affect 
the free-trade and autarkic equilibria. It is demonstrated that once this assumption is relaxed, the possibility of multiple autarkic equilibria arises. Interestingly. while there remains only one free-trade equilibrium, the possibility exists that a country that seems to have an apparent comparative advantage in one good. may in free trade export the other Second, the Ricardian production structure is replaced with a Heckscher-Ohlin structure. Once this change has been made the possibility exists that a fish-exporting country may be better under free trade than in autarky, contrary to the results of the Ricardian model

\subsubsection{Relaxing the preference assumption}

When the Cobb-Douglas preference assumption is dropped, then this model may have multiple autarkic equilibria. This is illustrated by Figure +12 below where the CobbDouglas preference assumption is dropped. Instead. the SCC used in this diagram has the "conventional" shape for the price consumption curve and corresponds (roughly) to a linear demand curve for fish. There are now three possible autarkic equilibria. Only A and $A^{\prime \prime}$ are stable. $A^{\prime}$ is unstable for the following reason. If one started at $A^{\prime}$ and there was a small shock to the fish stock (an increase for example). then autarkic consumption and production would take place at C2. This harvest of fish is less than that which would be needed to prevent the stock from growing (to the left of the sustainable locus) and consequently the temporary PPF would pivot out until the sustainable (stable) equilibrium is reached at $\mathrm{A}$

The possibility of multiple equilibria breaks the link between comparative advantage and 
the trade pattern that arises in free trade. As shown in the Figure 4.12, the movement from autarky to free trade may involve the economy importing fish even if in autarky the world price of fish exceeds the autarkic price. Point $\mathrm{A}$ is the autarkic equilibrium. $\mathrm{Pl}$ is the equilibrium under free trade, and $\mathrm{Cl}$ is consumption under free trade.

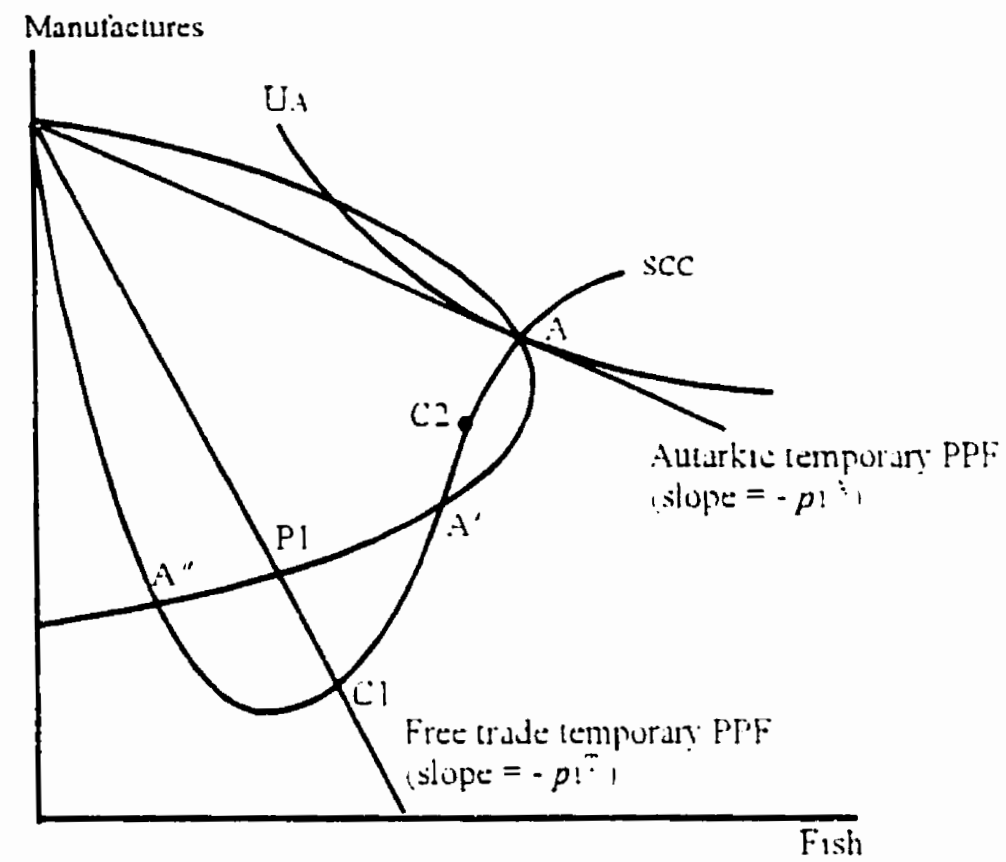

Figure 4.12

Multiple equilibria in the Ricardian open-access model

\subsubsection{A Heckscher-Ohlin production structure}

In the Ricardian model. one of Brander and Taylor's most striking results was that a country that has an apparent comparative advantage in fish is necessarily harmed by the move from autarky to free trade (Brander and Taylor (1997a)). However, using the Heckscher-Ohlin version of the model. it can be shown that opening the economy to free trade may improve economic welfare when the relative price of fish on the world market 
exceeds the autarkic domestic price. This is illustrated below by Figure 4.13 (note the resemblance to Figure 3.4). In Figure 4.13 the opening of trade leads to a new temporary equilibrium point on the locus $\mathrm{JJ}$ at point $\mathrm{G}$ (i.e. where the trade line and temporary PPF are tangent). Fishing effort and the fish harvest increase and exceed the sustainable level. Over time, the fish population contracts and the temporary PPF pivots inwards. As the PPF pivots in. the production point moves along $\mathrm{JJ}$ until a new sustainable equilibrium production point is reached at P1. Notice that the new consumption possibilities set permits consumption at a point such as $\mathrm{Cl}$. Therefore it is possible that free trade may be welfare improving. even when the world price of fish exceeds the domestic autarky price. Thus, for a country with an apparent comparative advantage in fish. the effect on welfare of moving form autarky to tree trade is ambiguous Interestingly. the result that welfare is improved by moving from autark! to free trade when the country has a comparative advantage in manufactures is not compromised. In this case. opening the domestic market to international competition reduces the level of fishing effort and hence results in an increase in the stock of fish and an outward expansion of the temporary PPF. As a result. the original autarkic consumption point is always feasible under free trade. ${ }^{2+}$

${ }^{27}$ Figure 4.14 bears some resemblance to that employed by Scott and Southey who also asked the question of whether a small open economy with an open-access renewable resource would gain from a move from autarky to free trade. However. although they posited a Ricardian model similar to that of Brander and Taylor, they did not formally derive their results. Consequently Scott and Southey results were somewhat erroneous: and, their conclusion that under open access. if the terms of trade had raised the relative price of fish. free trade might "surprisingly. lead to an increase in welfare" seems to have been in error. Nevertheless, Scott and Southey"s result is reestablished when the production structure is Heckscher-Ohlin. Scott and Southey seem to 
$\mathrm{X} 2$ (Manutactures)

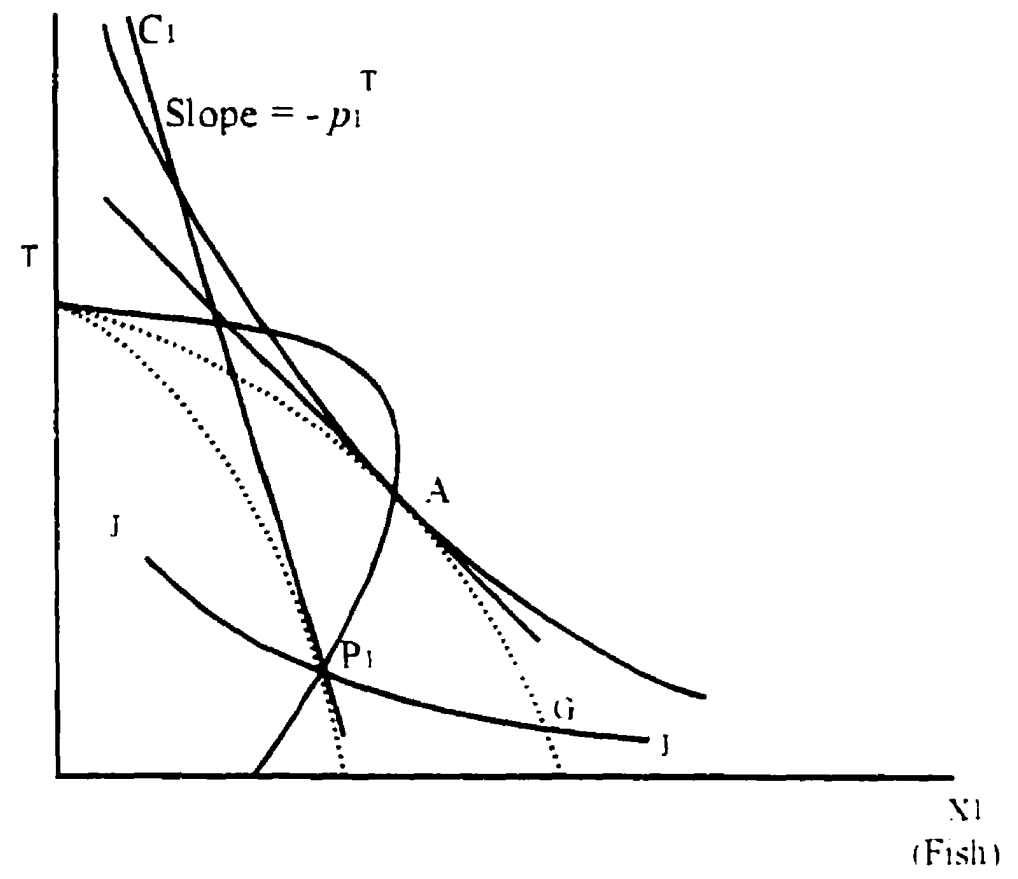

Figure +13

Free trade may dominate autarky for a fish exporter

\subsection{Conclusion}

This chapter was devoted to essentially two issues: First. some of the different regulator: regimes that have been suggested as possible first-best solutions to the open-access problem were considered. It was concluded that the harrest tax had some theoretic advantages over other solutions. such as sole ownership or a system of transferrable

have strayed further with their conclusion that if "the terms of trade are such that the relative price of fish falls, [the market may] fail to achieve an equilibrium level of social welfare as high as that found in the pre-trade state". In the analysis presented in this chapter, trade liberalization that results in a fall in the relative price of fish leads to both a removal of the consumption distortion and an increase in the fish stock: and. as a result. the opening of trade unambiguously improves welfare. 
quotas which restrict entry and may convey the fishing industry with monopsony power in the factor markets. The exploitation of this power may rcsult in under-fishing and a lower harvest than is optimal. The well-known result that a total allowable catch may induce rent-seeking behaviour was also illustrated. Using the Ricardian model it was shown that welfare under a total allowable catch quota may be the same as under open access. Interestingly, it was shown that employment in the fishery may actually be greater than under open access if the size of the potential rents is large enough.

The latter part of the chapter examined the role of trade policy as a second-best instrument. It was demonstrated that an open-access country that exports fish can generally gain from an export tax on fish. while a fish-importing country generally gains from a trade subsidy. In the case where the country exports fish. a reversal of the trade pattern. engineered by a prohibitive export tax combined with a trade subsidy. may be the second-best policy. These results reveal an inconsistency in the call for restrictions to trade made by environmentalists. although the argument that exporters of renewable resources may benefit from a tariff is justified, the same logic that supports this claim suggests importers of the resource good (fish) may gain from a trade subsidy. These results have a strong implication for trade policy in the developing world where many countries have. under severe population pressure. depleted natural resources such as fresh water fisheries. As a result. these countries often depend on exports of manufactures to trade for food. Rather than finding salvation in restricted trade. the model presented here suggests that. for developing countries such as these. policies that promote 
industrialization, through export subsidies to manufacturing may be an appropriate solution 


\section{Appendix 4.1: The Equivalence Between the Harvest Tax and Smith's Catch}

\section{Charge}

The harvest tax rate derived in Section 4.2.1 and the catch charge derived by Smith (1974) can be shown to be equivalent. In Smith's model there is one primary factor of production. labour, which is mobile between the two sectors. Unlike the Ricardian model of Brander and Taylor used in this thesis, labour exhibits diminishing margiral returns in the Smith model. As a result. the opportunity cost of fishing effort is an increasing function, a characteristic shared by the Heckscher-Ohlin version of the model developed in Chapter 3 of this thesis. Furthermore. Smith assumes that the harrest function could be written as $H=H(F, S)$ with $H_{:}=0 . H_{: F}<0$ and $H_{>}>0, H_{:} \div 0$. The assumption the the har est exhibits positive. but diminishing. returns to the fish stock gives rise to the possibility that the open economy model may have multiple equilibria a possibility that is ruled out given the "constant retums" assumption used in the Ricardian and Heckscher- Ohlin models used in this thesis. Otherwise. the models presented in Chapter 3 and the Smith model are essentially the same. Smith showed that if authorities set a "catch charge" per unit of fish caught. $C H$

$$
C H=\left[-H_{\Im} / L(S)\right]\left(q S F_{. y}\left(F_{: .}\right)\right.
$$

then the social optimum would be attained. (Smith assumes that the authorities are attempting to maximize steady-state welfare)

Smith's catch charge implies the competitive tangency condition (4.7) be replaced with

$$
\left.\frac{d X_{2}}{d X_{1}}\right|_{\text {remp }}=-\left(p_{1}-C H\right)
$$


To demonstrate that Smith's catch charge and the harvest tax are equivalent. first recall that $\left.\frac{d X_{2}}{d X_{1}}\right|_{\text {remp }}=-\frac{G_{N}}{q S F_{N}}$ (from Equation (3.10)) and make the substitutions into (A+1.1) and (A4.1.2) to arrive at

$$
\left.\frac{d X_{2}}{d X_{1}}\right|_{\text {remp }}=-\left(p_{1}-\left.\frac{H^{\prime}(S)}{L^{\prime}(S)} \frac{d X_{2}}{d X_{1}}\right|_{\text {remp }}\right)
$$

Equation (A+.1.3) can be rearranged to give

$$
\frac{d X_{2}}{d X_{1}} !_{\text {temp }}\left(1-\frac{H^{\prime}(S)}{L^{\prime}(S)}\right)=-p_{1}
$$

or.

$$
\left.\frac{d X_{2}}{d X_{1}}\right|_{t e m p}=-p_{1}\left(\frac{L^{\prime}(S)}{L^{\prime}(S)-H^{\prime}(S)}\right)
$$

or.

$$
\left.\frac{d X_{2}}{d X_{1}}\right|_{\text {temp }}=-p_{1}\left(1+\frac{H^{\prime}(S)}{L^{\prime}(S)-H^{\prime}(S)}\right)
$$

Now. since $H=q . S F . H^{\prime}(S)=q F$. and $(A+1+4)$ becomes

$$
\left.\frac{d X_{2}}{d X_{1}}\right|_{\text {remp }}=-p_{1}\left(1+\frac{q F}{L^{\prime}(S)-q F}\right)
$$

All that is necessary now is to show that $(q F),\left[I^{\prime}(S)-q F\right]=\eta$. This can be seen by simply. totally differentiating the condition for biological equilibrium. i e that $L(S)=q . S F$. Totally differentiating gives $\frac{d S}{d F}=\frac{q S}{L^{\prime}(S)-q F}$. from which it follows immediately that $\frac{q F}{L^{\prime}(S)-q F}=\frac{d S}{d F} \frac{F}{S}=\eta$. Thus the condition derived in this chapter and that derived by Smith are equivalent. 


\section{Appendix 4.2 Equilibrium Under Open Access; the Optimal Harvest Tax; and}

\section{Equilibrium When Steady-State Welfare is Maximized.}

This appendix derives the Ricardian general equilibrium model. The first part of the appendix derives the equilibrium solutions to the endogenous variables under conditions of open access. The second part of the appendix derives the optimal harvest tax that maximizes steady-state welfare, and the equilibrium values of the endogenous variables at the optimum.

i) Equilibrium under open accesis

The production functions tor the Ricardian economy are given by

$$
\begin{aligned}
& V_{1}=4 S \% \\
& F=V_{1} \\
& V_{2}=V_{2}
\end{aligned}
$$

where $F_{1}$ is the harrest of fish. $F$ is the amoun of fishing effort. and $F_{2}$ is the output of the numeraire good. manufactures. $V_{1}$ and $V_{2}$ are the inputs of labour to fishing effort and manufacturing respectively

In diversified equilibrium the wage rate is given by the marginal product of labour. From (A4.2.3)

$$
\begin{aligned}
w & =d t_{2} i d N_{2} \\
& =1
\end{aligned}
$$


In diversified equilibrium, the zero profit condition for competitive fishing firms in a diversified economy are given by

$$
p_{1} Y_{1}=w N_{1}
$$

Which after substituting for $w$ and $X_{1}$ gives.

$$
p_{1} \varphi S=1
$$

or.

$$
S=1 /\left(p_{1} q\right)
$$

In the model. fishers take the fish stock as a parameter. however in reality the fish stock is an endogenous variable. Equation $(A+2.6)$ says that the equilibrium fish stock is one that produces zero profits in the fishery such that the private value of the marginal product of fishing effort is equal to the wage Given the functional forms for the harest and fishing effort used here. this implies that the equilibrium value of $S$ depends solely. on the relative price of fish in the world market and the catchability of fish for productivity of fishers) in its domestic fisher.

Although the equilibrium level of the fish stock is independent of the parameters of the grouth function of the fishery, the equilibrium level of employment. the harest and manufactures are not.

The condition for biological equilibrium requires the harvest rate to equal the natural rate of growth of the fish population

$$
Y_{1}=L(S)
$$


or,

$$
q S F=\gamma S(1-S i c)
$$

which gives.

$$
N_{1}=\left(1-S^{\prime} c\right) / \mathrm{q}
$$

Substituting for the equilibrium value of $S$. gives the equilibrium level of employment in the open-access case:

$$
V_{1}=\gamma q\left[\left(p_{1} q c-1\right) p_{1} q c\right]
$$

Employment in manufacturing is theretore.

$$
V_{2}=V-v^{\prime} q\left[\left(p_{1} q c-l\right) p_{1} q c^{\prime}\right]
$$

And hence the equilibrium hariest of fish and output of manufactures is given by

$$
\begin{aligned}
& X_{1}=\frac{1}{p_{1}} \frac{\gamma}{q}\left(\frac{p_{1} q c-1}{p_{1} q c}\right) \\
& X_{2}=N-\gamma q\left[\left(p_{1} q c-1\right) p_{1} q c\right]
\end{aligned}
$$

ii) Equilibrium when stead-state welfare is maximized

When steady-state welfare is maximized, the sustainable production possibilities locus tangent to the world trade line

$$
\left.\frac{d X_{2}}{d X_{1}}\right|_{\text {sust }}=-p_{1}
$$

The slope of the sustainable locus. depends on how the fish stock (and hence the productivity of fishing effort) changes as fishing effort is changed.

$$
\left.\frac{d X_{2}}{d X_{1}}\right|_{\text {sust }}=\frac{d X_{2}}{q S d F+q F \frac{\partial S}{\partial F} d F}
$$




$$
\begin{aligned}
& =\frac{1}{q S\left(1+\frac{F}{S} \frac{\partial S}{\partial F}\right)} \frac{d X_{2}}{d F} \\
& =\frac{1}{q S(1+\eta)} \frac{d X_{2}}{d F}
\end{aligned}
$$

Thus (At.2.12) becomes.

$$
\frac{1}{q S(1+\eta)} \frac{d X_{2}}{d F}=-p_{1}
$$

The elasticity of the fish stock with respect to fishing effort can be derived by first totally differentiating the condition for biological equilibrium. i.e $L(S)=q . S F$. to get

$$
\frac{d S}{d F}=\frac{q S}{L^{\prime}(S)-q F}
$$

from which it follows immediately that

$$
\begin{aligned}
\eta & =\frac{d S}{d F} \frac{F}{S} \\
& =\frac{q F}{L^{\prime}(S)-q F} \\
& =\frac{L(S) / S}{L^{\prime}(S)-L(S) / S}
\end{aligned}
$$

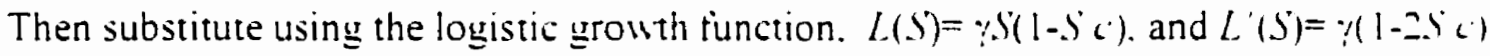
to derive an expression for $\eta$ that depends on $S$

$$
\eta=\frac{\gamma(1-S / c)}{\gamma(1-2 S / c)+\gamma(1-S / c)}
$$

or, simply,

$$
\eta=1-c / S
$$

Now substitute $(A+2.15)$ into $(A+2.14)$ to get.

$$
\frac{1}{q S(2-c / S)} \frac{d X_{2}}{d F}=-p_{1}
$$

After re-arranging. (A4.2.16) gives the fish stock that maximizes steady-state welfare 


$$
S^{*}=\frac{c}{2}-\frac{1}{2 p_{1} q} \frac{d X_{2}}{d F}
$$

As was described in section 4.2 of the chapter, this steady-state equilibrium can acheived by the imposition of an ad valorem harvest tax, $1^{*}$. equal to $-\eta$ Substituting (A+.2.17) into (A4.2.16) gives an expression for the optimal harest tax

$$
\begin{aligned}
t^{*} & =c S^{*}-1 \\
& =\left(c-S^{*}\right) / S^{*} \\
& =\frac{c / 2+\frac{1}{2 p_{1} q} \frac{d X_{2}}{d F}}{c / 2-\frac{1}{2 p_{1} q} \frac{d X_{2}}{d F}} \\
& =\frac{p_{1} q c+\frac{d X_{2}}{d F}}{d X_{2}} \\
& p_{1} q c-\frac{-}{d F}
\end{aligned}
$$

Equation $(A+2.19)$ holds for any transformation function that transforms fishing effor into manufactures and satisfies the usual second order conditions. When the production structure is Ricardian. and $d K_{2} d F=-1$, then the formula for the optimal har est tax is given by

$$
t^{*}=\frac{p_{1} q c-1}{p_{1} q c+1} .
$$

Lastly. the level employment in the fishery (and the level of fishing effort) under a system of optimal regulation can be calculated using (A4.2.7). $V_{i}^{*}=\left(I-S^{*} \cdot c^{\prime}\right) q$. Thus.

$$
F^{\prime}=\frac{\gamma}{2 q}\left(1-\frac{1}{p_{1} q c}\right)
$$

While the optimal level of employment in manufacturing is simply

$$
N_{2}=N-F^{*}
$$




\section{Chapter 5}

\section{Foreign Investment}

\subsection{Introduction}

Spurred by the increasing globalization of world capital markets. the relationship between capital mobility and environmental resources has become a point of discussion in both international and environmental economics. For example. the question of whether competition for foreign investment can lead to a "race to the bottom" - a situation in which governments successively lower the level of environmental regulation in order to attract foreign capital - is openly debated in the literature (see Klevorick (1996) and Wilson (1996) amongst others). Despite this, the case where the environmental resource is renewable. as is the case with a fishery. has yet to be formally: analysed. The objective of this chapter is to partially fill this gap and provide an analysis of the relationship between international capital mobility and environmental regulation for a small open economy dependent on renewable resources.

Throughout this chapter. the two-sector Heckscher-Ohlin model of a small open economy developed in Chapters 2 and 3 is employed. Free trade in goods is assumed. and the fishery is regulated through the use of a harvest tax on fish. The only extension to the basic model of the earlier chapters is that foreign investment in the domestic economy is permitted. In order to develop an understanding of the relationship between 
the hariest tax, capital mobility, and national welfare (as measured by GNP). a methodical step-by-step approach is followed. Initialiy, the relationship between the level of fisheries regulation and foreign capital inflow will be examined assuming perfect capital mobility. Second, it will be assumed that the level of foreign capital in the economy is fixed and unresponsive to the level of regulation. With this assumption. the optimal level of regulation, given the stock of foreign owned capital, can be determined. The next step keeps the level of regulation fixed and allows the stock of foreign capital to become a choice variable for the government. Once these three relationships have been understood. then an analysis of the relationship between regulation. capital mobility and welfare can be made. To simplify matters, the dynamic aspects of the model developed in Chapter 3 are ignored and it is assumed that social welfare is maximised if steady-state GNP is maximised.

The approach taken here is a variation on previous studies such as Brecher and DiazAlejandro (1977) and the more recent analysis by Wong (1995) that explore the relationship between tariffs and foreign capital inflow. They demonstrate that tariff induced capital inflow may be welfare worsening. However. this chapter ignores trade policy and examines regulation of renewable resources instead. It is shown that the effects of changes to the regulation of the fishery (as proxied by a change in the hariest tax) are amplified in the presence of capital mobility. Thus. a small change in the harest tax has a greater impact on welfare when capital is mobile than when it is not. This result is similar to that found by Copeland (1994). who considers environmental 
regulation in the presence of a production-induced pollution externality and international capital mobility. However, in his model pollution adversely affects the utility of consumers, but does not affect the productivity of production. In the model considered here the opposite is true: the external effects of fishing effor do not directly influence consumers. but the productivity of other fishers.

Aside from the welfare effects. the distributional effects of a harvest tax on the fishery under perfect capital mobility are also examined A particularly neat result is that steadystate factor rewards are left unaffected by changes in the harrest tax. Consequently, the government can maximise steady-state welfare simply by choosing the size of the harrest tax to maximise revenue.

\subsection{Perfect Capital Mobility}

\subsubsection{The relationship between the harvest tax. the foreign capital stock and factor prices.}

To begin. assume that the supply of foreign capital is perfectly elastic at the fixed world rate of return and responds to any discrepancy between the domestic and world rate of retum. $r^{*}$. In equilibrium. the return to capital in both sectors of the economy must be equal to the world rate of return. $r^{*}$. Formally, the equilibrium condition is therefore

$$
\begin{aligned}
& p_{i} S(1-l) q F_{k l}=r^{*} ; \text { and, } \\
& G_{k}=r^{*}
\end{aligned}
$$

Where $F_{i: i}$ and $G_{k:}$ are the marginal product of capital in fishing and manufacturing 
respectively, $S$ denotes the fish stock, $t$ is the $a d$ valorem harvest tax rate, and $p_{1}$ is the relative price of fish on the world markets.

Consider the effect of a change in the tax rate $t$ (recall that $t$ is the ad valorem tax on fish landings, or a harvest tax). Any change in the tax rate will immediately affect the domestic return to capital. Assuming that manufacturing is capital intensive and tishing effort labour intensive, an increase in the landings tax rate causes a decrease in the return to fishing effort, an increase in the return to manufacturing and. therefore. an increase in the demand for capital relative to labour. The higher return on capital induces a capital inflow and. a la Rybczynski. an increase in manufacturing. a decrease in fishing effort and. consequently. an increase in the stock of fish. If the stock of fish were fixed. the model would behave in the same way as the standard Heckscher-Ohlin model, foreign capital would continue to flow in. attracted by the differential in rates of return. until the economy became specialised in the production of manufactures. Once complete specialisation had occurred, factor prices would respond in the fashion outlined by MacDougall (1960). That is, with the economy's entire labour supply employed in manufacturing, any additional capital inflow would be subject to diminishing returns. and the return to capital would fall until the differentral between the domestic return to capital and the world return is eliminated. However, in this model the fish stock is not fixed. but endogenous. and it is the fish stock that adjusts to restore equilibrium. Hence. the equilibrium size of the capital inflow is that which is sufficient to generate a fall in fishing effort and an increase in the fish stock such that the return to capital, both 
economy wide and in the fishing sector, equals $r^{*}$ and the equilibrium conditions (5.1a) and $(5.1 \mathrm{~b})$ are restored. The relationship between the tax rate and the equilibrium stock of foreign capital, $\kappa$, is illustrated as an upward sloping function labelled $r r$ in Figure 5.1

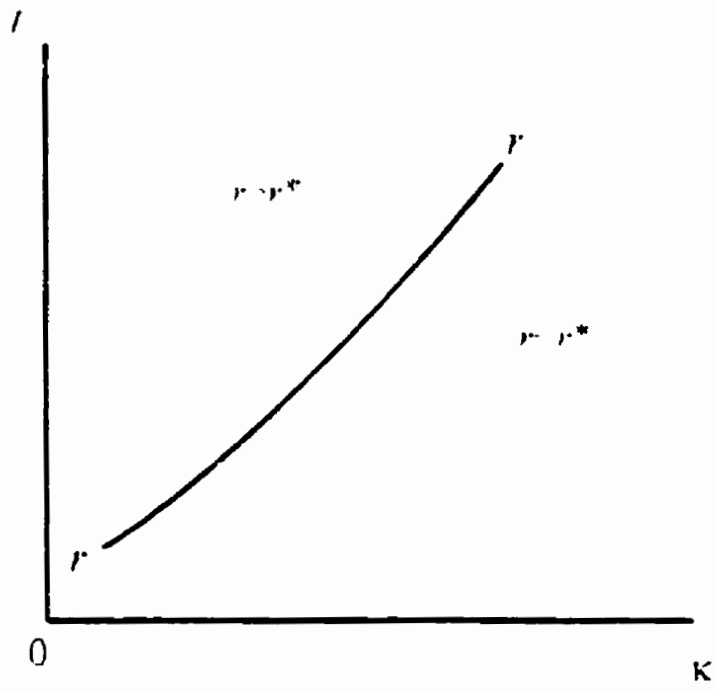

Figure 51

The relationship between the harest tax and foregn capital under perfect capital mobility

Interestingly, the mechanism by which the fish stock adjusts to bring about equilibrium also ensures that the capital to labour ratio in the two sectors is left unaffected by a change in the harvest tax. This can be seen by re-writing equations (5.la) and (5.1b) as follows

$$
\begin{aligned}
& p_{i} S(I-I) q f^{\prime}\left(k_{1}\right)=r^{*} ; \text { and } \\
& g^{\prime}\left(k_{2}\right)=r^{*} .
\end{aligned}
$$

where the functions $f$ and $g$ indicate the outputs of fishing effort and manufactures per 
unit of labour, $k_{1}$ and $k_{2}$ are the capital to labour ratios in fishing and manufacturing respectively, and a prime denotes the first derivative. Since $f$ and $g$ are strictly positive functions, in a diversified equilibrium, the equilibrium condition $\left(5.1 \mathrm{~b}^{\prime}\right)$ uniquely determines the capital to labour ratio in manufacturing and therefore in fishing. independent of the tax rate. This has important implications which are summarised in Proposition 5.1

Proposition 5.1: A.s long as the e'conom! remains incompletely specialised in steded. state. an increase (decrease) in the fish harvest kax:

i) leaves the capital os lahour ratio in fishing effort and mamufacturing unchanged: ii) leaves the returns on capital and lahour unchanged and as a result the toral income' that accrues directly to domestic onners of copital and labour is left unaffected hy changes to the harvest lax; and. iii) produces a linear expansion (contraction) in mamufacturing and a linesar contraction (expansion) in fishing effort.

Proof: See Appendix 51

Part (iii) of the Proposition is a Rybszynski-type result with respect to the output of manufacturing and fishing effort (i.e.. the change in the tax rate generates a linear increase in manufacturing and a reduction in fishing effort at constant private factor rewards). In Figure 5.2. the Rybczynski line $R R$ illustrates the change in the output of 
fishing effort and manufacturing in response to a change in the tax rate. However, this Rybczynski result does not hold with respect to the sustainable harvest of fish, which is governed in part by the properties of the (logistic) growth function and may rise or fall as a result of the capital inflow. The locus of sustainable production points under perfect capital mobility is also illustrated by Figure 5.2 using the same technique as that used in Chapter 2 to derive the sustainable locus in the absence of capital mobility. The diagram shows the original transformation frontier $\mathrm{TT}^{\prime}$. drawn for a given stock of capital, in the upper left-hand side quadrant of the diagram. The onginal equilibrium combination of fishing effort and manufactures is given by point $A$ and the corresponding sustainable output of manufactures and harvested fish is given by $A^{\prime}$. Following an increase in the tax rate. with manufacturing capital intensive. the return to capital increases and foreign capital flows in according to the process described above. In the long-run. after the fish stock has adjusted and the foreign capital inflow has ceased. with the capital to labour ratio in both sectors unaffected by the change in the tax rate. a new equilibrium is reached on the Rybczynski line $R R$ at $B$. The corresponding output bundle of manufactures and fish is illustrated by point B'. Similarly, using the Rybczynski line. the entire sustainable production possibilities locus under perfect capital mobility can be traced out as illustrated by the locus passing through $A^{\prime} B^{\prime}$ in the upper right-hand quadrant. 


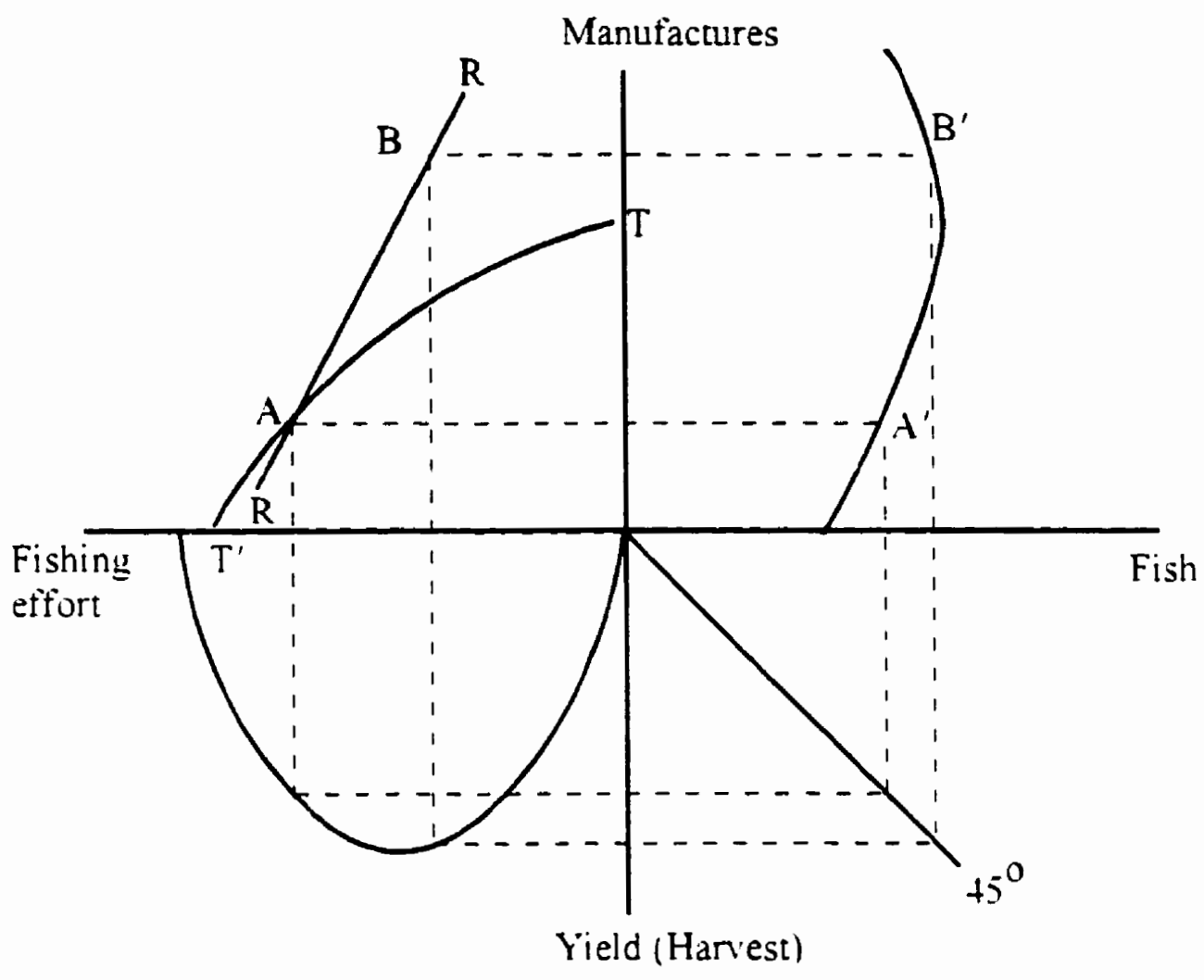

Figure 52

The sustainable production possibilities under perfect capital mobility

\subsubsection{The optimal harvest tax under perfect capital mobility}

Since private factor rewards are unchanged by the change in the harest tax. all the government must do to maximise domestic welfare is to simply set the optimal tax so as to maximise its own tax revenue. Therefore, the optimal harvest tax can be found simply by choosing $t$ to maximise steady-state tax revenue

$$
T=t p, S q \Phi
$$

where $\Phi$ is defined, as in Chapter 4 , as the equilibrium value of fishing effort that arises 
from the solution to Equations (4.3)- (4.6) taking $S$ as a parameter. Specifically. recall that $\Phi=\Phi(\pi)$, where $\pi=\left(p_{1}-i\right) q S$. and $\Phi^{\prime}(p)>0$

Differentiating (5.2) with respect to $t$ and setting equal to zero gives

$$
\begin{aligned}
& \frac{\partial T}{\partial t}=p_{1} q S \Phi+\frac{t p_{1} q \partial(S \Phi)}{\partial t}=0 \\
& p_{1} q\left[S \Phi+\frac{t \partial(S \Phi)}{\partial t}\right]=0 \\
& p_{1} q\left(S \Phi+\frac{t \Phi \partial S}{\partial t}+\frac{t S \partial \Phi}{\partial t}\right)=0
\end{aligned}
$$

This can be simplified by noting from $(5 \mathrm{l}$ a $)$ that $I$ as a function of $t$ and a constant. To see this. rearrange $\left(5.1 a^{\prime}\right)$ to give

$$
S=\frac{1}{(1-t)} \frac{r *}{p_{1} q f^{\prime}\left(k_{1}\right)} \text {. }
$$

or. since the capital to labour ratio is fixed by the capital mobility assumption

$$
S=\frac{1}{(1-t)} b
$$

where $\mathrm{b}$ is a constant. equal to $\frac{r *}{p_{1} q f^{\prime}\left(k_{1}\right)}$

Differentiating (5.4) then gives

$$
\frac{\partial S}{\partial t}=\frac{S}{(1-t)} \text {. }
$$

Substituting (5.5) into (5.3) gives.

$$
p_{1} q S\left[\Phi+\frac{t \Phi}{(1-t)}+\frac{t \partial \Phi}{\partial t}\right]=0
$$


which can be rearranged to obtain.

$$
p_{1} q S\left[\frac{\Phi}{(1-t)}+t \frac{\partial \Phi}{\partial t}\right]=0
$$

Substituting for ( $1-t)$ using (5.5) again gives

$$
p_{1} q S\left[\frac{\Phi}{S} \frac{\partial S}{\partial t}+t \frac{\partial \Phi}{\partial t}\right]=0
$$

Finally. note that $S^{\prime}$ can be written as a function of fishing effort. Thus using the chain rule $(56)$ can be re-written as

$$
p_{1} q S\left[\frac{\Phi}{S} \frac{\partial S}{\partial \Phi}+t\right]=0
$$

or.

$$
t=-\eta
$$

Where $\eta$ is the elasticity of the fish stock with respect to tishing effort. Simply put. the optimal tax rate is one that equates the har est tax $t$ with the percentage decrease in the stock of fish induced by an increase in fishing effort (i.e. $t$ is the Pigovian tax) It is interesting to compare this result with the result found in Chapter 4 . It says that the optimal hanest tax policy. in the absence of capital mobility is the same as that with capital mobility (if foreign capital is paid the fixed world rate). The reason is straight forward. The tax policy requires that a tax equal to the loss in productivity imposed on other fishers (in the form of a permanent reduction in the fish stock) induced by any additional fishing effort be paid be each fisher. This is the optimal Pigovian tax that internalizes the externality irrespective of where the fisher hired his factors of production. Furthermore, since the price paid on foreign capital is constant. the 
government has no monopsony power on the international capital market to extract rents from, albeit indirectly, the level of regulation.

\subsection{The Optimal Harvest Tax - Stock of Foreign Capital Fixed}

Now if the assumption that capital is perfectly mobile is replaced with the assumption that the foreign capital stock is fixed. the objective for the govemment is now to choose the optimal har'est tax taking as given the existing stock of foreign and domestic capital It is useful to begin by defining the indrect utility function. $l$. for the citizens of the domestic economy

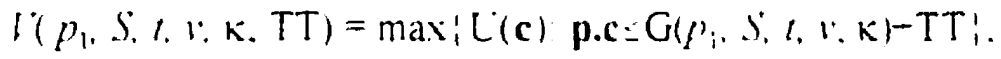

where $G$ is the steady-state value of GDP accruing to labour and capital (including that owned by foreigners). $\mathrm{l}$ is the vector of domestically owned factors. capital and labour. $\kappa$ denotes the level of foreign capital. and TT stands for net transfers to nationals TT is the tax revenue from the harvest tax. $t p_{1} q S F$ minus remittances (transfers) of rents earned bỵ foreign capital $k r^{\prime}$. (which may differ from $r^{*}$ ).

Treating transfers and private income as two separate components is useful because it discriminates between that aspect of GDP that is produced due to the actions of private agents and that determined by government intervention. $I$ is considered the solution to 
the maximisation problem of private agents treating the value of $S$ as a parameter. That is, for a small country with world goods prices taken as given. $V$ can be written as a function of the competitive supply of effor. $\Phi=\Phi\left(p_{1}, S, t, v, \kappa\right)$. and the lump-sum transfers minus remittances, TT.

$$
V=p_{1}(1-t) q S \Phi+X_{2}(\Phi)+T T
$$

While private agents treat $S$ as a parameter. the government chooses $t$ to explicitly affect $S$ and. consequently, the level of fishing effort and revenues associated with the fishery By differentiating the indirect utility function with respect to $t$. and setting the derivative to zero. the optimal value of $t$ can be determined for a given amount of foreign capital

Applying the chain-rule to (5.8).

$$
\frac{d V}{d t}=\mu\left(\frac{\partial V}{\partial t}+\frac{\partial V}{\partial S} \frac{\partial S}{\partial t}+\frac{\partial V^{*}}{\partial T T} \frac{\partial T T}{\partial t}\right)=C
$$

Where $\mu$ is the marginal utility of income. From (5.9) the following partial derivatives

can be calculated

$$
\begin{aligned}
& \frac{\partial V}{\partial t}=-p_{1} q S \Phi+p_{1}(1-t) q S \frac{\partial \Phi}{\partial t}+\frac{\partial X_{2}}{\partial \Phi} \frac{\partial \Phi}{\partial t} . \\
& \frac{\partial V}{\partial S} \frac{\partial S}{\partial t}=p_{1}(1-t) q \Phi \frac{\partial S}{\partial t}+p_{1}(1-t) q S \frac{\partial \Phi}{\partial S} \frac{\partial S}{\partial t}+\frac{\partial X_{2}}{\partial \Phi} \frac{\partial \Phi}{\partial S} \frac{\partial S}{\partial t} \text {. and } \\
& \frac{\partial V}{\partial T T} \frac{\partial T T}{\partial t}=p_{1} q S \Phi+t p_{1} q S \frac{\partial \Phi}{\partial t}-\kappa \frac{\partial r}{\partial t}
\end{aligned}
$$


Also, we make use of the condition for competitive equilibrium that the private opportunity cost of fish (as given by the slope of the temporary PPF) equals the world price less the harvest tax, $\frac{\partial X_{2}}{q S \partial \Phi}=-p_{1}(1-t)$. Using this expression and the partial derivatives, (5.10) can be re-written as

$$
\mu\left[-p q S \Phi+p q(1-t) \Phi \frac{\partial S}{\partial t}+p q S \Phi+t p q S \frac{\partial \Phi}{\partial t}+t p q \Phi \frac{\partial S}{\partial t}-\kappa \frac{\partial r^{f}}{\partial t}\right]=0
$$

where $\mu$ is the marginal utility of income Equation (5.11) simplifies to

$$
p q(1-t) \Phi \frac{\partial S}{\partial t}+t p q S \frac{\partial \Phi}{\partial t}+t p q \Phi \frac{\partial S}{\partial t}-\kappa \frac{\partial r^{j}}{\partial t}=0
$$

or.

$$
p q \Phi \frac{\partial S}{\partial t}+t p q S \frac{\partial \Phi}{\partial t}-\kappa \frac{\partial r^{f}}{\partial t}=0
$$

Then. making use of the fact that the fish stock is a function of fishing effort (which in turn is a function of the harvest tax) substitute $\frac{\partial S}{\partial \Phi} \frac{\partial \Phi}{\partial t}$ for $\frac{\partial S}{\partial t}$. so that (5.12) may be rewritten as

$$
p q\left(\frac{\Phi}{S} \frac{\partial S}{\partial \Phi}+t\right) \frac{\partial \Phi}{\partial t}-\kappa \frac{\partial r^{f}}{\partial t}=0
$$

If foreign capital earns the fixed world rate. $r^{*}$. then $r^{r}$ is unaffected by the change in the $\operatorname{tax}$ rate and $\frac{\partial r^{f}}{\partial t}=0$. With this assumption. (5.13) becomes 


$$
t=-\frac{\partial S}{\partial \Phi} \frac{\Phi}{S}
$$

or,

$$
F-\eta
$$

Equation (5.14) implies that the tax policy: in the absence of capital mobility, is the same as that found for the case when capital was mobile, as given by Equation (5.7). It should be noted however that this does not mean that the tax rate will be the same under a regime of perfect capital mobility and one in which capital is immobile. The reason being that the value of $\eta$ is endogenous and depends on the level of tishing effort. From the logistic equation it can be confirmed that the absolute value of $\eta$ will be higher the greater the value of fishing effort. This is simply because as the stock becomes smaller. a percentage increase in tishing effor will have a greater percentage impact on the fish stock. Thus if the level of fishing effor was greater in the absence of capital restrictions then the optimal tax would be higher. though the policy rule given by equation $(51+)$ is the same. The derivation of $(5.14)$ serves to prove proposition 5.2

Proposition 5.2: When foreign capital earns the world rate of return and the amoum of foreign capital is fixed, the optimal rax policy requires $t=-\eta$.

Proposition 5.2 was derived holding the return paid to the stock of foreign capital constant: however, if the (fixed) stock of foreign capital earns the domestic rate. then the 
rate of retum being paid on foreign capital is no longer independent of the harvest tax. The government can therefore use the tax policy to appropriate some of the rents that would otherwise accrue to foreign firms How this influences the choice of the tax rate depends on the factor intensities in the two industries.

Proposition 5.3: Assuming that manufacturing is capital intensive, the optimal tan rate will he lower for a counmy that pays the domestic rate on foreign capital than for the country that pans the fixed world rate on foretgn capital. This result is resersed if fishing effort is capital intensives.

Proof: Suppose that manufacturing is capital intensive. so that an increase in the tax on the fish harvest causes an increase in manufacturing. an increase the demand for capital and hence the rate of return on capital to increase. This implies that the last term on the LHS of $(513)$ is less than zero, that $15 .-k \frac{\partial r^{f}}{\partial t}<0$ If $t$ is set such that $t=-\frac{\partial S}{\partial \Phi} \frac{\Phi}{S}$ (i.e. ignoring the possibility that a change in the tax rate will affect the return on (foreign) capital). then the whole left hand side of $(5.13)$ is less than zero. To bring it back to an equality. with $\frac{\partial \Phi}{\partial t}<0$. the tax rate would need to be reduced (thereby reducing the amount of rent paid on foreign capital). Intuitively, the government can indirectly reduce the amount of remittances paid to foreigners by lowering $t$ way from the optimal Pigovian tax thereby reducing the relative demand for capital which is assumed to be employed intensively in manufacturing. 
On the diagram below (Figure 5.3) illustrates the locus of points relating the optimal tax rate to the level of foreign capital for the case where manufacturing is capital intensive When foreign capital earns the world rate. this locus, $t t$. is negatively sloped for the following reason: With more foreign capital present, fishing effort is lower and the stock of fish is greater. Given the presumed shape of the logistic function, the elasticity of the fish stock to fishing effort, $\eta$ (recall $\eta=-\frac{\partial S}{\partial \Phi} \frac{\Phi}{S}$ ), is lower and therefore the optimal tax is lower 28 The point where $t l$ curs the vertical axis. $t_{11}$, is the optimal tax rate in the absence of foreign capital. Since the optumal tax rate can never be equal to or less than zero. $t l$ asymptotically approaches but never cuts the horizontal axis

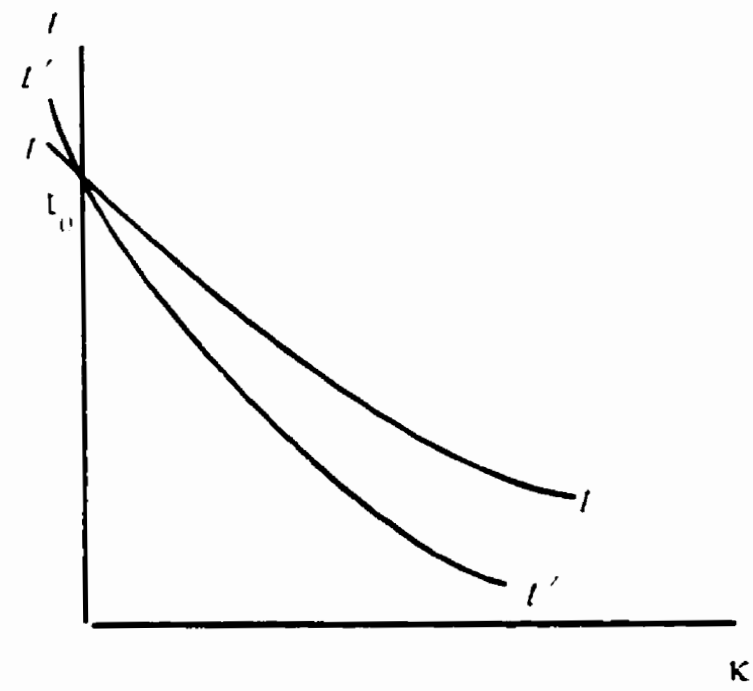

Figure 5.3

The optimal harvest tax with a fixed stock of foreign capital

${ }^{28}$ The $\|$ curve if Figure 5.3 would be positively sloped had fishing effort been capital intensive 
The locus showing the optimal tax rate when the stock of foreign capital earns the domestic rate is shown by $t^{\prime} t^{\prime}$. In the absence of foreign capital, the locus $t^{\prime} t{ }^{\prime}$ has a vertical intercept of $t_{0}$ but otherwise. by Proposition 5.3, it lies below $t t$ for any positive value of $k$

\subsection{Foreign Investment with an Exogenous Level of Fisheries Regulation}

In some cases. perhaps for political reasons or because the resource is open access. the government may be unable to change the level of regulation. When the inability to optimally regulate leads to over-fishing. an inflow or outtlow of foreign capital can lead to a more efficient level of production by inducing an expansion in manufacturing and a contraction in fishing. To begin with. consider the case when foreign capital earns the world rate of return. i.e. $r^{\prime}=r^{*}$.

The government s objective remains to maximise GNP: however. in this section the harvest tax is considered fixed. and the choice variable is the stock of foreign capital." Recall (5.8)

$$
I\left(p_{1}, S, t, v, \kappa . \mathrm{TT}\right)=\max \left\{\mathrm{U}(\mathbf{c}): \mathbf{p . c} \leq \mathrm{G}\left(p_{1}, S, t, v, \kappa\right)+\mathrm{TT}\right\} .
$$

Once again, the optimal level of $\kappa$ can be found by differentiating the indirect utility

${ }^{29}$ Of course the government may not always be able to directly choose the level of foreign capital. This would be true if the domestic rate of return on capital was less than the world rate. However, in this section the question is purely hypothetical. and allows us to at least consider the realistic possibility that the government may wish to choose to restrict the inflow of capital if the domestic rate exceeded the world rate. 
function with respect to $\mathrm{k}$ and setting the derivative to zero

$$
\frac{d V^{*}}{d \kappa}=\frac{\partial V^{\bullet}}{\partial \kappa}+\frac{\partial V^{\circ}}{\partial S} \frac{\partial S}{\partial \kappa}+\frac{\partial V^{*}}{\partial T T} \frac{\partial T T}{\partial \kappa}=0
$$

From (5.9), the partial derivatives can be found to be

$$
\begin{aligned}
& \frac{\partial V}{\partial K}=(1-t) p_{1} q S \frac{\partial \Phi}{\partial K_{1}} \frac{\partial K_{1}}{\partial K}+\frac{\partial X_{2}}{\partial K_{2}} \frac{\partial\left(K-K_{1}\right)}{\partial \kappa} \\
& =\left[(1-t) p_{1} q S \frac{\partial \Phi}{\partial K_{1}}-\frac{\partial X_{2}}{\partial K_{2}}\right] \frac{\partial K_{1}}{\partial \kappa}+\frac{\partial X_{2}}{\partial K_{2}} \\
& =\frac{\partial X_{2}}{\partial K_{2}}=r \\
& \frac{\partial I^{*}}{\partial S} \frac{\partial S}{\partial K}=(1-t) p_{1} q \Phi \frac{\partial S}{\partial K}+(1-t) p_{1} q S \frac{\partial \Phi}{\partial S} \frac{\partial S}{\partial K}+\frac{\partial X_{2}}{\partial \Phi} \frac{\partial \Phi}{\partial S} \frac{\partial S}{\partial K} \\
& \frac{\partial I^{*}}{\partial T T} \frac{\partial T T}{\partial K}=t p_{1} q \Phi \frac{\partial S}{\partial K}+t p_{1} q S \frac{\partial \Phi}{\partial K}-r *
\end{aligned}
$$

Then applying the envelope theorem as before. and using the partial derivatives. (5.15) becomes

$$
r+p_{1} q \Phi \frac{\partial S}{\partial \kappa}+t p q S \frac{\partial \Phi}{\partial \kappa}-r *=0 .
$$

Then applying the chain rule. 


$$
p_{1} q S\left(\frac{\Phi}{S} \frac{\partial S}{\partial \Phi}+t\right) \frac{\partial \Phi}{\partial \kappa}+r-r *=0
$$

or, using the definition of $\eta$,

$$
p_{1} q S(t+\eta) \frac{\partial \Phi}{\partial \kappa}+r-r *=0
$$

The locus of points indicating the optimal level of foreign investment in the domestic economy, given the value of $t$. is illustrated in Figure 5.4 by the $k k$ locus Also shown in Figure $\Sigma+$ are the $r$ and the $t l$ loci From Section 5.2 it will be recalled that $r r$ shows the combination of $t$ and $\mathrm{k}$ which equates the domestic rate of interest with the world rate: while $/ t$ shows the locus of optimal values of $t$. given $\mathrm{K}$ (that is the locus of points such that $t=-\eta$. given $k^{*}$ ). Notice that when $t=-\eta$. then equation $(5,16)$ is equal to zero when $r=r^{*}$ implying that $k k$ passes through the intersection of $\|$ and $r$. Since fishing effort is labour intensive. the Rybczynski derivative $\frac{\partial \Phi}{\partial \kappa}$ is negative. and therefore for any value of $k$ such that $r>r^{*}$. (5.16) requires $r>-\eta$ for the equality to hold. Consequently. Equation (5.16) implies that $k k$ must lie to the right of $t /$ when $r>r^{*}$. and to the left of $r$ when $>-n$. Intuitively: this can be understood as follows: Consider a point on $\|$ such as $A$ where $t=-\eta$ and $r>r^{*}$. Since the return on foreign capital is lower than the domestic rate (which equals the social marginal product of capital), the economy can gain from importing additional capital. Hence when $r>r^{* *}$ the $k k$ locus lies to the right of the $t$ locus. Similarly when $r<r^{*}$ the $k k$ locus lies to the left of the $t$ locus. Now suppose instead that the foreign capital earns the foreign rate and $r=r^{*}$ but $r-\eta$, as would be the 
case at point B. At B, since $P-\eta$ the economy is over-regulated and under-fished. If $t$ is fixed, then the economy could gain by a fall in the capital stock which, by the Rybczynski Theorem, leads to a fall in manufacturing and an expansion in fishing effor Thus the $k k$ locus lies to the left of the rr locus when $r-\eta$.

Intuitively, this result is an application of McDougall (1960). Simply put, if the economy is optimally regulated. and the rate of return paid to foreign capital is less than that paid on domestic capital, then the country can gain by permitting a limited amount of capital inflow. Thus when $r>r^{*}$ the $k k$ locus lies to the right of the $\|$ locus and when $r<r^{*}$ the $k k$ locus lies to the left of the $\|$ locus

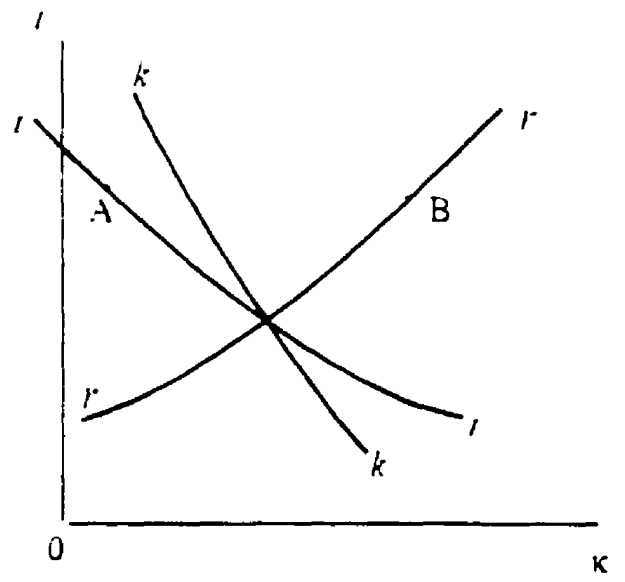

Figure 5.4

The welfare maximizing stock of foreign capital with fixed fisheries regulation - the $k k$ locus 
To this diagram add a map of iso-welfare curves as shown in Figure 5.5. Recall that $d l^{\prime} d t=0$ at points on $t l$. while $d l^{\prime} d d_{k}=0$ at points on $k k$. Hence the iso-welfare contours are vertical where they cut $t$ and horizontal where they cut $k k$ Welfare is maximised at point $E$. At $E$, the economy is optimally regulated given the level of foreign investment, and the level of investment is determined by the free flow of capital in response to the differential between the world and domestic rates of return

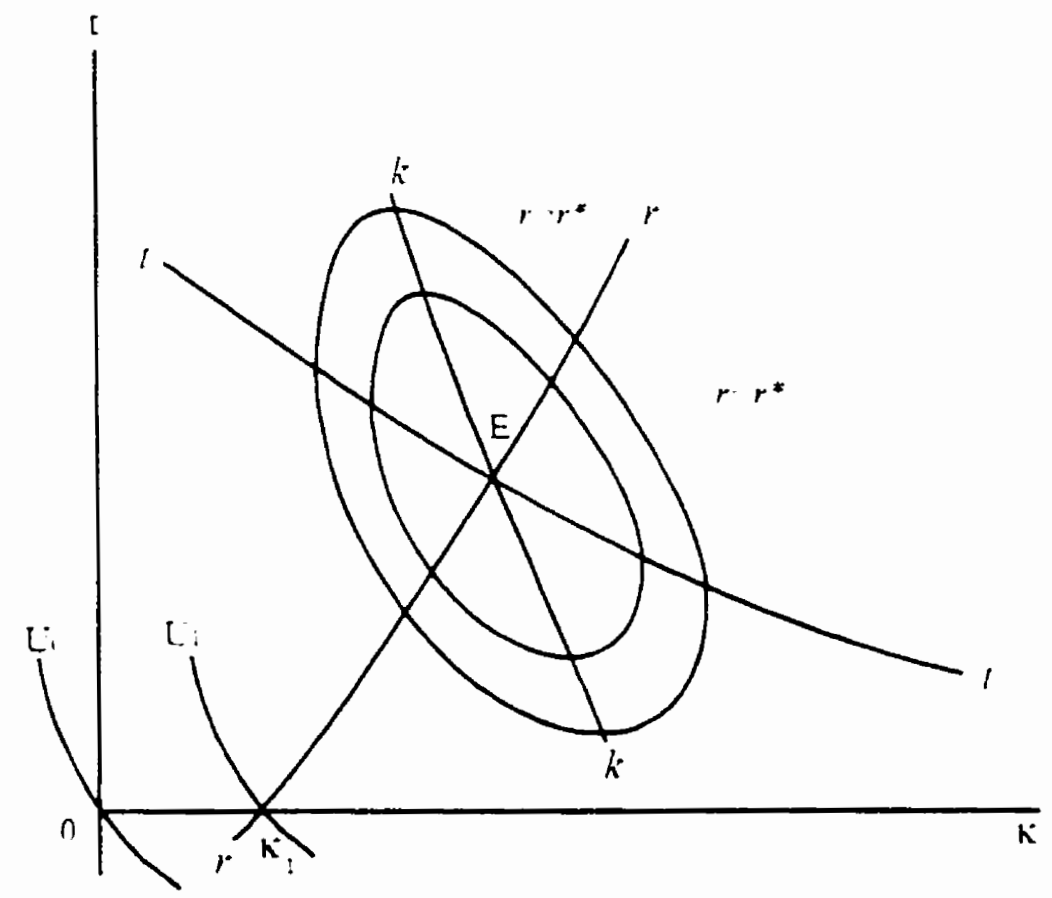

Figure 5.5

Steady-state welfare. fisheries regulation and foreign capital

This section was largely devoted to deriving the diagram illustrated in Figure 5.5. The rest of this chapter makes extensive use of this diagram to address a number of important issues. There are three particular issues that are examined. The first issue to be 
considered is whether the economy gains from capital flows under conditions of open access. Second, the benefits of marginal reforms to the management of the fishery are examined. It is asked whether the country would benefit more from regulatory reform under perfect capital mobility or regulated capital mobility? Lastly this section asks whether government's have any incentive to deviate from the optimal policy. and if so what the nature of the equilibrium would be.

\subsection{Government Policy Towards Foreign Investment and Fisheries Management.}

\subsubsection{Policy towards capital mobility when the fishery is open access.}

Figure 5.5 provides a useful tool that summarıes the steady-state welfare properties of the model In keeping with the flavour of the previous chapters. first consider government policy towards foreign investment when the fishery is open access In this case. the harrest tax is zero. and the government s problem is whether or not to restrict international capital movement. Suppose that. with its initial endowment of capital. the domestic rental rate exceeds the foreign rental rate. In Figure 5.5 the economy is operating at the origin. and initially there is no foreign capital. Lnder the perfect capital mobility assumption, an inflow of capıtal equal to $\kappa_{1}$ will occur. This capital inflow leads to an improvement in social welfare, as shown by the movement to the higher social welfare contour. $U_{1}$ from $U_{0}$. The intuition is that the inflow of capital leads to an expansion in manufacturing and a contraction in fishing effort and hence. a reduction in the over-fishing problem. 
Alternatively, if $r r$ intersects the horizontal $\kappa$ axis to the left of the origin, then the world rental rate on capital exceeds the domestic rate and the removal of any restrictions on capital mobility results in a capital outflow of domestic capital. There are two possibilities to consider. These are illustrated below in Figures 5.6 and 5.7. In the first case. although the $r r$ locus intersects the horizontal axis to the left of the origin. the $k k$ locus intersects the $\mathrm{k}$ axis to the right of the origin (Figure 5.6). In this case. the induced capital outflow leads to an increase in fishing effort. exacerbating the over-fishing problem. and a reduction in domestic welfare $\left(\mathrm{L}_{2}\right.$ to $\left.\mathrm{L}_{3}\right)$ While the captal owned by domestic nationals is earning a higher rate abroad than is possible in the domestic market. the gain in income from the capital outflow is not sufficient to counteract the induced increase in fishing effort (due to the Rybzynski result) and the corresponding reduction in fishing productivity: Hence. in this case. the liberalization of international capital markets is welfare worsening. Next. consider the case when $k k$ intersects the horizontal axis to the left of the origin. This is shown in Figure 5.7. The diagram shows that a small outflow of capital can improve welfare $\left(\mathrm{L}_{\downarrow}\right.$ to $\left.\mathrm{L}_{\xi}\right)$. This is true even though it leads to an increase in fishing effor - in this case the gain to domestic owners of capital exported abroad and earning the world rate of rerum exceeds the loss due to the expansion in fishing effort. Notice, however, that once the outflow of capital exceeds $x^{\prime}$. where the social indifference curce, $U_{\xi}$, is tangent to the horizontal axis. any further outflow is welfare reducing $\left(\mathrm{U}_{\varsigma}\right.$ to $\left.\mathrm{U}_{6}\right)$. Hence, when the world rental rate on capital exceeds the domestic rate. a limired outflow of domestic capital may improve welfare. 
The foregoing discussion is summarised by the following proposition:

Proposition 5.4: For a small economy with free trade in goods and an open-access fishery, the opening of capital markets to international competition:

i) unambiguously improves steady-state welfare if the country imports capital; and.

ii) may raise or lower steady-state welfare if the country is an exporter of capical.

Proof of Proposition 5 t:

From (5.16)

$$
\frac{d l^{*}}{d \kappa}=p_{1} q S(t+\eta) \frac{\partial \Phi}{\partial \kappa}+r-r *
$$

Since the elasticity of the fish stock with respect to fishing effort is negative. as is the Rybczynksi derivative $\frac{\partial \Phi}{\partial x}$ (fishing effor is labour intensive). then when $t=0$ the first term on the left-hand side. i. e. $p_{1} q S(l+\eta) \frac{\partial \Phi}{\partial \mathrm{K}}$. must be positive. Thus if $r>r^{*} . \frac{d l^{-}}{d \mathrm{~K}}>0$ and welfare is improved by a capital inflow If $r^{*} r^{*}$. then the sign of $\frac{d l^{*}}{d k}$ is ambiguous and welfare may be raised or lowered by a capital inflow. 


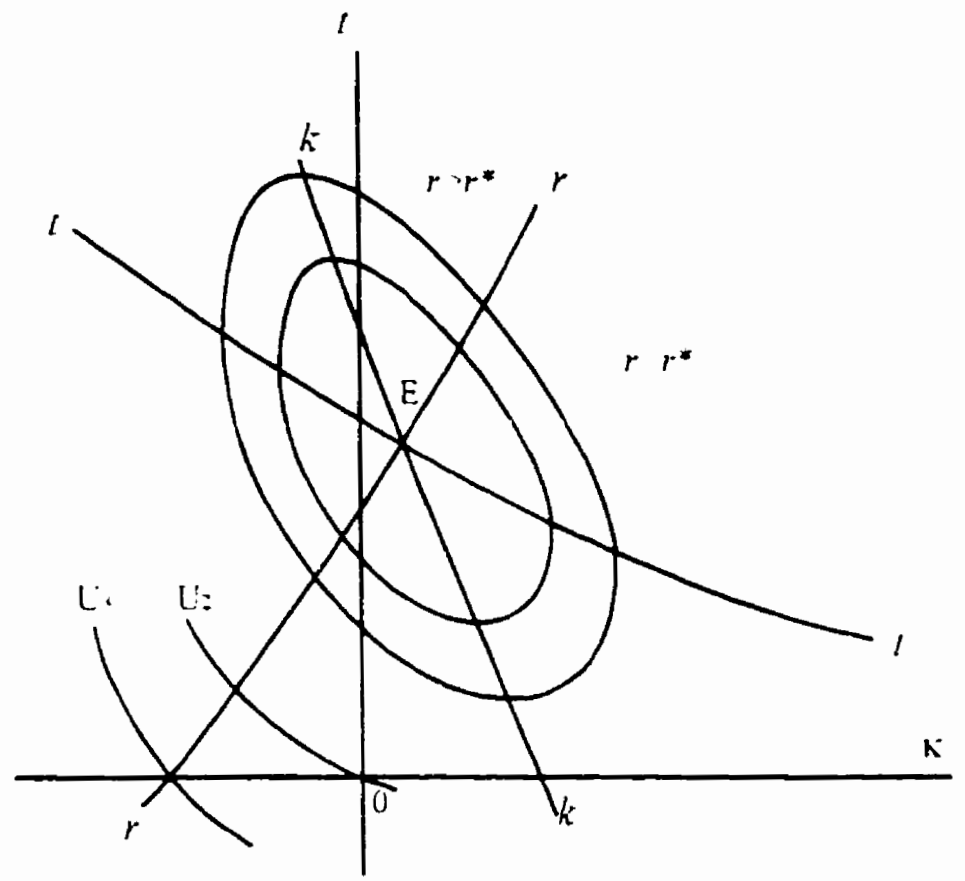

F1gure 56

Welfare worsening capital outflow

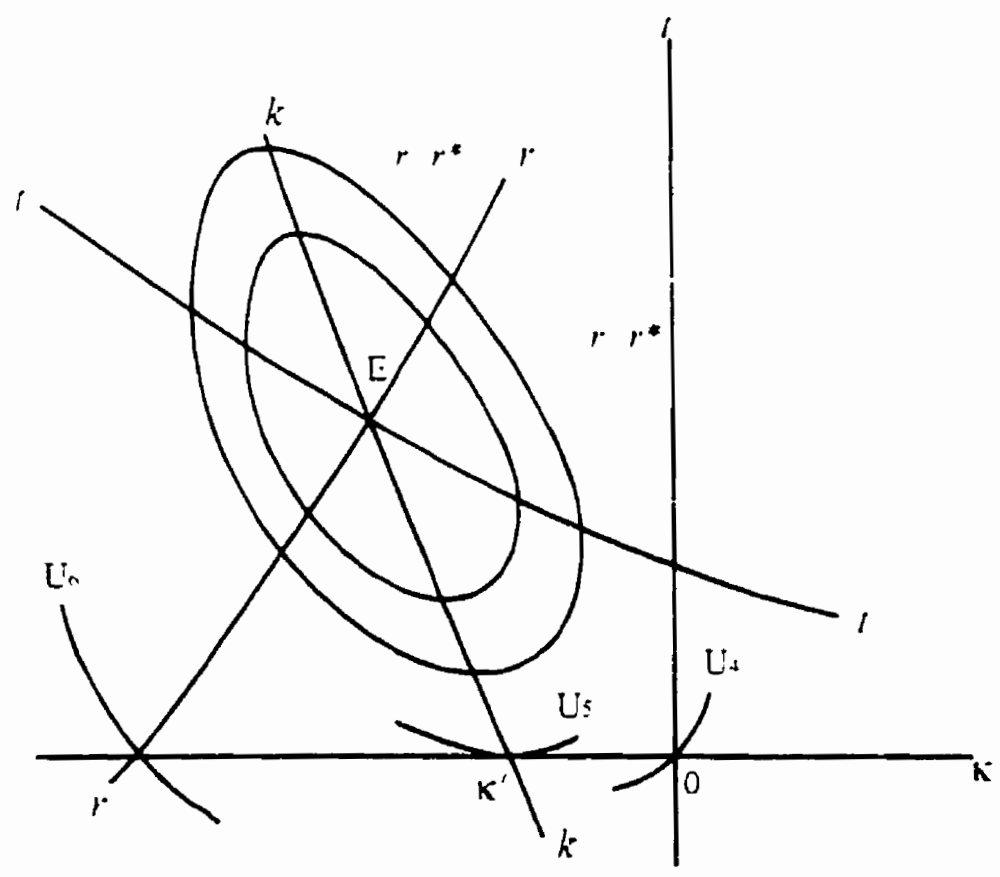

Figure 5.7

Welfare improving capital inflow 


\subsubsection{Regulatory reform in the presence of international capital mobility}

Next consider the situation faced by a government intending to reform the fishery by introducing a harvest tax. Copeland (1995) compares the benefits from a small improvement in the tax rate when capital is mobile with the benefits when capital is immobile. He shows that the welfare improvement is amplified under conditions of perfect capital mobility. This result also holds here. Referring now to Figure 5.8 . starting with an initial stock of foreign capital $k_{11}\left(\kappa_{11}\right.$ may be zero). consider the effects of an increase in $t$ from $t_{11}$ to $t_{1}$. In the absence of capital mobility, welfare is increased from $\mathrm{L}_{\mathrm{a}}$ to $\mathrm{L}_{\mathrm{h}}$. However. in the presence of perfectly mobile capital, the increase in 1 causes (as explained above) an increase in the rental rate. and hence a capital inflow. raising the stock of foreign capital to $\kappa_{1}$. The effect amplifies the improvement in welfare from just a change in the tax rate alone. This is the Copeland amplification effect It is worth noting a change in the harest tax, away from the optimal level. causes a greater reduction in welfare under perfect capital mobility than under a ș̣stem where capital mobility is prohibited 


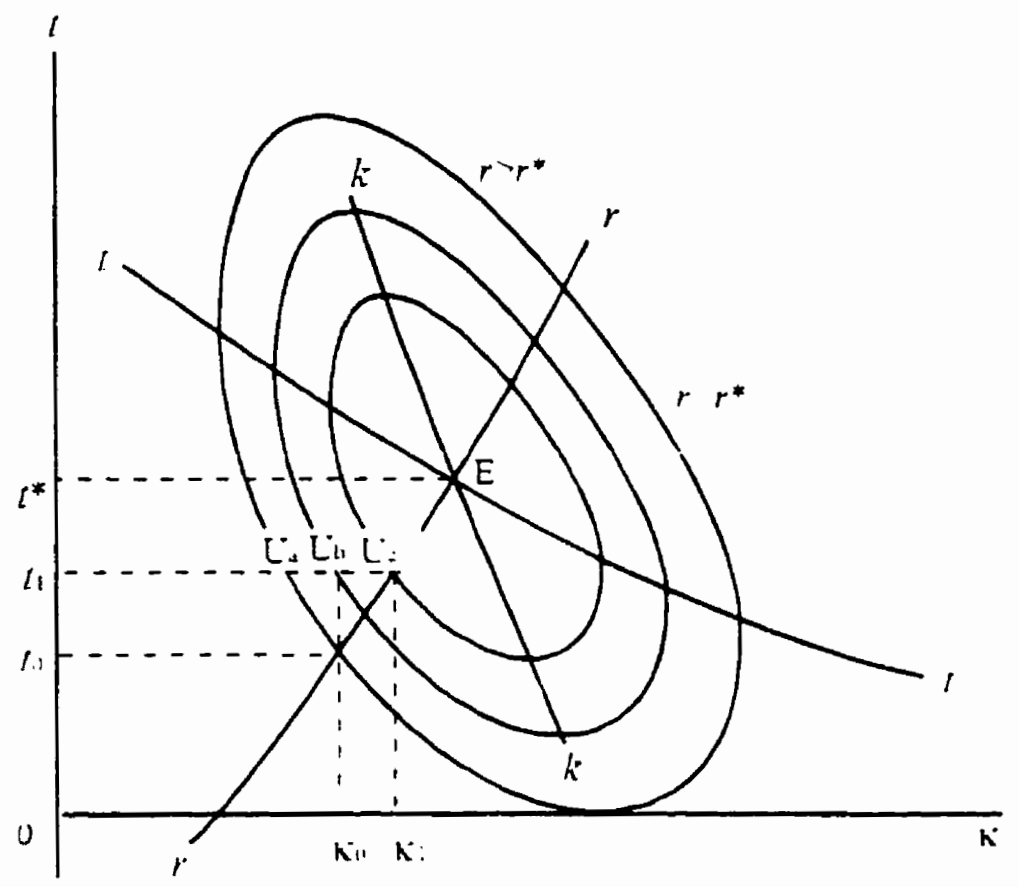

Figure 58

The amplification effect

The amplification result gives rise to the following proposition

Proposition 5.6: For a small open economy enguging in free track in goods, heginming from an equilihrium in which world and domestic interest rates are equalised, a small change in the regulation of the fishery will improve welfare by more if capital is perfectly. mohile internationally tham if it is internationally immohile.

Proof: Recall from (5.13) that in the case where capital is immobile. the improvement in welfare from an increase in $t$, starting from $t=0$ is given by

$$
\frac{d V}{d t}=\left.p_{1} q S(t+\eta) \frac{\partial \Phi}{\partial t}\right|_{\text {refixed }}-\kappa \frac{\partial r^{f}}{\partial t}
$$


While from $\left(5.6^{\prime}\right)$, the improvement in welfare from an increase in $t$, when capital is internationally mobile, is given by

$$
\left.\frac{d V}{d t}\right|_{\text {cfree }}=\left.p_{1} q S(t+\eta) \frac{\partial \Phi}{\partial t}\right|_{\text {triee }} \text {. }
$$

Thus, the difference in welfare induced by the change in $t$ under the two regimes is given by

$$
\left.\frac{d V}{d t}\right|_{k f r e c}-\left.\frac{d V}{d t}\right|_{\text {xyixed }}=p_{1} q S(t+\eta)\left(\left.\frac{\partial \Phi}{\partial t}\right|_{\text {xfree }}-\left.\frac{\partial \Phi}{\partial t}\right|_{\text {rfixed }}\right)+\kappa \frac{\partial r^{f}}{\partial t}
$$

When the fishery is under-regulated. then $k-\eta$ and hence the term $(t+\eta)$ is negative. The term $\left(\left.\frac{\partial \Phi}{\partial t}\right|_{\text {kfree }}-\left.\frac{\partial \Phi}{\partial t}\right|_{\text {kfixed }}\right)$ is also negative since fishing effort decreases in response to an increase in the harest tax Furthermore, in a diversified equilibrium. the induced capital tlow makes fishing effor more responsive to a tax change than if capital was internationally immobile. Next, note that if $r^{\prime}=r^{*}$ then $\frac{\partial r^{f}}{\partial t}=0$, otherwise it is positive Thus the right-hand side of $(5.17)$ is positive if $x^{\circ}-\eta$. and welfare is improved by a greater amount when capital is mobile than in the case when it is not

One must be careful interpreting the amplification result It simply says that starting from an equilibrium where the domestic and world returns to cupital are equalised. an increase in the harvest tax. towards the optimum level, will have a greater effect on welfare in the case when capital is mobile. This should not be confused with the policy prescription that an economy may enjoy a greater improvement in welfare if it first removed capital controls and then increased the hariest tax. As explained in the previous subsection, if, in the absence of capital mobility, the world rate of return on 
capital exceeds the domestic rate of retum, then the opening of capital markets may lower national welfare when the fishery is under-regulated. If an elimination of capital controls was combined with only a small improvement in the harvest tax, then the overall effect of the combination of policies may lead to a reduction in welfare.

\subsubsection{The issue of a capital mobility and the strategic use of environmental policy.}

The model developed in this chapter can be used to clarify some of the issues surrounding "races" in which government s strategically choose non-optimal levels of regulation to attract foreign capital. First. consider the standard hypothesis Governments may try to use their environmental taxes strategically to attract foreign capital. Presumably this argument is based on a misunderstanding of the MacDougall (1960) result that liberalisation of the international capital market leads to a welfare gain. even for a capital importing country. Iso long as it earns the fixed lower foreign rate of return) Here. with manufacturing capital intensive, an increase in the hanest tax away from its optimal level will lead to a rise in the domestic rate of return (as manufacturing

- the capital intensive industry - becomes profitable relative to fishing). and an immediate loss in welfare before any capital inflow occurs.

There are two possible sources of this welfare loss. First. suppose that the existing foreign capital continues to be paid the foreign rate of return. The deviation from the optimal policy immediately lowers welfare. In Figure 5.9 this is indicated by a move 
from point $\mathrm{E}$ to $\mathrm{A}$ (directly above point $\mathrm{E}$ ) The reduction in welfare results from under exploitation of the fish stock. Domestic welfare falls since the social marginal cost of catching additional fish has fallen below the social marginal benefit, given that the rent paid to the fixed stock of foreign capital is being held constant. The second possible source of loss arises if foreign capital is paid the domestic return. Because an increase in the fish tax leads to increased manufacturing, the demand for the factor used intensively in that sector is increased. The rental rate is therefore bid up and the rent being repatriated on foreign capital is increased Hence. when foreign capital is paid the domestic rate of return. welfare is hurt twice in the absence of any induced capital flow

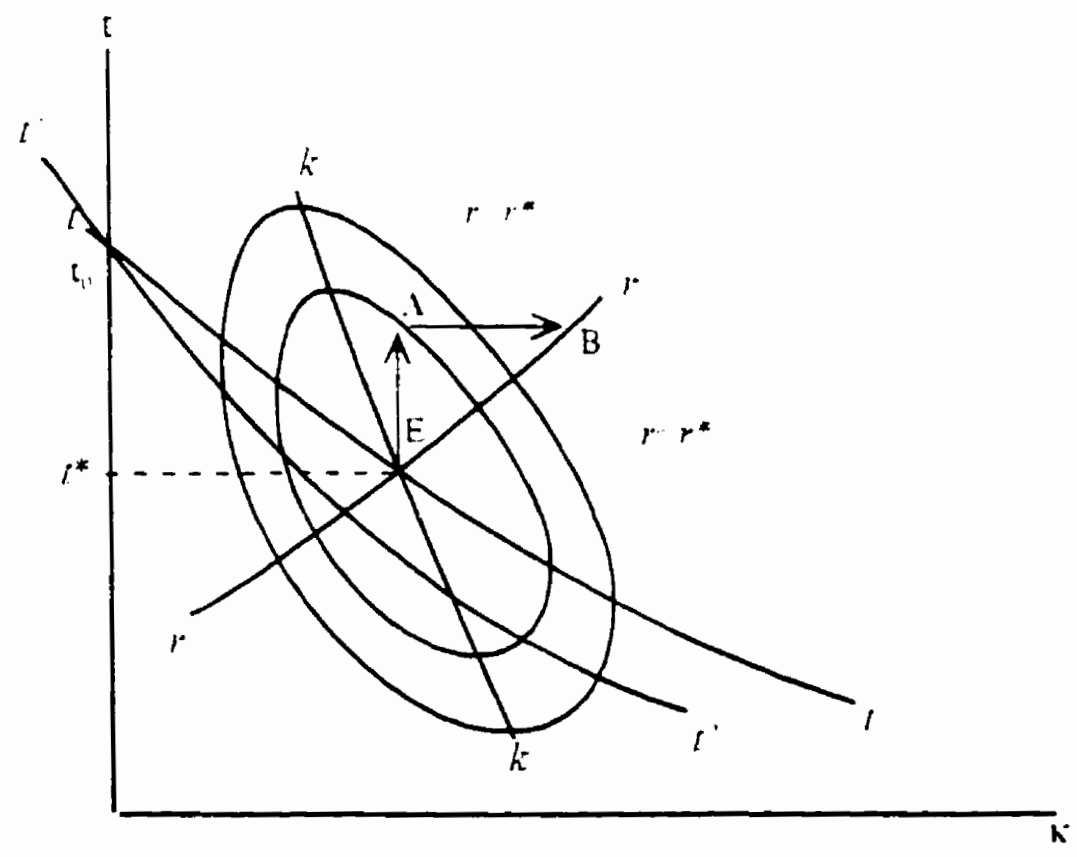

Figure 5.9

A deviation from the optimum worsens welfare 
Therefore, in the absence of any foreign capital inflow, welfare is reduced by an increase in the harvest tax away from its optimum value at point $E$. However, the higher return on capital will attract a capital inflow - perhaps this will improve matters? If foreign capital earns the foreign rate then welfare must be continuously worsened in the transition from $\mathrm{A}$ to $\mathrm{B}$. In this example, this is so because $k k$ is negatively sloped Thus. after the tax rate is raised, the new temporary equilibrium at point $\mathrm{A}$ must lie to the right of $k k$. and any capital inflow from any point to the right of $k k$ worsens welfare. given a fixed value of $t$. There seems to be no basis for a change in the tax rate to attract capital in this case - the economy would be better off without any induced capital inflow "

Vevertheless. government failure exists. just as market failure exists. In this model. if governments lack foresight they may do two things incorrectly. First. if the government is impatient. it may set / too low in the first place, i.e the "government "s" $/$ may lie below the true $t l$. This would be possible even if capital mobility is not allowed Second. the government may ignore the long term consequences of its actions on the level of foreign investment and try to appropriate some of the rents of foreigners. Recall Proposition 5.2 which stated that if the level of foreign investment was fixed. the optimal tax rate would be lower than that shown by $t$ (assuming manufacturing to be capital intensive). Any government that had the foresight to be able to regulate the fishery

${ }^{30}$ This result is reminiscent of the Brecher Diaz-Alejandro (1977) result. In the case when $k k$ is positively sloped, capital inflow may initially improve welfare following the increase in the tax. but it can be seen that it will never be sufficient to offset the loss generated by the increase in the tax in the first place. 
optimally, but had the naivete (or lack of foresight) to imagine that it could appropriate the returns to foreign capital, would lower the optimal tax to that given by $t^{\prime} t^{\prime}$ This would lower the domestic return to capital and hence reduce the short-run rents paid to foreigners. Ultimately, after capital had the opportunity to adjust, such a policy would lead to a lower level of foreign capital and a lower level of domestic welfare, as shown by the intersection of $t t^{\prime}$ 'with $r r$ in Figure 5.9 .

Ultimately. both the lack of foresight to regulate the fishery optimally. and the failure to anticipate the endogenous nature of international capital mobility. act to lower economic welfare of the countries citizens by reducing the level of regulation. But providing the government with the additional option of adjusting taxes to affect the return on foreign investment, acts to exacerbate the problem further

\subsection{Conclusion}

This chapter introduces international capital mobility into the static version of the Heckscher-Ohlin version of the model developed in Chapters 2 and 3 . and establishes a number of interesting results. When the fishery is open access and cannot effectively be regulated, the welfare consequences of removing restrictions on international capital mobility is predicted to depend starkly on the capital intensity of fishing effort. and whether the country will import or export capital. In the case when fishing is labour intensive and the country imports capital. welfare is shown to improve unambiguously: Intuitively, this result is an application of the Rybczynski Theorem. that an inflow of 
capital reduces the output of the labour-intensive good. Hence, the capital inflow causes an expansion in manufacturing and contraction in fishing - thereby alleviating the overfishing problem. On the other hand. when removal of international capital controls leads to a capital outflow, the consequence for national welfare is ambiguous. While the outflow of capital is beneficial to its owners, who can now invest in international markets at higher rates of return, the resulting contraction in manufacturing and expansion in fishing effort acts to exacerbate the over-fishing problem. Hence. the net welfare effect is ambiguous. As a result. restrictions to international capital movements may well be justified on welfare grounds

This chapter also examined the effect of fisheries policy reform with capital mobility Under perfect capital mobility. factor prices are exogenously determined by world prices. and interestingly. the wage and rental rates remain unresponsive to changes in the harrest tax. Instead. changes in the harest tax simply determine the size of the foreign capital stock, and hence. via the Rybczynski theorem, the amount of fishing effor Since labour and capital earnings are independent of the size of the tax rate. the government can therefore maximise GNP by choosing the tax rate that maximises tax revenues Interestingly, this involves setting $\iota$ equal to $-\eta$. which is the same tax formula that would be employed in the absence of capital mobility. It was also shown that starting from an equilibrium point, in which world and domestic rental rates are equalised. a small improvement in the level of regulation of the fishery leads to an improvement in welfare This improvement is magnified if capital is internationally mobile compared to the case 
when it is not. The reason being that the economy is more responsive to a change in policy when international capital mobility is permitted than when it is not. As Copeland (1994) has pointed out. the globalization of international capital markets therefore tends to make the argument for policy reform more compelling. Nevertheless, it was pointed out that the reverse is not generally true. an improvement in fisheries regulation does not make the argument for international capital market liberalization more desirable

Although "race to the bottom" arguments suggest that countries will lower their standards to attract international capital. this chapter found that such arguments lacked foundation in the context of the model developed here. Nevertheless. a case in which a short-sighted government may be tempted to use environmental policies to appropriate rents from (fixed) foreign capital invested in the domestic economy was demonstrated to be consistent with the model. If capital is not internationally mobile in the short-run. then by lowering the hariest tax. the government may be able to drive down domestic rents on capital. While such a policy leads to temporary gains, it will ultimately lead to lower levels of foreign investment and welfare

The results of this chapter reveal that if governments have the ability to regulate the fishery optimally and are willing to act. then restrictions to capital mobility ultimately harm welfare. However, when the fishery is open access. or governments are constrained in their ability to regulate, then national welfare may be harmed by liberalisation of capital markets 


\section{Appendix 5.1 Proof of Proposition 5.1}

From (5.1) note that international arbitrage fixes the rental rate and hence capital to labour ratio in the manufacturing sector. This can be seen simply by using the homogeneity property of the production functions to write $(5.1)$ as

$$
\begin{aligned}
& p_{1} S(l-l) \mathscr{q} f^{\prime}\left(k_{1}\right)=r^{*}, \text { and. } \\
& g^{\prime}\left(k_{2}\right)=r^{*}
\end{aligned}
$$

where the functions $f$ and $g$ indicate the outputs of fishing effort and manufactures per unit of labour. and a prime denotes the first derivative. Since $f$ and $g$ are strictly positive functions, when the equilibrium is diversified. condition (5.la') also series to fix the unique capital to labour ratio for each sector It follows that when the tax rate changes. only $S$ is free to adjust to restore equilibrium 


\section{Chapter 6}

\section{Trade Policy in The Two Country Model}

\subsection{Introduction}

In Chapter 4 it was argued that, in the absence of first-best policies towards fisheries regulation, a fish exporter may wish to use trade policy to restrict trade or even reverse its trade pattern. On the other hand. it was shown that a fish importer has no incentive to restrict trade. rather expansionary trade policy maybe welfare improving. However. in Chapter $f$ it was assumed that world prices were fixed in a small-country setting In this chapter I relax that assumption. and consider the effects of trade policy in a two-country setting in which each country is large enough to affect its terms of trade

One of the pressing issues in the trade and the environment debate has been whether trade is harmful for the environment (including the state of open-access resources) Environmentalists. and some economists. advocate the imposition of trade barriers as a method of "protecting" environmental resources. The environmentalists" argument is not without justification. The theory of the second best (Lipsey and Lancaster (1956-57)) has demonstrated that. in the presence of a market failure, such as open access, the implementation of free trade may worsen welfare. Nevertheless. it is not clear that this implies that restricting trade will improve matters. For example. through trade. a country that is highly dependent on renewable resources and has severely depleted its own stock 
of resources, can improve its welfare (and improve its environment) by trading with a country that manages its resources optimally (Brander and Taylor (1997b). Thus, under some circumstances, the environmentalists call for restricted trade may do more harm than good. Section 6.3 of this chapter shows that when resource depletion is severe, the open-access economy would benefit from subsidizing trade, not restricting it

As will become apparent, many of the interesting results that come out of this chapter are driven by the fact that the supply of fish may be backward bending when the fishery is open access. From the point of view of trade policy. this characteristic can lead to a type of Metzler's paradox. That is, the possibility that a tariff may cause the terms of trade to change in a penerse way. or may cause the relative price of fish on the world market to change so much that the domestic relative price of fish moves in the same direction (albeit by less).

This chapter is structured as follows. First. in contrast to the finding of Chapter $t_{\text {, it is }}$ shownthat if the home country imports fish. then the imposition of a tariff on tish imports may benefit the home country. Brander and Taylor (1998a) derive a similar result however they argue that a tariff also harms the fish stock in the tariff imposing country. However, when Brander and Taylor's model is generalized by relaxing some of the constraints on parameter values, it is possible to demonstrate that there exists a set of possible equilibria in which both the fish stock and welfare are increased. Furthermore. such a tariff is shown to improve welfare and alleviate the over fishing problem in the 
foreign country. Similarly, it is shown that an export tax on fish imposed by the foreign country may lead to an improvement in the welfare of both countries.

The third and fourth sections of this chapter deal with the case in which trade between the two countries is driven by differences in access to the respective fisheries. There are two different cases considered. First, in Section 6.3 each country seeks to maximize steady-state welfare but one lacks the ability to regulate the fishery. while the other regulates at no cost. Second. Section 6.4 assumes that the differences in regulation are due to tastes - one country wishes to conserve the stock. whilst the other places no value on the fish stock (implicitly placing no value on the future rents that can be had from the stock) While it is quite concervable that there may exist (Pareto) welfare improving trade policies in the former situation, it is less clear that the possibility exists in the second Nevertheless. Section $6 .+$ demonstrates trade restrictions may still lead to an improvement in welfare. even when trade is based solely on differences in tastes over environmental regulation. The explanation for this finding can be found in the fact that the model does not allow for intermational trade in the property rights associated with the resource. Interestingly. in the case in which the open-access country has an open-access resource because it lacks the ability to restrict access. it is shown that there is always a trade policy that leads to an improvement in the welfare of both the conservationist and open-access economies.

This chapter employs the model as set out in Chapter 4; that is. the economy has a 
Ricardian production structure, the fishery is open access (unless otherwise stated) and consumer preferences are Cobb-Douglas. In addition. it is assumed that the representative agent cares only about his own steady-state welfare. This assumption will be relaxed in Section 6.4 . In section 6.4 the home country heavily discounts the future. Finally the assumption that each country is incompletely specialized in steady state is made throughout the chapter. As discussed in Chapter 4 , these assumptions are strong. however. they greatly simplify the analysis and facilitate a relatively simple diagrammatic approach to describe the results. Moreover, even with simplifying assumptions such as these. a number of new and interesting results are derived.

\subsection{Trade Between Open-access Economies}

This section explores the interaction between two large economies. each having a renewable. open-access resource. This is a useful starting point since it has already been studied in some detail by Brander and Taylor (1998a). One of the key findings in their paper was that. under some circumstances. free trade could be improved upon. in the sense that glohal welfare could be improved. by an import tariff imposed by the fishimporting country. Moreover, the Brander and Taylor result does not require the use of transfers or side payments. This finding gives some support to the recommendation by Daly (1993. pg. 52) that tariffs should be used as a kind of countervailing measure against countries which export goods produced under lax regulatory conditions. The analysis here follows Brander and Taylor very closely, making use of the Ricardian production structure and Cobb-Douglas preference assumption. This confirms the 
aforementioned findings of Brander and Taylor. but also shows that, under some circumstances. global welfare may be improved by a tariff imposed by the fish-exporting country. This section also extends the analysis of Brander and Taylor (1998a) by considering the second-best trade policy facing each country in isolation. As in Chapter 4, the second-best policy may also include trade subsidies. however in such cases. welfare in the rest of the world is reduced.

The effect of trade policy in a two-country world. when each has an open-access renewable resource. such as a fishery, is a complicated process to describe: the simplest way fonvard relies on diagrammatic techniques to illustrate the effects of trade policy on the steady-state equilibrium and weltare of the home and foreign countries. To this end. a diagrammatic technique is used. similar to that developed in Chapter 4 , to trace out the sustainable consumption locus for different values of the trade tax. However, in this section the effects of trade policy on the terms of trade must be accounted for. This requires deriving the foreign offer curve. Once this has been done. the sustainable consumption locus for the home country can be determined. using the same technique developed in Chapter 4 , by tracing out the set of sustainable consumption points as the trade tax is varied

\subsubsection{The offer curve for the open-access economy}

The sustainable offer curve for the open-access economy can be derived in a fairly straightforward manner. The first step is to write impor demand as a function of world 
prices. Recall that in the absence of taxes and tariffs, the consumption of manufactures is determined by the share of income spent on manufactures. Since the wage rate is unity (given the Ricardian production structure) and the total labour supply is $N$, the aggregate consumption of manufactures is therefore

$$
C_{2}=(1-\beta) N
$$

Production of manufactures is given by

$$
Y_{2}=N_{2}=\left(N-N_{1}\right)
$$

The equilibrium level of fishing effort. $V_{1}$ can be derived as follows: In a sustainable equilibrium, the temporary hariest of fish must be equal to the natural rate of fish population growth

$$
X_{1}=L(S) \text {. }
$$

or. using the logistic equation.

$$
q S N_{1}=\gamma S(1-S / c) .
$$

Recall that in a sustainable equilibrium the slope of the temporary PPF is equal to the relative price of fish. $p_{1}$. That is.

$$
p_{1}=1 / q S \text {. }
$$

Rearranging (6.5) and substituting into (6.4)

$$
N_{1}=\frac{\gamma}{q}\left(1-\frac{1}{q c p_{1}}\right)
$$

Hence from (6.2)

$$
X_{2}=N-\frac{\gamma}{q}\left(1-\frac{1}{q c p_{1}}\right)
$$

and therefore imports of manufactures, denoted $\mathrm{M}_{2}$, are given by 


$$
M_{2}=C_{2}-X_{2}=(1-\beta) N-N+\frac{\gamma}{q}\left(1-\frac{1}{q c p_{1}}\right)
$$

or.

$$
M_{2}=\frac{\gamma}{q}\left(1-\frac{1}{q c p_{1}}\right)-\beta N
$$

This gives imports of manufactures as a function of the world relative price of fish and other parameters of the model. To derive the offer curve note that the economy s budget constraint (the value of imports $M_{2}$ equals the value of exports, $p_{1} E_{1}$ ) can be used to substitute for $p_{1}$

$$
M_{2}=\frac{\gamma}{q}\left(1-\frac{E_{1}}{q c M_{2}}\right)-\beta N
$$

For purposes of illustration it proves helpfui to re-write $(69)$ as follows

$$
E_{1}=\frac{q}{\gamma} q c\left[\left(\frac{\gamma}{q}-\beta N\right) M_{2}-M_{2}^{2}\right]
$$

Equation $(6,10)$ is the open-access economy 's offer curve Note that the economy's offer of fish is a quadratic function of the import of manufactures

In Figures 6.1 to 6.4. the offers cure are derived diagrammatically. . Vote that there are two distinct cases to be considered depending on the sign of $(\beta . \gamma-\gamma, q)$. Recall that $\beta . V$ reflects the level of employment in the fishery in the steady-state autarkic equilibrium. while $\gamma / q$ is the level of fishing effort required to extinguish the fish stock. In the first case. illustrated by Figures 6.1 and $6.2 . \quad \beta .1<\% / q$. In this case. the fish stock is not extinguished in autarky and the autarkic equilibrium involves production of both fish and manufactures. As a result. the economy imports fish when $p_{1}$ is relatively low, and exports fish when $p_{1}$ is relatively high. More importantly the offer curve can be seen to 
have an inelastic region, reflecting the quadratic nature of the offer curve equation (6.10). The inelastic region is due to the fact that an increase in the relative price of fish may induce a fall in the harvest and a fall in fish exports. despite the increased demand for manufactures from abroad. In the second case, $\beta \lambda>y / q$. and preferences are such that the economy never exports fish and depends on imports of fish to meet domestic demand at any relative fish price. Notice that, irrespective of the sign of $(\beta N-\gamma / q)$, the offer curve for the open-access economy is always elastic if the economy is importing fish and may be inelastic only if the economy exports fish 


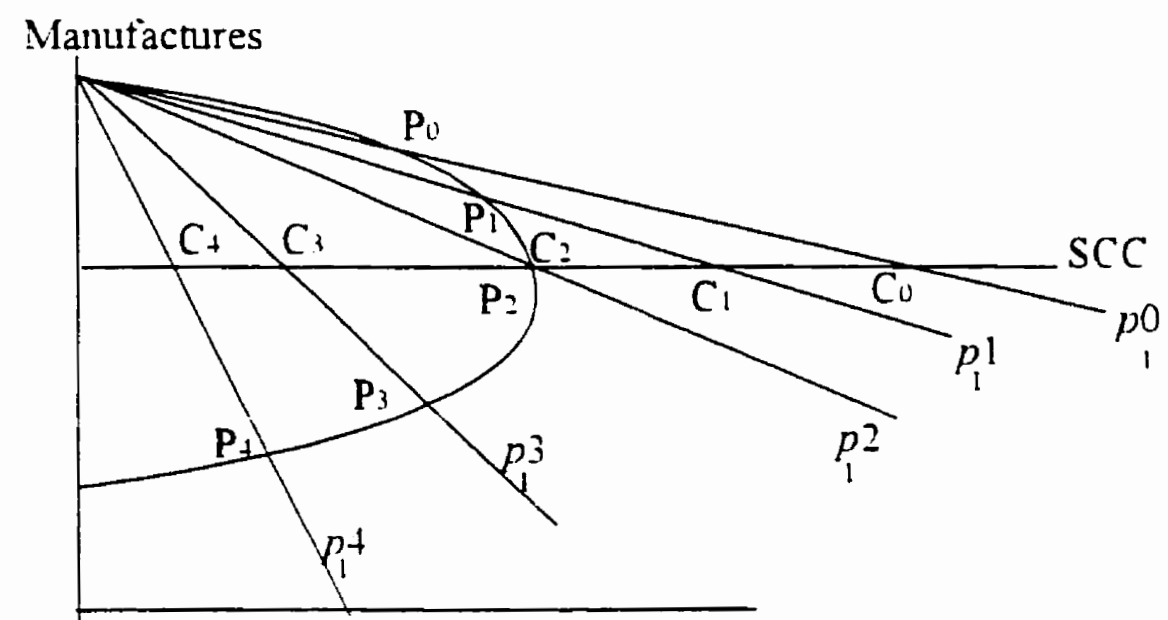

Fish

Figure 61

Consumption and production under free trade - I 


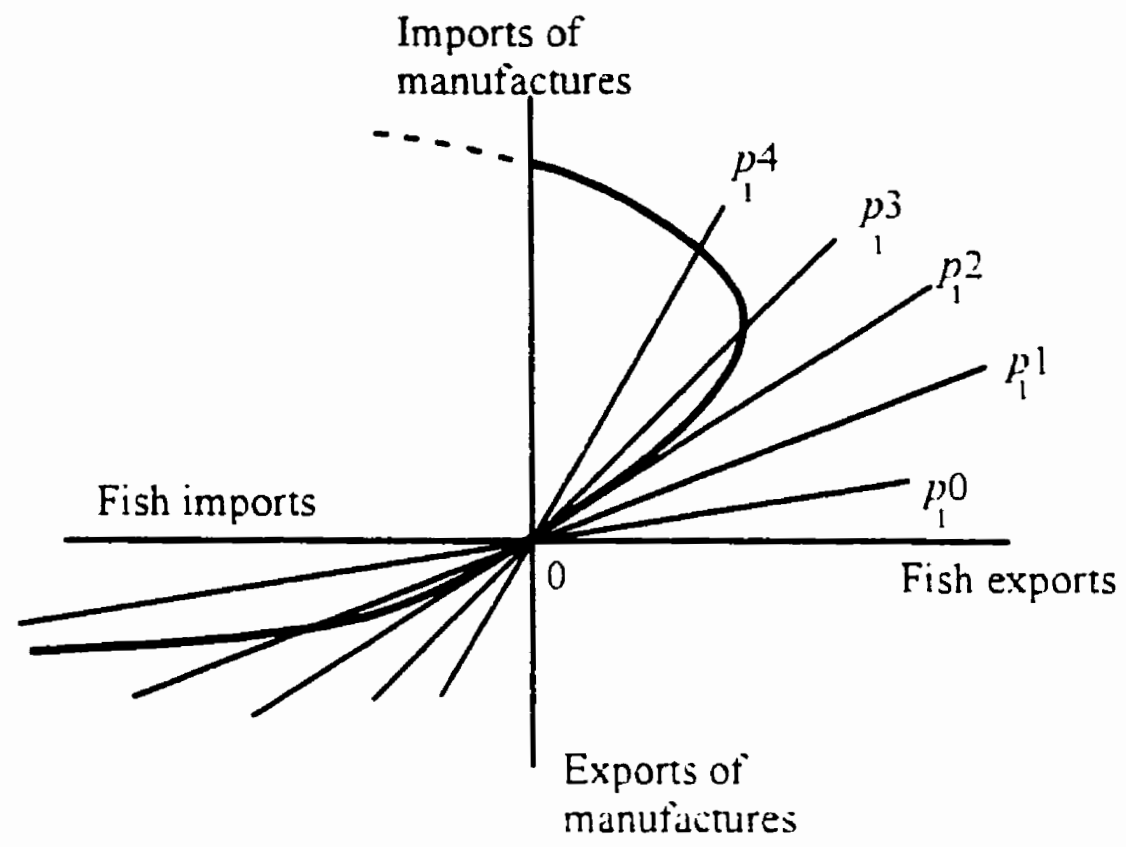

Figure 62

The offer curve for the fish-exporing country 


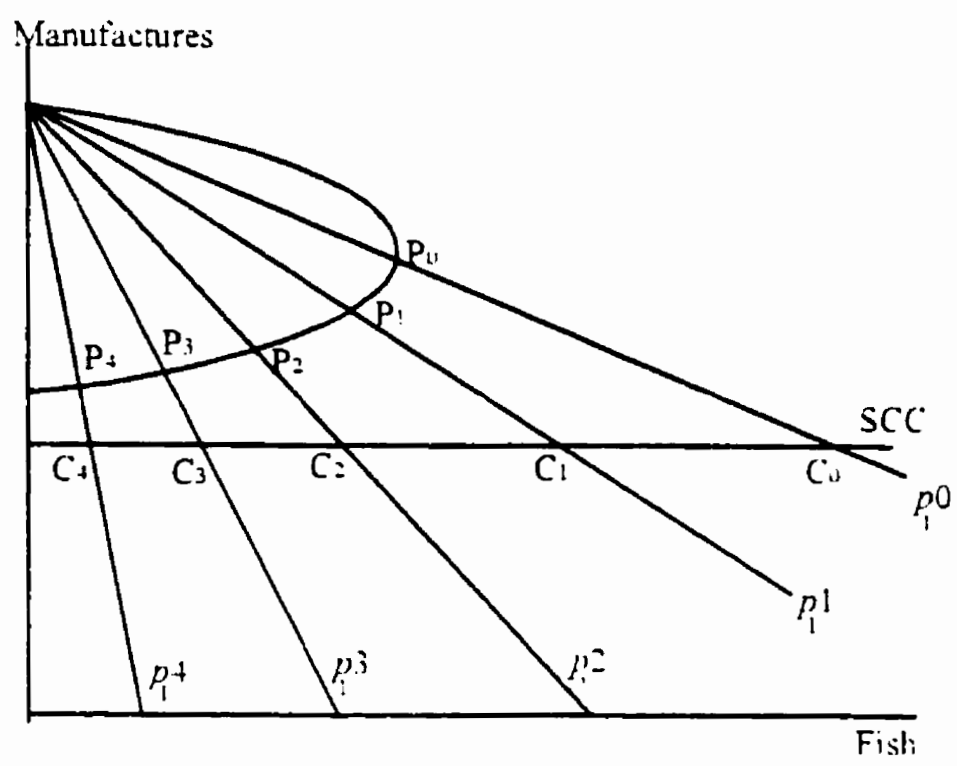

Figure 63

Consumption and production under free trade - II

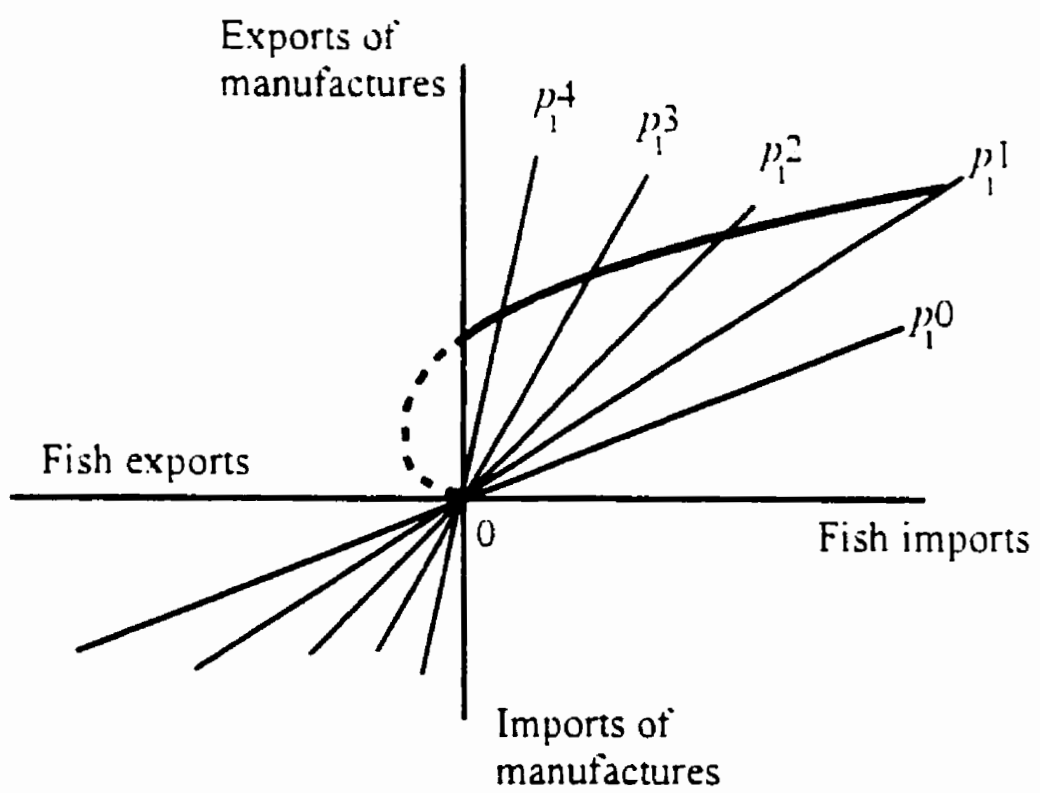

Figure 6.4

Offer curve for a fish-importing country 


\subsubsection{Free trade equilibrium}

The offer curves for the home and foreign countries can be combined on the same diagram to solve for the equilibrium trade pattem and relative price of fish. Apparent comparative advantages can be determined by examining the slope of the offer curves at the origin. Note that if $\beta N>\gamma / q$, so that the share of labour devoted to fishing in autarky is not sufficient to extinguish the fish stock. then the economy imports fish at any price and hence it has an apparent comparative advantage in manufactures. The more interesting case occurs when $\beta . \%<\% q$. By differentiating the Equation (6.10) the slope of the offer curve at the autarkic equilibrium can be found to be

$$
\left.\frac{d M_{2}}{d E_{1}}\right|_{E=t=0=0}=\frac{1}{q^{2} c}\left(\frac{\gamma / q}{\gamma / q-\beta N}\right)
$$

which is positive if $\beta N<\% / q$.

Inspection of equation (6.11) gives rise to the following proposition

Proposition 6.1: ('ompared to a situation in which both coumtries are iclentical, the homs' commiry has an apparem comparative adiantage in mamufacture's if:

i) home's share of expenditure devoted to fish, $\beta$, is greater than that in the forcign country:

ii) the home country is relatively resource scarce, as measured by the ratio of $: 10 . \mathrm{V}$. compared to the foreign country:

iii) $\beta N>1 / 2(-\% / q)$. and home productivin in fishing, as measured by $q$, is greater than that abroad or if $\beta \mathrm{V}>12(\gamma q)$ and $q$. is less than that abroad. 
Proposition 6.1 can be understood by considering the effects of changes in each of the relevant parameters on the autarkic equilibrium. For example, in part $i$ ) an increase in expenditure on fish causes an increase in demand and drives up the relative price of fish in the domestic market, this causes an increase in fishing effort and a reduction in the fish stock. Consequently, the Ricardian temporary PPF pivots inwards. Compared to the original situation, the economy has an apparent comparative advantage in manufactures. The second part of the proposition is due to Brander and Taylor (1997a. 1998a) who suggest that the ratio of the intrinsic grouth rate of the fish population. $\%$ to the labour supply. $V$ can be used as a measure of factor proportions in the Ricardian version of the renewable resource model. A decrease in the growth rate of the fish population implies that the harvest per worker falls relative to the demand per worker. Once again this creates an aggregate excess demand for fish and hence the relative price of fish rises. the Ricardian temporary PPF pivots inwards and. once again. compared to the original situation, the economy has an apparent comparative advantage in manufactures The third part of the equation is easily understood once it is appreciated that if $\beta N>12(\% q)$ the economy will be operating on the backward bending portion of the production possibilities locus. In this case. an improvement in $q$. which leads to an increase in the amount of "effective" fishing effort. results in a decrease in the sustainable harrest. Thus. if $\beta N>1 / 2\left(\gamma^{\prime} q\right)$ an increase in $q$ results in an excess demand for fish. an increase in the relative price, and hence the temporary PPF pivots inwards (due to the fall in the fish stock) and the economy has an apparent comparative advantage in manufactures. 
Now consider the impact of permitting free trade between the two countries. Suppose that the home country has a comparative advantage in manufactures. The resulting equilibrium is illustrated by Figure 6.5. It shows that the home country exports manufactures in the free trade equilibrium while the foreign country exports fish. As a result, the free trade price of fish will end up somewhere between the home and foreign autarkic relative fish prices.

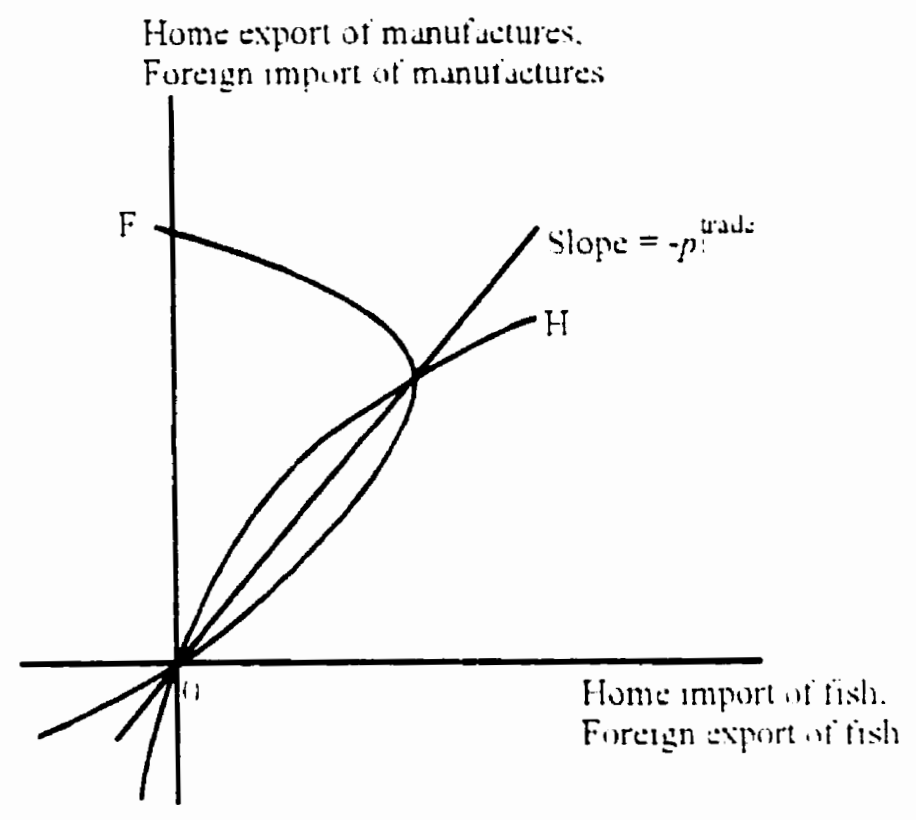

Figure 6.5

Free trade equilibrium in the two country model

The effects on welfare from establishing free trade can be understood using the same analysis as in Chapter 3. At home. which had an apparent comparative advantage in manufactures, the relative price of fish falls. This causes a reduction in fishing effort. an increase in the fish stock and the Ricardian temporary PPF pivots outwards. The feasible 
consumption set therefore lies everywhere above its original position and welfare is unambiguously improved. In the foreign country the reverse is true. The relative price of fish rises and fishing effor increases As a result, the fish stock is reduced and the Ricardian PPF pivots inwards. The resulting consumption set (which coincides with the PPF) therefore lies everywhere inside its original position and welfare is unambiguously worsened. These results confirm the findings of Brander and Taylor (1998a). It is therefore clear that the foreign (fish-exporting) country may benefit from a restriction in trade The next subsection examines this case in more detail.

\subsubsection{Trade policy for a fish-exporting country}

Brander and Taylor examine trade and trade policy between two open-access economies. They show that the foreign (fish-exporting) country can gain from the imposition by the foreign country of a small tariff on manufactures or export tax on fish. They argue that welfare in the home (fish-importing) country is unambiguously worsened by such a policy This section demonstrates that it may be possible for the fish-importing country to enjoy an improvement in welfare when the foreign country introduces an export tax. The reasoning lies in the fact that a fall in the relative price of fish faced by foreign producers may result in an increase in the relative supply of fish. This is a possibility if the foreign country is operating on the backward bending portion of the production possibilities locus. Hence, a foreign export tax may actually result in an increase in the relative supply of fish and cause the relative price of fish to fall in the home country (fish-importing market). Moreover, the foreign country can still gain. despite the 
worsening in its terms of trade, from the partial alleviation of its over-fishing problem

The diagrammatic method employed in Chapter 4 can be adapted to derive the locus of sustainable consumption points for the country imposing the trade policy. To begin, suppose that the foreign country exports fish as illustrated by Figure 6.6. In the free trade equilibrium, the foreign economy produces at point $\mathrm{Pl}$ and consumes at $\mathrm{Cl} \mathrm{Cl}$ lies on the SCC. which illustrates points of tangency between foreign social indifference curves and temporary PPFs. The home offer curve has been added and emanates from $\mathrm{Pl}$, and passes through $\mathrm{Cl}$. The home offer curve is elastic since it is a fish importer For illustrative purposes assume that $\beta \cdots y q$ at home.

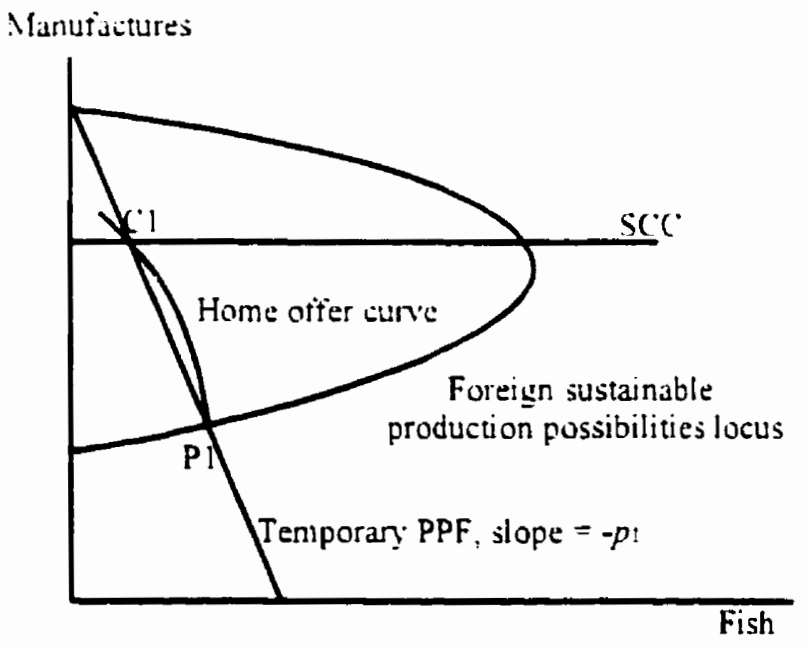

Figure 6.6

Free trade equilibrium 
Using Figure 6.6, the locus of steady-state foreign consumption points. such as $\mathrm{Cl}$, corresponding to different values of the foreign tariff on imports of manufactures. or equivalently, a foreign export tax on fish exports (by Lemer's symmetry theorem the two have the same effects) can be derived as illustrated by Figure 6.7

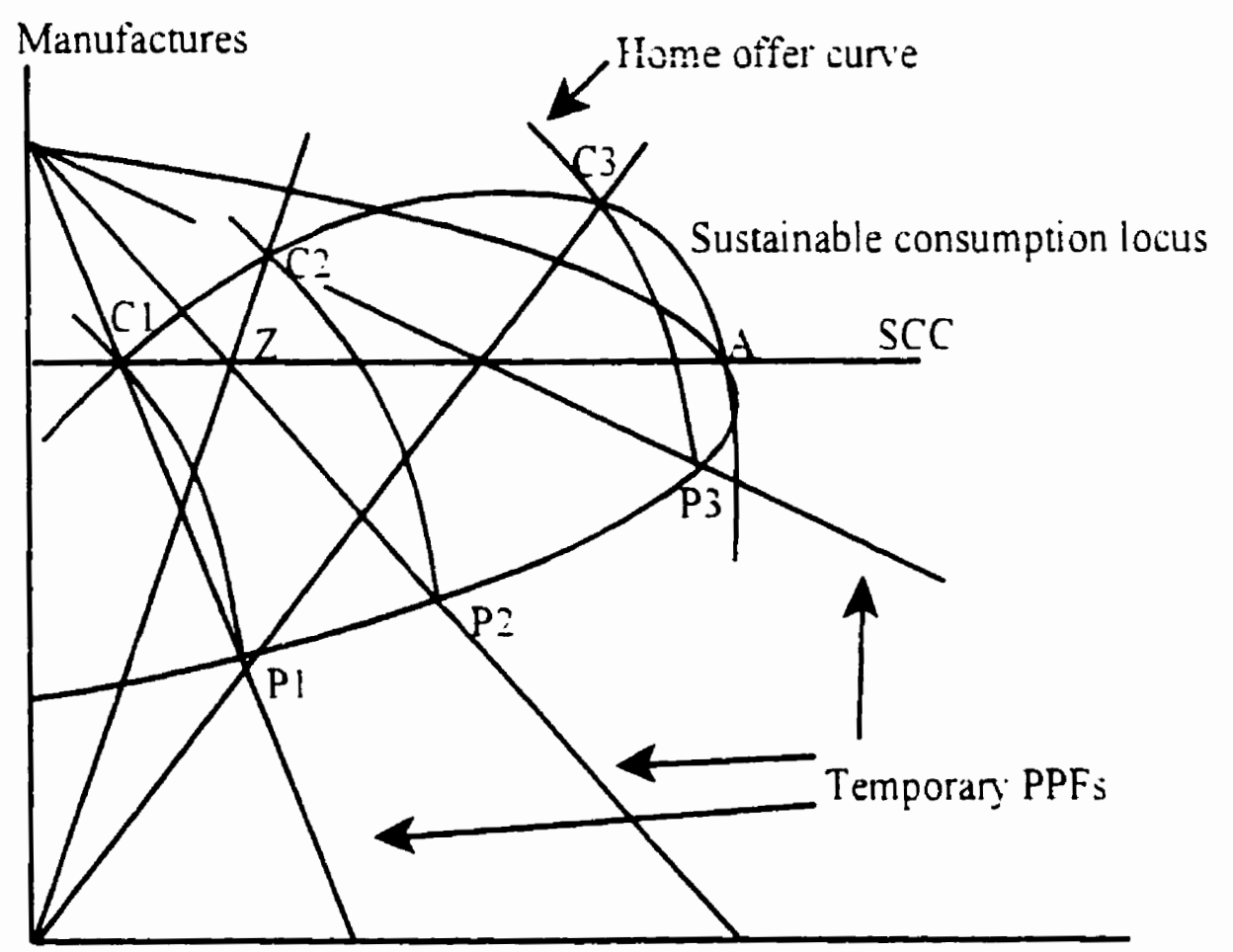

Fish

Figure 6.7

The sustainable consumption locus for the fish-exporting country

The diagram appears somewhat complicated, but in reality is straight forward. being similar to Figure 4.10 in Chapter 4. Recall that the fish-exporting (foreign) country is originally producing at a point such as $\mathrm{Pl}$ and consuming at $\mathrm{Cl}$. The elastic home offer 
curve is illustrated as emanating from $\mathrm{Pl}$ and passing through $\mathrm{Cl}$. The foreign export tax on fish is to drive a wedge between the home and foreign relative prices of fish such that the home price exceeds the foreign price. Thus, the trade tax lowers the foreign fish price causing a reduction in fishing effort, an increase in the fish stock, and hence the temporary PPF to expand outwards. The new production point is at $P_{2}$. To determine the consumption point, the properties of Cobb-Douglas preferences are exploited. as in Figure 4.10. Recall that the SCC (absence tariffs) is a horizontal line passing through $\mathrm{Cl}$. The SCC passes through the new temporary PPF at point $Z$ where the community indifference curve (not shown) is tangent to the temporary PPF Because foreign consumers and producers face the same relative price of fish. and because preferences are homothetic. the new consumption point after the tariff must lie on the ray $\mathrm{OZ}$ Thus the solution is found by the intersection of the home offer curve emanating from $P_{2}$ and the ray $\mathrm{OZ}$. This point is labeled $\mathrm{C} 2$. By repeating this process for successively higher export tax rates, the foreign sustainable consumption locus $\mathrm{C} / \mathrm{C} 2 \mathrm{C} 3 \mathrm{~A}$. can be traced out Point $A$ is the autarkic equilibrium and corresponds to the case when the trade tax is prohibitive

If the social rate of discount approaches zero, then the second-best export tax is one that leaves a tangency between the sustainable consumption locus $(\mathrm{CIC} 2 \mathrm{C} 3 \mathrm{~A})$ and the community indifference curve (not shown). The foreign second-best export tax may result in foreign consumption at $\mathrm{C} 3$, for example. Thus, the implementation of a tariff (or export tax on fish) raises steady-state welfare for the fish-exporting (foreign) country: 
Note that the consumption locus can be pushed beyond the autarkic equilibrium (which involves a prohibitive tariff) by imposing an export subsidy on manufactures In some cases, the consumption locus at the autarky point (i.e. where the tariff is prohibitive) may be flatter than the price ratio. That is, the consumption locus cuts the autarkic equilibrium from the left, but from below the temporary production possibilities set passing through the social indifference curve at that point. In this case. foreign welfare may be improved further by a trade subsidy on exports of manufactures. reversing the pattern of trade.

Lastly. note that the export tax may cause the relative price of tish to fall at home Referring to Figure 6.7. consider what happens as the tariff is increased from zero and the production point moves from $\mathrm{Pl}$ to $\mathrm{P} 2$ and the consumption point from $\mathrm{Cl}$ to $\mathrm{C}$. Over this region (i.e. $\mathrm{C} 1 \mathrm{C} 2$ ) it can be seen that the foreign sustainable consumption locus is steeper than the sustainable production possibilities locus This implies that. in this region. the relative price of fish at home must fall as the export tax is increased To understand the logic behind this result. imagine that the world price ratio is temporarily fixed. The export tax must therefore drive down the fish price at home and consequently: cause a reduction in fishing effor and an increase in the fish stock. If the economy is undertaking more fishing than that which produces the maximum sustainable yield of fish. then the yield must rise with the fall in fishing effort induced by the export tax. The fall in fish output has two effects: it increases the supply of both fish and manufactures. and it creates an income effect which also increases the demand for both goods. If the 
relative supply of fish to manufactures grows faster than the relative demand for the two goods, then world prices will be bid down. and a Metzler type paradox arises

Alternatively, the effect of a change in the foreign export tax on the relative price of fish in the home country could be determined using the offer curve diagram. In Appendix 6.1 it is shown that the imposition of the export tax affects the foreign offer curve in the manner illustrated by Figure 6.8. It can be seen that if the home offer curve intersects the foreign curve along the inelastic region then the relative price of fish in the home country may be reduced by the foreign country export tax.

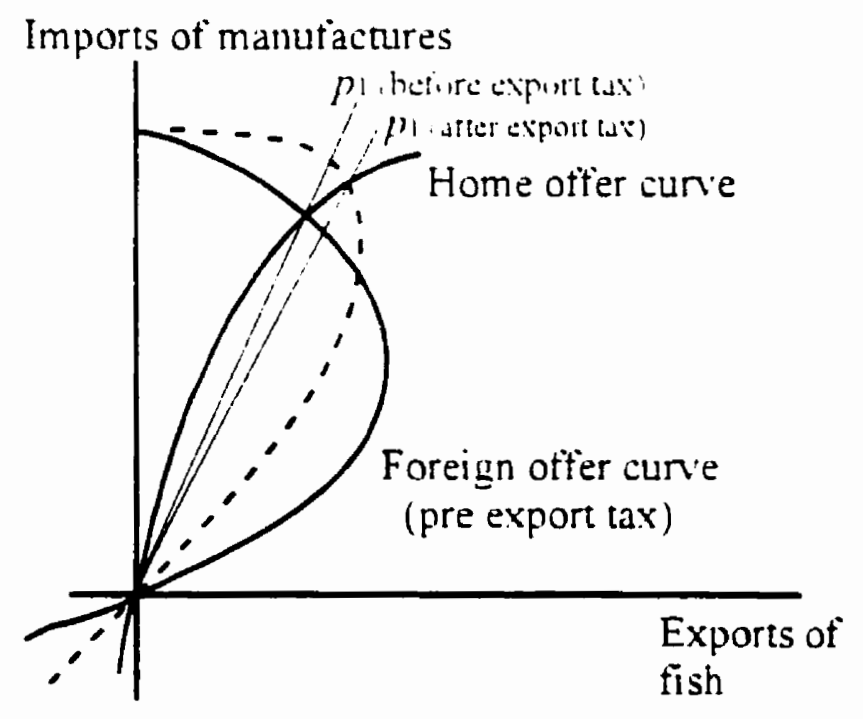

Figure 6.8

The effects of a foreign export tax on the relative price of fish at home 
If the relative price of fish at home falls as the foreign export tax rises, then home welfare is increased. Welfare increases for two reasons. Not only does the fall in the price of fish represent an improvement in the home country's terms of trade. but it also encourages a reduction in home fishing effort. The fall in home fishing effort partially reduces the over fishing problem at home and therefore causes an outward expansion of the Ricardian temporary PPF and the home country consumption set. The foregoing discussion is summarized by Proposition 6.2

Proposition 6.2: Begimning from a free-trade equilitrium, the imposition by the foreign country of a tax on the export of fish callses:

i) a fall in the steady-stane foreign relume price of fish. a fall in foreign fishing effort. an expansion in the foreign fish stock. and an expansion in the foreign production possibilities fromtier:

ii) a rise in foreign welfare:

iii) either a rise or full in the home price of fish: and.

iv) a decline in home sreath-stane welfare if the home relarive price of fish rises, and a rise in home steady-state welfare if the home relarive price of fish falls.

Proof: See Appendix 6.2

Proposition 6.2 differs somewhat from the result found by Brander and Taylor (1998a. Proposition 8). They also examine the relationship between two open-access economies 
and the effect trade policy has on the steady-state equilibrium. ${ }^{31}$ However they find that a small increase in the export tax away from zero results in a rise in the foreign relative price of fish only, and hence causes foreign welfare to fall. As shown in Appendix 6.2. the inelastic region of the home offer curve gives rise to the possibility that an export tax may lead to an improvement in foreign welfare. There are two factors that explain the difference between Brander and Taylor's result and the one derived here. First, Brander and Taylor implicitly assume, in their proof, that preferences in the fish-importing home country are such that the economy can not extinguish the fish stock even in autarky. I.e $\beta V<y / q$. However, it is perfectly possible for $\beta A>/ q$ in the fish-importing country Once this possibility is allowed for. the export tax may lead to an improvement in both home and foreign welfare. Second, in their formal analysis Brander and Taylor considered only differences in factor proportions as possible sources of comparative advantage However. differences in tastes. the capacities of the respective fisheries and productivity are all possible sources of comparative advantage. Once these sources of comparative advantage are allowed for. the possibility of a Metzler's type paradox arises (see proot of Proposition 6.2 in Appendix 6.2)

\subsubsection{Trade policy for a fish-importing country}

Now consider the effects of a trade policy adopted by the fish-importing home country In Chapter 4. it was found that a small fish-importing country is always hur by any tariff

${ }^{31}$ Brander and Taylor assume that trade arises because of differences in factor proportions, as proxied by difference in the ratio of $\gamma$ to $N$, across countries. 
it imposes. However, once terms of trade effects are allowed for, then it is possible that the terms of trade effects may be sufficient for the home country to improve its welfare by imposing a tariff. This possibility has been demonstrated by Brander and Taylor (1998a, proposition 7). However, in their result, home welfare improves solely from the terms of trade effect. Brander and Taylor find that the relative price of fish at home rises and hence adds to the over-fishing problem. Not disputing Brander and Taylor's finding. this section demonstrates that a tariff on fish imports may not only improve welfare but also conserve the fish stock. From Section 6.1 it is known that the foreign (fishexporting) country's offer curve may have an inelastic region. When this is the case. a home country's tariff on fish imports may cause the foreign relative fish price to fall by so much that the home relative price of fish also falls. In such a situation. a tariff on fish imports will tend to reduce fishing effor at home and alleviate the home country sover fishing problem, thereby causing an expansion in the fish stock as well as welfare. Because Brander and Taylor assume that the only difference between the two countries is the ratio of the intrinsic growth rate of the fish population to the size of the labour force. and furthermore do not consider parameter values that permit the extinction of the fish stock in autarky. Brander and Taylor overlook the possibility that a tariff may help to preserve the fish importing country's fish stock. This section addresses these issues as well as illustrates the second-best tariff.

Consider first a situation in which the foreign offer curve is highly inelastic at the freetrade equilibrium, as illustrated in Figure 6.9. This figure illustrates the home country is 
production possibilities and uses the foreign offer curve to derive the home country's sustainable consumption locus. Using the same technique as in Section 6.2.2. Figure 6.9 illustrates that a small home tariff on fish imports may cause the relative price of fish to fall not only abroad, but also at home. Consider the free-trade equilibrium involving production at $\mathrm{Pl}$ and consumption at $\mathrm{Cl}$ The imposition of a tariff on fish imports causes a fall in the demand for fish impored from the foreign country. The fall in the foreign price causes a reduction in foreign fishing effort and. given that the foreign country is operating on the inelastic region of its offer curee. an increase in the foreign export of fish. If the increase in foreign fish supply is large enough. then the world price of fish falls so much that the relative price of tish facing home country producers also falls. despite the tariff Due to the fall in the relative price of tish at home. home country tishing effor falls. and both the home fish stock and harrest may rise This possibility is proven in Appendix 63 Graphically, the production point moves to P2, and the consumption point to C2. Domestic welfare is increased for two reasons. First. the fall in the domestic price partially remedies the over-fishing problem and increases the fish stock Second. the country gains from using its monopoly power in trade to lower the price of its imports and collect the associated rents 


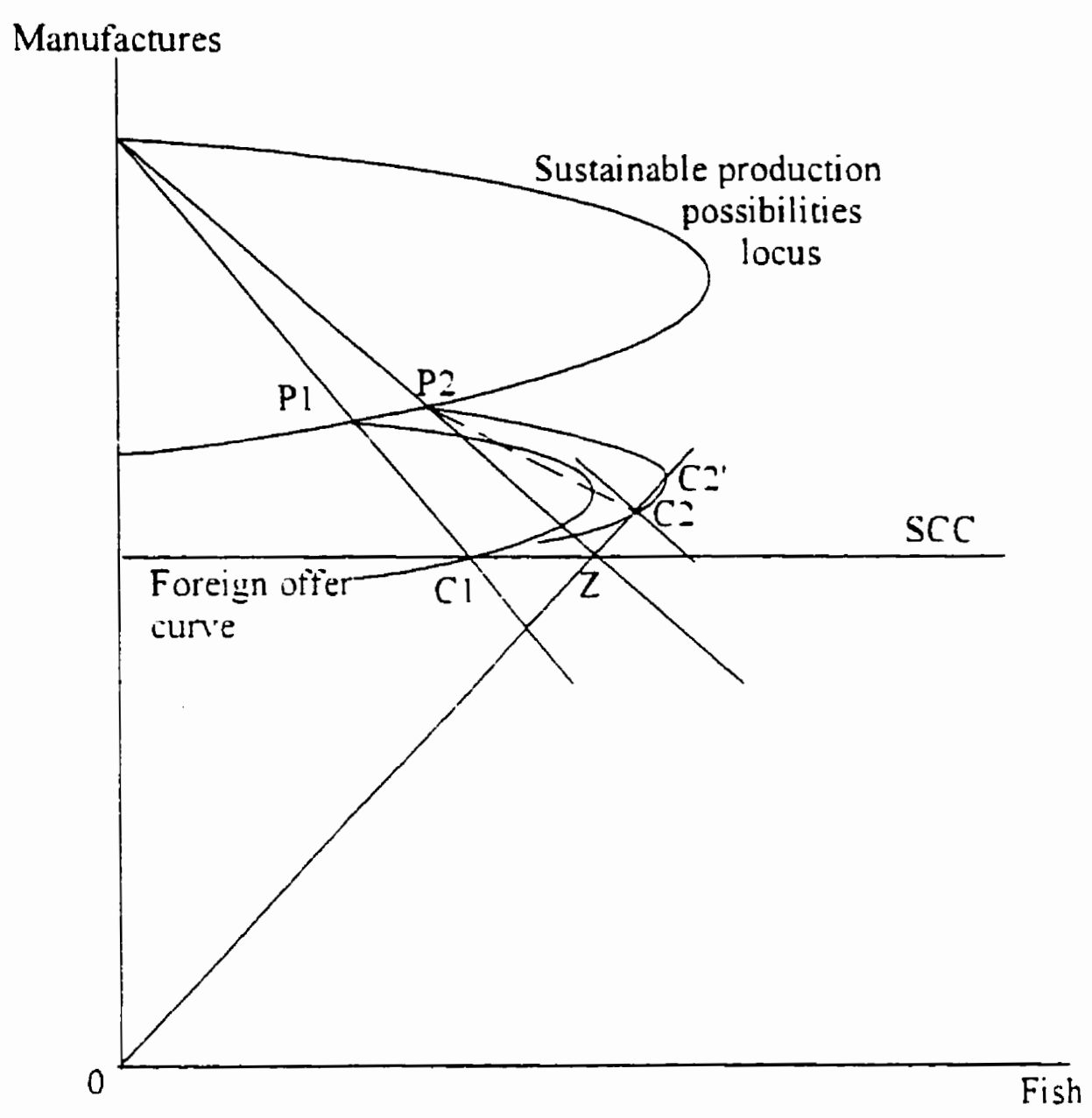

Figure 60

The home country tariff when the foreign offer cure is highly inelastic

Cerain elements of this special case warrant explanation. First. note that there is a larger tariff that would leave the domestic steady-state production point at P2 in Figure 6 9. but result in (a) an even lower foreign relative fish price: and. (b) home consumption at C?'. and consequently a higher level of home welfare than at $\mathrm{C} 2$. The sustainable consumption possibilities locus therefore starts at $\mathrm{C} 1$, passes through $\mathrm{C} 2$, and as the tariff is raised further, through C2' $^{\prime}$. If the tariff was raised beyond that which generates the consumption point $\mathrm{C2}^{\prime}$. the steady-state home price would be driven up (for the usual 
reasons) and the domestic fish stock would decline. Using this technıque. it can be seen that there is a tariff that leaves the domestic price of fish, production points, and consequently the fish stock at their free trade levels. However, since the terms of trade have improved further. domestic welfare is greater. In addition, it follows that there is a tariff larger still, that will raise the domestic price of fish. lower the domestic fish stock. but raise domestic welfare compared to the free-trade equilibrium as suggested by Brander and Taylor. However, as shown in the diagram, this would not be the secondbest tariff for the case illustrated in Figure 6.9. That would occur when the tariff left consumption at $\mathrm{C} 2^{\prime}$. where the sustainable consumption locus is tangent to a community indifference curve. Secondly. this is a special case and relies on a highly inelastuc foreign offer curve The question arises - what happens if the foreign offer curre is more elastic'?

If the foreign offer curve is elastic. then the home country may not benefit from imposing a tariff. rather. as was the case for the smail country. a trade subsidy may prove beneficial. This is shown in Figure 6.10 where the free-trade equilibrium is shown by production at point $\mathrm{Pl}$ and consumption at $\mathrm{Cl}$. A tariff on fish imports causes the home fish price to rise, and fishing effort increases. The fish stock falls and the temporary PPF pivots inwards. The production point moves to P2. Since producers and consumers face the same domestic prices under a tariff. there is a community indifference curve tangent to the temporary PPF passing through P2 at $Z$. Because of homotheticity, the new consumption point. $\mathrm{C} 2$. must lie on the ray $\mathrm{OZ}$. $\mathrm{C} 2$ can therefore be found as the 
intersection of $\mathrm{OZ}$ and the foreign offer curve. This clearly illustrates that welfare has been reduced by the tariff, despite any improvement in the terms of trade and tariff revenue collected. Similarly, a trade subsidy that subsidizes exports of manufactures produces an equilibrium production point at $\mathrm{P} 3$ and consumption point at $\mathrm{C} 3$ and raises steady-state welfare by reducing fishing effort (and increasing the fish stock) despite worsening the terms of trade.

The two cases examined in Figures 6.9 and 6.10 are the extremes In general, the less elastic the foreign offer curve. the less likely that the optimal policy is an expor subsidy and the more likely that it is a tariff. Figure 6.11 illustrates how the shape of the sustainable consumption pattem is affected by the elasticity of the foreign offer curve In Figure 6.11, the region above the SCC has been divided into four sections In order for the consumption locus to pass through regions $A . B$, and $C$ the foreign offer cure must be inelastic. The consumption locus derived in Figure 6.9 for the inelastic foreign offer curve passes through region $A$. As the foreign offer cunce becomes more elastic. the consumption locus effectively pivots anti-clockwise through the free-trade equilibrium point $\mathrm{Cl}$. Eventually, as the foreign offer curve becomes elastic. the consumption locus, traced out by a tariff, passes though region D only 


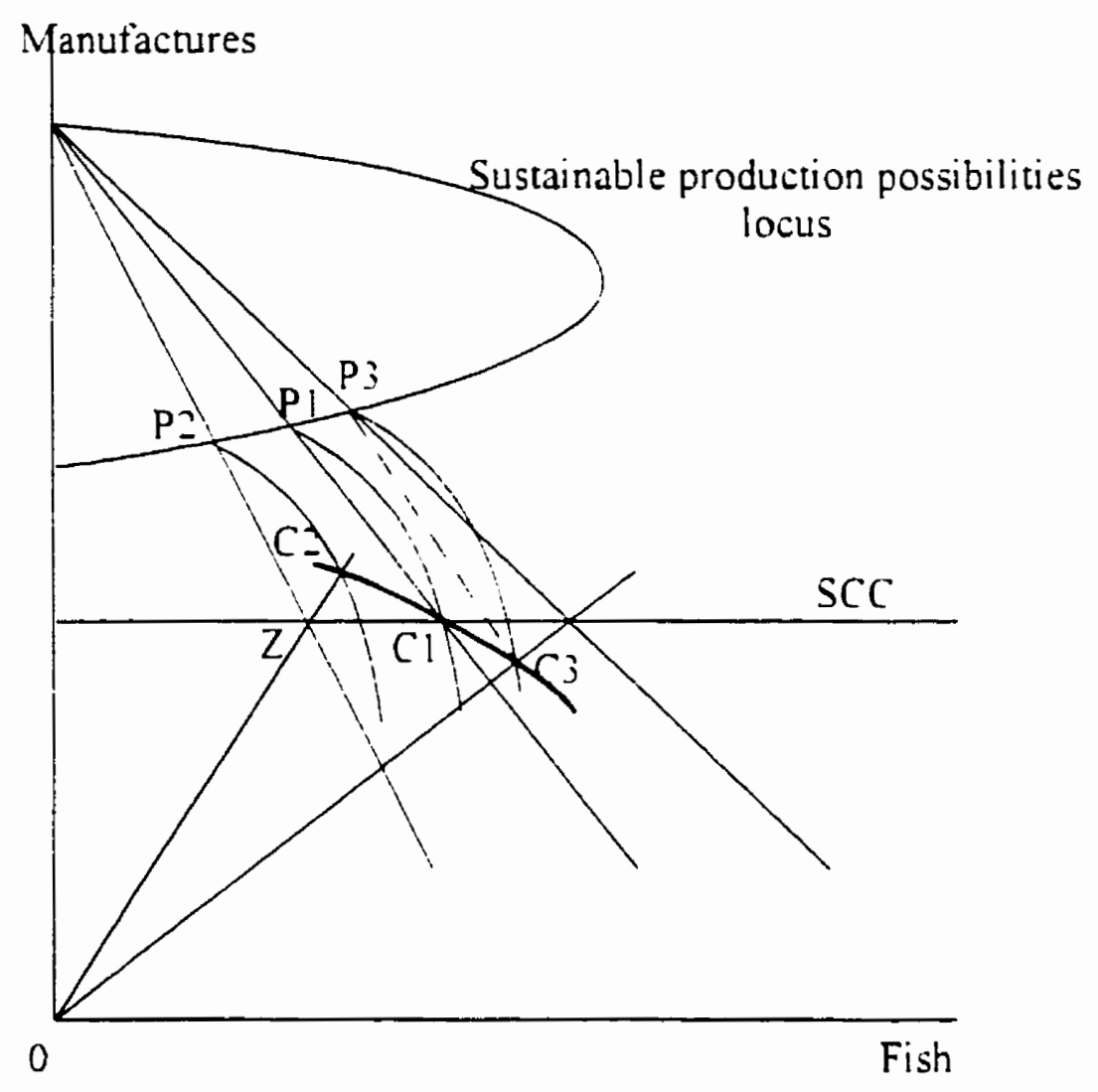

Figure 6.10

The home country tariff when the foreign offer curve is elastic 


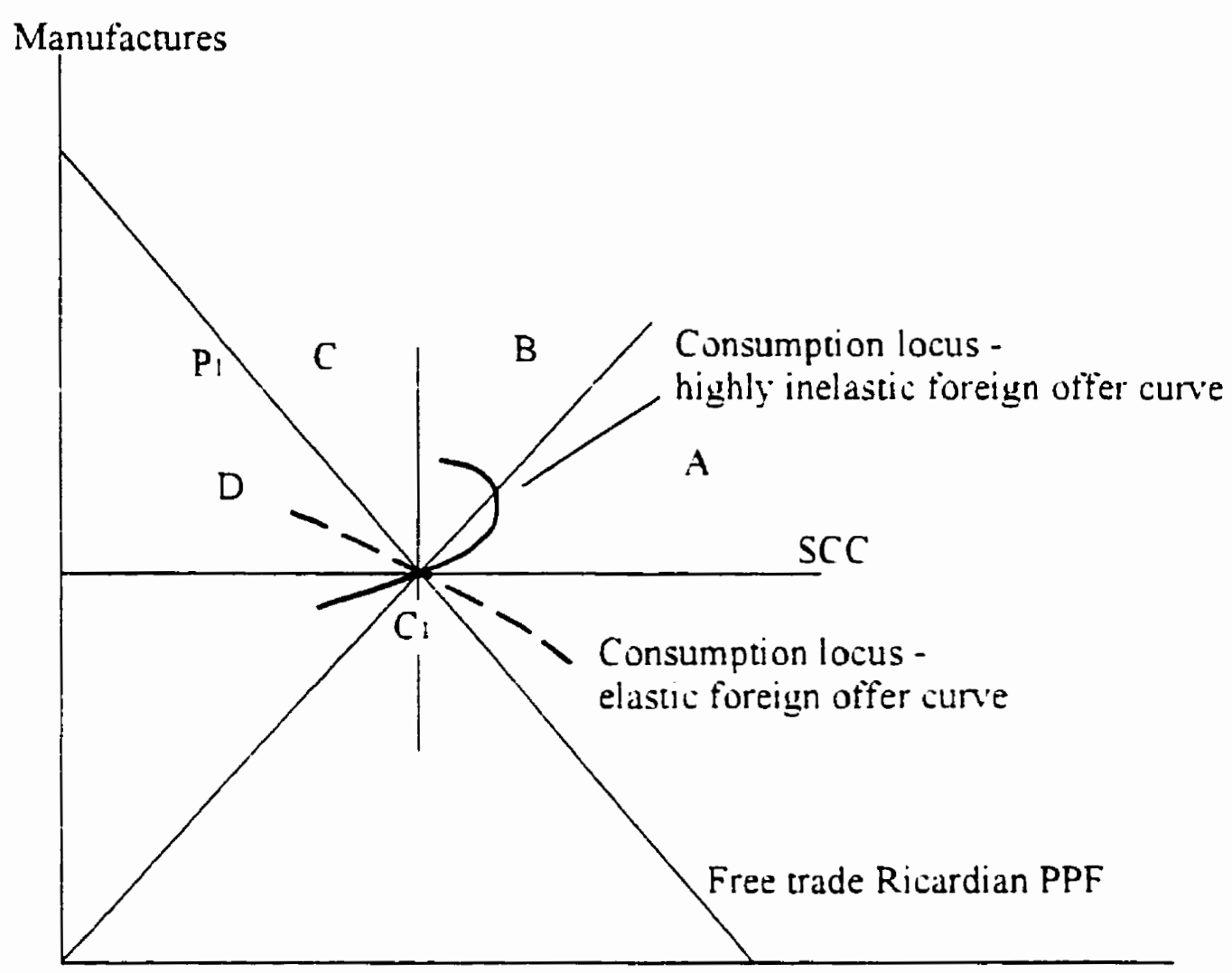

Fish

Figure 6.11

The effect of changes in the elasticity of the toreign offer curve on home consumption

It can be seen that a tariff will generally raise welfare if the foreign offer curve is inelastic. If the foreign offer curve is so inelastic that the consumption locus passes through region $\mathrm{A}$ then welfare is increased for two reasons. First. the tariff on fish imports drives the world price down by so much that domestic prices also fall (note that region $\mathrm{A}$ involves manufactures being consumed in a smaller proportion than in free 
trade, therefore the relative price of fish faced by consumers and producers must be lower than in free trade). Second. the economy gains from exploiting its monopoly power in trade. For less inelastic offer curves, that generate a consumption locus that passes through either regions $B$ and $C$. or $C$ but not $B$, welfare can be improved by a tariff. However, in each of these cases the domestic price of fish is greater than in the free-trade equilibrium due to the protecting influence of the tariff. The higher relative price of fish induces a higher level of fishing effort. a lower fish stock, and consequently reduces steady-state welfare at home. Nevertheless. in these cases, the gain from exploiting monopoly power in trade is sufficient to improve welfare. If the toreign offer curve is elastic (as demonstrated in Figure 6.10) then a tariff generates a point on the consumption locus in region $\mathrm{D}$. In this case. the effect of a decline in the fish stock. from an induced increase in over fishing. dominates the benefit of the improved terms of trade and welfare is worsened. However, as shown above. when the foreign offer curve is elastic. the home country can gain from a trade subsidy

In summary, the following proposition (and its corollary) has been demonstrated for a country (home) with an open-access fishery that imports fish and exports manufactures

Proposition 6.3: Beginning from a free-trade equilihrium, the imposition of a home tariff on fish imports results in

i) a fall in the foreign relative price of fish, and an improvement in foreign welfare: ii) either an increase or decrease in the home price of fish if the foreign offer curne is 
inelastic. Consequently, the steady-state home stock of fish may either fall (if the home price was to rise) or rise (if the home price was to fall). Welfare at home rises if the relative price of fish at home falls, or may either rise or fall if the relative price of fish rises at home. The more elastic the foreign offer curve, the less benefit the home country receives from the terms of trade effect and the more likely that domestic welfare will fall: and.

ii) a decrease in the home price of fish. and consequently a fall in the home steady-stale fish stock if the foreign offer curve is elastic. Stend-state welfare is worsened by the imposition of a home tariff if the foreign offer curve is elastic.

As a corollary to this.

Corollary 6.1: Beginning fiom a free-1rade equilibrium. the imposition of a trade suhsidt (for excmple on fish imports) results in:

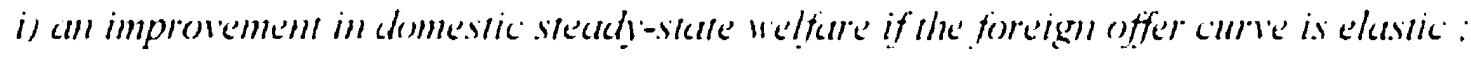
(ind.

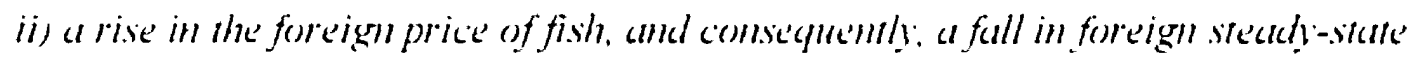
welfare.

This section proved that there are situations in which restrictive trade policy could be employed by either the home (fish-importing) country, or the foreign (fish-exporting) country and lead to improvements in global welfare. However, it is not certain that. left to their own devices. countries will implement policies that lead to Pareto improvements 
in welfare. For example, the home country may find it best to employ a trade subsidy While this policy will raise welfare at home, it worsens foreign welfare. In the case of the foreign country, a tariff may prove beneficial at home but the effects on the home country are ambiguous. Nevertheless. the argument that trade policy can be used as a countervail against countries who fail to properly regulate. and thus give their fisheries a competitive advantage, seem to have some justification. The next two sections explore the North-South aspect of the debate. and consider trade between a conservationist economy that chooses to optimally regulate. and an open-access economy

\subsection{Trade Between Conservationist and Open-Access Economies}

This section considers trade between a conser ationist country (the foreign country) and an open-access country (home). The conservationist economy internalizes all costs of fishing by optimally regulating the use of the resource. while the open-access economy is assumed to refrain from implementing any regulations. despite caring about its steadystate welfare. ${ }^{32}$ Furthermore. it is assumed that the only difference between the two economies is the institutional regime. This section of the thesis derives a particularly interesting result: no matter what the pattern of trade, there is always a trade policy that can improve the welfare of both countries.

As explained in Chapter 4. although the absence of regulation in the home country can be

32The case in which the open-access country chooses not to regulate because it cares only about the present and totally discounts the future is left to the next section. 
thought of as giving the fishery a competitive advantage, which allows it to expand beyond its optimal level, the lax regulation may or may not translate into an apparent comparative advantage for the fishıng industry in the home (open-access) country compared to the foreign (conservationist) country If preferences are sufficiently biased towards consumption of fish, then the open-access home country depletes its resource to the extent that it has a steady-state apparent comparative advantage in manufactures compared to the conservationist foreign country. If, on the other hand. preferences are biased towards manufactures, then the open-access home economy has a steady-state apparent comparative adrantage in fish As a result in free-trade equilibrium. the openaccess home countrỵ may expor either good

\subsubsection{Trade policy undertaken by the un-regulated open-access country}

Begin by considering a special case in which, despite the absence of any restriction to trade. no trade takes place between the two countries. In this particular case. the secondbest trade policy for the open-access home economy is a trade subsidy to encourage the import of fish and export of manufactures. The conservationist foreign country benefits because any trade induced movement away from its autarkic equilibrium is welfare improving for the optimally regulated economy. This case is interesting because it clearly indicates that expansionary trade policies may generate Pareto improvements in welfare, despite the presence of environmental externalities such as the open-access problem. While such a policy recommendation runs contrary to the free-trade doctrine. it also conflicts with the anti-trade philosophy of many environmentalists 
Consider Figure 6.12; because the two countries are assumed to be identical, other than for the regulation of the resource. Figure 6.12 can be used to illustrate equilibrium in each of the two countries. The figure shows a situation in which the autarkic relative price of fish is the same in both countries. In the open-access home country, the initial free-trade equilibrium is shown by $E_{\mathrm{H}}$ while the foreign (conservationist) equilibrium is shown by $E_{F}$ Using the same technique as in Section 6.2, consider the effects of a home country trade subsidy that encourages the export of manufactures to the foreign country The export subsidy to manufactures (or a fish import subsidy) causes the relative price of fish to fall at home and hence a reduction in home fishing effort. The fall in fishing effort causes the fish stock to increase at home and the Ricardian PPF pivots outwards through $\mathrm{T}$. The new production point under open access at home is indicated by $\mathrm{P}_{\mathrm{H}}$. As before, the home consumption point under the subsidy. $C_{H}$, can be found as the intersection of the ray $\mathrm{OZ}$ and the foreign offer curve. Notice that utility under open access in the home country has been improved by the expansion in the production possibilities frontier, despite the trade subsidy which causes consumption to take place inside the, post subsidy. Ricardian PPF (PPF2). The relative price of fish in the foreign (conservationist) country has been driven up by the trade subsidy that increased the demand for fish relative to manufactures. The new production point in the foreign country is illustrated by point $P_{F}$ and the consumption point by $C_{F}$. Welfare in the foreign country (under a regime of optimal regulation) has been improved because the home trade subsidy provided the opportunity for the optimally regulated foreign country to trade away from its autarkic equilibrium. An important result has been established: under 
some circumstances, welfare in both the open access and conservationist countries can be improved by the creation of trade

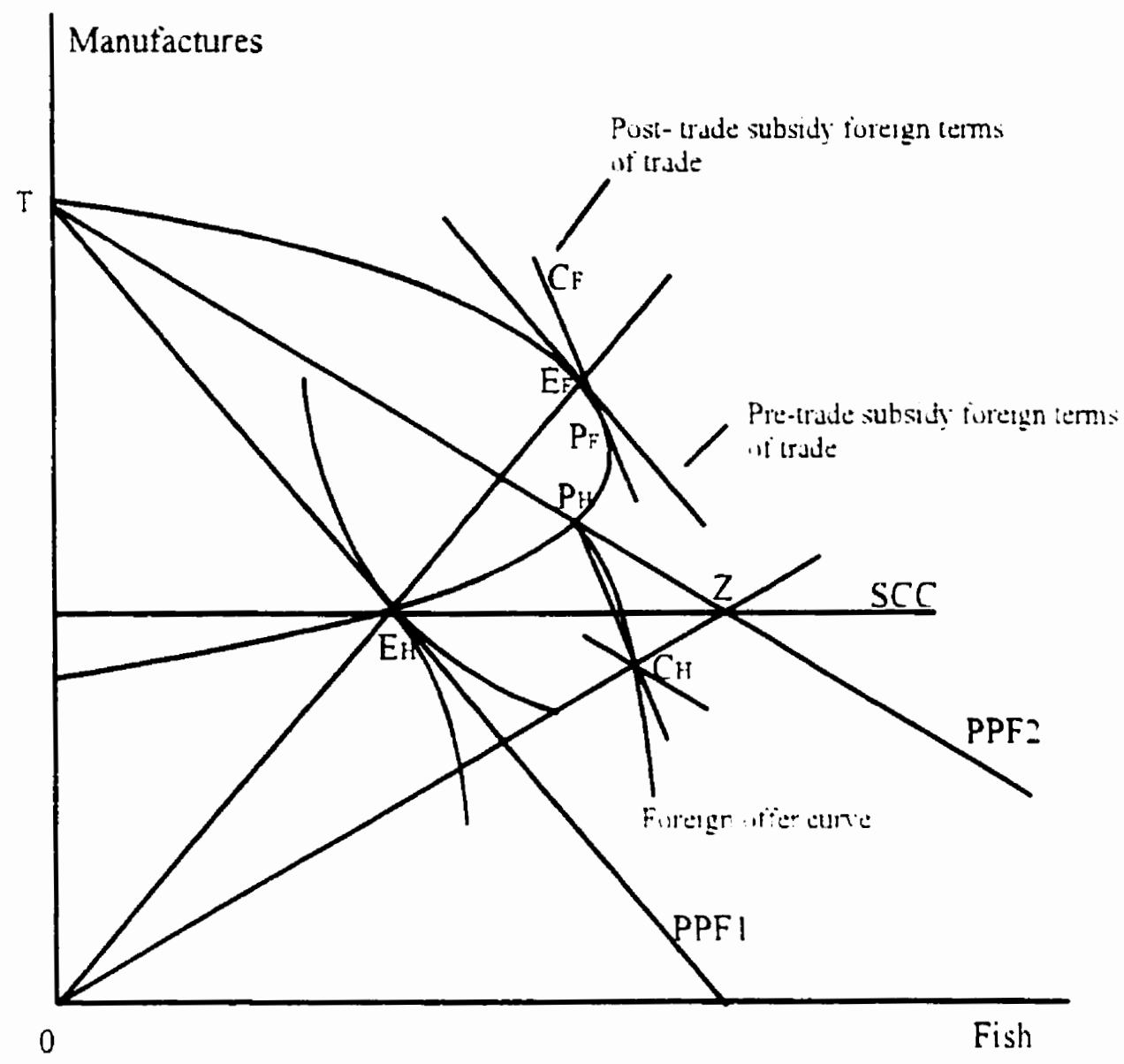

Figure 6.12

A Pareto improving trade subsidy

The case in which no trade occurs, despite the differences in institutional regime, is clearly a special case. In general. either country may have a comparative advantage in either good, as explained in Chapter 4. The results from Section 6.2 can be applied to consider the different possible cases. First, it is important to recall the differences in terminology used in Section 6.2 and that used in this section. In Section 6.2, the fish- 
importing country was referred to as the home country. In this section, the home country denotes the open-access economy. Conversely, in Section 6.2 , the fish-exporting country was referred to as the foreign country, where as in this section, the foreign country is optimally regulated, irrespective of the good it exports. Bearing this in mind, Propositions 6.2 and 6.3 can be applied to consider the effect of trade policy undertaken by the home country. However. the effects of home trade policy on the foreign (optimally regulated) country cannot be directly inferred from Propositions 6.2 and 6.3 because of the difference in the regulatory regimes (in section 6.2 it was assumed that both economies were open access). Thus, only the effects of trade policy undertaken by the open-access (home) economy on vartables pertaining to the home country and foretgn prices is valid. Nevertheless, the effect on forengn welfare is easily determined If the change in the relative price of fish in the foreign (conservationist) country reflects an improvement in its terms of trade. then its welfare is improved. Conversely. a worsening of the foreign terms of trade implies a reduction in foreign welfare Lastly. while the offer curve for the open-access economy may have an inelastic region, the offer curve for the optimally regulated country is always elastic ${ }^{33}$

With this in mind. Propositions 6.2 and 6.3 may be re-written to consider the effects of trade policy undertaken by the open-access home economy on the welfare of both the home and foreign economies. Doing so gives Propositions 6.4 and 6.5 .

\footnotetext{
${ }^{33}$ That the offer curve for a conservationist country is elastic can be illustrated simply using the same diagrammatic technique in Figures 6.1-6.4.
} 


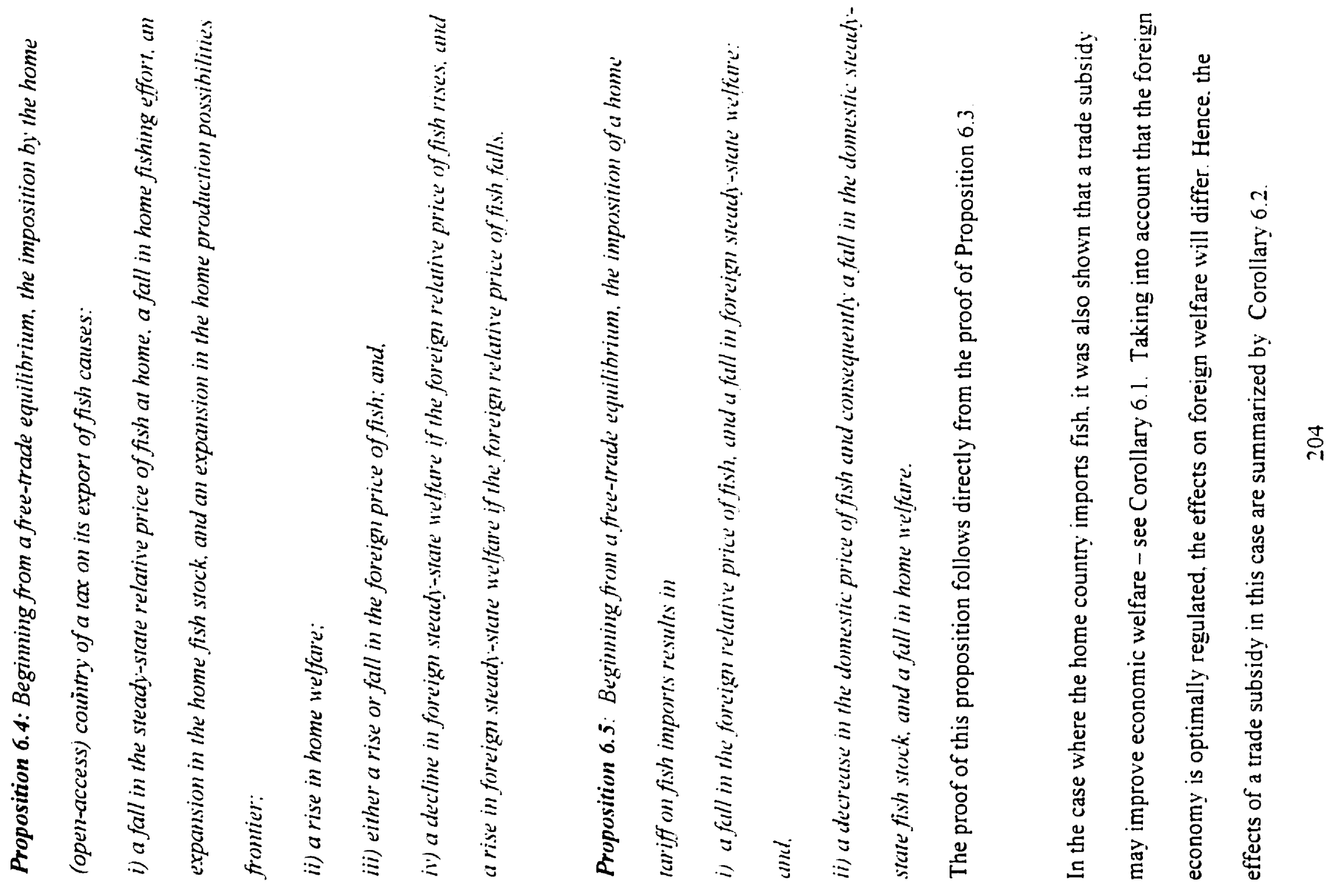


Corollary 6. 2: Beginning from a free-trade equilibrium, the imposition of a home country trade subsidy (say on fish imports) results in:

i) an improvemem in steady-state welfare at home; and.

ii) a rise in the foreign price of fish, and consequently because of the improvement in the foreign country's terms of trade, an improvement in foreign welfare.

The analysis of this sections has demonstrated that the open-access economy can improve its welfare through the use of trade restrictions if the open-access economy exports fish and through the use of either restrictive trade measures or trade subsidies if open-access economy imports fish. Only in the case where the home (open-access) country imports fish and benefits from imposing a trade subsidy is foreign welfare unambiguously improved. Otherwise. the welfare effects on the conservationist country are ambiguous The next subsection explores the effect of trade policy undertaken by the conservationist country

\subsubsection{Trade policy for the conservationist country}

\subsubsection{The conservationist country imports fish}

As is well known (Bhagwati (1971)) the first-best policy for the foreign (conservationist) country involves the imposition of an optimal harvest tax in conjunction with an optimal tariff. The foreign country is already considered to be optimally regulated. hence one needs only to consider the impact of the tariff. First, suppose that the foreign country imports fish and hence the home country is a fish exporter. The effect of the foreign 
country's fish tariff on the welfare of each of the two countries is straight forward to derive. First, by exploiting its monopoly power in trade, the foreign (conservationist) country gains from the imposition of the tariff; since it is optimally regulated. there is no other distortion to be concerned with in the foreign country. Second, the home (openaccess) country faces a fall in the relative price of fish due to the impact of the foreign tariff. In Figure 6.13 the fall in the relative price of fish follows from the impact of the foreign tariff which causes the foreign offer curve to pivot downwards as shown by the dashed curve. The fall in the relative price of fish at home causes the home fishing industry to contract, the fish stock to grow. and the production possibilities set (and hence the consumption possibilities set) expands. As a result the production point moves from $\mathrm{Pl}$ to $\mathrm{P} 2$ and consumption from $\mathrm{Cl}$ to $\mathrm{C} 2$ Thus, welfare in the open-access home country is improved by the foreign tariff.

Whether or not the tariff leads to an expansion or contraction of the fishing sector in the foreign country: depends on the elasticity of the home offer curve. If. in the free-trade equilibrium. the home country was operating on the inelastic portion of its offer cure (as is the case in Figure 6.13), then the possibility of a Metzler paradox arises. Under such circumstances the foreign fish tariff may result in a fall in the relative price of fish in the foreign economy. If the relative price of fish falls in the foreign (optimally regulated) country, then the foreign fishing industry contracts and the foreign fish stock increases If, however. the home offer curve is elastic in the free-trade equilibrium, then the Metzler paradox is ruled out and the foreign tariff causes an expansion in the foreign fishery. 
The above findings are particularly interesting because they confirm the case made by Daly (1993) who argued that it was inefficient for conservationist countries to import goods from low-standard countries. In such circumstances Daly (1993, p52) argued that "the most practical solution is to permit nations that intermalize costs to levy compensating tariffs on trade with nations that do not." Moreover, it has been demonstrated that such a policy recommendation is "fair" in the sense that the gains from increased efficiency are distributed between both countries. and do not accumulate only in the tariff imposing conservationıst country

Furelgn exports of manufidures.

Home importsot manuiditures
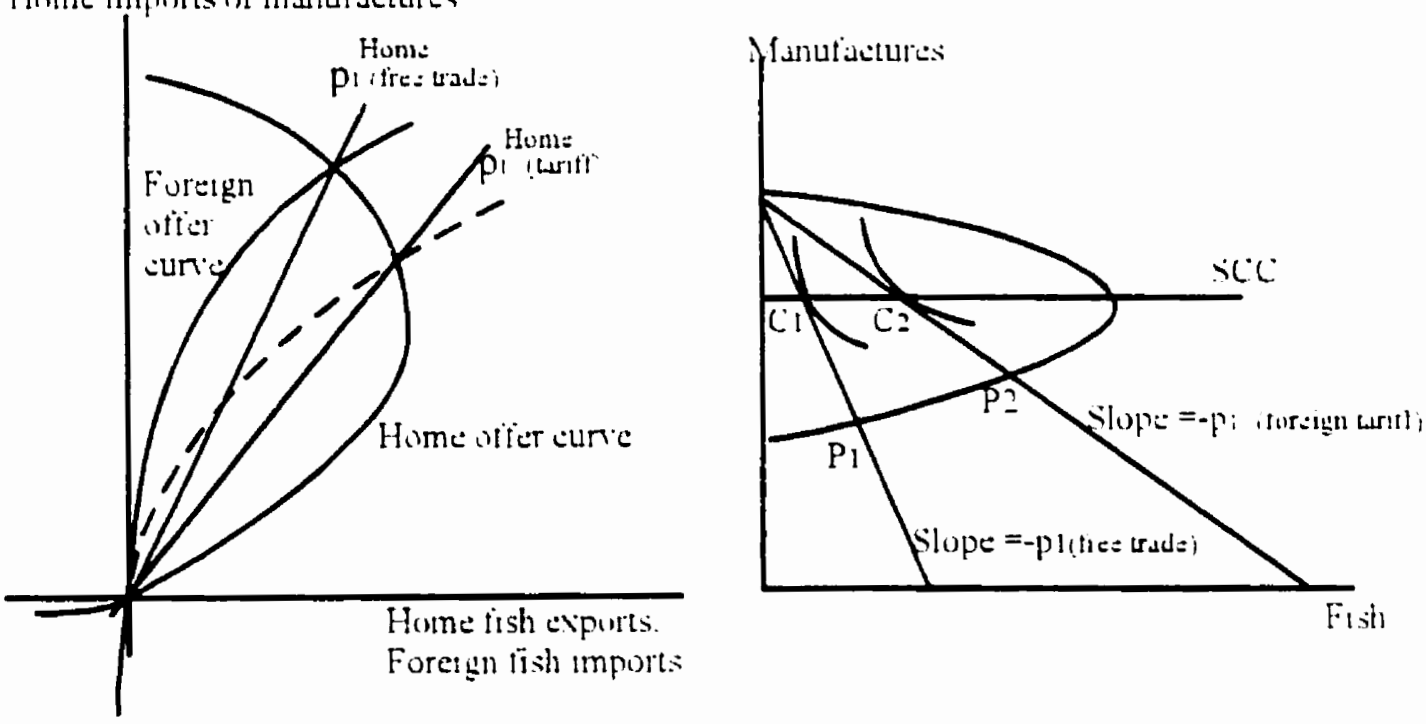

Figure 6.13

The effects of a conservationist's fish tariff on the home (open-access) economy 


\subsubsection{The conservationist country exports fish}

Next. consider the case when the regulated foreign country is a fish exporter and imposes an export tax on fish. Once again, the welfare effects are straight forward. The foreign country benefits from the imposition of the export tax by exploiting its monopoly power in trade. In this case however, welfare in the home country is worsened. The relative price of fish at home is driven up by the imposition of the foreign fish export tax. This results in an increase in the relative price of fish, an expansion in fishing effort. a fall in the home fish stock, and hence the home Ricardian PPF pivots inwards. Welfare at home is unambiguously worsened by the foreign trade policy Refer to Figure 6.14

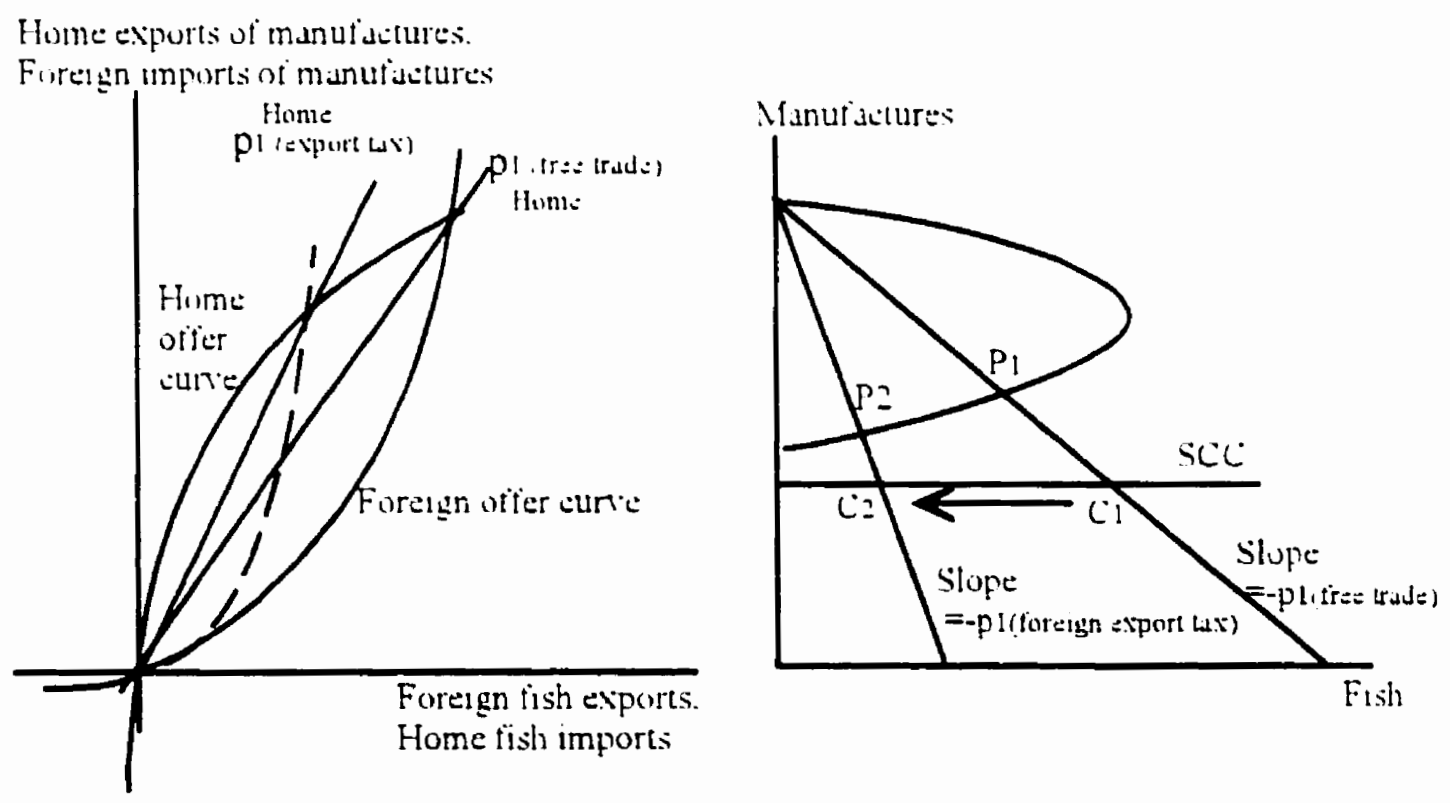

Figure 6.14

The effects of a conservationist's fish export tax on the home (open-access) economy 
Because the home offer curve is elastic in this case (recall section 6.1), there is no possibility of a Metzler's paradox and consequently the foreign fishing industry contracts with the imposition of an export tax on fish.

Proposition 6.6 summarizes the findings of this subsection so far Proposition 6.6. When the home country is open access and the foreign country is conservationist, the imposition of the optimal tariff hy the foreign countr: i) raises welfare in hoth the foreign and home country if the foreign county imports fish: (n)ct: ii) raises foreign welfare and reduces home welfare if the foreign country exports fish.

Proposition 6.6 is interesting because it suggests that in the face of the over-fishing problem in the home country, a global improvement in welfare is possible if the optimally regulated foreign country imposes a tariff as a type of countervail against the fish exports of the open-access home country. This suggestion has been made by Daly: (1993) who suggested that possibly "most practical solution is to permit nations that internalize costs to levy compensating tariffs on trade with nations that do not". However, before one advocates the imposition of tariffs on countries that export renewable resources and maintain open-access regimes. it is worth noting that. in this model. the open-access home country would have been better off in autarky (this can be seen by noting that the autarkic relative price of fish in the home country, as given by the slope of the offer curve in Figure 6.14 is less than in the restricted trade equilibrium). 


\subsection{Trade Between Conservationist and Open-Access Countries - the Case of Differences in Tastes.}

This section examines the extremely hypothetical situation in which the home country chooses not to regulate its open-access fishery because home's citizens place no value on the future, and hence the "optimal" harvest tax is zero (see Chapter 3 ). Conversely citizens in the foreign country are assumed to value only their steady-state utility and hence choose to set a harvest tax $=-\eta$. While this scenario may be extreme, it is worth examining because it is often argued that if trade is based on differences in regulator. regimes that reflect differences in preferences. then deviations from free trade are not

justified (see Bhagwati (1993) for example). The objective of this section is not to delve into the philosophical or ethical issues raised by an infinite discount rate. but to address the purely theoretical question of whether free trade between the conservationist and open-access economy is efficient'? By efficient. it is meant that there is no tariff policy. that may lead to a Pareto improvement in welfare

\subsubsection{The effects of tariffs}

As before. the first-best policy for the foreign (conservationist) country is to impose an optimal tariff along with the optimal harvest tax no matter which good it exports. While the foreign country cares about the long-term consequences of the tariff, the home country cares only about the instantaneous effects of its implementation. Thus, in this case. both the immediate effects of a change in policy on the welfare of the home 
country, and the long-term steady-state effects of trade policy on the foreign economy must be considered. Because of the Ricardian production structure. and since the fish stock is fixed at any instant, the instantaneous opportunity cost involved in producing fish in the home country is constant. Therefore, the imposition of any tariff would cause the production point to move along the temporary PPF until trade is balanced, leaving home consumption and welfare unaffected in the short-run (assuming the tariff does not result in complete specialization). Strictly speaking, since the home country places no value on the future. the imposition of a tariff by the forengn country would generate a Pareto improvement in welfare. This is because foreign steady-state welfare is improved by the imposition of the tariff, and home instantaneous welfare is left unaffected. This proves the result that free trade may be Pareto dominated by restricted trade. Generally. one may not expect this result to be valid If. for example. the countries had a Heckscher-Ohlin production structure, then any foreign tariff worsens the terms of trade facing the home country and, hence. Its immediate welfare. In general. a tariff imposed by the foreign country will not lead to a Pareto improvement in welfare.

On the other hand. regardless of whether the home country exports or imports fish. a tariff imposed by the home country can improve instantaneous welfare by exploiting home's monopoly power over its terms of trade. Therefore, to determine whether a tariff imposed by the home country can generate a Pareto improvement in global welfare it is simply a matter of determining whether the imposition of a home tariff can improve steady-state foreign welfare. From the results of the previous section. we know that when 
home exports fish, an export tax on fish (or tariff on manufactures imports) may improve the welfare of the fish-importing foreign country if the export tax leads to a long-run decrease in the foreign relative price of fish. As discussed in Section 6.3. this was likely to be the case if the fall in the price faced by home fishers lead to a sufficiently large increase in the home harvest fish harvest. For this to occur, it is necessary that the level of home fishing effor exceeds that which produces the maximum sustainable yield of fish Hence, under such circumstances, where the home country heavily over fishes. there is room for the fish-exporting home country to impose a trade tax and create a Pareto improvement in global welfare it

This raises the question: How is it that. in two seemingly optimally regulated economies. a tariff imposed by one country can improve welfare in both'? There is no externality explicitly related to trade per se. so something else must explain this phenomenon. The answer lies in the fact that citizens of the foreign country place a higher value on home's fishery than home citizens do. and there is no market through which citizens in the foreign country can convey their preference for the future to the regulators of the home fishery. The problem is one of incomplete markets - there needs to be some way in which the foreigners can pay the domestic fishers to do less fishing.

${ }^{34}$ The case when the home (open-access) country imports fish is easily dealt with. In section 6.3 it was demonstrated that a tariff on fish imports unambiguously lowers the foreign relative price of fish. Hence the foreign country's welfare is unambiguously reduced by the worsening of its terms of trade and a Pareto improvement is not possible in this case. 
Potentially, this could be achieved through a system of internationally traded fishing quotas. However, there remains the problem of determining the size of the quota. One possibility would be for the government of the short-sighted country to set the quota in order to maximize the rent from the fishery, or, alternatively, it could sell the right to exploit the fishery to the highest bidder However it is unlikely that such a policy would be optimal since this would allow the owner to exploit both its monopoly power in trade and its monopsony power in the market for fishing effort.

Other mechanisms could be considered. For example. it could be argued that this may be one reason why the US Senate passed the "Tropical Forest Conservation Act" in July of 1998. The act gives the US President authority to make debt for rainforest conservation swaps. Although, the 'knowledge' aspect of rainforests (i.e finding a cure for cancer etc.) is not an aspect of this model, it is plausible that the logic provided in the illustration above for another type of renewable resource, at least in part. explains the bill.

However. there may be organizational costs involved in government's pursuing such policies. Environmental organizations have also attempted "rainforest for debt" swaps. but face problems associated with free-riding, not to mention the jurisdictional problem of enforcing the conservation policy in a foreign country. When these problems prevent a direct payoff to encourage a reduction in harvesting or fishing effort at home, an export tax imposed by the South may be a possible solution. 


\subsection{Conclusion}

This chapter considered a two-country world. and derived a number of interesting results First, trade between two open-access economies was considered. The analysis of Brander and Taylor (1998a) was extended to consider trade under more general circumstances than considered in their paper. Consequently, new results were derived. Most notably: it was shown that it is possible for an export tax on fish to improve the welfare of not only the fish-exporting country. but the fish-importing country as well

The second case that was considered involved trade between a "conservationist" optimally regulated country and an open-access economy. Much of the debate in the literature regarding this case revolves around whether the resource in the open-access country is freely accessible because of tastes (due to a very high discount ratel or an inability to regulate the resource. To address this issue the two cases were considered separately. In each case interesting results were found.

When trade takes place between a well-regulated conservationist country and an openaccess economy that is unable to control access to its fishery, it was found that there is always some trade policy which can be used to improve the welfare of both countries. When the conservationist country exports fish to the open-access country, it was shown that the open-access economy can improve its own welfare by imposing a trade subsidy The trade subsidy alleviates the over fishing problem in the open-access economy by 
encouraging an expansion in manufacturing and a contraction in fishing. Welfare of the conservationist country is improved by the improvement in its terms of trade. Therefore. both countries enjoy an improvement in welfare.

In the case where the conservationist country imports fish, then the conservationist country can improve its own welfare, in the usual manner. through the use of a tariff on fish imports. The tariff causes the relative demand for fish to fall in the world market and hence the relative price of fish in the home country falls. The consenationist country's tariff has the effect of reducing the profitability of the fishing sector in the open-access economy, and thereby reduces the magnitude of the over-fishing problem there. Consequently, welfare in the open-access country also improves

This establishes an extremely interesting result: when trade takes place between a conservationist country and an open-access economy. and both care about steady-state welfare, then there is a trade policy that can be implemented by one or the other that leads to an improvement in the welfare of both

In the case where differences in regulation of the fishery arose because of differences in the discount rates of the two countries, another important result was found: free trade is still not likely to be optimal. The reason being that the market for the property right to the fisheries of each of the respective countries may be missing. The citizens of the patient (low discount rate) country place a higher value on the fishery of the impatient 
country than the impatient country's own citizens. Therefore there are potential gains from trade in the property rights to the fisheries. In the absence of tradable property rights, and hence a missing market, free-trade in goods is not necessarily optimal

The results of this chapter add weight to the argument that free-trade is not best when property rights regimes fail. However, it does not recommend that free traúe should necessarily be abandoned in favour of restricted trade. Indeed. the same welfare arguments that can be used to justify trade restrictions have been shown to justify trade subsidies 


\section{Appendix 6.1: The Effects of Home (Open-Access) Country Trade Policy on the}

\section{Home Offer Curve.}

In the presence of an export tax, total income is labour income plus revenue from the export tax. Since the wage rate is unity total income is therefore

$$
\begin{aligned}
& I=N+\tau E \\
& C_{2}=(1-\beta)(N+\tau E) .
\end{aligned}
$$

Following the derivation of the offer curve in the text. production of manufactures is given by

$$
K_{2}=V_{2}=\left(N-N_{1}\right)
$$

The equilibrium level of fishing effort, $N_{1}$ can be derived as follows : In a sustainable equilibrium the temporary har.est of fish must be equal to the natural rate of fish population growth

$$
X_{1}=L(S)
$$

or. $\quad g S N_{1}=\gamma S(1-S / c)$

It will be recalled that in a sustainable equilibrium the slope of the temporary PPF is equal to the relative price of fish faced by domestic producers which equals the world price minus the tax on fish exports, $p_{1}-\tau$. That is,

$$
p_{1}-\tau=1 / q S \text {. }
$$

Substituting (6.5) into (6.4)

$$
N_{1}=\frac{\gamma}{q}\left(1-\frac{1}{q c\left(p_{1}-\tau\right)}\right)
$$

Hence from (6.2) 


$$
X_{2}=N-\frac{\gamma}{q}\left(1-\frac{1}{q c\left(p_{1}-\tau\right)}\right),
$$

and therefore imports of manufactures, denoted $\mathrm{M}_{2}$, are given by

$$
M_{2}=C_{2}-X_{2}=(1-\beta)\left(N+\tau \frac{E_{1}}{p_{1}}\right)-N+\frac{\gamma}{q}\left[1-\frac{1}{q c\left(p_{1}-\tau\right)}\right],
$$

or,

$$
M_{2} q c\left(p_{1}-\tau\right)=\frac{\gamma}{q}\left[q c\left(p_{1}-\tau\right)-1\right]-\beta N q c\left(p_{1}-\tau\right)+(1-\beta) \tau E_{1} q c\left(p_{1}-\tau\right)
$$

or,

$$
\left[M_{2}-(\gamma / q-\beta N)\right] q c\left(p_{1}-\tau\right)=(1-\beta) \tau E_{1} q c\left(p_{1}-\tau\right)-\frac{\gamma}{q}
$$

Then substituting $\mathrm{M}_{2} / \mathrm{E}_{1}$ for $p_{1}$ gives.

or.

$$
\left[M_{2}-(\gamma / q-\beta N)\right] q c\left(\frac{M_{2}}{E_{1}}-\tau\right)=(1-\beta) \tau E_{1} q c\left(\frac{M_{2}}{E_{1}}-\tau\right)-\frac{\gamma}{q}
$$

$$
\left[M_{2}-(\gamma / q-\beta N)\right] q c\left(M_{2}-E_{1} \tau\right)=(1-\beta) \tau E_{1} q c\left(M_{2}-E_{1} \tau\right)-\frac{\gamma}{q} E_{1} .
$$

Using Equation (A6.2) it can be established that the offer curve with the export tax has a similar shape to the free trade offer curve derived in the text. First. notice that it intersects the manufactures axis at $(\% / q-\beta N)$ while the slope of the offer curve is given by

$$
\frac{d M_{2}}{d E_{1}}=\frac{\left[M_{2}-\left(\frac{\gamma}{q}-\beta N\right)\right] q c \tau+(1-\beta) \tau M_{2} q c-2(1-\beta) \tau^{2} q c E_{1}-\frac{\gamma}{q}}{2 M_{2} q c-\left(\frac{\gamma}{q}-\beta N\right) q c-q c \tau E_{1}-(1-\beta) \tau E_{1} q c}
$$

The effect of the export tax can be seen to have the following two effects:

1) at the origin the offer curve is made steeper by the tax 


$$
\left.\frac{d M_{2}}{d E_{1}}\right|_{E_{1}=M_{2}=0}=\frac{(\gamma / q-\beta N) q c \tau+\frac{\gamma}{q}}{(\gamma / q-\beta N) q c} \text {, and }
$$

2) while at the intercept, where $M_{2}=\gamma / q-\beta N$. the offer curve is made flatter (the slope becomes less negative) by the export tax

$$
\left.\frac{d M_{2}}{d E_{1}}\right|_{E_{1}=0}=\frac{(\gamma / q-\beta N) \tau q c(1-\beta))-\frac{\gamma}{q}}{(\gamma / q-\beta N) q c}
$$

Thus the shape of the offer curve is affected in a manner as shown by the dashed offer curve in Figure (A6.11)

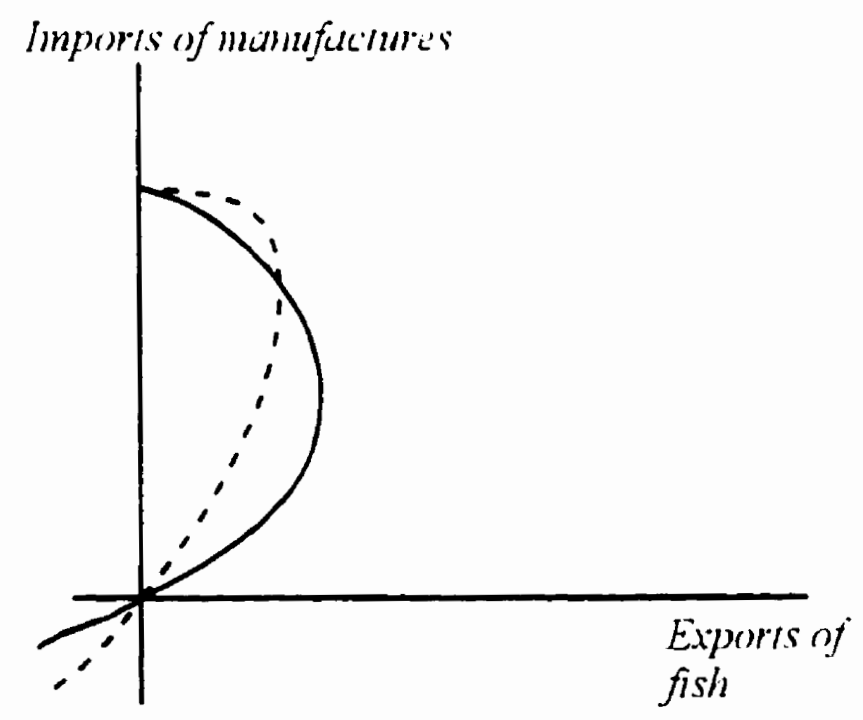

Figure A6.1.I

It is now straightforward to show that the relative price of fish on the world market may. fall as a result of the export tax. This is confirmed by adding the foreign offer curve to the home offer curves from Figure A6.1.1 


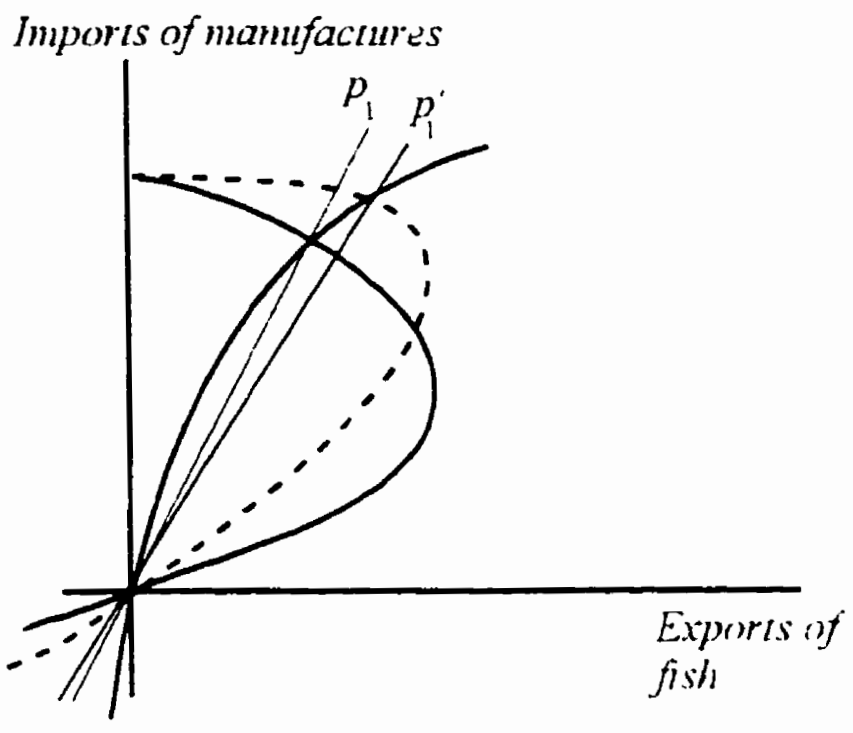

Figure .6 .1 .2 


\section{Appendix 6.2 Proof of Proposition 6.2: The Effect of an Export Tax Imposed by}

\section{the Foreign (Fish-exporting) Country.}

The derivation of the following results draws heavily on the analysis of Brander and Taylor (1998b). In equilibrium. global demand for fish must equal supply

$$
\beta I / p_{1}-\beta^{*} I^{*} / p_{1}^{*}=\gamma S\left(1-S(c)+\gamma^{*} S^{*}\left(1-S^{*} / c^{*}\right)\right. \text {. }
$$

(A6.2.1)

where foreign variables are denoted by an asterisk *. Foreign income. I* is equal to the sum of labour income and tax revenue. Since the wage is unity. $I^{*}=N^{*}-\tau * E_{1}^{*}$ and home income is just $N$. After substitution. ( $A 62.1)$ becomes

$$
\left.\beta N i p_{1}-\beta^{*}\left(N^{*}+\tau^{*} E_{1}^{*}\right)^{*} p_{1}{ }^{*}=\psi S\left(1-S^{*} c\right)-y^{*} S^{*}\left(1-S^{*} c^{*}\right) . \quad \text { (A6 } 22\right)
$$

The home price of fish is equal to the foreign price of fish plus the export tax That is

$$
p_{1}=p_{1}^{*}+\tau^{*}
$$

Using the equilibrium conditions for diversified steady-state equilibrium. $p_{1}=l(q \varsigma)$ and $p_{1}{ }^{*}=1:\left(q^{*} S^{*}\right) .(-A 6 \cdot 2.3)$ can be re-written as

$$
l /(q S)=1 /\left(q^{*} S^{*}\right)-\tau^{*}
$$

Equations (A6.2.2) and (A6.2.4) form a simultaneous system that solves for the steadystate values of $S$ and $S^{*}$ as functions of $\tau$ and the other parameters of the system. The system can be totally differentiated (A6.2.2) and (A6.2.4) and arranged in matrix notation as follows:

$$
\left[\begin{array}{cc}
\beta N q-\gamma(1-2 S / c) & \beta^{*}\left(N^{*}+\tau^{*} E_{1}^{*}\right) q-\gamma^{*}\left(1-2 S^{*} / c^{*}\right) \\
-\mathrm{i} /\left(q S^{2}\right) & -1 /\left(q S^{* 2}\right)
\end{array}\right]\left[\begin{array}{l}
d S \\
d S^{*}
\end{array}\right]=\left[\begin{array}{c}
-\beta^{*} E_{1}^{*} q S^{*} \\
1
\end{array}\right][d \tau](A 6.2 .5)
$$


Cramer's rule can be used to solve for the steady-state comparative static effects of the export tax

For the purposes of the analysis, assume that all the parameters may differ across the two countries except the parameter. $q$. which is assumed to be identical in each. Because $S=1 / q p_{1}$ in diversified steady state. the assumption that the $q$ s are identical is particularly useful since it implies that. under free trade. the steady-state fish stock will be equalized in each country. regardless of the values of the other parameters

Thus starting from a free-trade equilibrium. where $\tau=0$ and.$S^{*}$ The application of Cramer's rule gives

$$
\frac{d S^{*}}{d \tau^{*}}=\frac{(1-\beta) E_{1}^{*}+\gamma S^{2} / c}{\left(\gamma / c+\gamma^{\prime} / c^{\prime}\right) S^{2}} \text {. }
$$

which is positive since the foreign country is assumed to be an exporter of fish and so $E_{1}^{*}>0$

The effect of the foreign export tax on the foreign relative price of fish can be inferred from the the induced change in the steady-state fish stock. Using the condition for 
equilibrium $p_{1}^{*}=1 / q S^{*}$, it follows that $d p_{1} / d \tau$ is negative. This completes the proof of part (i) of Proposition 6.2.

The effect of the export tax on foreign utility can be found by differentiating the indirect utility function. $U^{*}=\alpha^{*} I^{*} /\left(p_{1}+\tau\right)$, with respect to $\tau$

$$
\frac{d U^{*}}{d \tau^{*}}=-\frac{\beta^{*} \gamma^{*} N^{*}}{p_{1}^{*}(\beta+1)} \frac{\partial p_{1}^{*}}{\partial \tau}+\gamma^{*} E_{1}^{*} / p_{1}^{*}>0
$$

This proves part (ii) of Proposition 6.2

To prove part (iii) first determine the effects of the foreign export tax on the home steady-state fish stock. Once this is determined. the effect of the export tax on the relative price of fish at home can be determined. Using Cramer's rule.

$$
\frac{d S}{d \tau^{*}}=\frac{\left(\beta^{\circ}-1\right)\left(\beta^{*} N^{*} q^{\prime}-\gamma^{\prime}\right)+(\beta-2) \gamma^{*} / c \cdot\left[\frac{\gamma+\gamma^{*}-q\left(\beta N+\beta^{*} N^{*}\right)}{\gamma / c+\gamma^{*} / c^{*}}\right]}{\left(\gamma / c+\gamma^{*} / c^{\circ}\right) S^{2}}
$$

Brander and Taylor (1998a) considered the case where the two countries differ in factor proportions as measured by the ratio of $\gamma$ to $N$ in each country. In their proof of their Propositions 7 and 8 in Brander and Taylor (1998a), they implicitly assume that ( $y / q$ $\beta N)>0$ in both the home and foreign countries. Recall that this is the requirement that the fish stock not be extinguished in autarky. This requirement must be satisfied for the fishexporting (foreign) country, but need not be for the fish-importing country. Brander and 
Taylor prove that when the condition holds for both, $d S / d \tau^{*}<0$. It can be easily verified from (A6.2.8) that $d S / d \tau^{*}>0$ for some parameter values when $(\gamma / q-\beta N)<0$. However. this is a special case because it implies that home country imports fish at any relative price of fish.

A more interesting example occurs when comparative advantage is due to differences in the capacity of the fishery, $c$. In this case the home country will import fish when the relative price of fish is low and export fish for higher relative prices. Thus its offer curve does not have the unusal shape that it would if it solely imported fish for all values of $p$ : It can be verified from (A6.2.8) that $d S d \tau^{*}>0$ if the capacity of the foreign fishery is significantly larger than that of the home fishery. despite no other differences between the two countries. In the case where $\beta=\beta^{*}=0.5 . q=q^{*}=1, y=z^{*}=1, V=i t^{*}=1$. and $c=1$. then $d S d \tau^{*}>0$ if $c^{*}>5$. otherwise if $c^{*}<5$, the home fish stock falls with the imposition of a foreign export tax.

Once again the effect on the relative price is easily inferred since the relative price of fish is inversely related to the fish stock. It follows that the relative price of fish may rise or fall in the home economy as a result of the imposition of a foreign export tax. This serves to prove part (iii) of Proposition 6.2.

Differentiating the indirect utility function for the home economy gives: 


$$
d U / d \tau=-\left[\alpha N / p_{1}^{(\beta-1)}\right] \partial p_{1} / \partial \tau
$$

It follows that utility at home falls if the relative price of fish at home rises: while utility rises if $p_{1}$ falls. This proves part (iv) of the proposition. 


\section{Appendix 6.3: Proof of Proposition 6.3}

The proof of the part (i) of the proposition follows closely the proof of Proposition 6.2 In this case the home country imposes a tariff. $\tau$. on the import of fish from the foreign country.

As before, in equilibrium, global demand for fish must equal supply

$$
\beta I / p_{1}-\beta^{*} I^{*} i p_{1}{ }^{*}=\gamma S(1-S / c)+I^{*} S^{*}\left(1-S^{*} c^{*}\right) .
$$

\section{(A6.2.1)}

In this case however. the home country receives the revenue from the trade tax thus home income is equal to wage income plus tariff revenue. or $l=.1+\tau M /$ Thus $(A 621)$ becomes

$$
\beta\left(L^{\prime}-\tau L_{1}\right) p_{1}-\beta^{*} I^{*} p_{1}{ }^{*}=\% S\left(1-S(c)+1^{*} S^{*}\left(1-S^{*}\right)^{*}\right) . \quad(A 6+1)
$$

The home price of fish is equal to the foreign price of fish plus the tariff. That is.

$$
p_{1}=p_{1}{ }^{*}+\tau
$$

Hence $(A 62.3)$ can be re-written as before as

$$
1 /(q S)=1 /\left(q^{*} S^{*}\right)+\tau^{*}
$$

Equations (A6.2.11) and (A6.2.4) form simultaneous equation system that can be used to solve the comparative static effects of a change in the tariff. Totally differentiating gives:

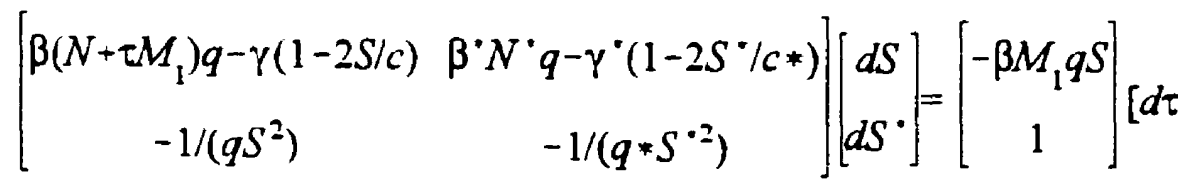


As before Cramer's rule can be used to solve for the comparative static effects of a change in the tariff rate on the steady-state foreign fish stock. Evaluating the derivatives at $\tau=0$, and using the fact that, in the original free-trade equilibrium, $S=S^{*}$.

$$
\frac{d S^{*}}{d \tau}=\frac{q(1-\beta) M_{1}+\gamma S / c}{\left(\gamma / c+\gamma^{*} / c^{*}\right) q S^{2}}>0
$$

Thus, using the inverse relationship between the fish stock and the relative price and the positive relationship between the steady-state fish stock and utility, it can be inferred that $p_{1}{ }^{*}$ falls in response to the change in the tariff. while foreign utility rises This proves part (i) of the proposition.

It can also be shown that the fish stock at home may rise or fall in response to the tariff. This requires using Cramer's rule again. and. as was done in Appendix 6.2. considering different parameter values. However. to prove Proposition 6.3 parts (ii) and (iii) it is necessary to consider the elasticity of the foreign offer curve. Thus to this end replace the foreign export supply. $E_{1}^{*}=\gamma^{*} S^{*}\left(1-S^{*} c^{*}\right)-\beta^{*} I^{*} / p_{1}^{*}$. in (A6 31$)$ with the foreign offer curve. $E_{1}{ }^{*}=\Omega\left(\mathrm{M}_{2}{ }^{*}\right)$ so that $(. A 6.3 .1)$ becomes

$$
\beta\left(N-\tau M_{1}\right) q S-\psi \beta(1-S c)+\Omega\left(M_{2}{ }^{*}\right)=0
$$

As before the home price of fish is equal to the foreign price of fish plus the tariff. i.e.. $p_{1}=p_{1}{ }^{*}+\tau$. As before, it is useful to substitute $p_{1}$ with $1 / q S$. While the foreign relative price of fish, can be eliminated from the system by using the trade constraint facing the foreign country, $p_{1}{ }^{*}=E_{1}{ }^{*} / M_{2}{ }^{*}=\Omega\left(M_{2}{ }^{*}\right) / M_{2}{ }^{*}$ 


$$
1 / \mathrm{q} S-\Omega\left(M_{2}{ }^{*}\right) / M_{2}{ }^{*}-\tau=0 \text {. }
$$

This leaves a two equation system to solve for two steady-state variables, the home fish stock, $S$, and the level of foreign imports of manufactures. $M_{2}{ }^{*}$. Totally differentiating (A6.3.3) and (A6.3.4) and putting into matrix form,

$$
\left[\begin{array}{cc}
\beta\left(N+\tau M_{1}\right) q-\gamma(1-2 S / c) & -\Omega^{\prime}\left(M_{2}^{\prime}\right) \\
-1 /\left(q S^{2}\right) & -\left[\frac{1}{\Omega\left(M_{2}^{\prime}\right)}-\frac{M_{2}^{*} \Omega^{\prime}\left(M_{2}^{*}\right)}{\Omega^{2}\left(M_{2}^{*}\right)}\right]
\end{array}\right]\left[\begin{array}{c}
d S \\
\alpha M_{2}^{*}
\end{array}\right]\left[\begin{array}{c}
\beta M q S] \\
1
\end{array}\right][d \tau](\text { A6.3.5) }
$$

The first step is to evaluate the determinant of the left-hand side matrix, D.

$$
\begin{aligned}
& \mathrm{D}=-[\beta N q-\gamma(1-2 S / c)]\left[\frac{\Omega\left(M_{2}^{*}\right)-M_{2}^{*} \Omega^{\prime}\left(M_{2}^{\prime}\right)}{\Omega^{2}\left(M_{2}^{\prime}\right)}\right]-\frac{\Omega^{\prime}\left(M_{2}^{\prime}\right)}{q S^{2}} \\
& \mathrm{D} q S^{\prime \prime}=-q S S\left[\beta N_{q}-\gamma(1-2 S / c)\right]\left[\frac{\Omega\left(M_{2}^{\prime}\right)-M_{2}^{\prime} \Omega^{\prime}\left(M_{2}^{\prime}\right)}{\Omega^{2}\left(M_{2}^{\prime}\right)}\right]-\Omega^{\prime}\left(M_{2}^{\prime}\right) \\
& =-\frac{\Omega\left(M_{2}^{*}\right)}{M_{2}^{*}} M_{1}\left[\frac{\Omega\left(M_{2}^{*}\right)-M_{2}^{\prime} \Omega^{\prime}\left(M_{2}^{*}\right)}{\Omega^{2}\left(M_{2}^{*}\right)}\right]-\Omega^{\prime}\left(M_{2}^{*}\right)
\end{aligned}
$$

Substituting $E_{1}^{*}=\Omega\left(M_{2}^{*}\right)$ for $M_{1}$.

$$
\begin{aligned}
& =-\frac{\Omega\left(M_{2}^{*}\right)}{M_{2}^{*}}\left[\frac{\Omega\left(M_{2}^{*}\right)-M_{2}^{*} \Omega^{\prime}\left(M_{2}^{*}\right)}{\Omega\left(M_{2}^{*}\right)}\right]-\Omega^{\prime}\left(M_{2}^{*}\right) \\
& =-\frac{\Omega\left(M_{2}^{*}\right)}{M_{2}^{*}} \\
& =-\frac{E_{1}^{*}}{M_{2}^{*}}<0
\end{aligned}
$$

Thus the determinant is negative. Now use Cramer's rule to solve for the effect of the 
tariff on the steady-state home fish stock.

$$
\frac{d S}{d \tau}=\frac{\left|\begin{array}{cc}
\beta M_{1} g S & -\Omega^{\prime}\left(M_{2}^{*}\right) \\
1 & -\left[\frac{\Omega\left(M_{2}^{*}\right)-M_{2}^{*} \Omega^{\prime}\left(M_{2}^{*}\right)}{\Omega^{2}\left(M_{2}^{*}\right)}\right.
\end{array}\right|}{D}
$$

$$
=\frac{-\beta M_{1} q S\left[\frac{\Omega\left(M_{2}^{*}\right)-M_{2}^{*} \Omega^{\prime}\left(M_{2}^{\prime}\right)}{\Omega^{2}\left(M_{2}^{\prime}\right)}\right]+\Omega^{\prime}\left(M_{2}^{*}\right)}{D}
$$

Then substituting $M_{1}=\Omega\left(M_{2}^{*}\right)$ and $\Omega\left(M_{2}^{*}\right) M_{2}{ }^{*}=1 / p_{1}$ for $q S$.

$$
\frac{d S}{d \tau}=\frac{-\beta \frac{\Omega^{2}\left(M_{2}^{*}\right)}{M_{2}^{*}} \frac{\Omega\left(M_{2}^{*}\right)-M_{2}^{\prime} \Omega^{\prime}\left(M_{2}^{*}\right)}{\Omega^{2}\left(M_{2}^{\prime}\right)}+\Omega^{\prime}\left(M_{2}^{*}\right)}{D}
$$

$$
=\frac{\frac{\Omega\left(M_{2}^{\prime}\right)}{M_{2}^{*}}+(1-\beta) \Omega^{\prime}\left(M_{2}^{*}\right)}{D}
$$

The term $\Omega^{\prime}\left(M_{z}^{*}\right)$ is the slope of the foreign offer curve. If $\Omega^{\prime}\left(M_{2}^{*}\right)<0$ then the offer curve is inelastic. on the other hand if $\Omega^{\prime}\left(M_{2}{ }^{*}\right)>0$ then the offer curve is elastic. Thus the effect of the tariff on the fish stock depends on whether the foreign offer curve is elastic or not. Suppose it is elastic, then $\Omega^{\prime}\left(M_{2}{ }^{*}\right)>0$ and hence $d S d \tau<0$, under such circumstances since the fish stock is inversely related to the domestic relative price of 
fish, the relative price of fish at home rises.

$$
\frac{d p_{1}}{d \tau}=-\frac{1}{q S^{2}} \frac{d S}{d \tau}
$$

$$
\begin{aligned}
& =\frac{\frac{\Omega\left(M_{2}^{*}\right)}{M_{2}^{*}}+(1-\beta) \Omega^{\prime}\left(M_{2}^{*}\right)}{-q S^{2} D} \\
& =1+\frac{(1-\beta) \Omega^{\prime}\left(M_{2}^{*}\right)}{\Omega\left(M_{2}^{*}\right) / M_{2}^{\prime}}
\end{aligned}
$$

The effect on weifare depends on two factors. On one hand the fish stock has fallen causing the Ricardian PPF to pivot inwards reducing welfare. On the other hand the terms of trade have been improved by the tariff and the economy is able to exploit some of its monopoly power in trade.

$$
\begin{aligned}
& \frac{d U}{d \tau}=\frac{\alpha}{p_{1}^{\beta}} \frac{\partial I}{\partial \tau}-\frac{\alpha I}{p_{1}^{\beta-1}} \frac{\partial p_{1}}{\partial \tau} \\
& =\frac{\alpha}{p_{1}^{\beta}} M_{1}-\frac{\alpha}{p_{1}^{\beta-1}} N \frac{\partial p_{1}}{\partial \tau}
\end{aligned}
$$

In order that welfare be improved, $d U / d t$ needs to be positive. From (A6.3.13) this requires

$$
\frac{\alpha}{p_{1}^{\beta}} M_{1}-\frac{\alpha}{p_{1}^{\beta+1}} N \frac{\partial p_{1}}{\partial \tau}>0
$$

or after rearranging. 


$$
M_{1}-\frac{N}{p_{1}} \frac{\partial p_{1}}{\partial \tau}>0
$$

Noting that $p_{1} M_{1}=-M_{2}=M_{2}^{*}$, the condition for an improvement in welfare becomes

$$
\frac{\partial p_{1}}{\partial \tau}<\frac{M_{2}^{*}}{N}
$$

Substituting for $\partial p_{1} / \partial \tau$

$$
1+\frac{(1-\beta) \Omega^{\prime}\left(M_{2}^{*}\right)}{\Omega\left(M_{2}^{*}\right) / M_{2}^{*}}<\frac{M_{2}^{*}}{N}
$$

Because inter-temporal borrowing is ruled out. the home country can not import in excess of GDP. thus the right-hand side is a positive fraction Hence whenever the foreign offer curve is elastic and $\Omega^{\prime}\left(1 K_{z}^{*}\right)>0$ the left-hand side of $(A 6.3 .15)$ is strictly: greater than I welfare must be worsened by the implementation of a tariff This proves part (iii) of Proposition 63

To prove part (ii). consider the case when the foreign offer curre is inelastic. In that case. $\Omega^{\prime}\left(M K_{*}^{*}\right)<0$ and $d S d \tau$ may be positive or negative depending on the degree of inelasticity of the foreign offer curve. If $d S ; d t>0$ then the relative price of fish at home falls. From (A6.3.12) welfare is unambiguously improved. The expansion in the Ricardian PPF complements the improvement in the terms of trade and both effects act to improve welfare. From (A6.3.14) it can be seen that the foreign offer curne need not be so inelastic so as to cause the relative price at home to fall in order that home welfare be improved. all that is required is that the foreign offer curve be inelastic and $\frac{\partial p_{1}}{\partial \tau}<\frac{M_{2}^{*}}{N}$ 


\section{Chapter 7}

\section{Conclusion}

\subsection{Motivation and Summary of Main Findings}

The last decade has seen the rise of a new protectionism that has been pushed by environmentalists who seek to use tariffs as a tool. not to protect industry, but to protect the environment. The anti-trade position of environmentalists has managed to ignite considerable debate and discussion amongst economists, who traditionally have taken a position strongly in favour of free trade This thesis was concerned with one particular. but important. aspect of the debate the relationship between international trade. trade policy and renewable open-access resources such as fisheries and forests t key finding of this thes is is that. although free trade is not optimal when resources are open access. this need not imply that restricted trade is necessarily better: at times. subsidized trade may be best. Similarly. it was shown that while unrestricted capital movement is not optimal. a capital scarce country may gain from unfettered capital inflou. Thus. one of the main points made in this thesis is that while environmentalists rightly question the validity of comparative advantage as the basis for trade, they must also acknowledge that trade has a role to play in advancing their cause. That is, the same arguments that can be used to justify an anti-trade position can be justified to support trade subsidies and increased foreign investment. 
In order to develop a model for analysis, a standard (Gordon-Schaefer) model of renewable resources was integrated into the general equilibrium Ricardian and Heckscher-Ohlin international trade models While such stylized models have limitations, they capture, in a simple and straightforward fashion, the property that overexploitation of renewable resources not only depletes the stock available for the future. but it also lowers the productivity of the industry, reducing output despite increased effort. Such assumptions suffice to allow an analysis of the inter-relationship between international trade. renewable resources and the open-access problem without the need for worrying about the complications of multiple equilibria and non-linearities (see McRae (1978) and Smith (1974) for example)

Under open access. the rents associated with the fishery are dissipated by the actions of fishers who enter the industry treating the fish it provides as a free resource. When the opportunity cost of fishing is constant. fishers enter the industry until all the rents associated with the fishery have been entirely dissipated. When the opportunity cost of fishing effort is increasing. some of the rents associated with the fishery are accumulated by the providers of fishing effort. This is a key difference between the Ricardian and Heckscher-Ohlin models and is examined in Chapter 3.

Once it is acknowledged that there is an open-access problem, free trade ceases to be the optimal policy prescription. This result is an application of the well-known theory of the second best due to Lipsey and Lancaster (1957). The idea is relatively straightforward. 
in the absence of first-best policies, such as taxes or property rights solutions. trade policy can be used to encourage a contraction in harvesting and an expansion in other industries, thus partially alleviating the over-fishing problem. The use of second-best trade policies for a small country was discussed in Chapter 4. In Chapter 4. it was shown that, for a small country exporting the resource intensive good, welfare can be improved by a tariff that protects manufacruring, and reduces pressure on its environmental resources. The timber exporting countries. such as those in South-East Asia and Cental America, are good examples of countries that one may expect could benefit from such policies. On the other hand. in countries such as the third world. population pressure is purting extreme pressure on renewable open-access resources such as fisheries (for food). woodlands (for fuel). These countries often rely on imports to supplement domestic supplies of these resources In countries such as this. Chapter 4 demonstrates that export subsidies. used to encourage an expansion in manufacturing and a reduction in the dependence on local food and fuel supplies. can improve both economic welfare and the state of the environment.

Chapter 4 also considers the form that optimal regulation might take. The analysis compares the use of a harvest tax. a quota, sole ownership, and transferrable quotas. It is shown that a quota would encourage rent seeking - a well-known result. The analysis demonstrates, using the Ricardian model, that rent-seeking behaviour results in the same level of income as under open access. Interestingly, it is shown that the amount of resources tied up in fishing may actually be greater than that under open access Linder 
sole ownership, the right to entry into fishing is limited. While this solves the openaccess problem, by assigning a property right, sole ownership also assigns the right to market power. In the context of general equilibrium, this grants the owner of the resource with power in the factor markets (and possibly the output market if the country is large - though this case was not considered). In the Ricardian model, the opportunity cost of fishing effort is constant and the owner of the fishery has no monopsony power. However, in a Heckscher-Ohlin model this is not the case. The owner may profit from restricting the amount of fishing effort he hires, and his harvest of fish. Ultimately, this results in less fishing effort and a smaller harvest than is optimal. In the absence of complementary regulation to prevent quotas from becoming concentrated amongst a few fishing firms, transferrable quotas suffer trom the same problem This is likely to be especially problematic in fishing communities that have limited alternative economic activities other than fishing - a problem that seems common to many fishing regions around the world

Generally. those who link environmental degradation to trade also fear that liberalization of foreign investment will exacerbate matters. As with trade, the theory of the second best suggests that where regulation is absent and renewable resources are open access. free capital mobility is not likely to be an optimal policy. Nevertheless, in Chapter 5 , it was demonstrated that a capital scarce open-access country could gain from an unrestricted capital inflow, if fishing was relatively labour intensive. Conversely, when the return to capital is below that abroad, exports of domestic capital may raise or lower 
domestic welfare and some controls on capital outflows may be justified Chapter 5 also considers marginal improvements in the regulation of the open-access resource. The analysis reveals that improvements in the regulatory regime lead to a greater improvement in welfare if capital is internationally mobile than if it is not (a result termed by Copeland (1994) as the amplification effect). However, the analysis in Chapter 5 shows that this is not itself a justification for eliminating capital controls. The reason is that the gain from a small improvement in regulation may be less than the loss from an elimination of capital controls so long as the elimination of those controls leads to a significant capital outflow.

In a two-country environment, this thesis extends the analysis of Brander and Taylor (1997b. 1998a). Brander and Taylor (1998a) demonstrate that when trade occurs between two open-access economies. the resource exporting country may gain from implementing trade restrictions. Chapter 6 demonstrates that the fish-importing country may also benefit from the actions of the fish-exporting country. When trade takes place between a "conservationist" country. which regulates its resource. and an open-access economy, which does not. it was demonstrated that the use of trade policy could lead to Pareto improvements in welfare. In this case. it was shown that if the open-access economy imports the resource intensive good, then trade subsidies under quite general circumstances could lead improvements in the welfare of both countries. This raises the question of whether the North, with relatively weil developed institutional arrangements for enforcing property rights, should be more tolerant of export subsidies used by the developing world were renewable resources are often severely over exploited. 
There is some argument in the literature as to whether differences in regulatory regimes reflect differences in tastes or the ability to regulate. It is widely accepted that free trade is not best in the latter case when authorities are not able to, or choose not to, regulate the use of the resource, despite the fact that it would lead to an improvement in efficiency However, in the former case, it is commonly thought that when comparative advantage is based on a difference in the degree of regulation which reflects a difference in tastes (such as a difference in the discount rate between the citizens of one country compared to the other) then free trade is optimal. This issue is examined in Chapter 6 . Interestingly. the analysis there shows that free trade is not necessarily optimal. even if use of the open-access renewable resource appears to be efficiently taxed! The reason is that differences in tastes, such as differences in discount rates. lead to differences in the valuation placed on the resource. In the case of a fishery, the country with a high discount rate places a lower value on its fishery than the country with a low discount rate. The welfare of both countries could be improved if each was permitted to trade in the property right to its fishery. If there is no market in which the property rights can be freely traded in international markets. then a market is missing. and free trade is no longer optimal.

\subsection{Limitations of the Analysis and Possibilities for Future Research}

In this thesis, wherever possible. diagrammatic techniques were used to complement the algebra. Such techniques are useful because they do not necessarily suffer from the constraints imposed by using specific functional forms or the need to resort to 
complicated algebra. In Chapter 4, the implication of relaxing the Cobb-Douglas preference assumption was illustrated diagrammatically. it was shown that multiple equilibria could arise, and a country may end up exporting a good for which, in autarky. it did not appear to have a comparative advantage. Other assumptions could also be relaxed and incorporated into the analysis in a similar manner for example. a noncompensatory population growth function could be used in place of the logistic growth function. This type of harvest function is considered plausible, especially for fish species that tend to school in large numbers (Clark (1990)). Similarly, a production function. for fish that permits diminishing returns to the fish stock could be introduced to the analysis Both these changes are known to produce vield-effort curves that take the form of a "loop" rather than the single peaked concave curre used in this thesis. Using the diagrammatic technique developed in Chapter 2. these extensions could be accommodated. One would expect that many of the results developed in this thesis concerning the effects of trade policy can be generated using such a model. however. the cost in terms of algebraic manıpulation is likely to be significant.

Throughout this thesis, the property right regime was taken as exogenous. However, it is likely that property rights regimes may develop in response to changes in the economic environment. It is not immediately clear what the effect of making the property rights regime endogenous would have on the trade policy prescription. Bhagwati (1993) has pointed to the level of income as a determinant of environmental regulation. Rich countries place a higher marginal value on environmental protection than poor (who care 
more about provision of disease control, for instance). He argues that countries are made richer through trade and hence the demand for more efficient environmental regulation is increased. However, the analysis of this thesis suggests that free trade may be welfare worsening and hence, applying Bhagwati's logic, reduce the demand for regulation' On the other hand, if trade worsens the welfare of a country with an open-access resource. then it may make the cost of maintaining open access too high, encouraging a property rights regime to develop. Both arguments seem sensible. Ultimately, the question of whether free trade leads to better property rights and higher welfare. or lower welfare and better property rights. is interesting and merits future research

In addition to the over-fishing problem. habitat degradation and destruction is an important problem affecting many of the world's inland fisheries. ${ }^{3 s}$ These problems are in part due to population pressure and in part due to the growth of new industries. This suggests that inter-industry externailities may be just as important as intra-industry externalities for the management of renewable resources. If this is so, a whole range of new issues is opened up with different ramifications. The benefits of trade policy. which reduces the over fishing problem, needs to be balanced against the costs of environmental degradation (both immediate and long-term) on the economy. To this end. progress has been made by Copeland and Taylor (1997) who have developed a dynamic model in which one industry inflicts a negative production externality on another. They show that

${ }^{35}$ See the Food and Agriculture Organization (1998) for details. 
trade may have significant environmental consequences in the absence of far-sighted government regulation.

The purpose of this thesis was to explore the relationship between international trade and renewable open-access resources. The bulk of the analysis was devoted to considering different aspects of the "trade and the environment" debate. The contribution of this thesis has been to show that, while the environmentalists may be right to question the validity of comparative advantage, the anti-trade position that they take is not necessarily. justified - in some cases, free-trade or even subsidized trade may be better than restricted or no trade 


\section{References}

Anderson, L. G. 1986, The Economics of Fisheries Management, the Johns Hopkins University Press.

Bhagwati. J. N., 1958, Immiserizing Growth: A Geometric Note, Review of Economic Studies 25, 201-205.

Bhagwati, J. N., 1971, The Generalized Theory of Distortions and Welfare, in Trade, Balance of Payments, and Growth. North Holland Publishing Company, Reprinted as Chapter 16 in J.N. Bhagwati (ed.), International Trade, $2^{\text {nd }}$ Edition. Cambridge. Mass. The MIT Press. 1987

Bhagwati, J. N.. 1993, The Case for Free Trade. Scientific American. November. 1993. $42-49$

Brander. J. A. and M. S. Taylor. 1997a. Intemational Trade and Open-Access Renewable Resources: The Small Country Case, Canadian Journal of Economics 30(3). 526552.

Brander, J. A. and M. S. Taylor, 1997b. International Trade Between Consumer and Conservationist Societies. Resource and Energy Economics 19. 267-297.

Brander. J. A. and M. S. Taylor, 1998a, Open-Access Renewable Resources: Trade Policy in a Two-Country Model. Journal of International Economics 44. 181-209

Brander. J. A. and M. S. Taylor. 1998b. The simple Economics of Easter Island: A Ricardo-Malthus Model of Renewable Resource Use. American Economic Review 88(1). 119-138.

Brecher, R. A. and C. F. Diaz-Alejandro, 1977, Tariffs, Foreign Capital and Immizerising Growth, Journal of International Economics, 7, 3 17-322.

Bromley, D. W., 1998, Property regimes in environmental economics, in H. Folmer and T.H. Tietenberg (eds) International Yearbook of Environmental and Resource Economics 199\%/1998, Cheltenham. Gloucester. U.K.. N.H. Lyne and E.Elgar

Casas, F.R., 1991, Lemer's Symmetry Theorem Revisited, Keio Economic Studies 28 , 15-19.

Chichilnisky, G., 1994. North-South Trade and the Global Environment. American 
Economic Review 84(4), 851-875

Clark, C. W., 1990, Mathematical Bieconomics: The Optimal Management of Renewable Resources, $2^{\text {nd }}$ edition, New York, John Wiley and Sons, Inc.

Conrad, J. M. and C. W. Clark, 1987, Natural Resource Economics, Cambridge, Cambridge University Press

Copeland, B. R., 1994, International Trade and the Environment: Polic: Keform in a Polluted Small Open Economy, Journal of Environmental Economics and Management, 26, 44-65.

Copeland, B. R., and M. S. Taylor, 1997, The Trade Induced Degradation Hypothesis. Resource and Energy Economics. 19, 321-344.

Corden, W M.. 1997, Trakle Policy and Economic Welfare, $2^{\text {nd }}$ edition. Oxford. Claredon Press.

Daly. H. E.. 1993. The Perils of Free Trade. Scientific American, November. 1993. 5057.

Food and Agriculture Organization. 1999. Review of the State of World Fishery Resources. Food and Agriculture Organization of the United Nations. Rome

Gordon, H. S., 1954. The Economic Theory of a Common Property Resource: the Fishery. Joumal of Political Economy 62. 124-142.

Hart, O. D.,1975, On the Optimality of Equilibrium When the Market Structure is Incomplete. Journal of Economic Theory. 11, 418-443

Johnson. H. G., 1967, The Possibility of Income Losses from Increased Efficiency or Factor Accumulation in the Presence of Tariffs. Economic Journal 77, 151-154

Leonard, D. and N. V. Long, 1992, Optimal Control Theory and Static Optimization in Economics. Melbourne, Cambridge University Press.

Lesourne. J., 1976, General Equilibrium with a Replenishable Natural Resource: A Comment, Review of Economic Studies, October, 557-560.

Lipsey, R.G. and K. Lancaster, 1956-57, The General Theory of the Second Best. Review of Economic Studies, XXIV(1), no. 63. 11-33.

Markusen, J.R., 1976, Production and Trade from International Common Property 
Resources, Canadian Journal of Economics 9, 309-319.

McRae, J, 1976, Optimal and Competitive Use of Replenishable Natural Resources by Open Economies, Journal of International Economics, 8, 29-54.

Meade, J. E., 1952, External Economies and Diseconomies in a Competitive Situation, Economic Journal 62, 54-67.

Munro, G. R. and A. D. Scott, 1985, The Economics of Fisheries Management. in Handbook of Natural Resource and Energy Economics, vol II, A.V. Kneese, and J.L. Sweeney (eds), Amsterdam, North Holland.

Quirk, J. P and Smith, V. L. Smith, 1970, Dynamic Economic Models of Fishing.in A.D Scott (ed.), Economics of Fisheries Management - A Symposium, Vancouver BC Institute of Animal Resource Ecology. University of British Columbia.

Scott, A.D., and C. Southey, 1969, The Problem of Achieving Efficient Regulation of a Fishery, in A.D. Scott (ed.), Economics of Fishery Management: A Symposium. Vancouver BC: Institute of Animal Resource Ecology. University of British Columbia.

Smith, V., 1974, General Equilibrium with a Replenishable Natural Resource, the Review of Economic Studies 58, 409-431.

Ulph. A.. 1998, International trade and the environment: a survey of recent economic analysis. in $\mathrm{H}$. Folmer and T.H. Tietenberg (eds) Imternational Yearbook of Environmental and Resource Economics 199-'1998. Cheltenham. Gloucester. Li.K. N.H. Lyne and E. Elgar.

Wong. K., 1995. International Trade in Goods and Factor Mobilin: Cambridge. MIT Press. 